\title{
The role of the different Kunitz domains of TFPI in the down-regulation of the extrinsic coagulation pathway
}

Citation for published version (APA):

Peraramelli, S. (2015). The role of the different Kunitz domains of TFPI in the down-regulation of the extrinsic coagulation pathway. [Doctoral Thesis, Maastricht University]. Uitgeverij BOXPress. https://doi.org/10.26481/dis.20150918sp

Document status and date:

Published: 01/01/2015

DOI:

10.26481/dis.20150918sp

Document Version:

Publisher's PDF, also known as Version of record

\section{Please check the document version of this publication:}

- A submitted manuscript is the version of the article upon submission and before peer-review. There can be important differences between the submitted version and the official published version of record.

People interested in the research are advised to contact the author for the final version of the publication, or visit the DOI to the publisher's website.

- The final author version and the galley proof are versions of the publication after peer review.

- The final published version features the final layout of the paper including the volume, issue and page numbers.

Link to publication

\footnotetext{
General rights rights.

- You may freely distribute the URL identifying the publication in the public portal. please follow below link for the End User Agreement:

www.umlib.nl/taverne-license

Take down policy

If you believe that this document breaches copyright please contact us at:

repository@maastrichtuniversity.nl

providing details and we will investigate your claim.
}

Copyright and moral rights for the publications made accessible in the public portal are retained by the authors and/or other copyright owners and it is a condition of accessing publications that users recognise and abide by the legal requirements associated with these

- Users may download and print one copy of any publication from the public portal for the purpose of private study or research.

- You may not further distribute the material or use it for any profit-making activity or commercial gain

If the publication is distributed under the terms of Article $25 \mathrm{fa}$ of the Dutch Copyright Act, indicated by the "Taverne" license above, 


\section{The role of the different Kunitz domains of TFPI in the down- regulation of the extrinsic coagulation pathway}


(c) Sameera Peraramelli. Maastricht 2015

No part of this book may be reproduced or transmitted in any form or any means, without prior permission in writing by the author, or when appropriate, by the publishers of the publications.

Printed \& Lay Out by:

Cover Design:

Published by:

ISBN no.:
Proefschriftmaken.nl || Uitgeverij BOXPress Sameera Peraramelli

Uitgeverij BOXPress, 's-Hertogenbosch

978-94-6295-353-6 


\title{
The role of the different Kunitz domains of TFPI in the down-regulation of the extrinsic coagulation pathway
}

\begin{abstract}
PROEFSCHRIFT
ter verkrijging van de graad van doctor aan de Universiteit Maastricht op gezag van de Rector Magnificus, prof. dr. L. L. Q. Soete, volgens het besluit van het College van Decanen, in het openbaar te verdedigen op vrijdag 18 september 2015 om 12:00 uur
\end{abstract}

door

Sameera Peraramelli 


\section{Promotors}

Prof. Dr. Tilman M. Hackeng

Prof. Dr. Jan Rosing

\section{Beoordelingscommissie}

Prof. Dr. Aalt Bast, chairman, MUMC

Prof. Dr. Erik Biessen, MUMC

Prof. Dr. Frans Ramaekers, MUMC

Dr. Kees van 't Veer, AMC Amsterdam

Financial support by the Dutch Heart Foundation for the printing of this thesis is gratefully acknowledged.

Publication of this thesis is further supported by Haematologic Technologies, Stago and Novo Nordisk and their contribution is gratefully acknowledged. 
If you can't explain it simply, you don't understand it well enough

- Albert Einstein 



\section{Contents}

$\begin{array}{lll}\text { Chapter } 1 & \text { General Introduction } & 9\end{array}$

Chapter $2 \quad$ TFPI-dependent activities of protein S 29

Chapter $3 \quad$ The Kunitz 1 and Kunitz 3 domains of 49

tissue factor pathway inhibitor are required

for efficient inhibition of factor Xa

Chapter $4 \quad$ Direct inhibition of factor VIIa by TFPI 91

and TFPI constructs

Chapter 5 Inhibition of TF-FVIIa catalyzed FIX and

FX activation by TFPI and TFPI constructs

Chapter $6 \quad$ Role of exosite binding modulators in the

inhibition of FXa by TFPI

Chapter 7

General discussion and summary

Appendix

Samenvatting

Valorisation

Curriculum Vitae

List of Publications 



\section{Chapter 1}

\section{General Introduction}


Chapter 1 


\section{Introduction}

\section{Coagulation Pathway}

Blood coagulation is initiated as a response to vascular damage. Vascular injury exposes the integral membrane protein tissue factor $(\mathrm{TF})(1,2)$ which binds the circulating coagulation factor VIIa (FVIIa) (3) and forms the TF-FVIIa complex. This complex activates FX $(4,5)$ to FXa, which subsequently assembles with its cofactor factor $\mathrm{Va}(\mathrm{FVa})$ in presence of calcium ions and an appropriate phospholipid surface into the so-called prothrombinase complex. The prothrombinase complex converts the zymogen prothrombin into its active form thrombin. Thrombin is a serine protease with several functions in haemostasis, which amongst others catalyzes the conversion of fibrinogen to fibrin and induces the aggregation of blood platelets resulting in the formation of stable thrombus consisting of aggregated platelets consolidated by a network of fibrin fibers.

Blood coagulation is carefully regulated by the positive and negative feedback loops that balance the clot formation (Fig. 1). The initial thrombin molecules that are formed by extrinsic coagulation pathway, activate the coagulation factors FV, FVIII and FXI leading to propagation of coagulation cascade (6-8). FVIIIa is a cofactor of activated FIX (FIXa) a serine protease that is formed by activation of FIX via either FXIa $(9,10)$ or TF-FVIIa $(5,11,12)$.

The hemostasisis regulated by the anticoagulant pathways, by ensuring to limit the thrombin formation and hemostatic plug at the site of vessel damage. The major 
anticoagulant proteins identified in plasma are tissue factor pathway inhibitor (TFPI), protein $\mathrm{C}$ and protein $\mathrm{S}$, antithrombin (AT), $\alpha_{2}$-macroglobulin, and the protein Z-dependent protease inhibitor. The complete absence of the major anticoagulant systems (TFPI, protein C/protein S or AT) leads to extensive fibrin deposition as well as bleeding due to consumptive coagulopathy and is not compatible with life (13-15). Out of all, one of the most important anticoagulant proteins is TFPI (16), a protease inhibitor that regulates at the initiation of blood coagulation by binding and inhibiting FXa (17) and TF-FVIIa (18) thereby shutting down the extrinsic coagulation pathway.

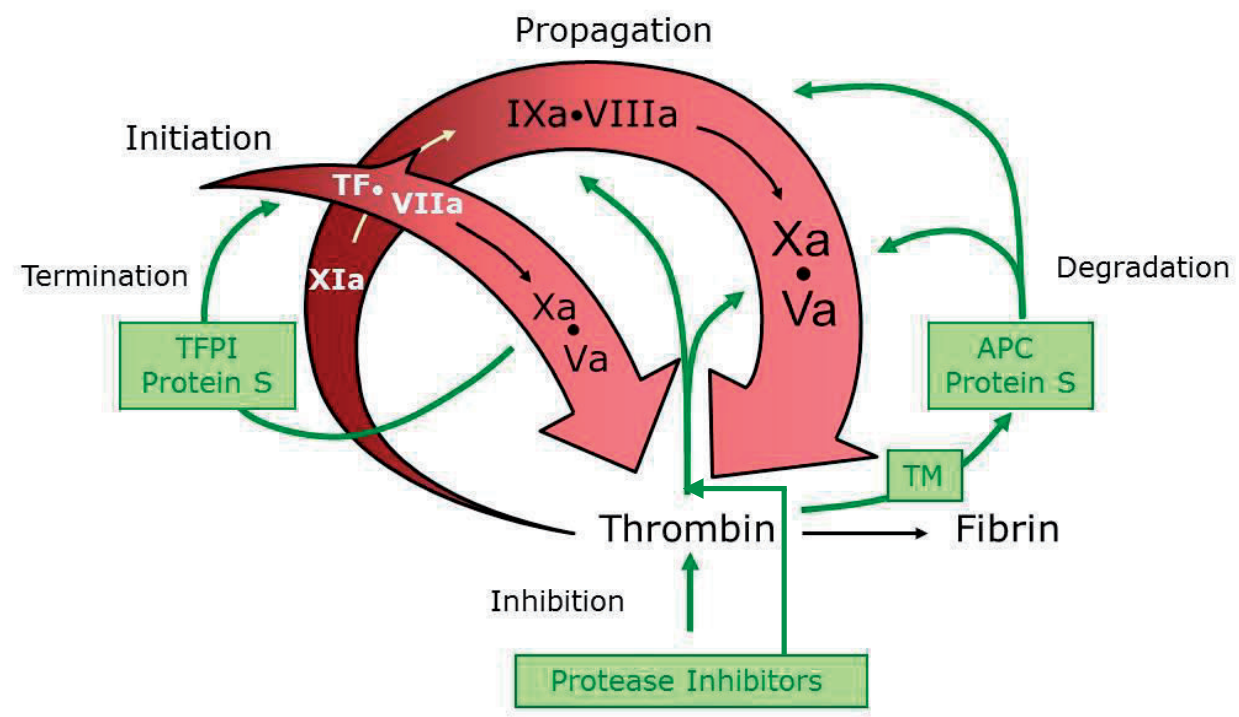

Figure 1.Blood coagulation cascade: Initiation, propagation, termination and degradation. 


\section{Tissue factor pathway inhibitor}

The TFPI gene is localized on chromosome 2 in region $2 q 32(19,20)$. The translated product of the tfpi gene (304 a.a. long) is subjected to removal of signal sequence (28 a.a) to give a mature 276 amino acid long TFPI protein called TFPI $\alpha$ $(16,21)$. Alternative splicing of TFPI mRNA results in TFPI $\beta$, an isoform of TFPI $(22,23)$

TFPI $\alpha$ is an endogenous Kunitz type serine protease inhibitor with an acidic amino terminus followed by three tandem Kunitz domains (K1-Asp13-Arg78, K2-Glu92Gly150, K3-Glu182-Lys241), each containing 3 disulphide bonds that pair in the pattern 1 to 6,2 to 4,3 to 5 and a basic carboxy terminus (16). The molecular mass of TFPI $\alpha$ is $32 \mathrm{kDa}$ but post-translational modifications result in an increase of mass of $43 \mathrm{kDa}$ (24). The post-translational modifications of TFPI $\alpha$ do not seem to be important for the inhibition of FXa or the TF-FVIIa complex, but they may influence its plasma clearance and cell binding properties $(25,26)$. TFPI $\beta$ lacks KD3 and has a different C-terminus. A GPI anchor is attached to this C-terminus which covalently associates TFPI $\beta$ to the endothelium (27).

TFPI expression and distribution: TFPI $\alpha$, which is subject of this thesis and which we will call TFPI from here on, is produced constitutively by microvascular endothelial cells (28), expressed by liver and monocytes/macrophages (29). It is distributed in the endothelium(50-80\%), plasma (10-50\%) and platelets (less than $2.5 \%)(30,31)$. Normal human plasma contains full length and variably truncated 
carboxy-terminal forms of TFPI (32). In vivo, approximately $80 \%$ of plasma TFPI circulates in complex with plasma lipoproteins $(18,33)$. TFPI has a rather short half-life of $60-120 \min (34,35)$. The total TFPI concentration in normal human plasma, which includes the variably truncated form of TFPI, is about $1.0-2.5 \mathrm{nM}$ $(33,36)$ and the full length TFPI concentration in plasma is $0.25-0.5 \mathrm{nM}(30)$. Castoldi and coworkers reported that at least part of the full length TFPI present in plasma circulates in complex with protein S (37) and FV (38).

TFPI anticoagulant function: The anticoagulant function of TFPI involves binding to and inhibition of FXa which can directly contribute to the down-regulation of coagulation (39) TFPI can also bind and inhibit TF-FVIIa, a reaction that is greatly stimulated by FXa and that results in the rapid formation of a tight quaternary TFPI-FXa-TF-FVIIa complex $(17,40)$. Detailed kinetic studies indicated that inhibition of TF-FVIIa actually occurs after binding of TFPI to the ternary TFFVIIa-FXa complex that is generated during FX activation (41). By targeting TFFVIIa and FXa, TFPI directly and efficiently inhibits the initiation of coagulation. It is well established that the K2 domain binds to FXa, K1 binds to FVIIa (18) and that the $\mathrm{K} 3$ domain is essential for binding to its cofactor protein $\mathrm{S}$ which in the presence of phospholipids and $\mathrm{Ca}^{2+}$-ions enhances FXa inhibition by TFPI (42). The binding of TFPI to FV (38), which results from an interaction between the Cterminus of TFPI (43) and an acidic region in the C-terminus of the B-domain of FV (44-46) may also contribute to the anticoagulant activity of TFPI in plasma 
because Wood et al. (46) reported that binding of TFPI to FVa that was activated by FXa is associated with inhibition of prothrombin activation.

Biochemistry of inhibition: TFPI inhibits FXa via a two-step mechanism known as slow-tight inhibition. Slow-tight inhibitors are characterized by the rapid formation of an initial encounter complex (FXa $\bullet$ TFPI) followed by a slow conversion into a tight FXa•TFPI" complex (Fig. 2) (40, 47, 48). Both initial encounter complex and tight complex formation are dependent on the concentration of TFPI and when the TFPI concentration increases both the rate and extent of FXa inhibition increases. The shape of progress curves of inhibition obtained with the slow-tight binding inhibitors is biphasic $(40,48)$.

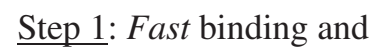
weak inhibition of FXa

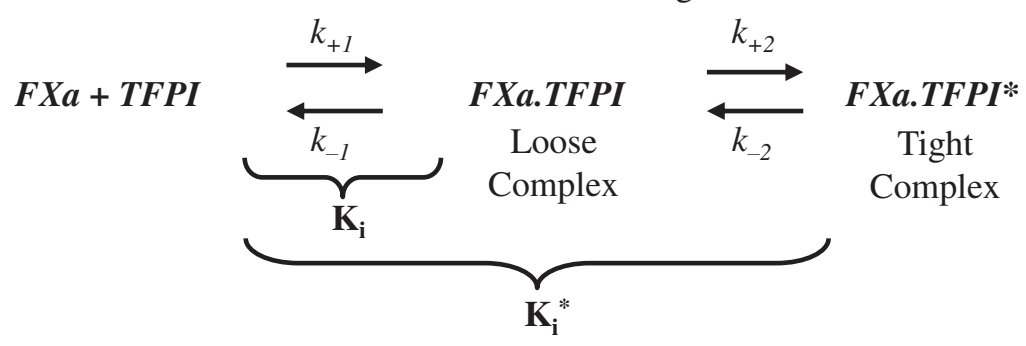

Figure 2. Slow-tight binding mechanism for inhibition of FXa by TFPI

Inhibition of FXa by TFPI can be quantified with FXa-specific chromogenic substrates. The progress curves of chromogenic substrate conversion can be followed in a spectrophotometer at $405 \mathrm{~nm}$ by measuring the production of $\mathrm{p}$ - 
nitroaniline (pNA) which in the case of a slow tight binding inhibitor is described by the integral rate equation presented below (48).

$A_{t}=A_{0}+\left(v_{s} \cdot t\right)+\left(v_{0}-v_{s}\right) \cdot\left(1-\exp \left(-k_{o b s} \cdot t\right)\right) / k_{o b s}$

In this equation $\mathrm{A}_{\mathrm{t}}$ is absorbance at $405 \mathrm{~nm}$ at time $\mathrm{t} ; \mathrm{A}_{0}$ is initial absorbance at 405 $\mathrm{nm}$; $\mathrm{v}_{\mathrm{s}}$ is final steady-state velocity; $\mathrm{v}_{0}$ is initial velocity; $\mathrm{k}_{\mathrm{obs}}$ is apparent rate constant for the transition from $\mathrm{v}_{0}$ to $\mathrm{v}_{\mathrm{s}}$ (FXa・TFPI to FXa・TFPI*). The $\mathrm{v}_{0}$ and $\mathrm{v}_{\mathrm{s}}$ values can be used to calculate the $\mathrm{K}_{\mathrm{i}}=[\mathrm{FXa}]$. [TFPI $] /[\mathrm{FXa}$.TFPI $]$ and the $\mathrm{K}_{\mathrm{i}}{ }^{*}=$ $[$ FXa $] \cdot[$ TFPI $] /\{[$ FXa.TFPI $]+[$ FXa.TFPI* $]\}$.

Inhibition of FXa by TFPI is modulated by several components that bind to either FXa or TFPI or both. Table 1 summarizes the effects of major modulators on the $\mathrm{K}_{\mathrm{i}}$ and $\mathrm{K}_{\mathrm{i}}{ }^{*}$ of FXa inhibition by TFPI.

Table 1. Effects of $\mathrm{Ca}^{2+}$, phospholipids and protein $\mathrm{S}$ on $\mathrm{K}_{\mathrm{i}}$ and $\mathrm{K}_{\mathrm{i}}^{*}$ of $\mathrm{FXa}$ inhibition by TFPI (Kinetic constants for FXa inhibition by TFPI)

\begin{tabular}{|c|c|c|}
\hline Addition & $\mathrm{K}_{\mathrm{i}}(\mathrm{nM})$ & $\mathrm{K}_{\mathrm{i}}^{*}(\mathrm{nM})$ \\
\hline None & $1.24^{\mathrm{a}}$ & $0.026^{\mathrm{a}}$ \\
\hline $\mathrm{Ca}^{2+}$ & $42.7^{\mathrm{a}}$ & $0.085^{\mathrm{a}}$ \\
\hline $\mathrm{Ca}^{2+}+\mathrm{PL}$ & $4.4^{\mathrm{b}}, 14.6^{\mathrm{a}}$ & $0.05^{\mathrm{b}}, 0.018^{\mathrm{a}}$ \\
\hline $\mathrm{Ca}^{2+}+\mathrm{PL}+$ protein $\mathrm{S}$ & $0.5^{\mathrm{b}}$ & $0.02^{\mathrm{b}}$ \\
\hline${ }^{\mathrm{a}}(47) ;{ }^{\mathrm{b}}(42)$
\end{tabular}




\section{Outline of this thesis}

TFPI is a multivalent Kunitz domain serine protease inhibitor. The aim of the thesis is to elucidate the role of the different domains of TFPI in the inhibition of extrinsic coagulation proteins (FXa and FVIIa). To obtain information on the function of the TFPI domains in the mechanism of inhibition of FXa and FVIIa, we have performed a detailed kinetic analysis of FXa and FVIIa inhibition by fulllength TFPI (TFPI $I_{\mathrm{FL}}$ ) and a number of chemically synthesized Kunitz domains and recombinant TFPI constructs both in the absence and presence of the TFPI cofactor protein S.

In chapter 2, we have reviewed the protein S cofactor activity of APC and TFPI and discussed experiments that show that at low TF concentration protein $\mathrm{S}$ has an APC independent cofactor activity which requires presence of TFPI and that at high TF concentration protein $\mathrm{S}$ only expresses anticoagulant activity in the presence of APC. Under these condition both the APC-cofactor and TFPI-cofactor activities of protein $\mathrm{S}$ contribute to its anticoagulant activity (49).

Kunitz 2 of TFPI is known to bind and inhibit FXa and although there have been several studies on FXa inhibition by different TFPI fragments $(18,50)$ there is limited information on the precise role of the different domains of TFPI in the 2 steps that describe the slow-tight binding inhibition of FXa (Fig. 2) and in the effects of phospholipids and protein $S$ thereon. In chapter $\mathbf{3}$, we describe the production of various truncated forms of TFPI which were generated either by 
recombinant expression or by solid phase peptide synthesis and native chemical ligation. Kinetic studies of FXa inhibition were performed and $\mathrm{K}_{\mathrm{i}}$ and $\mathrm{K}_{\mathrm{i}}^{*}$ values were obtained for all TFPI constructs.

Subsequently, the role of different domains of TFPI in the inhibition of TF-FVIIa was investigated using a chromogenic substrate specific for FVIIa to follow FVIIa inhibition by full length TFPI and by various TFPI fragments that were obtained by recombinant expression in a bacterial expression system. In chapter 4 , we present $\mathrm{K}_{\mathrm{i}}$ values for the FVIIa inhibition by TFPI and its constructs determined both in absence and presence of phospholipids, TF, soluble TF, protein S and FXa (51).

An alternative method to study TF-FVIIa inhibition by TFPI is by following the activation of the natural TF-FVIIa substrates, FIX and FX, to probe inhibition of TF-FVII by TFPI and the various TFPI constructs (Chapter 5). Particularly in the case of FX activation this system approaches the in vivo inhibition of TF-FVIIa by TFPI which under physiological conditions occurs via the formation of a quaternary TFPI-FXa-TF-FVIIa complex with in situ generated FXa (52).

FXa and TFPI interact with several proteins and compounds in plasma. These proteins and compounds can either bind to the active site of FXa, the Kunitz domains of TFPI or to so-called exosites on these proteins. Exosites are domains on the surface of enzymes and inhibitors that are physically separated from the active site and from the amino acid residues that determine the substrate or the 
inhibitor specificity $(53,54)$. Exosites present on TFPI and on FXa may play an important role in modulating the anticoagulant effects of TFPI e.g. in the inhibition of FXa. In Chapter 6 we report the effect of physiological concentrations prothrombin, FV, FVa, protein S, and phospholipids and heparin on FXa inhibition by TFPI and the importance of these modulators for the in vivo expression of anticoagulant activity of TFPI. 


\section{References}

1. Butenas S, Mann KG. Blood coagulation. Biochemistry 2002;67(1):3-12.

2. Wilcox JN, Smith KM, Schwartz SM, et al. Localization of tissue factor in the normal vessel wall and in the atherosclerotic plaque. Proc Natl Acad Sci U S A 1989;86(8):2839-43.

3. Morrissey JH, Macik BG, Neuenschwander PF, et al. Quantitation of activated factor VII levels in plasma using a tissue factor mutant selectively deficient in promoting factor VII activation. Blood 1993;81(3):734-44.

4. Nemerson Y. The reaction between bovine brain tissue factor and factors VII and X. Biochemistry 1966;5(2):601-8.

5. Osterud B, Rapaport SI. Activation of factor IX by the reaction product of tissue factor and factor VII: additional pathway for initiating blood coagulation. Proc Natl Acad Sci U S A 1977;74(12):5260-4.

6. Gailani D, Broze GJ, Jr. Factor XI activation in a revised model of blood coagulation. Science 1991;253(5022):909-12.

7. Naito K, Fujikawa K. Activation of human blood coagulation factor XI independent of factor XII. Factor XI is activated by thrombin and factor XIa in the presence of negatively charged surfaces. J Biol Chem 1991;266(12):7353-8.

8. von dem Borne PA, Koppelman SJ, Bouma BN, et al. Surface independent factor XI activation by thrombin in the presence of high molecular weight kininogen. Thromb Haemost 1994;72(3):397-402. 
9. Fujikawa $\mathrm{K}$, Thompson $\mathrm{AR}$, Legaz $\mathrm{ME}$, et al. Isolation and characterization of bovine factor IX (Christmas factor). Biochemistry 1973;12(24):4938-45.

10. Osterud B, Bouma BN, Griffin JH. Human blood coagulation factor IX. Purification, properties, and mechanism of activation by activated factor XI. J Biol Chem 1978;253(17):5946-51.

11. Zur M, Nemerson Y. Kinetics of factor IX activation via the extrinsic pathway. Dependence of Km on tissue factor. J Biol Chem 1980;255(12):5703-7.

12. Dahlback B. Blood coagulation. Lancet 2000;355(9215):1627-32.

13. Huang ZF, Higuchi D, Lasky N, et al. Tissue factor pathway inhibitor gene disruption produces intrauterine lethality in mice. Blood 1997;90(3):944-51.

14. Ishiguro K, Kojima $\mathrm{T}$, Kadomatsu $\mathrm{K}$, et al. Complete antithrombin deficiency in mice results in embryonic lethality. J Clin Invest 2000;106(7):873-8. 15. Jalbert LR, Rosen ED, Moons L, et al. Inactivation of the gene for anticoagulant protein $\mathrm{C}$ causes lethal perinatal consumptive coagulopathy in mice. J Clin Invest 1998;102(8):1481-8.

16. Wun TC, Kretzmer KK, Girard TJ, et al. Cloning and characterization of a cDNA coding for the lipoprotein-associated coagulation inhibitor shows that it consists of three tandem Kunitz-type inhibitory domains. J Biol Chem 1988;263(13):6001-4. 
17. Broze GJ, Jr., Warren LA, Novotny WF, et al. The lipoprotein-associated coagulation inhibitor that inhibits the factor VII-tissue factor complex also inhibits factor Xa: insight into its possible mechanism of action. Blood 1988;71(2):335-43.

18. Girard TJ, Warren LA, Novotny WF, et al. Functional significance of the Kunitz-type inhibitory domains of lipoprotein-associated coagulation inhibitor. Nature 1989;338(6215):518-20.

19. Girard TJ, Eddy R, Wesselschmidt RL, et al. Structure of the human lipoprotein-associated coagulation inhibitor gene. Intro/exon gene organization and localization of the gene to chromosome 2. J Biol Chem 1991;266(8):5036-41.

20. van der Logt CP, Reitsma PH, Bertina RM. Intron-exon organization of the human gene coding for the lipoprotein-associated coagulation inhibitor: the factor Xa dependent inhibitor of the extrinsic pathway of coagulation. Biochemistry 1991;30(6):1571-7.

21. Girard TJ, Gailani D, Broze GJ, Jr. Complementary DNA sequencing of canine tissue factor pathway inhibitor reveals a unique nanomeric repetitive sequence between the second and third Kunitz domains. Biochem J 1994;303 ( Pt 3):923-8.

22. Maroney SA, Ellery PE, Mast AE. Alternatively spliced isoforms of tissue factor pathway inhibitor. Thromb Res 2010;125 Suppl 1:S52-6. 
23. Chang JY, Monroe DM, Oliver JA, et al. TFPIbeta, a second product from the mouse tissue factor pathway inhibitor (TFPI) gene. Thromb Haemost 1999;81(1):45-9.

24. Diaz-Collier JA, Palmier MO, Kretzmer KK, et al. Refold and characterization of recombinant tissue factor pathway inhibitor expressed in Escherichia coli. Thromb Haemost 1994;71(3):339-46.

25. Hamik A, Setiadi H, Bu G, et al. Down-regulation of monocyte tissue factor mediated by tissue factor pathway inhibitor and the low density lipoprotein receptor-related protein. J Biol Chem 1999;274(8):4962-9.

26. Han X, Girard TJ, Baum P, et al. Structural requirements for TFPImediated inhibition of neointimal thickening after balloon injury in the rat. Arterioscler Thromb Vasc Biol 1999;19(10):2563-7.

27. Zhang J, Piro O, Lu L, et al. Glycosyl phosphatidylinositol anchorage of tissue factor pathway inhibitor. Circulation 2003;108(5):623-7.

28. Werling RW, Zacharski LR, Kisiel W, et al. Distribution of tissue factor pathway inhibitor in normal and malignant human tissues. Thromb Haemost 1993;69(4):366-9.

29. Petit L, Lesnik P, Dachet C, et al. Tissue factor pathway inhibitor is expressed by human monocyte-derived macrophages : relationship to tissue factor induction by cholesterol and oxidized LDL. Arterioscler Thromb Vasc Biol 1999;19(2):309-15. 
30. Novotny WF, Girard TJ, Miletich JP, et al. Purification and characterization of the lipoprotein-associated coagulation inhibitor from human plasma. J Biol Chem 1989;264(31):18832-7.

31. Sandset PM. Tissue factor pathway inhibitor (TFPI)--an update. Haemostasis 1996;26 Suppl 4:154-65.

32. Warshawsky I, Bu G, Mast A, et al. The carboxy terminus of tissue factor pathway inhibitor is required for interacting with hepatoma cells in vitro and in vivo. J Clin Invest 1995;95(4):1773-81.

33. Broze GJ, Jr. Tissue factor pathway inhibitor and the current concept of blood coagulation. Blood Coagul Fibrinolysis 1995;6 Suppl 1:S7-13.

34. Harenberg J, Malsch R, Heene DL. Tissue factor pathway inhibitor: proposed heparin recognition region. Blood Coagul Fibrinolysis 1995;6 Suppl 1:S50-6.

35. Valentin S, Ostergaard P, Kristensen H, et al. Simultaneous presence of tissue factor pathway inhibitor (TFPI) and low molecular weight heparin has a synergistic effect in different coagulation assays. Blood Coagul Fibrinolysis 1991;2(5):629-35.

36. Sandset PM, Abildgaard U. Extrinsic pathway inhibitor--the key to feedback control of blood coagulation initiated by tissue thromboplastin. Haemostasis 1991;21(4):219-39. 
37. Castoldi E, Simioni P, Tormene D, et al. Hereditary and acquired protein S deficiencies are associated with low TFPI levels in plasma. J Thromb Haemost 2010;8(2):294-300.

38. Duckers C, Simioni P, Spiezia L, et al. Low plasma levels of tissue factor pathway inhibitor in patients with congenital factor $\mathrm{V}$ deficiency. Blood 2008;112(9):3615-23.

39. Thomassen MC, Heinzmann AC, Herfs L, et al. TF-independent inhibition of thrombin generation by TFPIalpha. J Thromb Haemost 2015;13(1):92-100.

40. Broze GJ, Jr., Girard TJ, Novotny WF. Regulation of coagulation by a multivalent Kunitz-type inhibitor. Biochemistry 1990;29(33):7539-46.

41. Baugh RJ, Broze GJ, Jr., Krishnaswamy S. Regulation of extrinsic pathway factor Xa formation by tissue factor pathway inhibitor. J Biol Chem 1998;273(8):4378-86.

42. Hackeng TM, Sere KM, Tans G, et al. Protein S stimulates inhibition of the tissue factor pathway by tissue factor pathway inhibitor. Proc Natl Acad Sci U S A 2006;103(9):3106-11.

43. Ndonwi M, Girard TJ, Broze GJ, Jr. The C-terminus of tissue factor pathway inhibitor alpha is required for its interaction with factors $\mathrm{V}$ and Va. J Thromb Haemost 2012;10(9):1944-6.

44. Vincent LM, Tran S, Livaja R, et al. Coagulation factor V(A2440G) causes east Texas bleeding disorder via TFPIalpha. J Clin Invest 2013;123(9):3777-87. 
45. Broze GJ, Jr., Girard TJ. Factor V, tissue factor pathway inhibitor, and east Texas bleeding disorder. J Clin Invest 2013;123(9):3710-2.

46. Wood JP, Bunce MW, Maroney SA, et al. Tissue factor pathway inhibitoralpha inhibits prothrombinase during the initiation of blood coagulation. Proc Natl Acad Sci U S A 2013;110(44):17838-43.

47. Huang ZF, Wun TC, Broze GJ, Jr. Kinetics of factor Xa inhibition by tissue factor pathway inhibitor. J Biol Chem 1993;268(36):26950-5.

48. Morrison JF, Walsh CT. The behavior and significance of slow-binding enzyme inhibitors. Advances in enzymology and related areas of molecular biology 1988;61:201-301.

49. Peraramelli S, Rosing J, Hackeng TM. TFPI-dependent activities of protein S. Thromb Res 2012;129 Suppl 2:S23-6.

50. Higuchi DA, Wun TC, Likert KM, et al. The effect of leukocyte elastase on tissue factor pathway inhibitor. Blood 1992;79(7):1712-9.

51. Peraramelli S, Thomassen S, Heinzmann A, et al. Direct inhibition of factor VIIa by TFPI and TFPI constructs. J Thromb Haemost 2013;11(4):704-14.

52. Peraramelli S, Thomassen S, Heinzmann A, et al. Inhibition of tissue factor:factor VIIa-catalyzed factor IX and factor X activation by TFPI and TFPI constructs. J Thromb Haemost 2014; 12(11):1826-37.

53. Bing DH, Cory M, Fenton JW, 2nd. Exo-site affinity labeling of human thrombins. Similar labeling on the A chain and B chain/fragments of clotting 
alpha- and nonclotting gamma/beta-thrombins. J Biol Chem 1977;252(22):802734.

54. Furie B, Bing DH, Feldmann RJ, et al. Computer-generated models of blood coagulation factor Xa, factor IXa, and thrombin based upon structural homology with other serine proteases. The Journal of biological chemistry 1982;257(7):3875-82. 



\section{Chapter 2}

\section{TFPI-dependent activities of protein $\mathrm{S}$}

Peraramelli S, Rosing J, Hackeng TM

Thrombosis Research 2012; 129 Suppl 2:S23-6 
Chapter 2 


\section{Abstract}

Protein $\mathrm{S}$ is an essential anticoagulant protein that acts as a cofactor for full length tissue factor pathway inhibitor (TFPI) and activated protein C (APC) in the down regulation of coagulation. Protein S enhances APC-mediated inactivation of the coagulation factors Va and VIIIa, and it stimulates inhibition of factor (F) Xa by TFPI. Because TFPI is a tight binding, but slow inhibitor of FXa, the TFPI/protein $\mathrm{S}$ system fails to regulate FXa generation at high tissue factor/FVIIa concentrations. In this review, we explain how TFPI/protein $S$ can regain its activity at high tissue factor concentrations in the presence of APC, resulting in an intertwinement of TFPI- and APC-cofactor activities of protein S, and making TFPI a major determinant of APC-anticoagulant activity in plasma. 


\section{Introduction}

In the previous century, incidental observations were reported in which protein $S$ was shown to express anticoagulant activity in plasma, in the absence of activated protein $C(1,2)$. At the same time, similar activities were attributed to purified protein S preparations $(1,3,4)$. However, these activities could be explained by in vitro modifications during purification of protein $S$ (5-7). Later, the APCindependent activity of protein $\mathrm{S}$ in plasma was shown to be dependent on the amount of tissue factor (TF) used for initiation of coagulation (8), and subsequently the role of protein $\mathrm{S}$ as cofactor for TFPI was uncovered (9). The anticoagulant activity of the TFPI/protein S system on thrombin generation is particularly observed at low tissue factor concentrations. When TF concentrations were varied in thrombin generation assays, large procoagulant effects of neutralization of the TFPI/protein S pathway by anti-protein S antibodies were observed at low $(\sim 1$ pM) TF, whereas anti-protein S antibodies lost their effect at 14 pM TF and higher (8). An example is shown at $1 \mathrm{pM} \mathrm{TF}$, where neutralization of TFPI/protein $\mathrm{S}$ by anti-protein $\mathrm{S}$ antibodies resulted in doubling of thrombin generation in plasma (Fig. 1A).

When thrombin generation was initiated with the same amount of TF in TFPIdepleted plasma, thrombin generation was increased and lag times decreased because of the lack of an essential natural anticoagulant. However, anti-protein S antibodies had no effect on thrombin generation, indicating that the expression of 
APC-independent anticoagulant activity of protein $\mathrm{S}$ in plasma requires the presence of full length TFPI (Fig. 1B). When TF-concentrations are above a certain threshold for example at $14 \mathrm{pM}$ TF, FXa formation escapes regulation by TFPI (8) (Fig. 1C). Hence the TFPI/protein $\mathrm{S}$ system is unable to inhibit thrombin generation under these conditions. TFPI is a multi-modular Kunitz-(K)-type inhibitor that first needs to interact and inhibit FXa through its $\mathrm{K} 2$ domain before effectively inhibiting the physiological activator complex of TF and FVIIa through its K1 domain (11).

The inhibition of FXa is of a biphasic, slow tight binding nature, in which an initial rapidly formed encounter complex slowly rearranges into a tight FXa-TFPI* complex (Scheme 1), During the first step, a small amount of loose complex between K2 of TFPI and FXa is rapidly formed (FXa-TFPI, Scheme 1) which results in fast inhibition of part of the generated FXa. During the second step, slow rearrangement of this initial complex results in formation of the final tight FXaTFPI* complex (11).

The dissociation constant of the first rapid equilibrium is represented by $\mathrm{K}_{\mathrm{i}}$ and the overall equilibrium constant after the slow rearrangement is represented by $\mathrm{K}_{\mathrm{i}}{ }^{*}$. The $\mathrm{K}_{\mathrm{i}}^{*}$ for the final tight complex $(0.05-0.07 \mathrm{nM})$ is several orders of magnitude lower than $\mathrm{K}_{\mathrm{i}}$ for the initial encounter complex $(5-15 \mathrm{nM})(9,12)$. More recently it has become clear that protein $\mathrm{S}$ acts as a cofactor for full length TFPI in the inhibition of free FXa by stimulating the initial interaction with TFPI. It does so by 
decreasing the $\mathrm{K}_{\mathrm{i}}$ for the initial FXa-TFPI encounter complex formation 10-fold (9, 13) (Table 1).

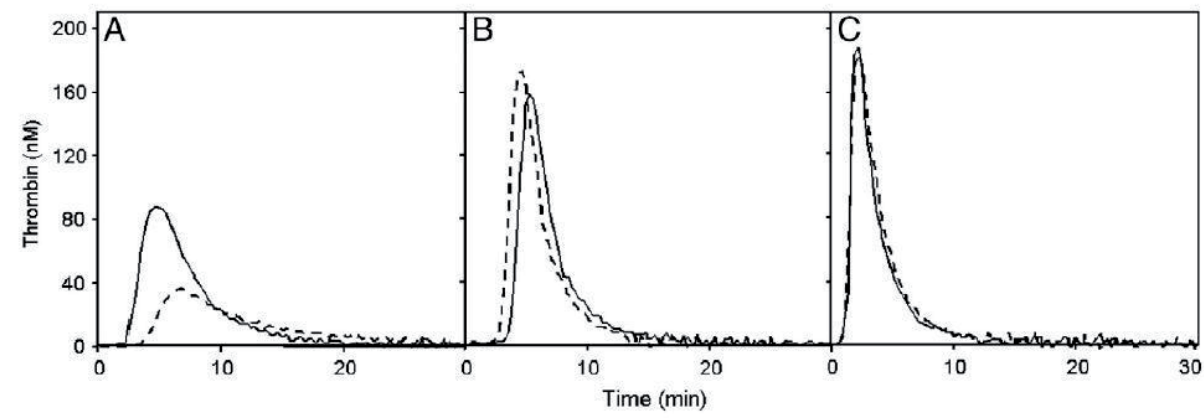

Fig. 1. TFPI/protein $S$ anticoagulant pathway and its dependence on TF concentration in the absence of APC. Thrombin generation in recalcified citrated plasma was continuously followed with fluorogenic substrate I-1140 (Z-Gly-Gly-Arg-AMC.HCl) in the presence of $20 \mu$ M phospholipid vesicles (20/60/20 DOPS/DOPC/DOPE), $16 \mathrm{mM} \mathrm{CaCl}$, and $30 \mu \mathrm{g} / \mathrm{ml}$ corn trypsin inhibitor (final concentrations) (8). Thrombin generation was initiated with TF in the absence (dashed lines) or presence (solid lines) of polyclonal anti-protein $S$ antibodies $(2.73 \mu \mathrm{M} \operatorname{IgG})$. A: Thrombin generation is initiated by $1.5 \mathrm{pM}$ TF in normal pooled plasma, anti-protein $S$ antibodies caused an increase in thrombin generation because of impairment of the TFPI/protein S system. B: Thrombin generation is initiated by 1.5 pM TF in TFPI depleted plasma, anti-protein $S$ antibodies showed no effect. C: Thrombin generation is initiated by 14 pM TF in normal pooled plasma, anti-protein $S$ antibodies showed no effect. Averages of duplicate measurements are shown. Adapted from (10). 


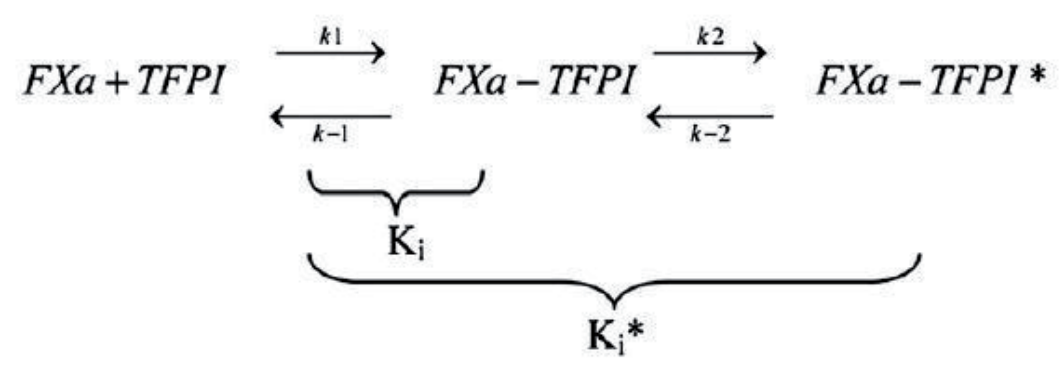

Scheme 1. Biphasic inhibition of FXa by TFPI.

TFPI cofactor activity is restricted to full length TFPI only, as protein S fails to stimulate truncated TFPI that lacks the K3 domain and the C-terminus (9). Later it was shown that protein $\mathrm{S}$ bound to the K3 domain of TFPI (14). The molecular mechanism by which protein $\mathrm{S}$ enhances the formation of the FXa-TFPI complex as well as the precise mechanism by which TFPI inhibits TF/FVIIa is still under debate. It was proposed that TFPI inhibits TF/FVIIa via a two step feed-back mechanism that involves formation of a bimolecular FXa/TFPI complex that subsequently interacts with TF/FVIIa, yielding an inactive quaternary complex and resulting in termination of TF/FVIIa-catalyzed FX activation $(11,15)$. In this model, the initial formation of a binary FXa-TFPI complex is a prerequisite for the inhibition of TF/FVIIa by TFPI (11). 
Table 1: Kinetic parameters for biphasic FXa inhibition by TFPI.

\begin{tabular}{|c|c|c|}
\hline & $\mathrm{K}_{\mathrm{i}}$ & $\mathrm{K}_{\mathrm{i}}^{*}$ \\
\hline TFPI & $5-15 \mathrm{nM}$ & $0.05-0.07 \mathrm{nM}$ \\
\hline TFPI + protein S & $0.5 \mathrm{nM}$ & $0.02 \mathrm{nM}$ \\
\hline
\end{tabular}

Data taken from $(9,12)$.

Alternatively, a more likely mechanism was proposed in which TFPI directly inhibits the trimolecular TF/FVIIa/FXa complex through primary Kunitz-2-FXa and secondary Kunitz-1-FVIIa interactions (16). Regarding the TFPI-cofactor activity of protein $S$, it was initially suggested that protein $S$ accelerated the total feedback inhibition of the TF-mediated coagulation pathway (9). However, more recently it was proposed that TFPI stimulation by protein $S$ only affects the inhibition of free FXa, and that protein $\mathrm{S}$ would be less important for the final inhibition of the TF-FVIIa-(FXa) complex by TFPI (13). The identification of protein $\mathrm{S}$ as a cofactor for TFPI explains why TFPI is such an important inhibitor despite its low physiological concentration of $0.25 \mathrm{nM}$ in plasma $(17,18)$. At a $\mathrm{K}_{\mathrm{i}}$ of $5 \mathrm{nM}$ for the formation of the FXa-TFPI encounter complex, full-length TFPI $(0.25 \mathrm{nM})$ would be a poor inhibitor of thrombin generation in plasma (19). By reducing the $\mathrm{K}_{\mathrm{i}}$ of initial FXa-TFPI encounter complex formation from $5 \mathrm{nM}$ to 0.5 $\mathrm{nM}$ (Table 1), protein S brings the TFPI concentration necessary for effective FXainhibition well within range of the full-length TFPI concentration $(0.25 \mathrm{nM})$ in 
plasma. The question remains why TFPI/protein $\mathrm{S}$ fails to regulate thrombin generation at high (14 pM) TF concentration, because under these conditions, the plasma concentration of free full length TFPI $(0.25 \mathrm{nM})$ is still in more than 10 fold excess of TF and 10-fold over the reported $\mathrm{K}_{\mathrm{i}}^{*}$ for the final tight complex of FXa/TFPI of $\sim 0.02 \mathrm{nM}$ (Table 1$)(9,12)$. Under these conditions theoretically $>90 \%$ of TF/FVIIa, FXa, and thrombin generation should be inhibited, which is not the case (Fig. 1C). The fact that TFPI is unable to regulate thrombin generation at high TF concentrations is likely caused by TFPI's slow acting inhibitory mechanism (20). At high TF concentrations the rate of FXa formation occurs at such a rapid rate that before appreciable inhibition of TF-FVIIa-FXa by TFPI occurs, the amounts of FXa formed are already sufficient for optimal thrombin generation. In this view, an experiment was designed to slow down FXa generation at high TF concentration by attenuating thrombin generation with APC. APC is a very effective inhibitor of thrombin generation even at high TF concentrations (Fig. 2). Interestingly, inhibitory antibodies against protein S almost fully blocked APC anticoagulant activity, making APC activity in plasma for more than 95\% dependent on protein S (Fig. 2). Under conditions of high TF concentrations in presence of APC, thrombin generation is substantially slowed down and TFPI might get sufficient time to block the TF pathway before thrombin generation and clotting can occur. Plasma depleted of protein S as well as TFPI was reconstituted with protein S, TFPI, or both, in the absence or presence of APC and thrombin 
generation was measured at a high TF concentration (14 pM). In the absence of APC, reconstitution of plasma with TFPI, protein $\mathrm{S}$ or both did not significantly decrease thrombin generation because FXa generation is too rapid at high TF concentrations and can escape regulation by TFPI (Fig. 3A). In the presence of APC, thrombin generation was not inhibited in the absence of protein $S$, because APC is fully dependent on its cofactor protein S for its anticoagulant activity in plasma (Fig. 3B). Also, reconstitution of TFPI had no effect, as thrombin generation in the presence of APC, but in the absence of protein S is still too rapid for TFPI to regulate (Fig. 3B). Reconstitution of protein S in presence of APC, but in the absence of TFPI, resulted in a significant reduction of thrombin generation by APC-mediated inactivation of FVa and FVIIIa (Fig. 3B). When TFPI was added in presence of protein $\mathrm{S}$ and $\mathrm{APC}$, an additional decrease was observed resulting in almost complete inhibition of thrombin generation (Fig. 3B).

Therefore, when coagulation is slowed down at high TF concentration by APC, TFPI/protein $\mathrm{S}$ regains grip on regulation of FX activation, very effectively inhibiting the residual thrombin generation. This observation also explains a previously interesting observation when analytical determinants were investigated from the so called normalized APC sensitivity ratio assay (nAPCsr). In this assay, the efficiency of added APC to plasmas of healthy individuals or patients can be measured (21). This assay is widely used to measure the plasma intermediate phenotype of genetic and acquired disorders leading to an increased risk for 
thrombosis, and the obtained nAPCsr strongly correlated with the relative risk on thrombosis of the disorders measured with this assay (22).

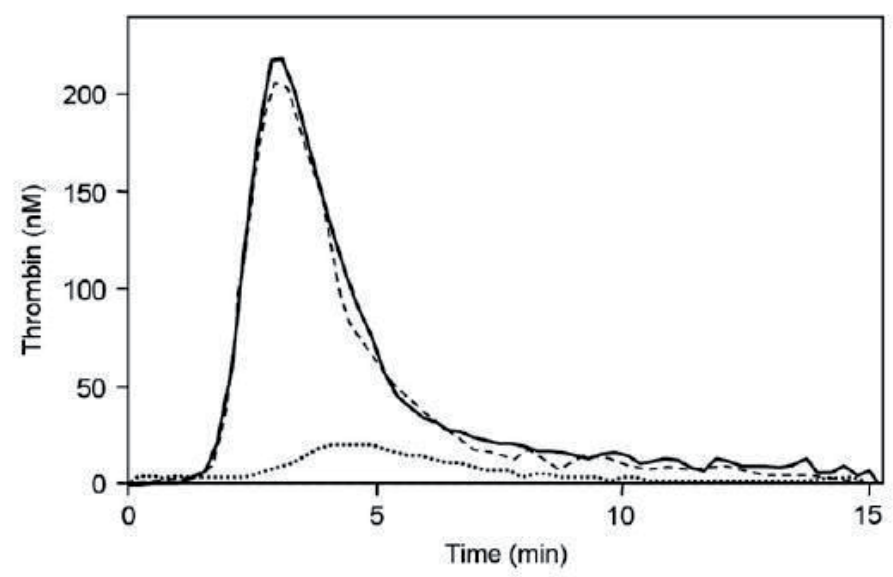

Fig. 2. Effect of APC and protein $S$ on thrombin generation at high TF concentration. Thrombin generation in recalcified citrated plasma was continuously followed with fluorogenic substrate I-1140 (Z-Gly-Gly-Arg-AMC.HCl) in the presence of $20 \mu \mathrm{M}$ phospholipid vesicles (20/60/20 DOPS/DOPC/DOPE), $16 \mathrm{mM} \mathrm{CaCl}$, and $30 \mu \mathrm{g} / \mathrm{ml} \mathrm{corn}$ trypsin inhibitor (final concentrations). Thrombin generation was initiated with $14 \mathrm{pMTF}$ in the absence (solid line) or presence (dotted line) of $3 \mathrm{nM} \mathrm{APC.} \mathrm{Polyclonal} \mathrm{antibodies}$ against protein $S(2.73 \mu \mathrm{MIgG})$ in the presence of APC fully inhibit APC function(dashed line). Averages of duplicate measurements are shown.

Next to protein S, TFPI was found to be the major determinant for this assay, although TFPI does not seem to be related directly to APC activity (24). From the experiment depicted in Fig. 3 this can now easily be understood. When APC is added to plasma, only part of the observed decrease in thrombin generation is actually caused by APC/protein S anticoagulant activity (Fig. 3B:a), the rest is 
caused by TFPI/protein S (Fig. 3B:b), regaining activity as a result of attenuation of coagulation by APC/protein S. In the nAPCsr assay, APC is added to plasma in which protein $\mathrm{S}$ and TFPI are present, and the overall decrease in thrombin generation is a combination of APC/protein S and TFPI/protein S anticoagulant activities (Fig. 3B:c).
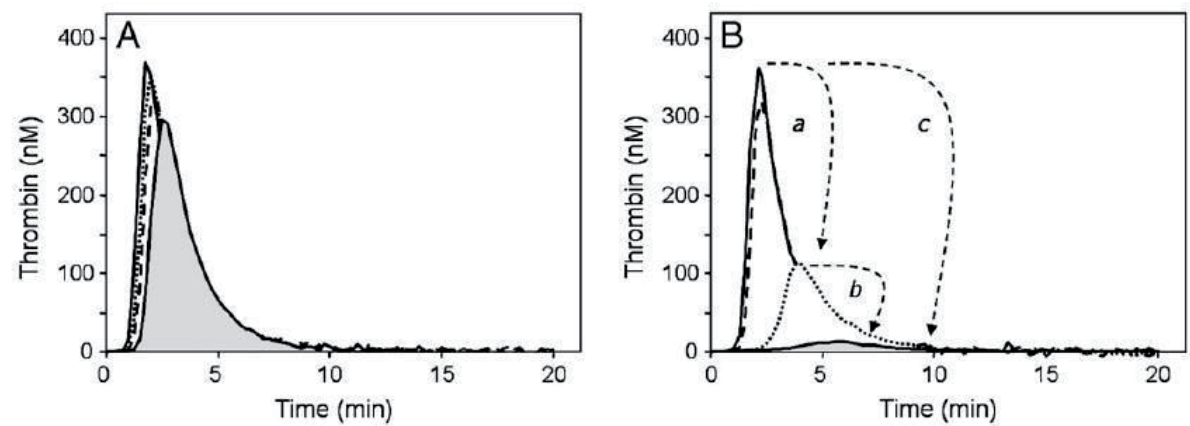

Fig. 3. TFPI/protein $S$ regains activity at high TF concentrations when thrombin generation is attenuated by APC. Thrombin generation in recalcified citrated plasma depleted from both protein $S$ and TFPI was continuously followed with fluorogenic substrate I-1140 (Z-Gly-Gly-Arg-AMC.HCl) in the presence of $20 \mu M$ phospholipid vesicles (20/60/20 DOPS/DOPC/DOPE) and $16 \mathrm{mM} \mathrm{CaCl} 2$ (final concentrations). Thrombin generation was initiated with 14 pM TF in the absence (A) or presence (B) of 3 nM APC. Protein S-TFPI depleted plasma was reconstituted with TFPI (dashed line), protein S (dotted line) or both (solid line; grey fill). Averages of duplicate measurements are shown. Adapted from (23).

Under these conditions, variations in endogenous TFPI will undoubtedly affect the inhibition of thrombin generation as a result of addition of APC, explaining why TFPI is a major determinant of the anticoagulant effect of APC in plasma. An 
important question to be addressed is whether the TFPI/protein S anticoagulant mechanism has in vivo significance. It is known that TFPI and protein S each are essential anticoagulants, as TFPI- as well as protein S-null mice die intra-uterine $(25,26)$, but the in vivo mutual dependence of these important anticoagulant factors still needs to be proven. As TFPI/protein S regulates thrombin generation only at low procoagulant stimuli, TFPI/protein $\mathrm{S}$ will be most effective as a first barrier against procoagulant events induced by low tissue factor exposure to the circulation. In this way, the TFPI system could act as a gate keeper to suppress prothrombotic effects of low levels of circulating tissue factor thereby maintaining the hemostatic balance $(8,27)$. In view of the combined TFPI/protein $S$ anticoagulant activity, it is interesting to note that all of TFPI and half of protein S is synthesized by endothelial cells (28-30), localizing production to a major site of anticoagulant need; the vessel wall. $80 \%$ of total TFPI remains associated with the vessel wall and represents a large depot of TFPI, of which the function and actual contribution to the anticoagulant potential still has to be elucidated $(18,31)$. Part of the vessel wall TFPI is full length TFPI bound to glycosaminoglycans, and can be released by addition of heparin, resulting in a 5-10 fold increase in circulating free, full length TFPI (32). The potential anticoagulant relevance of this vessel wall associated full length TFPI was illustrated by the observation that in young patients with venous thrombosis the amounts of releasable TFPI were significantly lower than in control subjects (33). The TFPI/protein S anticoagulant mechanism was 
confirmed by the observations that protein S levels correlate with TFPI-activity in normal individuals (34) and that TFPI and protein $\mathrm{S}$ form a complex in plasma (35). As a result, protein S and TFPI levels covariate in normal individuals and in hereditary as well as acquired states of protein S deficiency (35). It was proposed that binding to protein S protects TFPI against proteolysis in the lysine-rich Cterminus of TFPI, preventing truncation and inactivation of TFPI. The fact that protein $\mathrm{S}$ deficiency is accompanied by TFPI deficiency raised the question whether the decrease in TFPI is the actual key to the prothrombotic risk associated with protein $\mathrm{S}$ deficiency. At least in vitro studies show that normalization of TFPI levels in heterozygous protein S-deficient families had a much larger effect on decreasing thrombin generation than normalization of protein S levels (35). 


\section{References}

1. Hackeng TM, van 't Veer C, Meijers JC, et al. Human protein S inhibits prothrombinase complex activity on endothelial cells and platelets via direct interactions with factors Va and Xa. J Biol Chem 1994;269(33):21051-8.

2. van't Veer C, Hackeng TM, Biesbroeck D, et al. Increased prothrombin activation in protein S-deficient plasma under flow conditions on endothelial cell matrix: an independent anticoagulant function of protein $S$ in plasma. Blood 1995;85(7):1815-21.

3. Heeb MJ, Mesters RM, Tans G, et al. Binding of protein S to factor Va associated with inhibition of prothrombinase that is independent of activated protein C. J Biol Chem 1993;268(4):2872-7.

4. Heeb MJ, Rosing J, Bakker HM, et al. Protein S binds to and inhibits factor Xa. Proc Natl Acad Sci U S A 1994;91(7):2728-32.

5. Mitchell CA, Kelemen SM, Salem HH. The anticoagulant properties of a modified form of protein S. Thromb Haemost 1988;60(2):298-304.

6. Sere KM, Janssen MP, Willems GM, et al. Purified protein S contains multimeric forms with increased APC-independent anticoagulant activity. Biochemistry 2001;40(30):8852-60.

7. Sere KM, Willems GM, Rosing J, et al. Protein S multimers are generated in vitro and affect protein S structure-function analyses. Semin Hematol 2006;43(1 Suppl 1):S111-20. 
8. Sere KM, Rosing J, Hackeng TM. Inhibition of thrombin generation by protein $\mathrm{S}$ at low procoagulant stimuli: implications for maintenance of the hemostatic balance. Blood 2004;104(12):3624-30.

9. Hackeng TM, Sere KM, Tans G, et al. Protein S stimulates inhibition of the tissue factor pathway by tissue factor pathway inhibitor. Proc Natl Acad Sci U S A 2006;103(9):3106-11.

10. Castoldi E, Hackeng TM. Regulation of coagulation by protein S. Curr Opin Hematol 2008;15(5):529-36.

11. Girard TJ, Warren LA, Novotny WF, et al. Functional significance of the Kunitz-type inhibitory domains of lipoprotein-associated coagulation inhibitor. Nature 1989;338(6215):518-20.

12. Huang ZF, Wun TC, Broze GJ, Jr. Kinetics of factor Xa inhibition by tissue factor pathway inhibitor. J Biol Chem 1993;268(36):26950-5.

13. Ndonwi M, Broze G, Jr. Protein S enhances the tissue factor pathway inhibitor inhibition of factor Xa but not its inhibition of factor VIIa-tissue factor. $\mathrm{J}$ Thromb Haemost 2008;6(6):1044-6.

14. Ndonwi M, Tuley EA, Broze GJ, Jr. The Kunitz-3 domain of TFPI-alpha is required for protein S-dependent enhancement of factor Xa inhibition. Blood 2010;116(8):1344-51. 
15. Broze GJ, Jr., Warren LA, Novotny WF, et al. The lipoprotein-associated coagulation inhibitor that inhibits the factor VII-tissue factor complex also inhibits factor Xa: insight into its possible mechanism of action. Blood 1988;71(2):335-43. 16. Baugh RJ, Broze GJ, Jr., Krishnaswamy S. Regulation of extrinsic pathway factor Xa formation by tissue factor pathway inhibitor. J Biol Chem 1998;273(8):4378-86.

17. Sandset PM, Abildgaard U. Extrinsic pathway inhibitor--the key to feedback control of blood coagulation initiated by tissue thromboplastin. Haemostasis 1991;21(4):219-39.

18. Novotny WF, Brown SG, Miletich JP, et al. Plasma antigen levels of the lipoprotein-associated coagulation inhibitor in patient samples. Blood 1991;78(2):387-93.

19. Mast AE, Broze GJ, Jr. Physiological concentrations of tissue factor pathway inhibitor do not inhibit prothrombinase. Blood 1996;87(5):1845-50.

20. Broze GJ, Jr., Girard TJ, Novotny WF. Regulation of coagulation by a multivalent Kunitz-type inhibitor. Biochemistry 1990;29(33):7539-46.

21. Nicolaes GA, Thomassen MC, Tans G, et al. Effect of activated protein C on thrombin generation and on the thrombin potential in plasma of normal and APC-resistant individuals. Blood Coagul Fibrinolysis 1997;8(1):28-38. 
22. Curvers J, Thomassen MC, Rimmer J, et al. Effects of hereditary and acquired risk factors of venous thrombosis on a thrombin generation-based APC resistance test. Thromb Haemost 2002;88(1):5-11.

23. Hackeng TM, Maurissen LF, Castoldi E, et al. Regulation of TFPI function by protein S. J Thromb Haemost 2009;7 Suppl 1:165-8.

24. de Visser MC, van Hylckama Vlieg A, Tans G, et al. Determinants of the APTT- and ETP-based APC sensitivity tests. J Thromb Haemost 2005;3(7):148894.

25. Huang ZF, Higuchi D, Lasky N, et al. Tissue factor pathway inhibitor gene disruption produces intrauterine lethality in mice. Blood 1997;90(3):944-51.

26. Saller F, Brisset AC, Tchaikovski SN, et al. Generation and phenotypic analysis of protein S-deficient mice. Blood 2009;114(11):2307-14.

27. Hoffman M, Whinna HC, Monroe DM. Circulating tissue factor accumulates in thrombi, but not in hemostatic plugs. J Thromb Haemost 2006;4(9):2092-3.

28. Bajaj MS, Kuppuswamy MN, Saito H, et al. Cultured normal human hepatocytes do not synthesize lipoprotein-associated coagulation inhibitor: evidence that endothelium is the principal site of its synthesis. Proc Natl Acad Sci U S A 1990;87(22):8869-73. 
29. Stern D, Brett J, Harris K, et al. Participation of endothelial cells in the protein C-protein S anticoagulant pathway: the synthesis and release of protein S. J Cell Biol 1986;102(5):1971-8.

30. Burstyn-Cohen T, Heeb MJ, Lemke G. Lack of protein S in mice causes embryonic lethal coagulopathy and vascular dysgenesis. J Clin Invest 2009;119(10):2942-53.

31. Lindahl AK, Sandset PM, Abildgaard U. The present status of tissue factor pathway inhibitor. Blood Coagul Fibrinolysis 1992;3(4):439-49.

32. Sandset PM, Abildgaard U, Larsen ML. Heparin induces release of extrinsic coagulation pathway inhibitor (EPI). Thromb Res 1988;50(6):803-13.

33. Ariens RA, Alberio G, Moia M, et al. Low levels of heparin-releasable tissue factor pathway inhibitor in young patients with thrombosis. Thromb Haemost 1999;81(2):203-7.

34. Dahm AE, Sandset PM, Rosendaal FR. The association between protein S levels and anticoagulant activity of tissue factor pathway inhibitor type 1. J Thromb Haemost 2008;6(2):393-5.

35. Castoldi E, Simioni P, Tormene D, et al. Hereditary and acquired protein S deficiencies are associated with low TFPI levels in plasma. J Thromb Haemost 2010;8(2):294-300. 



\section{Chapter 3}

\section{The Kunitz 1 and Kunitz 3 domains of tissue factor pathway inhibitor are required for efficient inhibition of \\ factor Xa}

Peraramelli S, Suylen DPL, Rosing J, Hackeng TM

Thrombosis and Hemostasis 2012; 108(2):266-76 
Chapter 3 


\section{Abstract}

Tissue factor pathway inhibitor (TFPI) is a slow tight-binding inhibitor that inhibits factor $(\mathrm{F}) \mathrm{Xa}$ in a biphasic fashion: a rapid formation of loose FXa $\bullet$ TFPI encounter complex is followed by slow rearrangement into a tight FXa•TFPI* complex in which the Kunitz-2 (K2) domain of TFPI binds and inhibits FXa. In the current study, full-length TFPI (TFPI $\mathrm{FL}_{\mathrm{F}}$ ) and various truncated TFPI constructs were used to assess the importance of TFPI domains other than K2 in the inhibition of FXa. In the absence of $\mathrm{Ca}^{2+}$-ions, FXa was more effectively inhibited by $\mathrm{TFPI}_{\mathrm{FL}}$ than Gla-domain less FXa. In turn, $\mathrm{Ca}^{2+}$-ions impaired FXa inhibition by $\mathrm{TFPI}_{\mathrm{FL}}$ but not by TFPI constructs that lack the $\mathrm{C}$-terminus. This suggests that, in absence of $\mathrm{Ca}^{2+}$ ions, interactions between the C-terminus of TFPI and the Gla-domain of FXa promote FXa-inhibition. TFPI $\mathrm{FL}_{\text {and }}$ K2K3 had similar efficiencies for encounter complex formation. However, K2K3 showed monophasic inhibition instead of biphasic inhibition, indicating absence of rearrangement into a tight complex. $\mathrm{K} 1 \mathrm{~K} 2$ and $\mathrm{TFPI}_{1-161}$ showed biphasic inhibition, but had less efficient encounter complex formation than $\mathrm{TFPI}_{\mathrm{FL}}$. Finally, K2K3 was a 10-fold more efficient FXainhibitor than K2. These results indicate that K3-C-terminus enhances the formation of encounter complex and that $\mathrm{K} 1$ is required for isomerisation of the encounter- into tight complex. Since TFPI $\mathrm{FL}_{\mathrm{FL}}$ has a 10 -fold higher $\mathrm{K}_{\mathrm{i}}$ than $\mathrm{K} 2 \mathrm{~K} 3-\mathrm{C}$ terminus, we propose that $\mathrm{K} 1$ is not only required for the transition of the loose to 


\section{Chapter 3}

the tight FXa•TFPI* complex, but also inhibits FXa•TFPI encounter complex formation. This inhibitory activity is counteracted by $\mathrm{K} 3$ and $\mathrm{C}$-terminus. 


\section{Introduction}

Blood coagulation is initiated when the sub-endothelium is exposed to the blood after vascular injury. This injury exposes the integral membrane protein tissue factor (TF) $(1,2)$ which forms a complex with plasma factor VIIa (FVIIa) (3) that initiates the so-called extrinsic coagulation pathway by activating factor X (FXa) $(4,5)$. TF-FVIIa-catalysed FX activation is regulated by tissue factor pathway inhibitor (TFPI), a Kunitz type inhibitor present in plasma at a concentration of 2.5 $\mathrm{nM}$ (6-8). TFPI consists of an acidic amino terminus, three tandem Kunitz domains (K1, K2 and K3) connected by respective stretches of 20 and 41 amino acids and a basic carboxyl terminus (C-terminus) (9). It has been reported that the K2 domain of TFPI binds to and inhibits FXa and that the K1 domain is responsible for inhibition of FVIIa. K3 does not have any inhibitory function but appears to be involved in the binding of heparin-like substances (10) and protein $\mathrm{S}$ which enhances FXa inhibition by TFPI $(11,12)$. TFPI inhibits the TF-FVIIa complex through the formation of a quaternary FXa-TFPI-FVIIa-TF complex in which both the catalytic activities of FXa and FVIIa are inhibited $(13,14)$. FXa inhibition by TFPI takes place by a two-step mechanism called slow-tight binding inhibition. This inhibition is characterised by rapid formation of a loose encounter complex between enzyme (FXa) and inhibitor (TFPI) which subsequently slowly isomerises to a tight FXa•TFPI complex (14-16). Although K2 binds to and inhibits FXa, qualitative evidence was obtained that other Kunitz domains may also be required 
for efficient inhibition of FXa $(17,18)$. Our study is focused on understanding the mechanism of FXa inhibition by TFPI and the role of different Kunitz domains and the C-terminal domain of TFPI in the formation of loose and tight FXa•TFPI complexes. To obtain information on the function of the different TFPI domains in the mechanism of inhibition of FXa, we have performed a detailed kinetic analysis of FXa inhibition by $\mathrm{TFPI}_{\mathrm{FL}}$ and a number of chemically synthesized Kunitz domains and recombinant TFPI constructs.

\section{Materials and methods}

\section{Materials}

The chromogenic substrates CS-11(65) (N- $\alpha$-Benzyloxycarbonyl-D-arginylLglycyl-L-arginine-p-nitroaniline-dihydrochloride) and S2238 (H-D-PhenylalanylL-pipecolyl-L-arginine-p-nitroaniline-dihydrochloride) were purchased from Hyphen BioMed (Mason, OH, USA) and Instrumentation Laboratory BV (Breda, The Netherlands), respectively. 1,2-Dioleoyl-snglycero-3-phosphocholine (DOPC), 1,2-dioleoyl-sn-glycero3-phosphoserine (DOPS), and 1,2-dioleoyl-sn-glycero-3phosphoethanolamine (DOPE) were obtained from Avanti Polar Lipids (Delfzijl, The Netherlands). Phospholipid vesicles (20\% DOPS, 20\% DOPE, and 60\% DOPC) were prepared as described (19). $\mathrm{CaCl}_{2}, \mathrm{NaCl}$ and EDTA were obtained from Merck Chemicals (Darmstadt, Germany). HEPES, Tris-hydrochloride, bovine 
serum albumin (BSA), Ovalbumin and reagents for SDS-PAGE were obtained from Sigma Aldrich (Zwijndrecht, The Netherlands).

\section{Proteins}

Both full length TFPI (TFPI $\left.{ }_{\mathrm{FL}}\right)$ and truncated TFPI $\left(\mathrm{TFPI}_{1-161}\right)$ were a kind gift from Dr. Lindhout (Cardiovascular Research Institute Maastricht). TFPI $\mathrm{FL}_{\mathrm{FL}}$ was produced in bacterial expression system (Escherichia coli) and $\mathrm{TFPI}_{1-161}$ was produced in yeast expression system (Saccharomyces cerevisiae). Purification and characterisation of both TFPI forms has been discussed earlier $(20,21)$. Working stock solutions of full length and truncated TFPI of $200 \mathrm{nM}$ were made in $25 \mathrm{mM}$ HEPES, $175 \mathrm{mM} \mathrm{NaCl}(\mathrm{pH} 7.5)$ and $5 \mathrm{mg} / \mathrm{ml} \mathrm{BSA}$ (HNBSA) and stored at $-80{ }^{\circ} \mathrm{C}$. Kunitz 2 (amino acid residues 92-150, K2), Kunitz 1 linker Kunitz 2 (13-150, K1K2) and Kunitz 2 linker Kunitz 3 (92-241, K2K3) were obtained by solid phase peptide synthesis and native chemical ligation. Synthesized peptides were dissolved in $25 \mathrm{mM}$ HEPES and175 $\mathrm{mM} \mathrm{NaCl}$ ( $\mathrm{HN}$ buffer) and stored at $-20{ }^{\circ} \mathrm{C}$. Human FXa (FXa) has been purchased from Kordia (Leiden, the Netherlands) and bovine FXa was purified from bovine plasma (22). HLE was purchased from Elastin Products (Pacific, MO, USA) and Elastase inhibitor III (CMK) from Merck Chemicals. Gla-domain less human FXa (GD-FXa) and protein S were from Haematologic Technologies (Essex Junction, VT, USA). 


\section{Peptide synthesis}

$\mathrm{K} 2$, K1K2 and K2K3 were synthesized using solid phase peptide synthesis and native chemical ligation. Peptides were prepared by manual solid phase peptide synthesis (SPPS) using the in situ neutralisation/benzotriazole-N,N,N',N'tetramethyl-uronium-hexafluoro-phosphate (HBTU, Peptides International, Louisville, KY, USA) activation procedure for Boc chemistry (23). Each synthetic cycle consisted of Na-Boc-removal by a 1-2 minutes ( $\mathrm{min})$ treatment with neat trifluoroacetic acid (TFA, Halocarbon, River Edge, NJ, USA), a 1 min N,Ndimethyl formamide-flow (DMF, Biosolve, Valkenswaard, the Netherlands) wash, a 10-20 min coupling time with $1.0 \mathrm{mmol}$ pre-activated Boc-amino acid (Nova Biochem, San Diego, CA, USA) in the presence of excess N,N,-diisopropyl ethanolamine (DIEA, Biosolve, Foster City, CA, USA), followed by a second DMF-flow wash. N $\alpha$-Boc amino acids $(1.1 \mathrm{mmol})$ were pre-activated for $3 \mathrm{~min}$ with $1.0 \mathrm{mmol}$ (2-(6-Chloro-1H-benzotriazole-1-yl)-1,1,3,3-tetramethylaminium hexafluoro-phosphate HCTU (0.5 M in DMF, Peptides International) in the presence of excess DIEA (3 mmol). After coupling of Gln residues, a dichloromethane flow wash was used before and after TFA-deprotection to prevent possible high temperature (TFA/DMF)-catalysed pyrrolidone carboxylic acid formation (23). Side-chain protected amino acids were: Boc-Arg (ptoluenesulfonyl)-OH (Midwest, Fishers, IN, USA), Boc-Asn/Gln(xanthyl)-OH (Midwest, Fishers, IN, USA), Boc-Asp (O-cyclohexyl)-OH, Boc-Cys(4- 
methylbenzyl)-OH, Boc-Glu (O-cyclohexyl)-OH, Boc-His (dinitrophenyl)-OH, Boc-Lys(2-Cl-Z)-OH, Boc-Ser(benzyl)-OH, Boc-Thr (benzyl)-OH, and Boc-Tyr (2-Br-Z)-OH. Other amino acids were used without side-chain protection. After chain assembly, the peptides were deprotected and cleaved from the resin by treatment with anhydrous hydrogen fluoride (HF, Sigma-Aldrich, St Louis, MO, USA) for 1 hour (h) at $0{ }^{\circ} \mathrm{C}$ with $4 \%$ p-cresol as a scavenger. Dinitrophenyl (Dnp) protecting groups on His remained on the thioester fragments since Dnp-removal could reduce C-terminal thioester bonds. Dnp was gradually removed by thiols during the ligation reaction yielding unprotected His. After cleavage, peptides were precipitated with ice-cold diethylether, dissolved in aqueous HPLC-grade acetonitrile (Biosolve, Valkenswaard, the Netherlands) and lyophilised. K2 (92150) was synthesised in one piece on 4-methyl-benzhydrylamine(MBHA, Anaspec, Fremont, CA, USA) resin. Thioester resin was prepared as described previously (24). After deprotection and cleavage from the resin, the polypeptides were purified by HPLC, lyophilised and stored at $-20{ }^{\circ} \mathrm{C}$ until use. K1K2 (16-150) was synthesised from three peptide fragments, Asp92-Gly58-MPAL; Cys(Thz)59Phe96-MPAL; Cys97-Gly150andtwo native chemical ligation reactions. Thioester (MPAL) resin was prepared as described previously (24). To avoid cyclisation or polymerization of the bifunctional middle fragment (59-96) that requires both an N-terminal Cys and a C-terminal MPAL ester, the N-terminal cysteine functionality was replaced by an encrypted cysteine; thiaproline (Thz). For 
thiaproline deprotection, TFPI 130-142 was dissolved in $0.1 \mathrm{M}$ Acetate, pH 5.0 containing $6 \mathrm{M}$ guanidine, and $100 \mathrm{mM}$ hydroxylamine. After $6 \mathrm{~h}, 95 \%$ was deprotected generating a free cysteine residue, and purified on HPLC. K2K3 (92241) was synthesised from 3 peptide fragments; Glu92-Gly129MPAL;Cys(Thz)130-Trp188-MPAL; Cys189-Lys241 and 2 subsequent native chemical ligations as described for K1K2.

\section{Native chemical ligation}

Native chemical ligation of unprotected synthetic peptide segments was performed as follows: $0.1 \mathrm{M}$ Tris buffer, $\mathrm{pH} 8$, containing $6 \mathrm{M}$ guanidine, $1 \%(\mathrm{v} / \mathrm{v})$ benzylmercaptan and $1 \%(\mathrm{v} / \mathrm{v})$ thiophenol was added to dry peptides resulting in a final peptide concentration of $1-3 \mathrm{mM}$ at $\mathrm{pH}$. The ligation reaction was performed in a heating block at $37{ }^{\circ} \mathrm{C}$ and was vortexed periodically to equilibrate the thiol additives.

\section{Oxidative folding}

TFPI constructs were dissolved in $0.1 \mathrm{M}$ Tris, $\mathrm{pH} 8.0$ containing $3 \mathrm{M}$ guanidine and $1 \mathrm{mM}$ cystine/8 $\mathrm{mM}$ cysteine as a redox couple. Mixtures were stirred for $48 \mathrm{~h}$ at $4{ }^{\circ} \mathrm{C}$, followed by analytical HPLC and analytical mass spectrometry, and purified using preparative HPLC. 


\section{High pressure liquid chromatography}

Analytical reversed-phase HPLC was performed on a Varian Prostar system using Vydac C-18 columns (5 $\mu \mathrm{m}, 0.46$ x $15 \mathrm{~cm}$ ). Semipreparative reversed-phase HPLC was performed on a Waters HPLC system using Vydac C-18 columns $(10 \mu \mathrm{m}, 1.0$ $2.5 \times 25 \mathrm{~cm})$. Linear gradients of acetonitrile in water/0.1\% TFA were used to elute bound peptides. The flow rates used were $1 \mathrm{ml} / \mathrm{min}$ (analytical), and $5 \mathrm{ml} / \mathrm{min}$ (semi preparative).

\section{Mass spectrometry}

Electrospray ionisation mass spectrometry (ESI-MS) was performed on an API150 single quadrupole mass spectrometer (Applied Biosystems, Nieuwerkerk aan den IJssel, the Netherlands). Peptide masses were calculated from the experimental mass to charge $(\mathrm{m} / \mathrm{z})$ ratios from all the observed protonation states of a peptide. Matrix assisted laser-desorption ionisation mass spectrometry (MALDI-MS) was performed on a ABI 4800 MALDI TOF/TOF proteomics analyser (Applied Biosystems) using $\alpha$-cyano-4 hydroxycinnamic acid (Aldrich, Milwaukee, WI, USA) as a matrix. Theoretical masses of peptides and proteins were calculated using MacProMass software (Beckman Research Institute, Duarte, CA, USA). Concentration determination of TFPI modules before every experiment, the concentration of TFPI $\mathrm{FL}_{\text {a }}$ and TFPI constructs was determined by titrating bovine

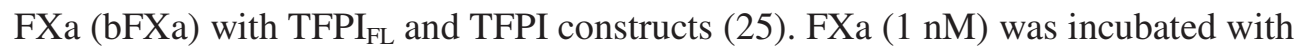


increasing concentrations of TFPI or TFPI constructs in $50 \mathrm{mM}$ Tris (pH 7.7), 175 $\mathrm{mM} \mathrm{NaCl}, 20 \mathrm{mM}$ EDTA and $0.5 \mathrm{mg} / \mathrm{ml}$ ovalbuminfor $60 \mathrm{~min}$ at room temperature. Since TFPI forms a 1:1 stochiometric complex with FXa $(6,13)$ the residual activity of bFXa determined with CS-11(65) allows calculation of the functional concentration of TFPI. Since the isolated K2 domain has a low affinity for bFXa, the concentration determination of $\mathrm{K} 2$ was performed at $50 \mathrm{nM}$ bFXa. Due to the high bFXa concentration, the residual FXa activity was measured with a chromogenic substrate with a low $\mathrm{k}_{\text {cat }}$ value for bFXa (S2238). The functional concentrations of TFPI and TFPI constructs were between $40 \%$ and $80 \%$ of the protein concentrations. We produced different preparations of the same constructs with different percentage functional activity, which yielded the same $\mathrm{K}_{\mathrm{i}}$ values in kinetic experiments (data not shown). This indicates that the fraction of the TFPI constructs that is not active does not interfere with FXa inhibition by TFPI.

\section{Inhibition of FXa by TFPI}

A reaction mixture containing $125 \mu \mathrm{M}$ of the FXa-specific chromogenic substrate CS-11(65), TFPI and if present, $100 \mathrm{nM}$ protein $\mathrm{S}$ and/or $40 \mu \mathrm{M}$ phospholipid vesicles (20:60:20 DOPS/DOPC/DOPE) were incubated in HNBSA buffer with 1 $\mathrm{mM}$ EDTA or $3 \mathrm{mM} \mathrm{CaCl}$ for $7 \mathrm{~min}$ at $37{ }^{\circ} \mathrm{C}$. Subsequently, human FXa was added and chromogenic substrate conversion, which is a measure for non-inhibited FXa, was followed at $405 \mathrm{~nm}$ in an Ultra Microplate Reader (Bio-Tek, Burlington, 
VT, USA) until a steady state rate of substrate conversion was achieved ( 40 min). The final concentrations in the well were: $0.1 \mathrm{nM}$ FXa, $125 \mu \mathrm{M} \mathrm{CS}-11(65)$, and 0$10 \mathrm{nM}$ TFPI $_{\mathrm{FL}}, 0-32 \mathrm{nM}$ TFPI $_{1-161}, 0-32 \mathrm{nM} \mathrm{K} 1 \mathrm{~K} 2,0-32 \mathrm{nM} \mathrm{K} 2$ or $0-8 \mathrm{nM}$ $\mathrm{K} 2 \mathrm{~K} 3$.

\section{Inhibition of Gla domain-less FXa by TFPI ${ }_{\mathrm{FL}}$ andTFPI $_{1-161}$}

Gla domain-less human FXa (GD-FXa) $(0.5 \mathrm{nM})$ was titrated with 0-40 nM $\mathrm{TFPI}_{\mathrm{FL}}$ in absence and presence of $\mathrm{Ca}^{2+}$ ions taking native human $\mathrm{FXa}$ as reference. TFPI $_{\mathrm{FL}}$ or TFPI $\mathrm{TF}_{1-161}$ and $125 \mu \mathrm{M}$ CS-11(65) were incubated in HNBSA with $1 \mathrm{mM}$ EDTA or $3 \mathrm{mM} \mathrm{CaCl} 2$ at $37{ }^{\circ} \mathrm{C}$. After $7 \mathrm{~min}$, FXa or GD-FXa was added and inhibition was followed by measuring CS-11(65) (N- $\alpha$-Benzyloxycarbonyl-Darginyl-Lglycyl-L-arginine-p-nitroaniline-dihydrochloride) conversion by FXa or GD-FXa as explained above.

\section{Kinetic analysis}

Inhibition of FXa by TFPI occurs via rapid formation of a loose FXa TFPI encounter complex that subsequently slowly isomerizes to a tight FXa TFPI* $^{*}$ complex $(14,16)$. 


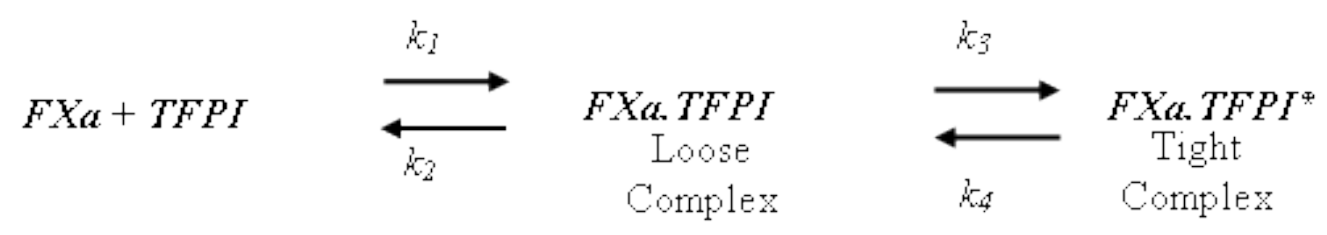

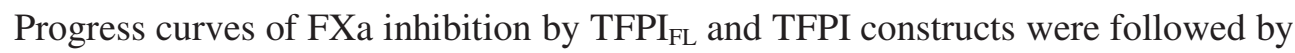
continuous measurement of chromogenic substrate conversion and fitting the data to the integrated rate equation (16) for slow-tight binding inhibition (eq. 1):

$A_{t}=A_{0}+\left(v_{s} \cdot t\right)+\left(v_{0}-v_{s}\right) \cdot\left(1-\exp \left(-k_{\text {obs }} \cdot t\right)\right) / k_{\text {obs }}($ eq. 1$)$

Where, $A_{t}$ is absorbance at $405 \mathrm{~nm}$ at time t; $A_{0}$ is initial absorbance at $405 \mathrm{~nm} ; \mathrm{v}_{\mathrm{s}}$ is final steady-state velocity; $\mathrm{v}_{0}$ is initial velocity; $\mathrm{k}_{\mathrm{obs}}$ is apparent rate constant for the transition from $\mathrm{v}_{0}$ to $\mathrm{v}_{\mathrm{s}}\left(\mathrm{FXa} \bullet\right.$ TFPI to FXa $\bullet$ TFPI*). The $\mathrm{v}_{0}$ and $\mathrm{v}_{\mathrm{s}}$ values were used to calculate the $\mathrm{K}_{\mathrm{i}}=[\mathrm{FXa}]$ [TFPI]/[FXa.TFPI] and the $\mathrm{K}_{\mathrm{i}}{ }^{*}=$ [FXa].[TFPI]/\{[FXa.TFPI] [FXa.TFPI*] $\}$.

\section{TFPI cleavage by human leukocyte elastase (HLE)}

$\operatorname{TFPI}_{\mathrm{FL}}(3 \mu \mathrm{M})$ was incubated with $100 \mathrm{nM}$ HLE in $0.05 \mathrm{M}$ Tris (pH 7.5), 0.1 M $\mathrm{NaCl}$ at room temperature. At specified time points ( $0,4,8$ and $24 \mathrm{~h}), 25 \mu \mathrm{l}$ of sample was removed from the reaction mixture and the elastase activity was blocked with $5 \mu$ l elastase inhibitor III (final concentration $385 \mathrm{nM}$ ). The HLE- 
cleaved TFPI present in the samples was analysed on 20\% SDS-PAGE and tested for its ability to inhibit human FXa. To this end, HLE-TFPI $(0,4,8$ and 24 h) or non-treated TFPI containing elastase inhibitor III were incubated with $125 \mu \mathrm{M}$ CS11(65) in HNBSA at $37{ }^{\circ} \mathrm{C}$. After 7 min pre-warmed FXa was added and FXa inhibition was monitored as described above. The final concentrations in the well were: $0.5 \mathrm{nM}$ FXa, $125 \mu \mathrm{M}$ CS-11(65) and 0, 0.2, 0.5, 1, 5, 10 and $20 \mathrm{nM} \mathrm{TFPI}_{\mathrm{FL}}$, $0,0.1,0.2,0.5,1,2$ and $5 \mathrm{nM}$ HLE-TFPI or $0,0.1,0.2,0.5,1,2$ and $5 \mathrm{nM} \mathrm{K} 2 \mathrm{~K} 3$. Similar experiments have also been performed in presence of $100 \mathrm{nM}$ protein $\mathrm{S}$ to check for the protein S co-factor activity in FXa inhibition by TFPI $_{\mathrm{FL}}$, HLE-TFPI and $\mathrm{K} 2 \mathrm{~K} 3$.

\section{Results}

\section{Chemical synthesis of TFPI constructs}

The amino acids comprising the TFPI constructs that were synthesized were chosen on basis of the intron exon boundaries of TFPI (Fig. 1A). Schematic representations of the rTFPI and synthesized TFPI modules used in the study are shown in Figure 1B. 


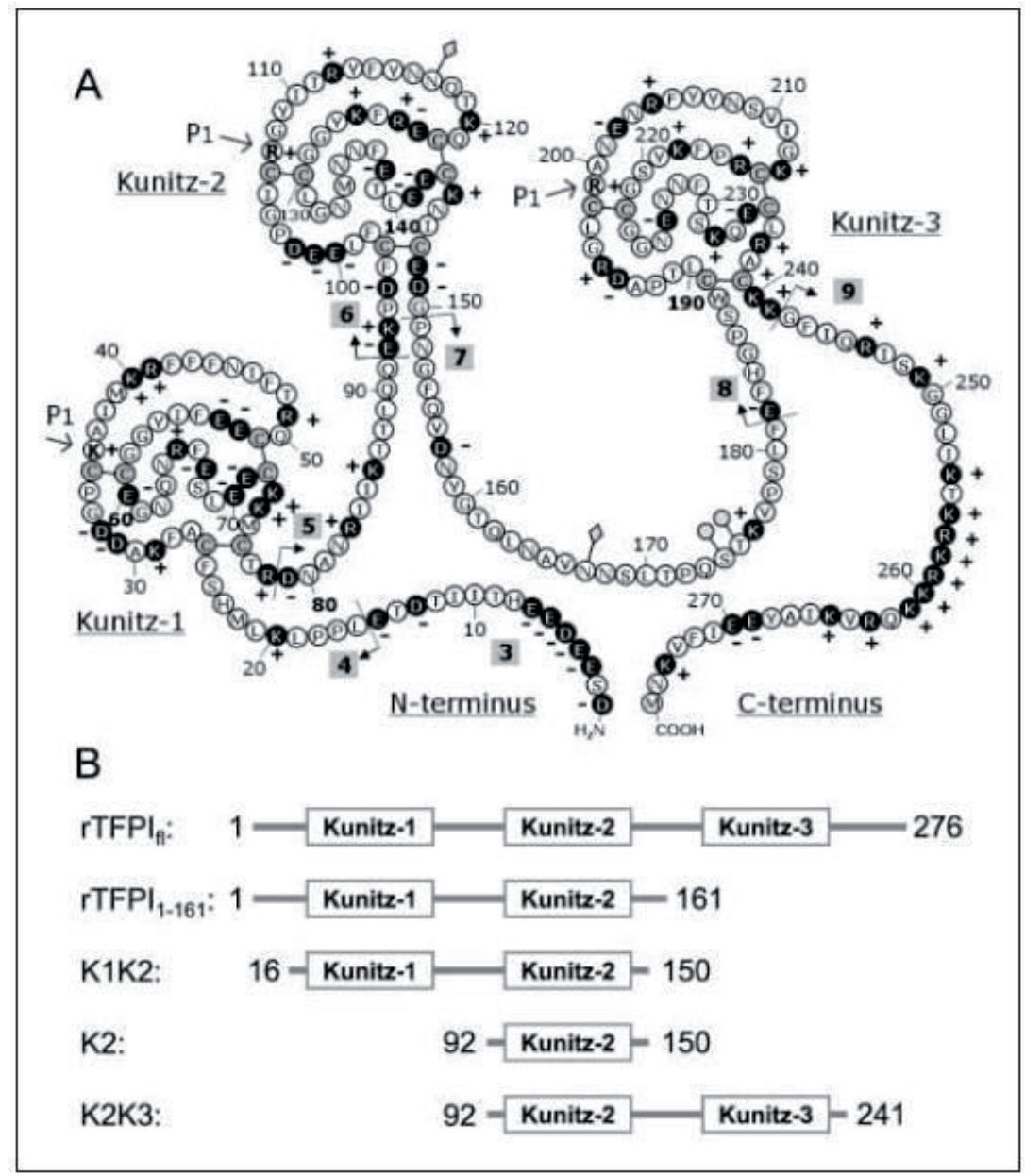

Figure 1: Primary structure of TFPI constructs. A) Primary structure of TFPI. Black amino acids indicate charged residues, grey diamonds and circles indicate potential $N$ linked and O-linked carbohydrates, grey numbered boxes indicate exons. P1 residues in the Kunitz domains are indicated by arrows. B) List of TFPI constructs used in the current study. 
The K2, K1K2 and K2K3 constructs were chemically synthesized by tBoc peptide synthesis (23) and native chemical ligation (NCL) (26). N-terminal peptide thioesters were activated to a thiophenol ester for the NCL reaction (Fig. 2A). The $\mathrm{N}$-terminal peptide thiophenol ester forms an initial thioester bridge with a Cterminal peptide containing an $\mathrm{N}$-terminal cysteine, thereby connecting the peptides. Subsequent spontaneous rearrangement of the trans thioester bond generates a native peptide bond at the site of ligation (Fig. 2A). As an example the synthesis of K2K3 (residues 92-241) is shown (Fig. 2B). This TFPI construct was synthesized from three peptide fragments; $\mathrm{Glu}^{92}-\mathrm{Gly}^{129}$-thioester; Cys(Thz) ${ }^{130}$ $\operatorname{Trp}^{188}$-thioester; and Cys ${ }^{189}$-Lys ${ }^{241}$. To avoid cyclisation or polymerization of the bifunctional middle fragment (130-188) that needs both an N-terminal Cys and a C-terminal thioester, the N-terminal $\mathrm{Cys}^{139}$ functionality was protected by incorporating a thiaproline (Thz). After ligation of fragments 130-188 and 189241, $\mathrm{Thz}^{130}$ was deprotected to yield a cysteine residue for participation in the second NCL reaction. The resulting polypeptide chain $92-241$ was folded at $4{ }^{\circ} \mathrm{C}$ for $48 \mathrm{~h}$, as a result of which the mass decreased from 17,144.6 Da. to 17,132.1 Da. The decrease of $12.5 \mathrm{Da}$ represents the loss of 12 protons as a result of the formation of six disulfide bonds (Table 1; Fig. 2C). The activity of TFPI constructs was determined by assessing inhibition of bFXa. To this end, a fixed amount of bFXa was titrated with the TFPI constructs. A linear decrease in bFXa activity was observed as a function of TFPI construct concentration, with the extrapolated X- 
axis intercept representing the amount of TFPI construct needed to fully inhibit bFXa (Fig. 2D). From this intercept the functional concentration of the TFPI preparations could be calculated (Fig. 2D). Using the same approach, TFPI constructs K2and K1K2 were synthesized, folded, and quantified. All experimentally obtained masses of TFPI constructs fitted well between their theoretical monoisotopic and average masses (Table 1).

Kinetics of FXa inhibition by TFPI $\mathrm{FL}_{\mathrm{L}}$ and TFPI constructs in the presence of EDTA

Inhibition of FXa by TFPI was studied by following time courses of chromogenic substrate conversion by FXa at different $\mathrm{TFPI}_{\mathrm{FL}}$ or TFPI construct concentrations. Biphasic inhibition progress curves representing slow-tight binding inhibition of FXa by TFPI were observed for TFPI $I_{\mathrm{FL}}, \mathrm{TFPI}_{1-161}$, and K1K2 (Fig. 3A-C), whereas monophasic inhibition was observed for $\mathrm{K} 2$ and $\mathrm{K} 2 \mathrm{~K} 3$ (Fig. 3D, E). The $\mathrm{K}_{\mathrm{i}}$ of the encounter complex and $\mathrm{K}_{\mathrm{i}}^{*}$ of the tight complex (Table 2) were calculated from $\mathrm{v}_{0}$ and $\mathrm{v}_{\mathrm{s}}$ values, respectively (eq.1). The fact that TFPI constructs $\mathrm{K} 2$ and $\mathrm{K} 2 \mathrm{~K} 3$ both lack K1 and both show monophasic inhibition strongly suggest that only an encounter complex was formed and that no transition to the tight complex took place. 

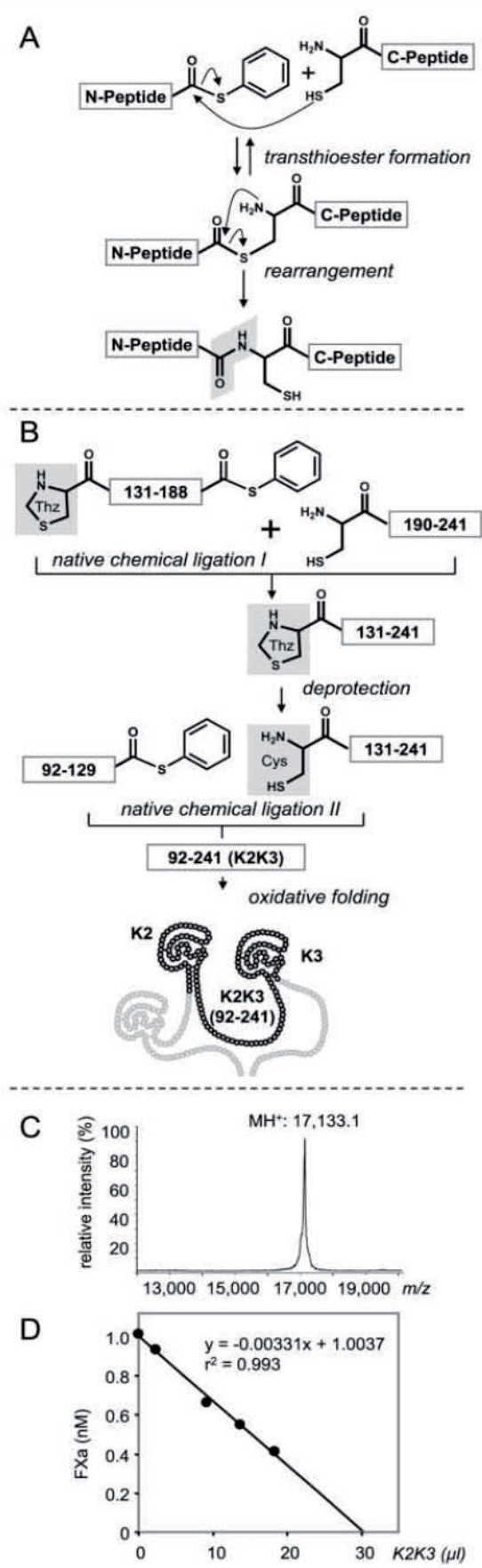

Figure 2: Chemical synthesis and analysis of TFPI domains. A) Native chemical ligation (NCL): an N-terminal peptide containing an activated thiophenol thioester allowing transthioester formation with a Cterminal peptide containing an $\mathrm{N}$ terminal cysteine. Spontaneous rearrangement yields a native peptide bond at the site of ligation. B) Reaction scheme for synthesis of $\mathrm{K} 2 \mathrm{~K} 3$ : In the first NCL reaction peptide 130-188-thioester is ligated to peptide 189-241. Note that the Cys 130 required for the second NCL reaction is encrypted as a thiaproline (Thz). For the second NCL reaction Thz in peptide 130-241 is converted to a cysteine that participates in a reaction with peptide 92-129-thioester. Oxidative folding of peptide 92-241 yields K2K3. C) Maldi TOF mass spectrum of folded K2K3. The single protonated mass of 17,133.1 Da indicates a molecular mass of 17,132.1 Da. D) Quantification of K2K3. A fixed amount of bovine FXa was titrated with purified K2K3. The $x$-axis intercept represents the amount of $K 2 \mathrm{~K} 3$ needed to inhibit 1 nM FXa which allows calculation of the functional concentration of $K 2 K 3$. 
$\mathrm{TFPI}_{\mathrm{FL}}$ appeared to be the most potent FXa inhibitor with $\mathrm{K}_{\mathrm{i}}$ and $\mathrm{K}_{\mathrm{i}}^{*}$ values of 4.2 $\mathrm{nM}$ and $0.06 \mathrm{nM}$, respectively. TFPI ${ }_{1-161}$ and $\mathrm{K} 1 \mathrm{~K} 2$, both lacking the $\mathrm{K} 3$ and Cterminal domain, have 10-to 13 -fold higher $\mathrm{K}_{\mathrm{i}}$ values than $\mathrm{TFPI}_{\mathrm{FL}}$ which indicates that the $\mathrm{K} 3$ and $\mathrm{C}$-terminal domain plays an important role in the encounter complex formation. Monophasic inhibition of FXa by K2 and K2K3, both lacking the $\mathrm{K} 1$ domain, indicates that $\mathrm{K} 1$ is responsible for the transition from the weak encounter to the tight FXa $\bullet$ TFPI* complex. The $\mathrm{K}_{\mathrm{i}}$ of FXa inhibition by K2K3 was six-fold lower than the $\mathrm{K}_{\mathrm{i}}$ of $\mathrm{K} 2$ which shows that the $\mathrm{K} 3$ domain significantly contributes to FXa inhibition by promoting FXa•TFPI encounter complex formation.

Kinetics of FXa inhibition by TFPI $_{\mathrm{FL}}$ and TFPI modules/fragments in the presence of $\mathrm{Ca}^{2+}$ ions

TFPI $_{\mathrm{FL}}$ appears to be a poor inhibitor of FXa in presence of $\mathrm{Ca}^{2+}$ ions $(10,15)$. It has been speculated that in absence of $\mathrm{Ca}^{2+}$ the $\mathrm{C}$-terminus of TFPI might interact with the Gla-domain of FXa and that $\mathrm{Ca}^{2+}$-binding to the Gla domain of FXa might prevent this interaction (15). To better understand the role of $\mathrm{Ca}^{2+}$ ions in the inhibition of FXa by TFPI, kinetic experiments were performed in the presence of $3 \mathrm{mM} \mathrm{Ca}^{2+}$ ions. 

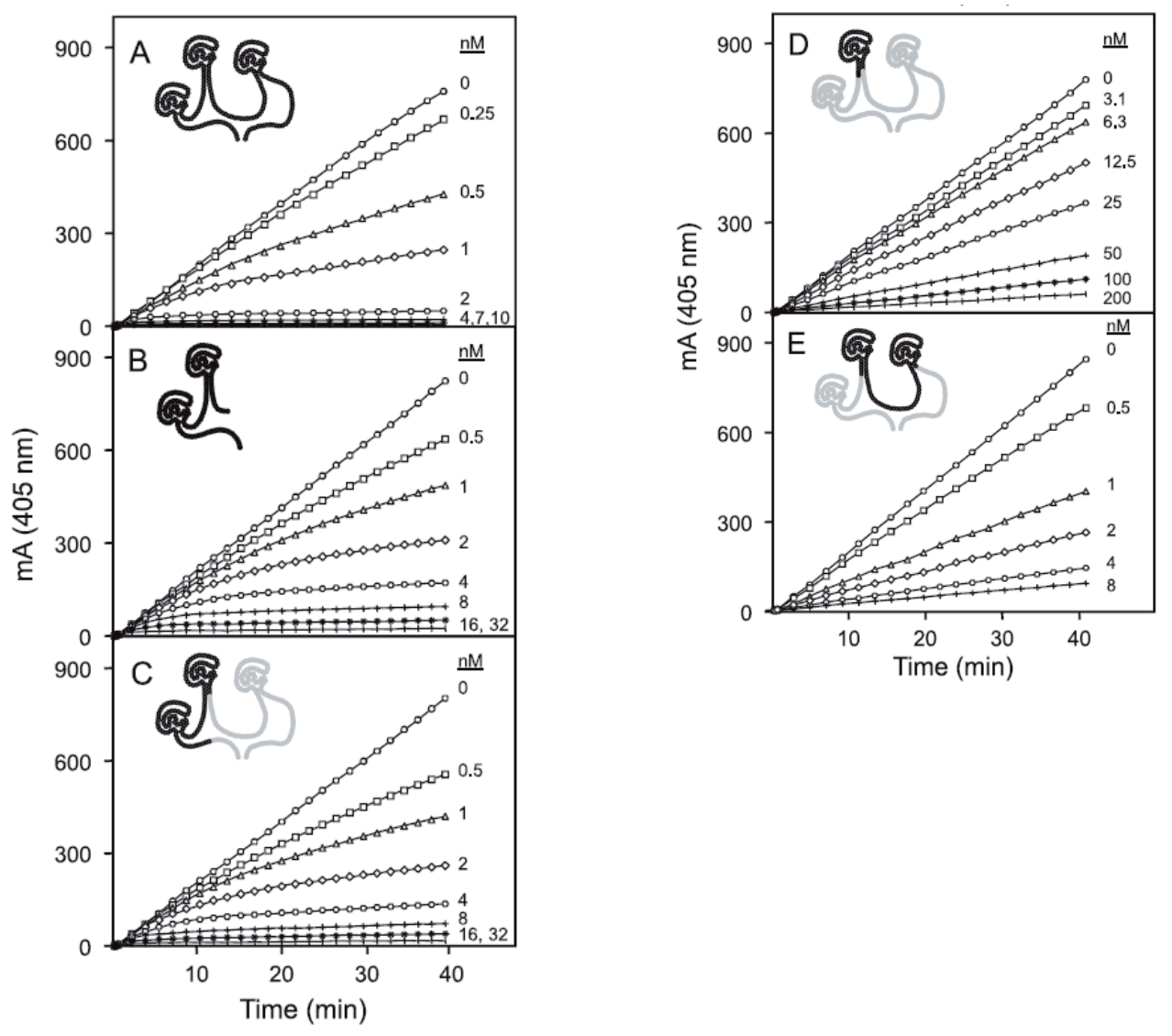

Figure 3: Inhibition of FXa by TFPI and TFPI modules and constructs in the presence of EDTA. Progress curves of $125 \mu M$ CS 11(65) substrate conversion by FXa at different TFPI and TFPI constructs concentrations. Inhibition of $0.1 \mathrm{nM}$ FXa by full-length TFPI $\left(T F P I_{F L}\right)(A)$, truncated TFPI $\left(T F P I_{1-161}\right)(B), K 1 K 2(C), K 2(D)$, and $K 2 K 3$ (E). Concentrations of TFPI and TFPI constructs are indicated in the figure. Solid lines in panels $A, B$ and $C$ represent least squares fits to the equation for biphasic inhibition (eq. 1). Solid lines in panels $D$ and E represent least squares fit to a straight line. 
Also, in the presence of $\mathrm{Ca}^{2+}$-ions biphasic inhibition of $\mathrm{FXa}$ was observed with TFPI $_{\mathrm{FL}}, \mathrm{TFPI}_{1-161}$ and $\mathrm{K} 1 \mathrm{~K} 2$ (Fig. 4A-C). In addition, monophasic inhibition was observed with $\mathrm{K} 2$ and monophasic inhibition was enhanced in the case of K2K3 (Fig. 4D, E). These observations confirmed the important roles of the K1 and K3 domains in the isomerisation and encounter complex formation, respectively. $\mathrm{Ca}^{2+}$ ions had a substantial effect on the initial encounter complex formation between TFPI $_{\mathrm{FL}}$ and FXa (Table 2), increasing the $\mathrm{K}_{\mathrm{i}}$ value $\sim 6$-fold when compared to the $\mathrm{K}_{\mathrm{i}}$ determined in the presence of $1 \mathrm{mM}$ EDTA. $\mathrm{Ca}^{2+}$ ions had no significant effect on $\mathrm{K}_{\mathrm{i}}{ }^{*}$ and hardly affected FXa inhibition by $\mathrm{TFPI}_{1-161}, \mathrm{~K} 1 \mathrm{~K} 2, \mathrm{~K} 2$ and $\mathrm{K} 2 \mathrm{~K} 3$ which all lack the C-terminal domain (Table 2).

Effect of calcium ions on the inhibition of Gla domain-less FXa by TFPI $_{\mathrm{FL}}$ and $\mathrm{TFPI}_{1-161}$

The above experiments show that $\mathrm{Ca}^{2+}$ ions impair the initial encounter complex formation of FXa and TFPI $\mathrm{FL}_{\mathrm{L}}$ but not between FXa and the other TFPI constructs. This suggests that $\mathrm{Ca}^{2+}$ ions interfere with the interactions between $\mathrm{FXa}$ and the $\mathrm{C}$ terminus of TFPI. FXa contains $11 \alpha$-carboxy glutamic acid residues in its Gla domain that are involved in binding of $\mathrm{Ca}^{2+}$ ions. Therefore, we compared the inhibition of native FXa and Gla domain-less FXa (GD-FXa) by TFPI $I_{\mathrm{FL}}$ and $\mathrm{TFPI}_{1-}$ 
${ }_{161}$ in presence and absence of $\mathrm{Ca}^{2+}$ ions. Inhibition of native FXa by $\mathrm{TFPI}_{\mathrm{FL}}$ was the only condition that was affected by $\mathrm{Ca}^{2+}$ ions (Fig. $5 \mathrm{~A}$ ).

Table 1: Molecular masses of synthetic TFPI constructs.

\begin{tabular}{|c|c|c|c|c|c|}
\hline \multirow{2}{*}{ TFPI } & Mono- & Average & Observed & Observed & $\Delta$ Mass \\
constructs & mass & mass & mass & mass folded & reduced \\
& reduced & & & & \\
\hline Kunitz-2 & $7,013.1$ & $7,017.9$ & $7,016.2$ & $7,010.3$ & -5.9 \\
\hline Kunitz-12 & $16,195.5$ & $16,206.6$ & $16,206.0$ & $16,194.0$ & -12.0 \\
\hline Kunitz-23 & $17,133.9$ & $17,145.3$ & $17,144.6$ & $17,132.1$ & -12.5 \\
\hline
\end{tabular}

$\mathrm{Ca}^{2+}$ ions had no significant effect on the inhibition of GD-FXa by TFPI $\mathrm{FL}_{\mathrm{L}}$ (Fig. 5B) and of FXa by $\mathrm{TFPI}_{1-161}$ (Fig. 5C) or GD-FXa by TFPI $\mathrm{T}_{1-161}$ (Fig. 5D). In addition, in the absence of $\mathrm{Ca}^{2+}$ ions GD-FXa was much less effectively inhibited by $\mathrm{TFPI}_{\mathrm{FL}}$ than native FXa. These data suggest that in the presence of EDTA, the Gla domain of FXa is involved in the inhibition by $\mathrm{TFPI}_{\mathrm{FL}}$, most likely through interactions of the positively charged C-terminus of TFPI with the negatively charged Gla residues in the Gla domain of FXa. Binding of $\mathrm{Ca}^{2+}$ ions to the Gla domain of FXa impairs the interaction with the C-terminus of $\mathrm{TFPI}_{\mathrm{FL}}$ resulting in less efficient inhibition of FXa by $\mathrm{TFPI}_{\mathrm{FL}}$. The interaction between $\mathrm{C}$-terminus of TFPI and Gla-domain of FXa likely contributes to the formation of the encounter 
complex since it was shown that; i) in absence of $\mathrm{Ca}^{2+}$ ions the $\mathrm{K}_{\mathrm{i}}$ of GD-FXa inhibition by TFPI $I_{\mathrm{FL}}$ is more than 10 -fold higher than the $\mathrm{K}_{\mathrm{i}}$ of native $\mathrm{FXa}$, ii) $\mathrm{Ca}^{2+}$ ions increase the $\mathrm{K}_{\mathrm{i}}$ but hardly affect the $\mathrm{K}_{\mathrm{i}}^{*}$ of $\mathrm{TFPI}_{\mathrm{FL}}$ for $\mathrm{FXa}$, and iii) $\mathrm{Ca}^{2+}$ ions have virtually no effect on the $\mathrm{K}_{\mathrm{i}}$ and $\mathrm{K}_{\mathrm{i}}{ }^{*}$ of inhibition of GD-FXa by TFPI $\mathrm{FL}_{\text {(Table }}$ $3)$.

Table 2: $K_{i}$ and $K_{i}^{*}$ values of FXa-inhibition by TFPI $I_{F L}$ and TFPI constructs.

\begin{tabular}{|c|c|c|c|c|c|c|}
\hline & \multicolumn{2}{|c|}{ EDTA } & \multicolumn{2}{|c|}{$\mathrm{CaCl}_{2}$} & \multicolumn{2}{|c|}{$\begin{array}{c}\mathrm{CaCl}_{2} \text { and } \\
\text { Phospholipids }\end{array}$} \\
\hline & $\mathrm{K}_{\mathrm{i}}(\mathrm{nM})$ & $\mathrm{K}_{\mathrm{i}}^{*}(\mathrm{nM})$ & $\mathrm{K}_{\mathrm{i}}(\mathrm{nM})$ & $\mathrm{K}_{\mathrm{i}}^{*}(\mathrm{nM})$ & $\mathrm{K}_{\mathrm{i}}(\mathrm{nM})$ & $\mathrm{K}_{\mathrm{i}}^{*}(\mathrm{nM})$ \\
\hline $\mathrm{TFPI}_{\mathrm{FL}}$ & $4.2 \pm 0.5$ & $\begin{array}{c}0.06 \pm \\
0.01\end{array}$ & $\begin{array}{c}26.7 \pm \\
4.4\end{array}$ & $\begin{array}{c}0.08 \pm \\
0.01\end{array}$ & $23.3 \pm 4$ & $\begin{array}{c}0.04 \pm \\
0.01\end{array}$ \\
\hline TFPI $_{1-161}$ & $\begin{array}{c}54.5 \pm \\
8.8\end{array}$ & $\begin{array}{l}0.2 \pm \\
0.02\end{array}$ & $\begin{array}{c}57.8 \pm \\
10.8\end{array}$ & $\begin{array}{c}0.07 \pm \\
0.01\end{array}$ & $\begin{array}{c}45.4 \pm \\
6.3\end{array}$ & $\begin{array}{c}0.14 \pm \\
0.02\end{array}$ \\
\hline K1K2 & $\begin{array}{c}38.1 \pm \\
4.6\end{array}$ & $\begin{array}{l}0.3 \pm \\
0.02\end{array}$ & $32.8 \pm 2$ & $\begin{array}{l}0.2 \pm \\
0.01\end{array}$ & $\begin{array}{c}25.8 \pm \\
3.2\end{array}$ & $\begin{array}{l}0.2 \pm \\
0.04\end{array}$ \\
\hline K2 & $\begin{array}{c}20.5 \pm \\
0.8\end{array}$ & & $\begin{array}{c}14.6 \pm \\
1.2\end{array}$ & & $\begin{array}{c}18.6 \pm \\
2.4\end{array}$ & \\
\hline K2K3 & $3.6 \pm 0.4$ & & $2.2 \pm 0.3$ & & $1.7 \pm 0.3$ & \\
\hline
\end{tabular}

$K_{i}$ and $K_{i}^{*} \pm S E M$ values for $T F P I_{F L}, T F P I_{1-161}$ and $K 1 K 2$ were obtained after least squares fitting of the raw data to eq $1 . K_{i}$ and $K_{i}^{*} \pm S E M$ values from $K 2$ and $K 2 K 3$ was obtained after least squares fitting of the raw data to a straight line. 

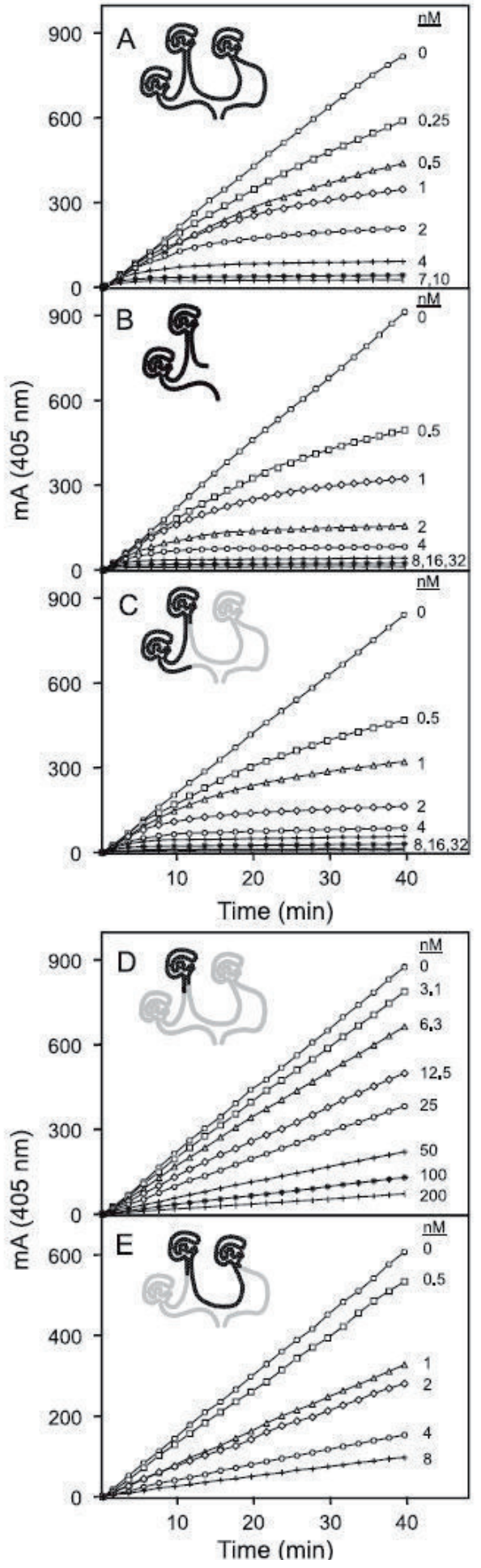

Figure 4: Inhibition of FXa by TFPI and different TFPI constructs in presence of $\mathrm{Ca}^{2+}$ ions. Progress curves of $125 \mu M C S$ 11(65) substrate conversion by $F X a$ at different TFPI and TFPI construct concentrations. Inhibition of $0.1 n M \quad F X a$ full-length TFPI (TFPI $F L)(A)$, truncated TFPI (TFPI $\left.I_{1-161}\right)(B), K 1 K 2(C), K 2(D)$, and K2K3 (E). Concentrations of TFPI and TFPI constructs are indicated in the figure. Solid lines in panels $A, B$ and $C$ represent least squares fits to the equation for biphasic inhibition (eq. 1). Solid lines in panels $D$ and E represent least squares fit to a straight line. 
Chapter 3

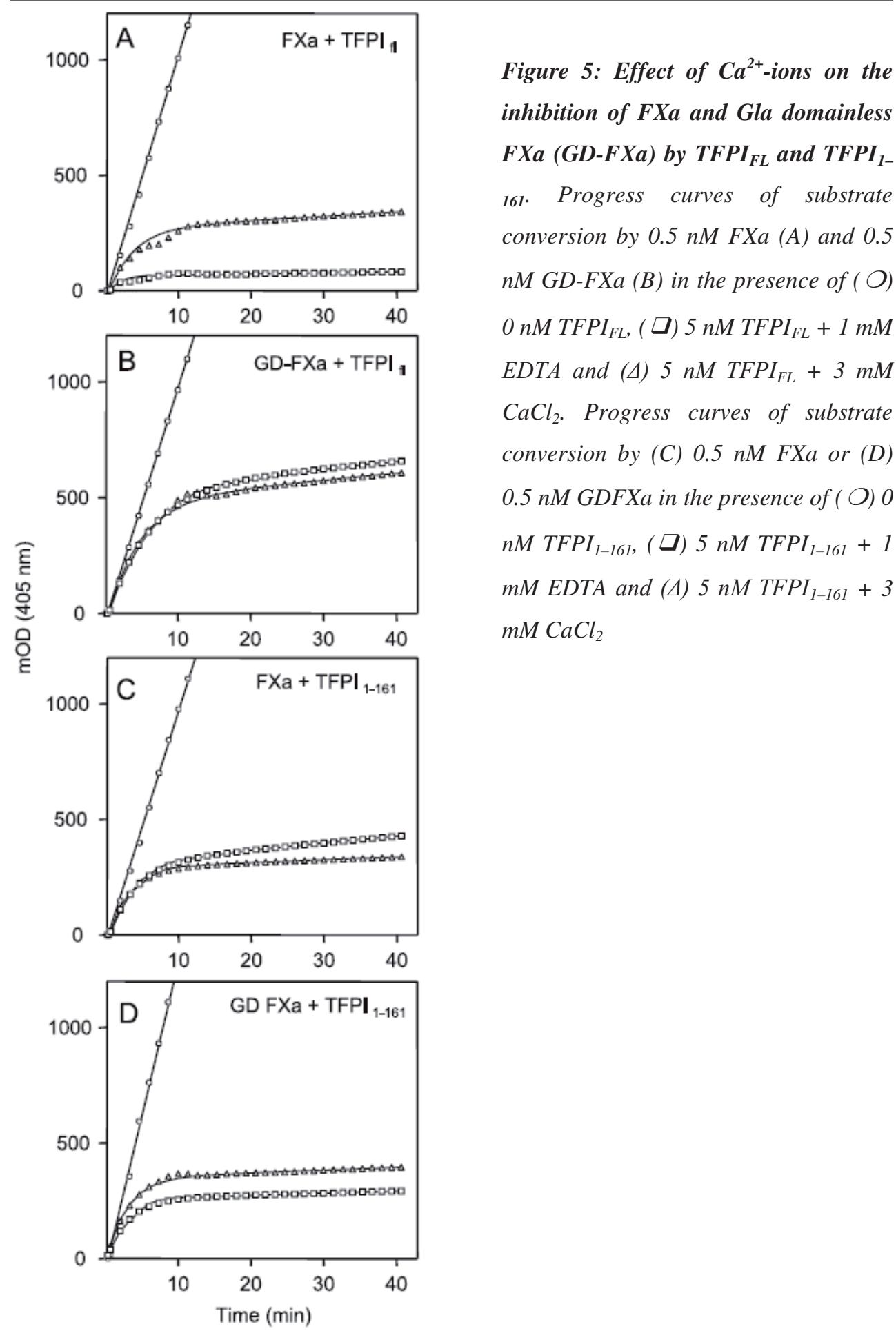



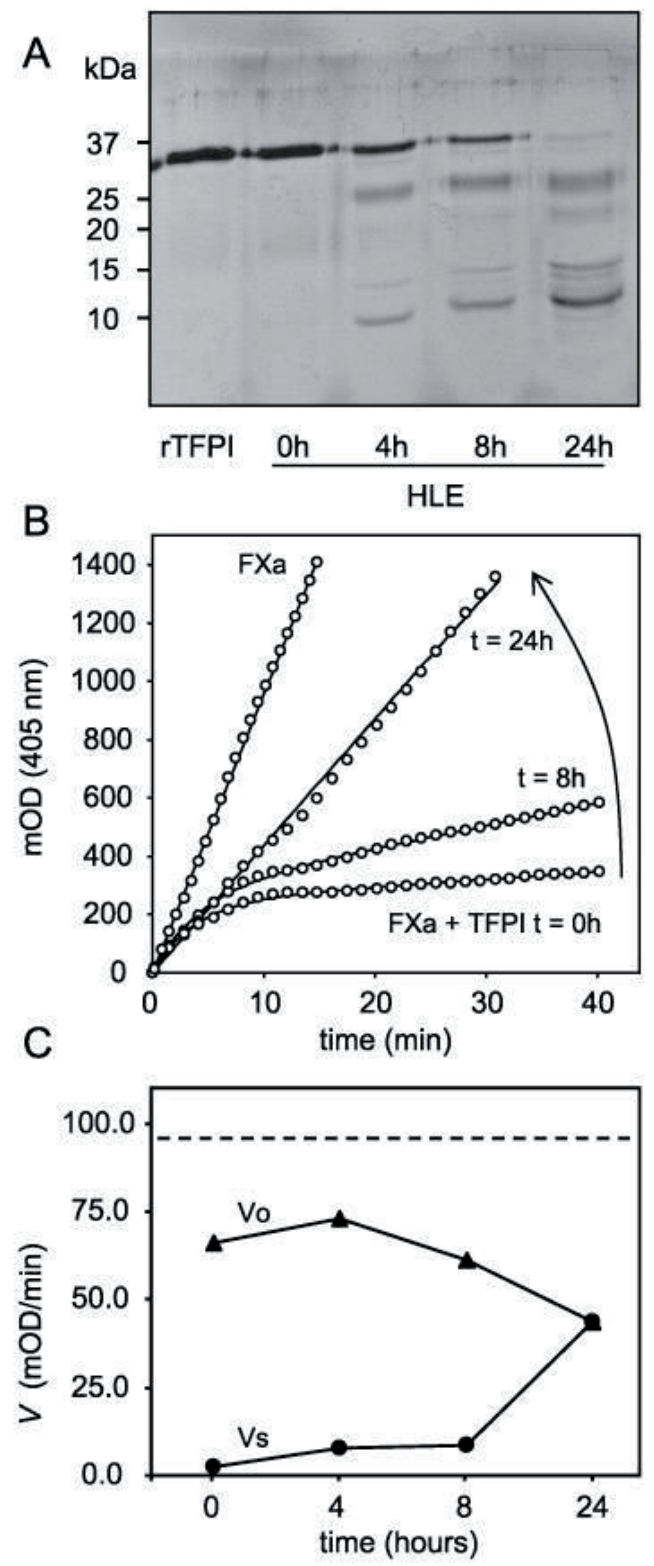

Figure 6: Effect of elastase (HLE)treatment of full-length TFPI on FXa inhibition. TFPI $_{F L}(3 \mu M)$ was incubated with 100 nM HLE and after 0, 4, 8 and 24 h samples were taken for SDS PAGE and kinetic analysis. A) 20\% SDSPAGE stained with Coomassie Brilliant Blue $R$ 250. Lane 1: TFPI $F L$ without HLE and Elastase inhibitor III. Lane 2, 3, 4 and 5: $T_{F P I} I_{F L}$ with HLE, reaction stopped with Elastase inhibitor III after 0, 4, 8 and 24 $h$, respectively. B) Progress curves of inhibition of $F X a$. The reaction mixture contained $0.5 n M \quad F X a, 125 \mu M$ CS 11(65), $1 \mathrm{mM}$ EDTA and $2 \mathrm{nM}$ TFPI treated with HLE during time intervals indicated in the figure. C) vo ( $\mathbf{\Delta})$ and $v s$ $(\bullet)$ determined from progress curves of FXa-inhibition by the different HLEcleaved TFPI samples. FXa without TFPI has been used as reference (dashed line). Solid lines in panel $B$ represent non-linear regression fits to the equation for biphasic inhibition (eq. 1) for HLE treatment $t=0$ and $t=8 \mathrm{~h}$ and least squares fit to a straight line for HLE treatment $t=24 \mathrm{~h}$ and for FXa. 


\section{Effect of HLE treatment of TFPI $\mathrm{FL}_{\mathrm{L}}$ on its inhibitory properties}

The above data indicate that $\mathrm{K} 1$ plays an important role in the transition from a loose FXa $\bullet$ TFPI to the tight FXa ${ }^{\mathrm{TFPI}}{ }^{*}$ complex. In order to confirm the role of $\mathrm{K} 1$ in the $\mathrm{FXa} \cdot \mathrm{TFPI}$ isomerisation process, $\mathrm{TFPI}_{\mathrm{FL}}$ was subjected to HLE treatment which has been reported to cleave TFPI between $\mathrm{Thr}^{87}-\mathrm{Thr}^{88}$ resulting in the removal of the K1 domain (18). Samples collected after various times of incubation of TFPI $\mathrm{FL}_{\mathrm{F}}$ with HLE were reduced and analysed on (SDS-PAGE). A gradual decrease of $34 \mathrm{kDa} \mathrm{TFPI}_{\mathrm{FL}}$ was observed with a simultaneous appearance of fragments of $\sim 24 \mathrm{kDa}$ and $\sim 10 \mathrm{kDa}$, which is indicative for removal of the K1 domain from $\mathrm{TFPI}_{\mathrm{FL}}$ (Fig. 6A). The aliquots taken at various time points from the HLE-TFPI mixture were also analysed for FXa inhibitory activity. The non-treated TFPI sample $(0 \mathrm{~h})$ inhibited FXa in a biphasic fashion (Fig. 6B) whereas the TFPI sample that was incubated with HLE for $8 \mathrm{~h}$ showed a loss of biphasic inhibition and an increasing $\mathrm{v}_{\mathrm{s}}$ value. The TFPI sample after $24 \mathrm{~h}$ with HLE showed monophasic inhibition with a $\mathrm{v}_{\mathrm{s}}$ that approached the $\mathrm{v}_{0}$, whereas HLE treatment hardly affected the $\mathrm{v}_{0}$ (Fig. $6 \mathrm{~B}, \mathrm{C}$ ). This experiment supports the hypothesis that $\mathrm{K} 1$ plays an important role in the isomerisation of the loose FXa $\bullet F P I$ to the tight FXa•TFPI* complex. 
Effect of protein $\mathrm{S}$ on the kinetics of FXa inhibition by $\mathrm{TFPI}_{\mathrm{FL}}$,

\section{HLE-treated TFPI and K2K3}

It has been reported that protein $\mathrm{S}$ promotes the formation of the encounter complex between FXa and TFPI $(12,27)$. As K3 promotes FXa TFPI encounter complex formation and $\mathrm{K} 1$ is responsible for the transition to the tight FXa・TFPI* complex, the effect of protein $\mathrm{S}$ on stimulation of FXa-inhibition by K2K3 was studied.

Inhibition of FXa by TFPI $\mathrm{FL}(0-20 \mathrm{nM}), 24$ h HLE-cleaved TFPI $(0-5 \mathrm{nM})$, and synthetic K2K3 $(0-5 \mathrm{nM})$ was studied in the presence or absence of $100 \mathrm{nM}$ of protein S. Representative progress curves of FXa inhibition at selected concentrations of TFPI and TFPI fragments are shown (Fig. 7). Compared to the biphasic inhibition of FXa by TFPI $_{\mathrm{FL}}$ (Fig. 7A), the FXa-inhibition changes from biphasic to monophasic with HLE-cleaved TFPI (Fig. 7B) and becomes purely monophasic with synthetic K2K3 (Fig. 7C). The fact that HLE-cleaved TFPI shows traces of biphasic inhibition (Fig. 7B) is most likely due to the presence of a small amount of uncleaved $\mathrm{TFPI}_{\mathrm{FL}}$. Even at a concentration of $1 \mathrm{nM}$ TFPI, 5\% uncleaved $\mathrm{TFPI}_{\mathrm{FL}}$ would represent $0.05 \mathrm{nM}$ TFPI $\mathrm{FL}_{\mathrm{FL}}$, which is close to the $\mathrm{K}_{\mathrm{i}}{ }^{*}$ of the final tight FXa $\bullet$ TFPI* complex $^{*}(0.04 \pm 0.01 \mathrm{nM}$; Table 2$)$, and therefore would still be able to induce biphasic FXa-inhibition. 

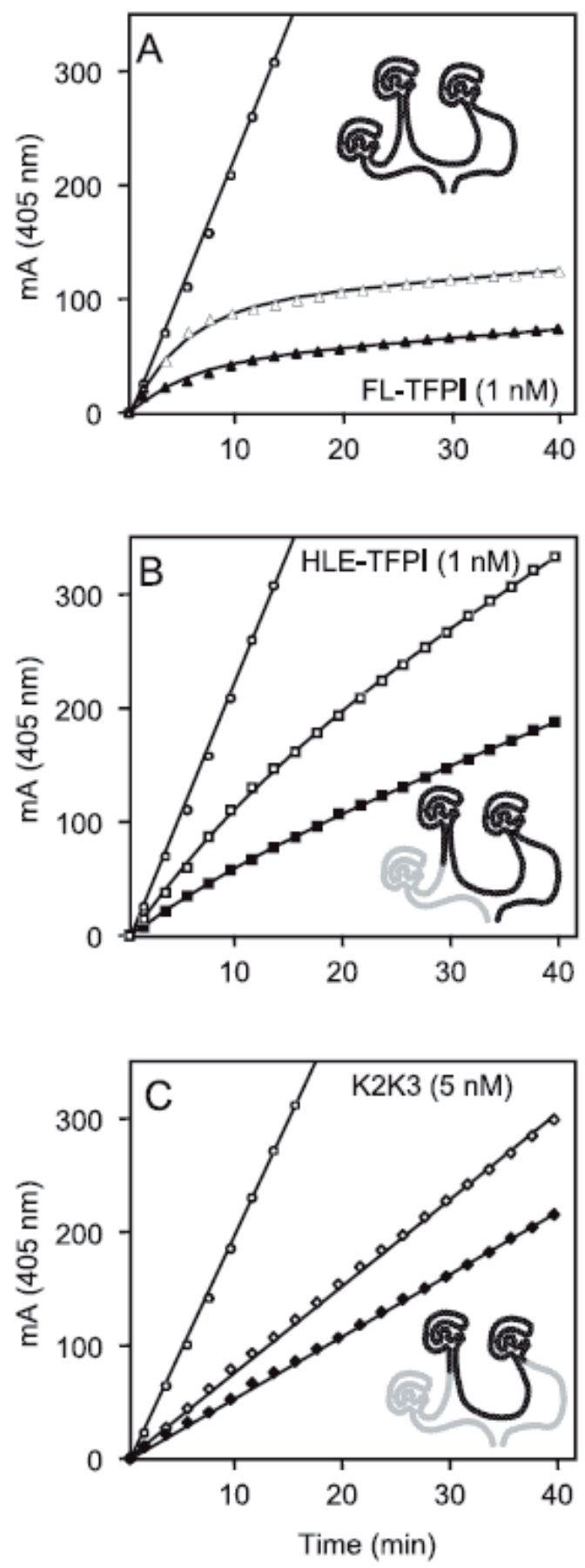

Figure 7: Effect of protein $S$ on $F X a$ inhibition by Kunitz 3-containingTFPI variants. Progress curves of inhibition of FXa by TFPI variants. The reaction mixture contained $0.1 \mathrm{nM} F X a, 125 \mu \mathrm{M}$ CS 11(65), $3 \mathrm{mM} \mathrm{CaCl}, 40 \mu \mathrm{M}$ phospholipids (20/60/20 PC/PS/PE; $\mathrm{mol} / \mathrm{mol} / \mathrm{mol}$ ) and A) $0 \mathrm{nMTFPI} \mathrm{TL}_{F L}(O)$, $1 \mathrm{nMTFPI} \mathrm{T}_{F L}(\Delta)$ and $1 \mathrm{nMTFPI} \mathrm{TFL}_{\mathrm{F}}+$ 100 nM protein $S(\mathbf{\Delta})$; B) 0 nM TFPI $I_{F L}$ (O), 1 nM HLE-treated TFPI ( $\square), 1$ $n M$ HLE-treated TFPI $+100 n M$ protein $S$ (-) and C) $0 n M K 2 K 3$ (O), 5 $n M K 2 K 3(\square)$ or $5 n M K 2 K 3+100 n M$ protein $S(\bullet)$. 
As can be observed, the initial deviation $\left(\mathrm{v}_{0}\right)$ from the linear substrate conversion by FXa alone $\left(\mathrm{v}_{\mathrm{x}}\right)$ that is due to the FXa-TFPI encounter complex formation is increased by the addition of protein $S$ (Fig. 7). After calculation of $K_{i}$ values it was shown that protein $\mathrm{S}$ stimulates the encounter complex formation in all $\mathrm{K} 2$-and K3-containing TFPI constructs 2- to 30-fold (Table 4). Even in the case of synthetic K2K3 stimulation by protein $\mathrm{S}$ can be readily observed, indicating that the efficiency of FXa•TFPI encounter complex formation that is governed by $\mathrm{K} 2$ of TFPI is enhanced by K3, and is even further enhanced by the presence of protein S.

Table 3: FXa and -GD FXa inhibition by TFPI $_{F L}$ and TFPI ${ }_{1-161}$.

\begin{tabular}{|c|c|c|c|c|}
\hline \multirow{2}{*}{ FXa } & \multicolumn{2}{|c|}{ EDTA } & \multicolumn{2}{|c|}{ Calcium } \\
\hline & $\mathrm{K}_{\mathrm{i}}(\mathrm{nM})$ & $\mathrm{K}_{\mathrm{i}}^{*}(\mathrm{nM})$ & $\mathrm{K}_{\mathrm{i}}(\mathrm{nM})$ & $\mathrm{K}_{\mathrm{i}}^{*}(\mathrm{nM})$ \\
\hline${ }^{\mathrm{a}} \mathrm{TFPI}_{\mathrm{FL}}$ & $4.2 \pm 0.5$ & $0.06 \pm 0.01$ & $26.7 \pm 4.4$ & $0.08 \pm 0.01$ \\
\hline${ }^{\mathrm{b}} \mathrm{TFPI}_{1-161}$ & $54.5 \pm 8.8$ & $0.2 \pm 0.02$ & $57.8 \pm 10.8$ & $0.07 \pm 0.01$ \\
\hline \multirow{2}{*}{ GD-FXa } & \multicolumn{2}{|c|}{ EDTA } & \multicolumn{2}{|c|}{ Calcium } \\
\hline & $\mathrm{K}_{\mathrm{i}}(\mathrm{nM})$ & $\mathrm{K}_{\mathrm{i}}^{*}(\mathrm{nM})$ & $\mathrm{K}_{\mathrm{i}}(\mathrm{nM})$ & $\mathrm{K}_{\mathrm{i}}^{*}(\mathrm{nM})$ \\
\hline TFPI $_{F L}$ & $48.4 \pm 4.7$ & $0.13 \pm 0.01$ & $55.2 \pm 6.4$ & $0.1 \pm 0.01$ \\
\hline $\mathrm{TFPI}_{1-161}$ & $43.1 \pm 10$ & $0.05 \pm 0.01$ & $44.1 \pm 6.4$ & $0.05 \pm 0.01$ \\
\hline
\end{tabular}

$K_{i}$ and $K_{i}^{*} \pm S E M$ values for $T F P I_{F L}$ and $T F P I_{1-161}$ were obtained after least squares fitting of the raw data to eq $1 .{ }^{a} K_{i}$ and $K_{i}^{*}$ values for $T F P I_{F L}$ are the average of several experiments (data coming from Table 2). ${ }^{b} K_{i}$ and $K_{i}^{*}$ values for $T F P I_{1-161}$ are average of several experiments (data coming from Table 2). 
Table 4: $K_{i}$ values of full-length and HLE-cleaved TFPI in presence and absence of protein $S$.

\begin{tabular}{|c|c|c|c|}
\hline & TFPI $_{\mathrm{FL}}$ & TFPI HLE & $\mathrm{K} 2 \mathrm{~K} 3$ \\
& $\mathrm{~K}_{\mathrm{i}}(\mathrm{nM})$ & $\mathrm{K}_{\mathrm{i}}(\mathrm{nM})$ & $\mathrm{K}_{\mathrm{i}}(\mathrm{nM})$ \\
\hline - PS & $19 \pm 5.4$ & $2.2 \pm 0.6$ & $3.4 \pm 0.2$ \\
\hline+ PS (100 nM) & $0.6 \pm 0.04$ & $0.6 \pm 0.12$ & $1.8 \pm 0.04$ \\
\hline
\end{tabular}

$K_{i} \pm S E M$ values for $T_{F P I} I_{F L}$ were obtained after least squares fitting of the raw data to eq 1. $K_{i} \pm$ SEM values from HLE-TFPI and K2K3 were obtained after least squares fitting of the raw data to a straight line. 


\section{Discussion}

TFPI is an inhibitor of the extrinsic coagulation pathway which inhibits FXa by socalled slow-tight binding kinetics characterized by rapid formation of a loose encounter complex $(\mathrm{FXa} \cdot \mathrm{TFPI})$ which slowly isomerises to a tight FXa・TFPI* complex. We have investigated the role of the three Kunitz domains (K1, K2 and $\mathrm{K} 3$ ) and the C-terminal domain of TFPI in FXa inhibition. TFPI $\mathrm{FL}_{\mathrm{L}}, \mathrm{TFPI}_{1-161}$ and K1K2 showed biphasic curves of FXa inhibition indicative for the two-step slowtight inhibition mechanism, whereas $\mathrm{K} 2$ and $\mathrm{K} 2 \mathrm{~K} 3$ of TFPI rapidly but less effectively inhibited FXa in a monophasic manner. Since TFPI $I_{F L}$ TFPI $_{1-161}$ and $\mathrm{K} 1 \mathrm{~K} 2$ contain the $\mathrm{K} 1$ domain and since $\mathrm{K} 2$ and $\mathrm{K} 2 \mathrm{~K} 3$ both lack $\mathrm{K} 1$, this indicates that the K1 domain of TFPI not only functions in FVIIa inhibition (28), but also supports the slow transition from the weak encounter to the tight FXa•TFPI* complex. However, TFPI $I_{1-161}$ and K1K2 inhibited FXa with a considerably higher $\mathrm{K}_{\mathrm{i}}$ value $(>40 \mathrm{nM})$, than $\mathrm{TFPI}_{\mathrm{FL}}(4.2 \mathrm{nM})$ emphasizing the role of the $\mathrm{K} 3+\mathrm{C}$ terminus domain in the formation of initial encounter complex. Interestingly, K2K3 was a much better FXa inhibitor $\left(K_{i}=3.6 \mathrm{nM}\right)$ than $\mathrm{K} 2$ alone $\left(\mathrm{K}_{\mathrm{i}}=21 \mathrm{nM}\right)$, which suggests that the $\mathrm{K} 3$ domain promotes the formation of the initial encounter complex. As $\mathrm{K} 1$ is involved in the isomerisation step, this domain might also interact with FXa which reframes the idea that only K2 of TFPI is involved in the FXa binding and inhibition. Treatment of $\mathrm{TFPI}_{\mathrm{FL}}$ with HLE, which has been reported to cleave and remove K1 from TFPI (18), leads to gradual transition from 
a biphasic to a monophasic inhibition mechanism which confirms the hypothesis that $\mathrm{K} 1$ is required for isomerisation of the loose to the tight FXa-TFPI complex. The $\mathrm{K}_{\mathrm{i}}$ value of HLE-cleaved TFPI was further decreased in presence of protein $\mathrm{S}$ which shows that $\mathrm{K} 1$ is not involved in the stimulation of TFPI by protein S. Notably, apart from its role in isomerisation to the tight complex, K1 seems to inhibit FXa $•$ TFPI encounter complex formation. An inhibitory effect of K1 on the formation of the encounter complexes suggested by i) the more than 10 -fold higher $\mathrm{K}_{\mathrm{i}}$ value for TFPI $\mathrm{FL}_{\mathrm{L}}$ when compared to $\mathrm{K} 2 \mathrm{~K} 3$ determined in the presence of $\mathrm{CaCl}_{2}$ or $\mathrm{CaCl}_{2}+$ phospholipids, ii) a seven- to 10 -fold higher $\mathrm{K}_{\mathrm{i}}$ value for $\mathrm{K} 1 \mathrm{~K} 2$ than for $\mathrm{K} 2 \mathrm{~K} 3$ (Table 2) and iii) the fact that the $\mathrm{K}_{\mathrm{i}}$ value of $\mathrm{TFPI}_{\mathrm{FL}}$ after proteolytic removal of the $\mathrm{K} 1$ domain decreases from $19 \mathrm{nM}$ to $2.2 \mathrm{nM}$ which is very close to the value of the $K_{i}$ of K2-K3 determined in the same experiment (Table 4). Hence, we propose that $\mathrm{K} 1$ inhibits the formation of the loose encounter complex resulting in higher $\mathrm{K}_{\mathrm{i}}$ values for TFPI constructs containing $\mathrm{K} 1$ than for constructs without K1. In addition it should be mentioned that the N-terminus of TFPI (residues 1-16) appears to have a small effect (two-fold) on formation of both the encounter complex and the tight FXa•TFPI* complex (compare TFPI ${ }_{1-161}$ and $\mathrm{K} 1 \mathrm{~K} 2$ in Table 2). $\mathrm{Ca}^{2+}$ ions have been reported to inhibit TFPI and increase the KI value of $\operatorname{TFPI}_{\mathrm{FL}}$ (15). We show that $\mathrm{Ca}^{2+}$ ions had no significant effect on FXa inhibition by all other tested TFPI constructs. Since of all TFPI derivatives tested, only TFPI $\mathrm{FL}_{\mathrm{L}}$ contained an intact C-terminus, this suggests that the C-terminus of TFPI interacts 
with FXa and that this interaction is impaired by $\mathrm{Ca}^{2+}$ ions. It was of interest to see whether the negatively charged Gla domain of FXa interacts with the positively charged C-terminus of TFPI. To test this, we compared inhibition of native FXa and GD-FXa by TFPI and TFPI $I_{1-161}$. In the absence of $\mathrm{Ca}^{2+}$ ions, the $\mathrm{K}_{\mathrm{i}}$ of inhibition of GD-FXa by TFPI $I_{F L}$ was 12 -fold higher than the $\mathrm{K}_{\mathrm{i}}$ value for native FXa. $\mathrm{Ca}^{2+}$ ions only inhibited the interaction between native FXa and TFPI $\mathrm{FL}_{\mathrm{L}}$ and had no effect on the inhibition of FXa by $\mathrm{TFPI}_{1-161}$ and of GD-FXa by either $\mathrm{TFPI}_{\mathrm{FL}}$ or $\mathrm{TFPI}_{1-161}$. This suggests that $\mathrm{Ca}^{2+}$ ions impair FXa-inactivation by $\mathrm{TFPI}_{\mathrm{FL}}$ by interfering with the interaction between the positively charged $\mathrm{C}$ terminus of TFPI and the negatively charged Gla domain of FXa. However, in reaction mixtures that contain $\mathrm{Ca}^{2+}$-ions there still is a two-fold difference between $\mathrm{K}_{\mathrm{i}}$ values of TFPI $\mathrm{FL}_{\text {and }}$ anPI $\mathrm{TH}_{1-161}$ (Tables 2 and 3), which indicates that even in the presence of $\mathrm{Ca}^{2+}$-ions the interaction between the C-terminus of TFPI and the Gladomain of FXa contributes to encounter complex formation.

In summary, our data show that in addition to $\mathrm{K} 2$ that is essential for FXa inhibition, the other TFPI domains play an important role in the mechanism of FXa inhibition. K1 of TFPI is not only involved in TF-FVIIa inhibition but is responsible for the transition of the loose to tight FXa-TFPI complex whereas the K3 domain of TFPI, which was initially thought not to have a role in inhibition, actually contributes to the initial encounter complex formation. In addition, the enhancement of FXa•TFPI encounter complex formation by K3 could be further 
enhanced by protein S. This newly proposed function of the $\mathrm{K} 3$ domain is supported by the observation that protein S binds to the K3 domain of TFPI (27). The absence of the N-terminus and $\mathrm{K} 1$ has no effect on the TFPI cofactor activity of protein S. Therefore, all Kunitz domains of TFPI are required for efficient inhibition of FXa.

What is known about this topic?

- Tissue factor pathway inhibitor (TFPI) interacts and inhibits factor (F)Xa through its Kunitz-2 domain.

- The Kunitz 1 and Kunitz-3 domains contribute to FXa inhibition by TFPI via as yet unknown mechanisms.

- Protein S binds to Kunitz-3 of TFPI and stimulates FXa-TFPI complex formation 10-fold.

What does this paper add?

- Enzyme kinetic studies with TFPI variants show that Kunitz-3 plays an important role in the inhibition of FXa. The presence of Kunitz-3 in TFPI stimulates formation of the FXa-TFPI complex 10-fold, which is further enhanced by protein S. 
- Enzyme kinetic studies with chemically synthesised TFPI domains show that the Kunitz-1 domain of TFPI is responsible for the isomerisation of the weak FXaTFPI complex into the tight enzyme inhibitor complex.

- Interactions between the positively charged C-terminus of TFPI and the negatively charged Gla-domain of FXa contribute to the inhibition of FXa by TFPI. Calcium ions block the interactions between the C-terminus and the Gla domain.

- The presence of $\mathrm{K} 1$ in $\mathrm{TFPI}_{\mathrm{FL}}$ increases the $\mathrm{K}_{\mathrm{i}}$ of FXa-inhibition more than 10fold when compared to K2K3-C-terminus; an inhibitory activity of $\mathrm{K} 1$ on FXa $\bullet$ TFPI encounter complex formation is proposed. This inhibitory activity is counteracted by $\mathrm{K} 3$ and $\mathrm{C}$-terminus.

\section{Conflicts of interest}

JR receives research support from, and acts as consultant of Baxter Innovations $\mathrm{GmbH}$. None of the other authors declares any conflict of interest. 


\section{References}

1. Butenas S, Mann KG. Blood coagulation. Biochemistry 2002;67(1):3-12.

2. Wilcox JN, Smith KM, Schwartz SM, et al. Localization of tissue factor in the normal vessel wall and in the atherosclerotic plaque. Proc Natl Acad Sci U S A 1989;86(8):2839-43.

3. Morrissey JH, Macik BG, Neuenschwander PF, et al. Quantitation of activated factor VII levels in plasma using a tissue factor mutant selectively deficient in promoting factor VII activation. Blood 1993;81(3):734-44.

4. Nemerson Y. The reaction between bovine brain tissue factor and factors VII and X. Biochemistry 1966;5(2):601-8.

5. Osterud B, Rapaport SI. Activation of factor IX by the reaction product of tissue factor and factor VII: additional pathway for initiating blood coagulation. Proc Natl Acad Sci U S A 1977;74(12):5260-4.

6. Girard TJ, Warren LA, Novotny WF, et al. Functional significance of the Kunitz-type inhibitory domains of lipoprotein-associated coagulation inhibitor. Nature 1989;338(6215):518-20.

7. Broze GJ, Jr. Tissue factor pathway inhibitor. Thromb Haemost 1995;74(1):90-3.

8. van 't Veer C, Golden NJ, Kalafatis M, et al. Inhibitory mechanism of the protein $\mathrm{C}$ pathway on tissue factor-induced thrombin generation. Synergistic effect 
in combination with tissue factor pathway inhibitor. $\mathrm{J}$ Biol Chem 1997;272(12):7983-94.

9. Wun TC, Kretzmer KK, Girard TJ, et al. Cloning and characterization of a cDNA coding for the lipoprotein-associated coagulation inhibitor shows that it consists of three tandem Kunitz-type inhibitory domains. J Biol Chem 1988;263(13):6001-4.

10. Wesselschmidt R, Likert K, Huang Z, et al. Structural requirements for tissue factor pathway inhibitor interactions with factor $\mathrm{Xa}$ and heparin. Blood Coagul Fibrinolysis 1993;4(5):661-9.

11. Ndonwi M, Tuley EA, Broze GJ, Jr. The Kunitz-3 domain of TFPI-alpha is required for protein S-dependent enhancement of factor $\mathrm{Xa}$ inhibition. Blood 2010;116(8):1344-51.

12. Hackeng TM, Sere KM, Tans G, et al. Protein S stimulates inhibition of the tissue factor pathway by tissue factor pathway inhibitor. Proc Natl Acad Sci U S A 2006;103(9):3106-11.

13. Broze GJ, Jr., Warren LA, Novotny WF, et al. The lipoprotein-associated coagulation inhibitor that inhibits the factor VII-tissue factor complex also inhibits factor Xa: insight into its possible mechanism of action. Blood 1988;71(2):335-43.

14. Broze GJ, Jr., Girard TJ, Novotny WF. Regulation of coagulation by a multivalent Kunitz-type inhibitor. Biochemistry 1990;29(33):7539-46. 
15. Huang ZF, Wun TC, Broze GJ, Jr. Kinetics of factor Xa inhibition by tissue factor pathway inhibitor. J Biol Chem 1993;268(36):26950-5.

16. Morrison JF, Walsh CT. The behavior and significance of slow-binding enzyme inhibitors. Advances in enzymology and related areas of molecular biology 1988;61:201-301.

17. Petersen LC, Bjorn SE, Olsen OH, et al. Inhibitory properties of separate recombinant Kunitz-type-protease-inhibitor domains from tissue-factor-pathway inhibitor. Eur J Biochem 1996;235(1-2):310-6.

18. Higuchi DA, Wun TC, Likert KM, et al. The effect of leukocyte elastase on tissue factor pathway inhibitor. Blood 1992;79(7):1712-9.

19. Sere KM, Rosing J, Hackeng TM. Inhibition of thrombin generation by protein $\mathrm{S}$ at low procoagulant stimuli: implications for maintenance of the hemostatic balance. Blood 2004;104(12):3624-30.

20. Diaz-Collier JA, Palmier MO, Kretzmer KK, et al. Refold and characterization of recombinant tissue factor pathway inhibitor expressed in Escherichia coli. Thromb Haemost 1994;71(3):339-46.

21. Petersen JG, Meyn G, Rasmussen JS, et al. Characterization of human tissue factor pathway inhibitor variants expressed in Saccharomyces cerevisiae. J Biol Chem 1993;268(18):13344-51.

22. Esnouf MP, Lloyd PH, Jesty J. A method for the simultaneous isolation of factor X and prothrombin from bovine plasma. Biochem J 1973;131(4):781-9. 
23. Schnolzer M, Alewood P, Jones A, et al. In situ neutralization in Bocchemistry solid phase peptide synthesis. Rapid, high yield assembly of difficult sequences. International journal of peptide and protein research 1992;40(3-4):18093.

24. Hackeng TM, Griffin JH, Dawson PE. Protein synthesis by native chemical ligation: expanded scope by using straightforward methodology. Proc Natl Acad Sci U S A 1999;96(18):10068-73.

25. Girard TJ, Broze GJ, Jr. Tissue factor pathway inhibitor. Methods Enzymol 1993;222:195-209.

26. Dawson PE, Muir TW, Clark-Lewis I, et al. Synthesis of proteins by native chemical ligation. Science 1994;266(5186):776-9.

27. Ndonwi M, Tuley EA, Broze GJ, Jr. The Kunitz-3 domain of TFPI-alpha is required for protein S-dependent enhancement of factor Xa inhibition. Blood 2010;116(8):1344-51.

28. Lindhout T, Franssen J, Willems G. Kinetics of the inhibition of tissue factor-factor VIIa by tissue factor pathway inhibitor. Thromb Haemost 1995;74(3):910-5. 



\section{Chapter 4}

\section{Direct inhibition of factor VIIa by TFPI and TFPI constructs}

Peraramelli S, Thomassen S, Heinzmann A, Rosing J, Hackeng TM, Hartmann R, Scheiflinger F, Dockal M Journal of Thrombosis and Haemostasis 2013; 11: 704-714 
Chapter 4 


\section{Abstract}

Background: Tissue factor pathway inhibitor (TFPI) is a multi-Kunitz domain protease inhibitor that down-regulates the extrinsic coagulation pathway by inhibiting FXa and FVIIa. Objectives: To investigate the role of the three Kunitz domains (KDs) of TFPI in FVIIa inhibition using full-length TFPI (TFPI ${ }_{F L}$ ) and truncated TFPI constructs. Methods: Inhibition of FVIIa with/without relipidated tissue factor $(\mathrm{TF})$ or soluble TF (sTF) by $\mathrm{TFPI}_{\mathrm{FL}} / \mathrm{TFPI}$ constructs was quantified with a FVIIa-specific chromogenic substrate. Results and Conclusions: TFPI $\mathrm{FL}_{\mathrm{L}}$ inhibited TF-FVIIa via a monophasic reaction, which is rather slow at low $\mathrm{TFPI}_{\mathrm{FL}}$ concentrations ( $\mathrm{t}^{1} / 2 \sim 5 \mathrm{~min}$ at $2 \mathrm{nM}$ TFPI) and has a $\mathrm{K}_{\mathrm{i}}$ of $4.6 \mathrm{nM}$. In the presence of sTF and without TF, TFPI $I_{F L}$ was a poor FVIIa inhibitor, with $\mathrm{K}_{\mathrm{i}}$ values of 122 $\mathrm{nM}$ and1118 nM, respectively. This indicates that phospholipids and TF significantly contribute to FVIIa inhibition by $\mathrm{TFPI}_{\mathrm{FL}}$. TFPI constructs without the KD3-c-terminus (TFPI ${ }_{1-150}$ and KD1-KD2) were 7-10-fold less effective than $\mathrm{TFPI}_{\mathrm{FL}}$ in inhibiting TF-FVIIa and sTF-FVIIa, indicating that the KD3-C-terminus significantly contributes to direct inhibition of FVIIa by TFPI. Compared with KD1-KD2, KD1 was a poor TF-FVIIa inhibitor $\left(\mathrm{K}_{\mathrm{i}}=434 \mathrm{nM}\right)$, which shows that the KD2domain of TFPI also contributes to FVIIa inhibition. Protein S stimulated TF-FVIIa inhibition by $\operatorname{TFPI}_{\mathrm{FL}}\left(\mathrm{K}_{\mathrm{i}}=0.7 \mathrm{nM}\right)$. In the presence of FXa, a tight quaternary TF-FVIIa-TFPI-FXa complex is formed with $\mathrm{TFPI}_{\mathrm{FL}}, \mathrm{TFPI}_{1-150}$ and KD1-KD2, with $\mathrm{K}_{\mathrm{i}}$ values of $<0.15 \mathrm{nM}, 0.5 \mathrm{nM}$ and $0.8 \mathrm{nM}$, respectively, 
Chapter 4

indicating the KD3-C-terminus is not a prerequisite for quaternary complex formation. Phospholipids and the Gla-domain of FXa are required for quaternary complex formation. 


\section{Introduction}

After tissue damage, initiation of blood coagulation takes place upon the exposure of tissue factor (TF) (1). TF acts as cofactor of factor (F) VIIa in the activation of the FX (2-4), a reaction that is greatly stimulated by the negatively charged phospholipids contributed by the damaged tissue $(5,6)$. Tissue factor pathway inhibitor (TFPI) is a major inhibitor of the extrinsic coagulation pathway, which inhibits both FXa and FVIIa (7). TFPI is a multivalent Kunitz type inhibitor that consists of an acidic N-terminus followed by three tandem Kunitz domains (KDs) and a basic C-terminus (8). Site-directed mutagenesis experiments showed that the Kunitz 1 domain (KD1) of TFPI inhibits FVIIa and that the Kunitz 2 domain (KD2) inhibits FXa (9). The physiological importance of TFPI is demonstrated by premature mortality during embryogenesis in mice expressing a mutant TFPI lacking KD1 (10). FXa inhibition by TFPI is a biphasic reaction that occurs via a so-called slow-tight binding mechanism (11). In the first step, TFPI and FXa rapidly form a loose binary complex that slowly isomerises to a tight FXa-TFPI complex. FXa inhibition by TFPI is inhibited by $\mathrm{Ca}^{2+}$ ions and stimulated by phospholipids and protein $\mathrm{S}(12,13)$. Although KD2 of TFPI directly binds and inhibits FXa, the other domains of TFPI (KD1, KD3 and C-terminus) also contribute to FXa inhibition $(14,15)$. In recent reports it was shown that KD1 is required for the transition of the loose to the tight FXa-TFPI complex and that KD3 promotes the formation of the loose FXa-TFPI complex (15) and is required for 
protein S stimulation of TFPI (16). Much less is known about the inhibition of FVIIa by TFPI. Many reports showed that TF-FVIIa inhibition occurs via quaternary complex formation in which the KD2 domain of TFPI binds to the active site of FXa and the TF-FVIIa complex is subsequently inhibited by the interaction of KD1 of FXa-TFPI complex with the active site of FVIIa $(17,18)$. TFPI can also inhibit TF-FVIIa in the absence of FXa $(19,20)$, but there is no information on the role of the different TFPI domains in FVIIa inhibition. In the present study, we focused on the direct inhibition of FVIIa by TFPI and by various truncated TFPI constructs in order to investigate the role of the different domains of TFPI in the inhibition of TF-FVIIa. In addition, we tested the effect of relipidated TF, soluble TF, FXa and protein $\mathrm{S}$ on FVIIa inhibition by TFPI $\mathrm{FL}_{\mathrm{FL}}$ and the TFPI constructs. Our work provides new information on the contribution of the various TFPI domains, TF, phospholipid, FXa and protein S to the down-regulation of the extrinsic coagulation pathway by TFPI.

\section{Materials and methods}

\section{Materials}

The chromogenic substrates CS-11(65) (N-a-Benzyloxycarbonyl-D-arginyl-Lglycyl-L-arginine-p nitroaniline-dihydrochloride) and Spectrozyme FVIIa (Methanesulphonyl-D-cyclohexylalanyl-butyl-arginine-paranitroaniline monoacetate salt) were purchased from Hyphen BioMed (Mason, OH, USA) and 
American Diagnostica (Stamford, CT, USA), respectively. Chromozyme t-PA (NMethylsulfonyl-DPhe-Gly-Arg-4-nitranilide acetate) was purchased from Roche Diagnostics (Mannheim, Germany). $\mathrm{CaCl}_{2}, \mathrm{NaCl}$ and EDTA were obtained from Merck Chemicals (Darmstadt, Germany). HEPES, Tris-hydrochloride, bovine serum albumin (BSA) and ovalbumin were obtained from Sigma Aldrich (Zwijndrecht, the Netherlands). Rivaroxaban was purchased from Bayer HealthCare (Leverkusen, Germany).

\section{Proteins}

Recombinant human full-length TFPI (TFPI $\mathrm{FL}_{\mathrm{FL}}$ ) (1-276), produced in a bacterial expression system (Escherichia coli), was kindly provided by T. Lindhout (Cardiovascular Research Institute Maastricht). Purification and characterization of $\mathrm{TFPI}_{\mathrm{FL}}$ was described earlier (21). TFPI $\mathrm{FL}_{\mathrm{L}}$ stocks were diluted to $380 \mathrm{nM}$ in $25 \mathrm{mM}$ HEPES, $175 \mathrm{mM} \mathrm{NaCl}$, pH 7.5 and $5 \mathrm{mg} \mathrm{mL}^{-1}$ BSA (HNBSA) and stored at - 80 ${ }^{\circ} \mathrm{C} . \mathrm{TFPI}_{1-150}(1-150)$, Kunitz 1 linker Kunitz 2 (22-150, KD1-KD2), N-terminus Kunitz 1 (1-83, N-KD1), Kunitz 1 (22-79, KD1) and Kunitz 2 (93-150, KD2) were expressed in a bacterial expression system (E. coli) BL21(DE3)pLysS (Merck, Darmstadt, Germany) using the expression vector pET19b (Merck, Darmstadt, Germany). The proteins were purified from inclusion bodies. Cell pellets were solubilised in $8 \mathrm{M}$ urea, $20 \mathrm{mM}$ DTT, $50 \mathrm{mM}$ Tris- $\mathrm{HCl}$, $\mathrm{pH}$ 8.0. All the constructs were folded in $50 \mathrm{mM}$ Tris- $\mathrm{HCl}, \mathrm{pH} 10.0,1.1 \mathrm{mM}$ oxidized 
glutathione by rapid dilution followed by dialysis against $20 \mathrm{mM}$ Tris/HCl, $\mathrm{pH}$ 7.0. Purification was performed by a two-step procedure, a Q-Sepharose column followed by a Streptavidin affinity column with an immobilized peptide specific towards TFPI. TFPI $\mathrm{FL}_{\mathrm{L}}$ and TFPI constructs were stored in HNBSA at $-80{ }^{\circ} \mathrm{C}$. Endogenous glycosylated full-length $\left(\mathrm{TFPI}_{\mathrm{FL}}\right)$ secreted from the human adenocarcinoma SK-Hep1 cell line (ATCC) was purified using a two-step affinity chromatography protocol. First, total TFPI was captured by an anti-TFPI peptide (Baxter Innovations GmbH, Vienna, Austria) followed by a monoclonal antibody affinity chromatography directed against the TFPI C-terminus (MW1848, Sanquin, Amsterdam, the Netherlands). The final purification product appears on SDSPAGE as a single band of $43 \mathrm{kDa}$ with a purity of $>98 \%$. Glycosylated TFPI $\mathrm{FL}$ stocks were diluted to $750 \mathrm{nM}$ in $25 \mathrm{mM}$ HEPES, $175 \mathrm{mM} \mathrm{NaCl}$, pH 7.5 and $5 \mathrm{mg}$ $\mathrm{mL}^{-1}$ BSA (HNBSA) and stored at $-80{ }^{\circ} \mathrm{C}$. TF (Innovin) was purchased from Siemens Healthcare (Marburg, Germany). FVIIa was purchased from Novo Nordisk (Bagsvaerd, Denmark). Recombinant Soluble TF (sTF) was purchased from Creative BioMart (New York, NY, USA). Human FXa (FXa) was purchased from Kordia (Leiden, the Netherlands) and bovine FXa (bFXa) was purified from bovine plasma (22). Gla-domainless human FXa (GD-FXa) and protein S were from Haematologic Technologies (Essex Junction, VT, USA). Sheep polyclonal anti-protein $\mathrm{S}$ antibodies were purchased from Enzyme Research Laboratories (South Bend, IN, USA). 


\section{Concentration determination of TFPI modules}

The concentrations of $\mathrm{TFPI}_{\mathrm{FL}}, \mathrm{TFPI}_{1-150}$ and $\mathrm{KD} 1-\mathrm{KD} 2$ were determined by titrating a known amount of bFXa with $\mathrm{TFPI}_{\mathrm{FL}}$ and TFPI constructs (23). bFXa (1 $\mathrm{nM}$ ) was incubated with increasing concentrations of TFPI $\mathrm{FL}_{\mathrm{L}}$ or TFPI constructs in HNBSA for $60 \mathrm{~min}$ at room temperature. As TFPI forms a 1:1 stoichiometric complex with FXa $(9,17)$, the X-axis intercept of a plot of residual activity of FXa determined with CS-11(65) as a function of the amount of TFPI allows calculation of the functional TFPI concentration. The concentrations of N-KD1, KD1and KD2 were determined by titration of a known amount of trypsin and calculation of the functional concentrations of constructs as described above for TFPI.

\section{Concentration determination of FVIIa}

The concentration of FVIIa was determined by titrating FVIIa with a known amount of $\mathrm{FXa}(0-1 \mathrm{nM})$ in the presence of $5 \mathrm{nM} \mathrm{TF}, 3 \mathrm{mM} \mathrm{CaCl}_{2}$ and an excess of TFPI ( $1 \mathrm{nM})$. After incubating the reaction mixture for $15 \mathrm{~min}$, residual FVIIa was quantified by adding $0.5 \mathrm{mM}$ Spectrozyme FVIIa and $40 \mu \mathrm{g} \mathrm{mL}^{-1}$ Rivaroxaban to inhibit free FXa. As FXa and TFPI form a tight stoichiometric complex with FVIIa, the x-axis intercept of a plot of the residual FVIIa activity as a function of the FXa concentration is equal to the functional FVIIa concentration in the reaction mixture. 


\section{Inhibition of relipidated TF-FVIIa by $\mathrm{TFPI}_{\mathrm{FL}}$}

A reaction mixture containing $0.3 \mathrm{nM}$ FVIIa, $5 \mathrm{nM}$ relipidated TF (a concentration supporting maximal stimulation of FVIIa) and $3 \mathrm{mM} \mathrm{CaCl}_{2}$ in $\mathrm{HNBSA}$ buffer was incubated for $15 \mathrm{~min}$ at $37{ }^{\circ} \mathrm{C}$. Subsequently, different amounts of TFPI were added and incubated for $15 \mathrm{~min}$ at $37{ }^{\circ} \mathrm{C}$, after which pre-warmed $0.5 \mathrm{mM}$ Spectrozyme FVIIa was added. Chromogenic substrate conversion, which is a measure for non-inhibited FVIIa, was followed at $405 \mathrm{~nm}$ in an Ultra Microplate Reader (Bio-Tek, Burlington, VT, USA) for $45 \mathrm{~min}$. The final concentrations in the well were: $0.3 \mathrm{nM}$ FVIIa, $5 \mathrm{nM}$ TF, $0.5 \mathrm{mM}$ Spectrozyme FVIIa and 0-18 nM $\mathrm{TFPI}_{\mathrm{FL}}$. To understand the mechanism of inhibition of relipidated TF-FVIIa by $\mathrm{TFPI}_{\mathrm{FL}}$ (monophasic or biphasic inhibition), we also performed experiments in which substrate was added simultaneously with $\mathrm{TFPI}_{\mathrm{FL}}$ (Fig. 2A).

\section{Inhibition of sTF-FVIIa and FVIIa by TFPI}

A reaction mixture containing $0.6 \mathrm{nM}$ FVIIa, $50 \mathrm{nM}$ sTF (a concentration supporting maximal stimulation of FVIIa) and $3 \mathrm{mM} \mathrm{CaCl}_{2}$ in $\mathrm{HNBSA}$ buffer was incubated for $15 \mathrm{~min}$ at $37^{\circ} \mathrm{C}$. Different amounts of TFPI were then added and the mixture was incubated for an additional $15 \mathrm{~min}$ at $37{ }^{\circ} \mathrm{C}$. Subsequently, prewarmed $0.5 \mathrm{mM}$ Spectrozyme FVIIa was added and chromogenic substrate conversion was followed at $405 \mathrm{~nm}$ in an Ultra Microplate Reader (Bio-Tek) for 45 min. The final concentrations in the well were: $0.6 \mathrm{nM}$ FVIIa, $50 \mathrm{nM}$ sTF, $0.5 \mathrm{mM}$ 


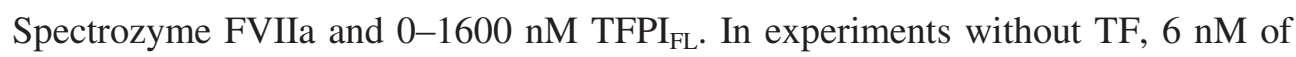
FVIIa was used instead of $0.6 \mathrm{nM}$ and $1 \mathrm{mM}$ Chromozyme t-PA substrate was used instead of $0.5 \mathrm{mM}$ Spectrozyme FVIIa, and chromogenic substrate conversion was followed as described above.

Inhibition of relipidated TF-FVIIa and sTF-FVIIa by TFPI constructs

Titrations of TF and STF with TFPI constructs were performed as described above at $0.3 \mathrm{nM}$ FVIIa, $5 \mathrm{nM}$ relipidated $\mathrm{TF}, 3 \mathrm{mM} \mathrm{CaCl} 2,0.5 \mathrm{mM}$ Spectrozyme FVIIa and 0-250 nM TFPI ${ }_{1-150}, 0-250 \mathrm{nM}$ KD1-KD2, 0-2000 nM N-KD1, 0-2000 nM KD1 or 0-800 nM KD2 (final concentrations in the well). For sTF-FVIIa inhibition the final concentrations in the well were: $0.6 \mathrm{nM}$ FVIIa, $50 \mathrm{nM} \mathrm{sTF}, 3 \mathrm{mM} \mathrm{CaCl}_{2}$, $0.5 \mathrm{mM}$ Spectrozyme FVIIa and 0-250 nM TFPI ${ }_{1-150}, 0-250 \mathrm{nM}$ KD1-KD2, 02000 nM N-KD1, 0-2000 nM KD1 or 0-800 nM KD2.

Inhibition of relipidated TF-FVIIa and STF-FVIIa by TFPI $\mathrm{FL}_{\mathrm{L}}$ and TFPI constructs in the presence of FXa

A reaction mixture containing $0.3 \mathrm{nM}$ FVIIa, $5 \mathrm{nM}$ relipidated $\mathrm{TF}, 3 \mathrm{mM} \mathrm{CaCl} 2$ and $1 \mathrm{nM}$ FXa in HNBSA buffer was pre-incubated at $37{ }^{\circ} \mathrm{C}$ for $15 \mathrm{~min}$. Subsequently, different concentrations of TFPI $\mathrm{FL}_{\mathrm{FL}}$ or TFPI constructs were added 
and incubated for $15 \mathrm{~min}$ at $37^{\circ} \mathrm{C}$. As Spectrozyme FVIIa is also a good substrate for FXa, prior to quantification of FVIIa, $10 \mu \mathrm{g} \mathrm{mL}^{-1}$ rivaroxaban was added to inhibit any free FXa present in the reaction mixture. As a control, $10 \mu \mathrm{g} \mathrm{mL} \mathrm{m}^{-1}$ rivaroxaban was added before the addition of FXa to prevent the quaternary complex formation and to test whether inhibition of FVIIa by TFPI (constructs) is affected by rivaroxaban, which did not appear to be the case. Rivaroxaban is a direct FXa inhibitor, which has been used in experiments with FXa to prevent quaternary complex formation. To keep the conditions similar, rivaroxaban was present in all the experiments. Rivaroxaban, which is a highly specific FXa inhibitor $(24,25)$, did not cause dissociation of pre-formed quaternary TFPI-TFFVIIa-FXa complexes. The final concentrations in the well were: $0.3 \mathrm{nM}$ FVIIa, 5 $\mathrm{nM}$ relipidated TF/50 nM sTF, $0.5 \mathrm{mM}$ Spectrozyme FVIIa, and 0-5 nM TFPI $\mathrm{FL}_{\text {, }}$ 0-50 nM TFPI ${ }_{1-150}$ or 0-50 nM KD1-KD2 and $1 \mathrm{nM}$ FXa. Similar experiments were also performed with $1 \mathrm{nM}$ GD-FXa.

\section{Inhibition of relipidated TF-FVIIa by TFPI/TFPI constructs in}

\section{the presence of protein $S$}

A reaction mixture containing $0.3 \mathrm{nM}$ FVIIa, $5 \mathrm{nM} \mathrm{TF}, 3 \mathrm{mM} \mathrm{CaCl} 2,10 \mu \mathrm{g} \mathrm{mL}^{-1}$ rivaroxaban and $100 \mathrm{nM}$ protein $\mathrm{S}$ was incubated in HNBSA buffer for $15 \mathrm{~min}$ at $37^{\circ} \mathrm{C}$. As the protein S preparation contained traces of $\mathrm{FX}, 10 \mu \mathrm{g} \mathrm{mL} \mathrm{L}^{-1}$ rivaroxaban was present in the reaction mixtures. Different concentrations of TFPI/TFPI 
constructs were then added and the reaction mixture was incubated for an additional $15 \mathrm{~min}$ at $37^{\circ} \mathrm{C}$. Subsequently, $0.5 \mathrm{mM}$ pre-warmed Spectrozyme FVIIa was added and chromogenic substrate conversion, which is a measure for noninhibited FVIIa, was followed at $405 \mathrm{~nm}$ an Ultra Microplate Reader (Bio-Tek) for $45 \mathrm{~min}$. The final concentrations in the well were: $0.3 \mathrm{nM}$ FVIIa, $5 \mathrm{nM}$ relipidated $\mathrm{TF} / 50 \mathrm{nM} \mathrm{sTF}, 10 \mu \mathrm{g} \mathrm{mL}^{-1}$ rivaroxaban, $100 \mathrm{nM}$ protein $\mathrm{S}, 0.5 \mathrm{mM}$ Spectrozyme FVIIa, and 0-40 nM TFPI $I_{\mathrm{FL}}, 0-250 \mathrm{nM} \mathrm{TFPI}_{1-150}$ or 0-250 nM KD1-KD2. A similar experiment was performed in the presence of $0.8 \mu \mathrm{M}$ sheep polyclonal antiprotein S antibody.

\section{Calculation of the $\mathrm{K}_{\mathrm{i}}$ values of inhibition of FVIIa by TFPI and TFPI constructs}

From the rates of chromogenic substrate conversion determined in the microplate reader the percentage inhibition of FVIIa by TFPI or TFPI constructs was calculated. The percentage FVIIa inhibition was plotted as a function of the TFPI (construct) concentration [TFPI] and fitted to the equation for the Langmuir binding isotherm:

$\mathrm{I}=\mathrm{I}_{\max } \cdot[\mathrm{TFPI}] /\left(\mathrm{K}_{\mathrm{i}}+[\mathrm{TFPI}]\right) \quad($ eq. 1$)$

where, I is the \% of inhibition of FVIIa, Imax is the maximal inhibition (\%) of FVIIa and $\mathrm{IC}_{50}$ is the inhibition constant (i.e. the concentration of TFPI or TFPI construct at which $50 \%$ of the maximal inhibition of FVIIa is observed). The 
presence of chromogenic substrate may affect the $\mathrm{IC}_{50}$ of TFPI inhibition through competition with TFPI for the active site of FVIIa. The extent of competition depends on the concentration of chromogenic substrate relative to its $\mathrm{Km}$ for FVIIa. The Km values of Spectrozyme FVIIa for FVIIa at the reaction conditions in our experiments were $0.9 \mathrm{mM}(+\mathrm{TF}), 2.6 \mathrm{mM}(+\mathrm{sTF})$ and6.1 $\mathrm{mM}$ (no TF) (data not shown). As the substrate concentration used in our experiments $(0.5 \mathrm{mM})$ was below the Km, Spectrozyme FVIIa had a small effect on the $\mathrm{IC}_{50}$ and $\mathrm{K}_{\mathrm{i}}$ values for inhibition of TF-FVIIa by TFPI and TFPI constructs were calculated from the $\mathrm{IC}_{50}$ using the equation $\mathrm{K}_{\mathrm{i}}=\mathrm{IC} 50 /([$ SpectrozymeVIIa]/Km + 1) (26).

\section{Results}

\section{TFPI constructs used in the study}

The following TFPI constructs (Fig. 1) have been used in this study: TFPI $\mathrm{FL}_{(1-276}$ a.a.), $\operatorname{TFPI}_{1-150}(1-150$ a.a.), which lacks KD3 and the C-terminus, KD1-KD2 (22150 a.a.), lacking KD3 and the C-terminus and acidic N-terminus of TFPI, N-KD1 (1-83 a.a.), lacking KD2, KD3 and the C-terminus, KD1 (22-79 a.a.), similar to NKD1 without the acidic N-terminus, and KD2 (93-150 a.a.). Because all TFPI constructs used in our study were derived from E. coli and therefore not glycosylated we have compared them with E. coli-derived full-length TFPI, which is also not glycosylated. A glycosylated form of TFPI expressed in human SK- 
Hep1 cells was used in a few control experiments (see below) to test whether glycosylation affected FVIIa inhibition by TFPI.

\section{Direct inhibition of FVIIa by TFPI $_{\mathrm{FL}}$}

In order to understand the mechanism of direct inhibition of FVIIa by $\mathrm{TFPI}_{\mathrm{FL}}$, experiments were performed at three different conditions (i.e. FVIIa in the presence of relipidated TF and soluble TF (sTF) and in the absence of TF). Titrations of FVIIa with TFPI $_{\mathrm{FL}}$ and TFPI constructs were carried out in the presence of $3 \mathrm{mM} \mathrm{CaCl}_{2}$. In the first experiment, TFPI $\mathrm{FL}_{\mathrm{FL}}$ was pre-incubated with relipidated TF-FVIIa, but was added simultaneously with chromogenic substrate.

The progress curves of chromogenic substrate conversion bend off at low TFPI concentrations (Fig. 2A). This is indicative of time-dependent inhibition of FVIIa at low TFPI concentrations, which can be either due to a biphasic slow-tight binding mechanism or slow monophasic binding (27) (see Discussion). The percentage of inhibition of FVIIa (calculated from the amidolytic activity) was plotted as a function of the TFPI concentration and fitted to a hyperbola yielding a $\mathrm{K}_{\mathrm{i}}$ value of $4.6 \mathrm{nM}$ (Fig. 2B, Table 1). Similar $\mathrm{K}_{\mathrm{i}}$ values were obtained when FVIIa inhibition was quantified with chromogenic substrate after 15 min of preincubation of relipidated TF-FVIIa with TFPI $\mathrm{FL}_{\mathrm{FL}}$. A glycosylated form of TFPI expressed in human SK-Hep1 cells inhibited TF-FVIIa with a $\mathrm{K}_{\mathrm{i}}$ that was $\sim 2$-fold 
higher than the $\mathrm{K}_{\mathrm{i}}$ of non-glycosylated TFPI (data not shown), which demonstrates that glycosylation has a small effect on the TF-FVIIa inhibitory activity of TFPI.

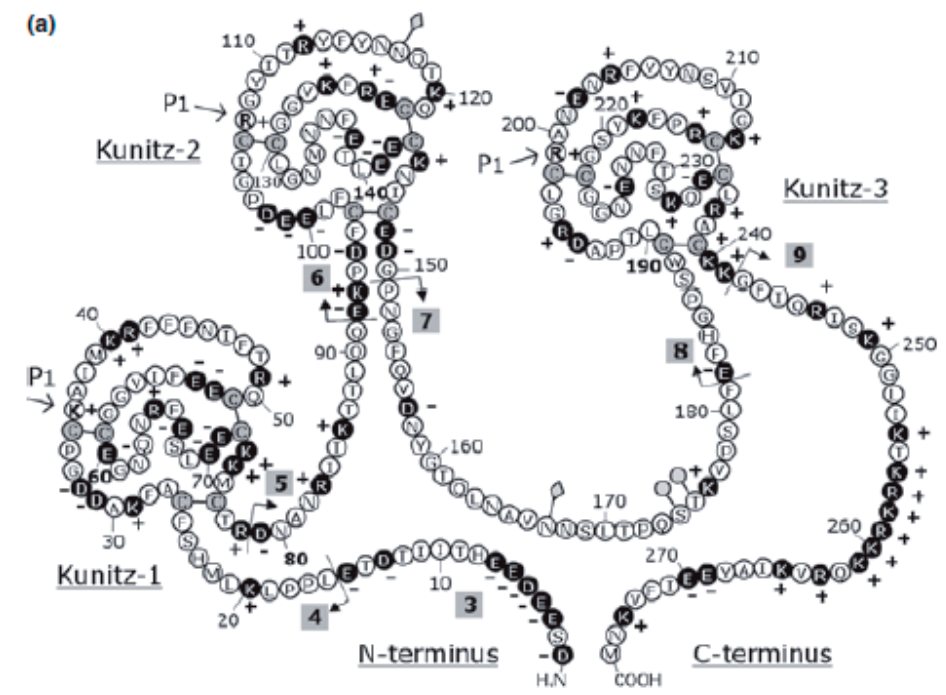

(b)

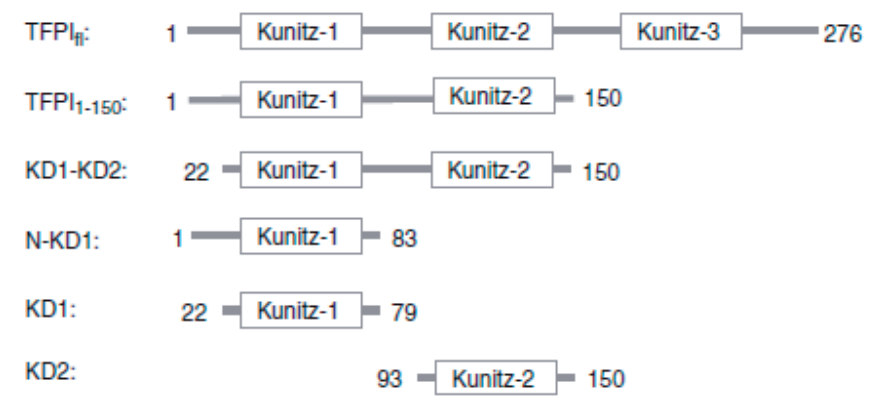

Figure 1: TFPI constructs used in the study. (A) Primary structure of TFPI. Black amino acids indicate charged residues, grey diamonds and circles indicate potential $N$-linked and O-linked carbohydrates, grey numbered boxes indicate exons. P1 residues in the Kunitz domains are indicated by arrows. (B) List of TFPI constructs used in the current study. 

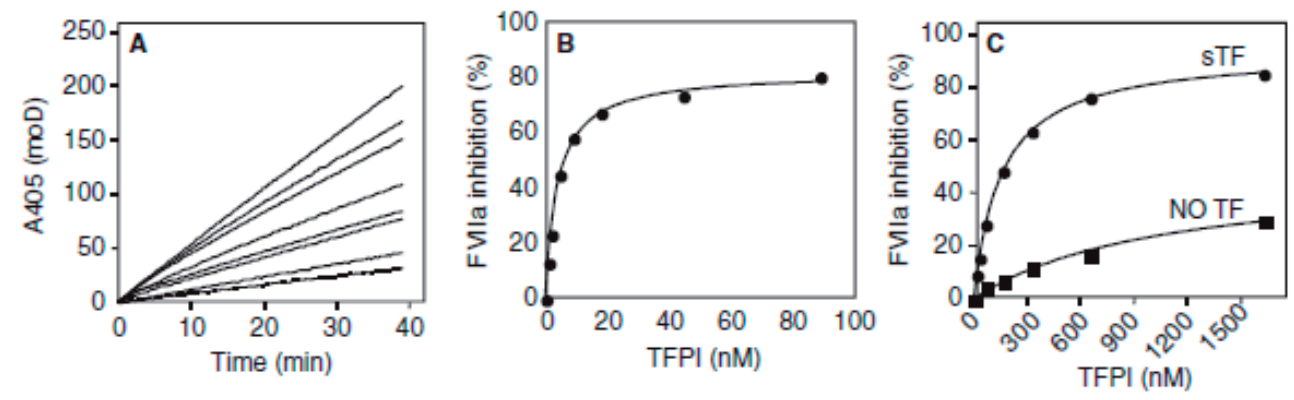

Figure 2: Direct inhibition of (s)TF-FVIIa by TFPI $_{F L}$. (A) Progress curves of $500 \mu M$ Spectrozyme FVIIa substrate conversion by relipidated TF-FVIIa at different TFPIFL concentrations. Inhibition of $0.3 \mathrm{nM}$ FVIIa, $5 \mathrm{nM}$ TF by $0-100 \mathrm{nM} \mathrm{TFPI}_{\mathrm{FL}}$ in the presence of $3 \mathrm{mM} \mathrm{CaCl}_{2}$ without pre-incubation. Concentrations of $\mathrm{TFPI}_{F L}$ are $0 \mathrm{nM}, 1 \mathrm{nM}, 2 \mathrm{nM}, 5$ nM, 10 nM, 20 nM, 50 nM and 100 nM. (B) Percentage of 0.3 nM FVIIa and $5 n M$ relipidated TF complex inhibited as a function of TFPI $I_{F L}(0-100 \mathrm{nM})$. Solid lines represent fits for hyperbolic function (equation 1, Materials and methods). (C) Percentage of $0.6 \mathrm{nM}$

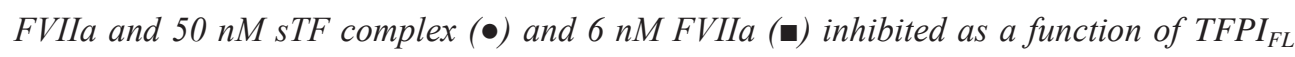
(0-1600 nM). Solid lines represent fits for hyperbolic function.

FVIIa was also titrated with TFPI $_{\mathrm{FL}}$ in the presence ofsTF and in the absence of TF. sTF (1-219 a.a.), which lacks the transmembrane and intracellular domain, does not contain lipid and does not bind to phospholipids (28). Compared with relipidated TF-FVIIa, sTF-FVIIa was inhibited by TFPI $_{\mathrm{FL}}$ with a $\sim 26$-fold higher $\mathrm{K}_{\mathrm{i}}$ value $\left(\mathrm{K}_{\mathrm{i}}=122 \mathrm{nM}\right.$, Table 1, Fig. 2C). In the absence of (s)TF-FVIIa was even more poorly inhibited by $\mathrm{TFPI}_{\mathrm{FL}}$ (Fig. 2C) and the $\mathrm{K}_{\mathrm{i}}$ value was more than 200 -fold higher $\left(\mathrm{K}_{\mathrm{i}} \sim 1.118 \mathrm{nM}\right)$ than that obtained in the presence of relipidated TF (Table 1). 
Direct inhibition of relipidated and soluble TF-FVIIa byTFPI ${ }_{1-150}$ and KD1-KD2

To investigate the importance of the KD3-C-terminus of TFPI for the inhibition of FVIIa, two truncated constructs were used: $\mathrm{TFPI}_{1-150}$ and KD1-KD2. Compared with TFPI $_{1-150}$, KD1-KD2 lacks the acidic N-terminus. The $\mathrm{K}_{\mathrm{i}}$ values obtained for inhibition of the relipidated TF-FVIIa by both constructs of TFPI were similar, but were $~ 7-10$-fold higher than those of $\mathrm{TFPI}_{\mathrm{FL}}$ (Fig. 3, Table 1). In presence of sTF, inhibition was even less efficient and the $\mathrm{K}_{\mathrm{i}}$ values were 15-30-fold higher than those obtained with relipidated TF. When titrations of FVIIa with TFPI ${ }_{1-150}$ and KD1-KD2 were performed in the absence of $\mathrm{TF}, \mathrm{K}_{\mathrm{i}}$ values were too high to be accurately determined $(>2.500 \mathrm{nM})$.

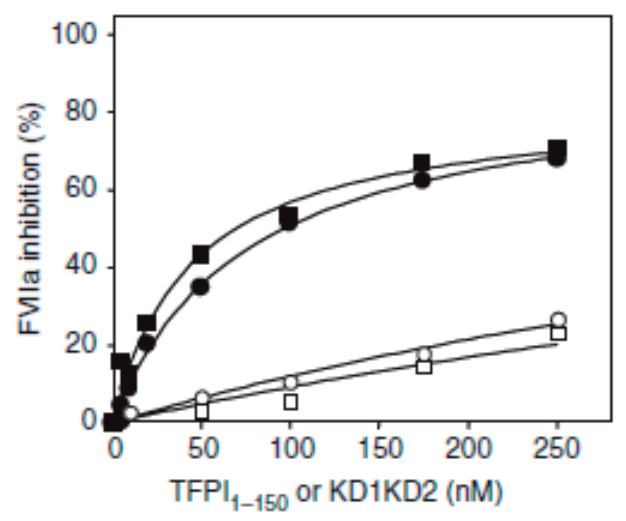

Figure 3: Direct inhibition of (s)TF-

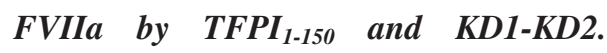
Percentage of $0.3 \mathrm{nM}$ FVIIa and $5 \mathrm{nM}$ relipidated TF complex or $0.6 \mathrm{nM}$ FVIIa and $50 \mathrm{nM}$ STF complex inhibited as a function of TFPI $I_{1-150}$ and KD1-KD2 (0$250 \mathrm{nM}$ ). Solid lines represent fits for hyperbolic function (equation 1). (•) Relipidated TF with TFPI $I_{1-150}$; (-) relipidated TF with KD1-KD2; (O) STF with TFPI $_{1-150}$; (口) sTF with KD1-KD2. 


\section{Direct inhibition of relipidated and soluble TF-FVIIa by NKD1,}

\section{$\mathrm{KD} 1$ and KD2}

It is generally accepted that KD1 of TFPI inhibits FVIIa and that KD2 inhibits FXa (9). Therefore, it was of interest to determine the inhibition of FVIIa by the isolated Kunitz domains, N-KD1, KD1 and KD2. High concentrations of these constructs were required for inhibition of relipidated TF-FVIIa and sTF-FVIIa. Surprisingly, FVIIa was not only inhibited by N-KD1 and KD1 but also by KD2, with similar $\mathrm{K}_{\mathrm{i}}$ values (Fig. 4). However, the $K_{i}$ values were much higher than those determined for (s) TF-FVIIa inhibition by TFPI ${ }_{\mathrm{FL}}, \mathrm{TFPI}_{1-150}$ and KD1-KD2 (Table 1), which indicates that the other Kunitz domains (KD2 and KD3) are required for efficient inhibition of TF-FVIIa by TFPI $I_{\mathrm{FL}}$.

The effect of protein S on the inhibition of FVIIa by TFPI and

\section{TFPI constructs}

It has been shown that protein $\mathrm{S}$ is a cofactor of $\mathrm{TFPI}_{\mathrm{FL}}$ in $\mathrm{FXa}$ inhibition (13). To study whether protein $\mathrm{S}$ also acts as cofactor for $\mathrm{TFPI}_{\mathrm{FL}}$ in relipidated TF-FVIIa inhibition, experiments were carried out in the presence of $100 \mathrm{nM}$ protein S. In the presence of protein $S$ there was a 6.5 -fold decrease in the $K_{i}$ value, which shows that protein $\mathrm{S}$ also promotes the inhibition of relipidated TF-FVIIa by TFPI (Fig. $5 \mathrm{~A})$. 
In order to confirm that it was not an artifact, the protein $\mathrm{S}$ titration was also performed in the presence of an anti-sheep polyclonal anti-protein S antibody. In the presence of the anti-protein $\mathrm{S}$ antibody, the cofactor activity of protein $\mathrm{S}$ was completely abrogated and the $\mathrm{K}_{\mathrm{i}}$ value for TFPI was similar to the one obtained in the absence of protein S. Titration of $\mathrm{TFPI}_{1-150}$ and $\mathrm{KD} 1-\mathrm{KD} 2$ has also been performed in the presence of protein S. Both truncated forms of TFPI lack the KD3-C-terminus of TFPI and were not stimulated by protein S (Fig. 5B). This observation is in line with the recent observation that $\mathrm{KD} 3$ is required for the binding of TFPI to protein $S(16,29)$. To study the role of phospholipids in the protein $\mathrm{S}$ cofactor activity for $\mathrm{TFPI}_{\mathrm{FL}}$, $\mathrm{STF}$ was used instead of relipidated TF. Protein S did not have any stimulatory effect on the inhibition of sTF-FVIIa by TFPI $_{\mathrm{FL}}$ (Fig. 5C), indicating that not only the KD3-C-terminus, but also phospholipids, are required for protein S cofactor activity in FVIIa inhibition by TFPI. As in the absence of protein S, glycosylated TFPI isolated from human SKHep1 cells inhibited TF-FVIIa with a $\mathrm{K}_{\mathrm{i}}$ that was $\sim$ 2-fold higher than that determined for non-glycosylated TFPI (data not shown).

\section{Effect of FXa on relipidated and soluble TF-FVIIa inhibition by}

\section{TFPI and TFPI constructs}

It has been shown that inhibition of relipidated TF-FVIIa by TFPI is greatly enhanced by FXa, which enables the formation of a tight quaternary TF-FVIIa- 


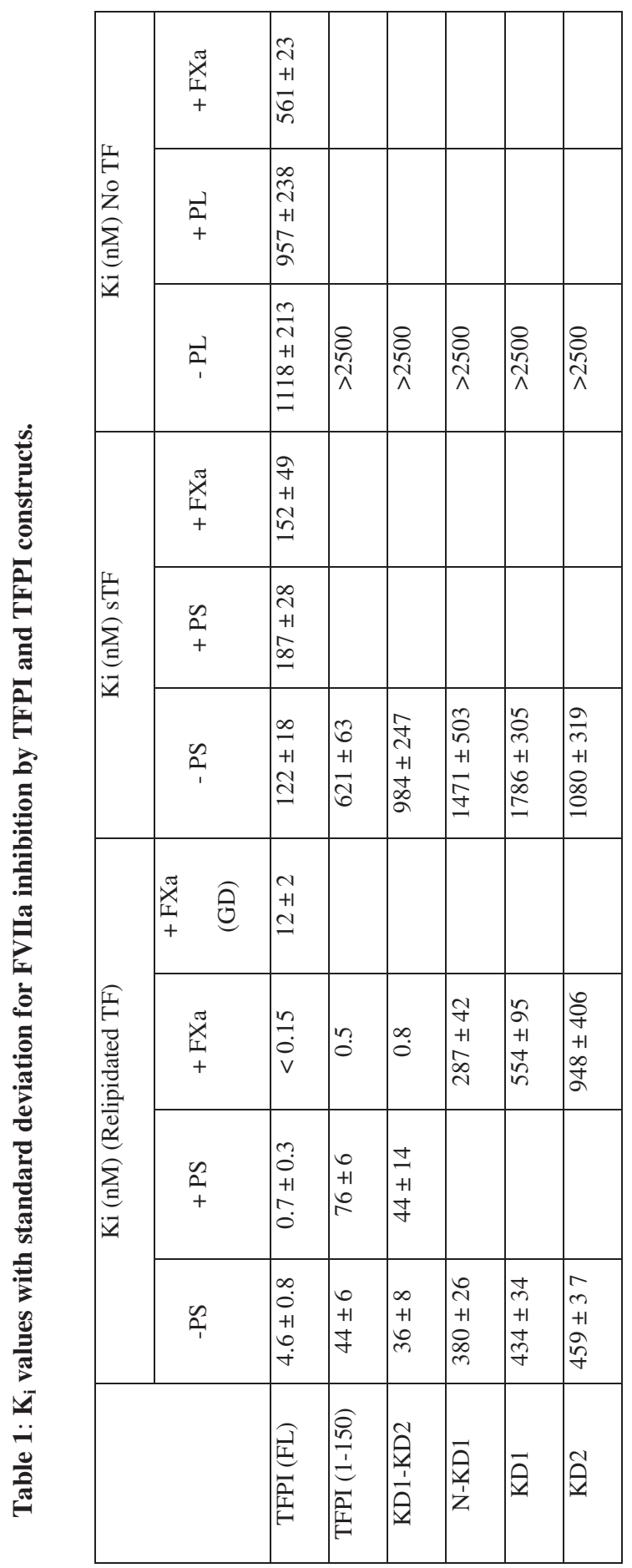




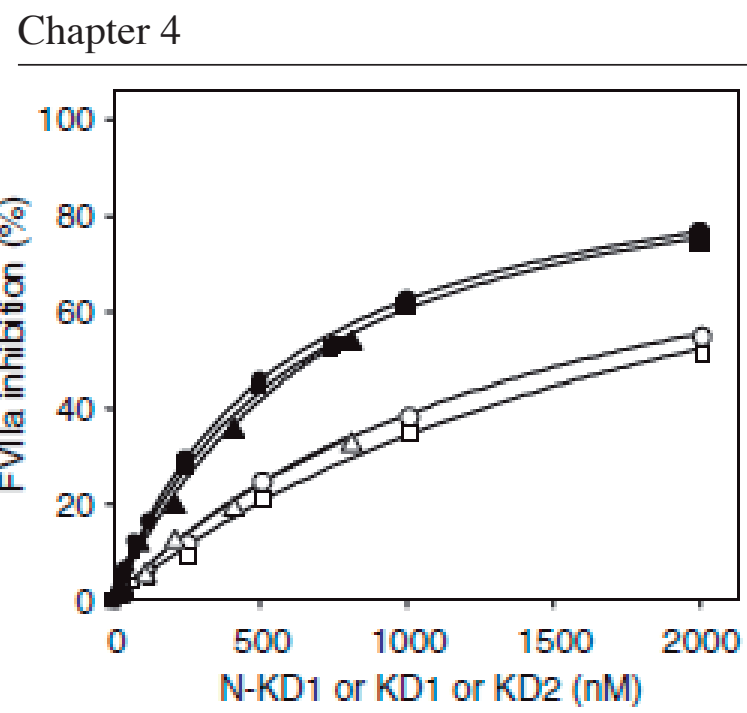

Figure 4: Direct inhibition of (s)TF-FVIIa by N-KDI and KD1 and KD2. Percentage of $0.3 n M \quad F V I I a$ and $5 \quad n M$ relipidated TF complex or 0.6 nM FVIIa and 50 nM sTF complex inhibited as a function of $\mathrm{N}$-KDI and KDI (0-2000 $n M) ; \quad K D 2(0-800 \quad n M)$. Solid lines represent fits for hyperbolic function (equation 1).

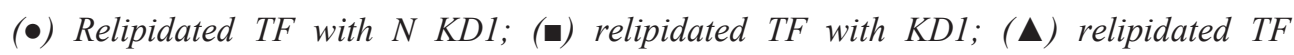

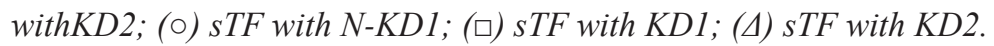

TFPI-FXa complex (19). In order to further study the role of the TFPI domains in quaternary complex formation, we have tested the effect of FXa on the inhibition of TF-FVIIa by TFPI $_{\mathrm{FL}}$ and TFPI constructs. $\mathrm{TFPI}_{\mathrm{FL}}$ formed a 1:1 stoichiometric quaternary complex (relipidated TF-FVIIa-TFPI-FXa) with a $\mathrm{K}_{\mathrm{i}}$ value that cannot be reliably determined and is $<0.15 \mathrm{nM}$ (i.e. $<50 \%$ of the concentration of FVIIa present in the reaction mixture) (Fig. 6A).

As the Gla-domain of FXa is essential for the $\mathrm{Ca}^{2+}$-dependent binding of FXa to phospholipids, GD-FXa was also used in the study. No quaternary complex was formed when GD-FXa was used instead of FXa (Fig. 6A). The phospholipid requirement for quaternary complex formation was studied by performing a similar experiment in which relipidated TF was replaced by sTF. sTF-FVIIa did not form a tight quaternary complex with TFPI and FXa (Fig. 6C). In the absence of FXa, 
$\mathrm{TFPI}_{1-150}$ and KD1-KD2 had 7-10-fold higher $\mathrm{K}_{\mathrm{i}}$ values than $\mathrm{TFPI}_{\mathrm{FL}}$ for inhibition of there lipidated TF-FVIIa complex (Table 1). Therefore, it was of interest to study the role of these two TFPI constructs in the inhibition of TF-FVIIa in the presence of FXa. Both $\mathrm{TFPI}_{1-150}$ and $\mathrm{KD} 1-\mathrm{KD} 2$ readily formed a quaternary complex, with $\mathrm{K}_{\mathrm{i}}$ values of $0.5 \mathrm{nM}$ and $0.8 \mathrm{nM}$, respectively (Fig. 6B). The observations with the truncated forms of TFPI show that the KD3-C-terminus is not absolutely required for quaternary complex formation.
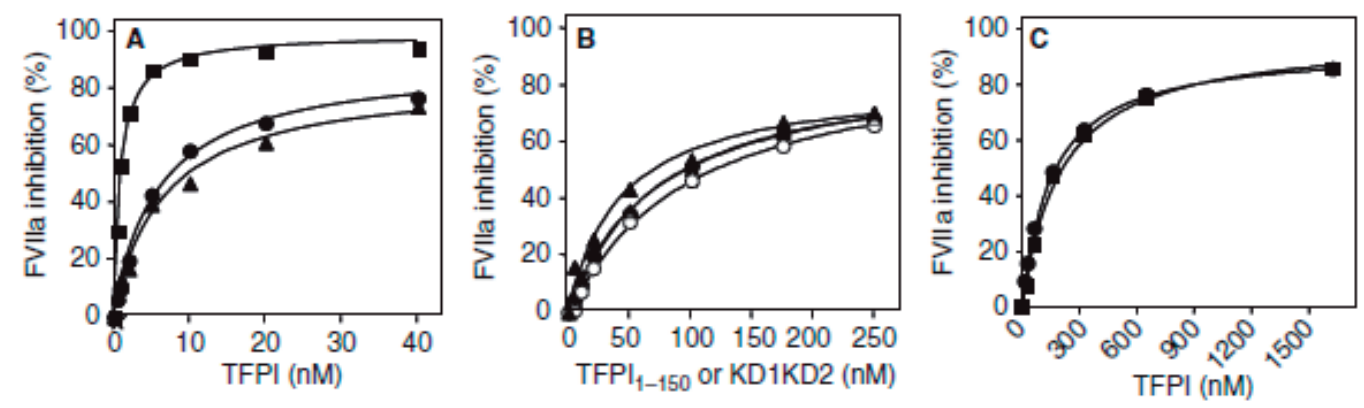

Figure 5: Direct inhibition of (s)TF-FVIIa by TFPI and TFPI constructs in the presence and absence of protein S. (A) Percentage of $0.3 \mathrm{nM}$ FVIIa and $5 \mathrm{nM}$ relipidated TF complex inhibited as a function of $T_{F P I}(0-40 \mathrm{nM})$ in the absence of protein $S$ represented by $(\bullet)$; in the presence of $100 \mathrm{nM}$ protein $S$ represented by (曰); in the presence of $100 \mathrm{nM}$ protein $S$ and $0.8 \mu \mathrm{M}$ sheep polyclonal anti-protein $S$ antibody represented by (৯). (B) Percentage of $0.3 \mathrm{nM}$ FVIIa and $5 \mathrm{nM}$ relipidated TF complex inhibited as a function of TFPI ${ }_{1-150}$ and KD1-KD2 (0-250nM) in the absence of protein $S$ represented by $(\bullet)$ and $(\mathbf{\Delta})$, respectively; in the presence of $100 \mathrm{nM}$ protein $S(0)$ and (4), respectively.

(C) Percentage of $0.6 \mathrm{nM}$ FVIIa and $50 \mathrm{nM}$ sTF complex inhibited as a function of TFPI $\mathrm{IL}_{\mathrm{F}}$ $(0-1600 \mathrm{nM})$ in the absence of protein $S(\bullet)$ and in the presence of $100 \mathrm{nM}$ protein $S(0)$. Solid lines represent fits for hyperbolic function (equation 1). 

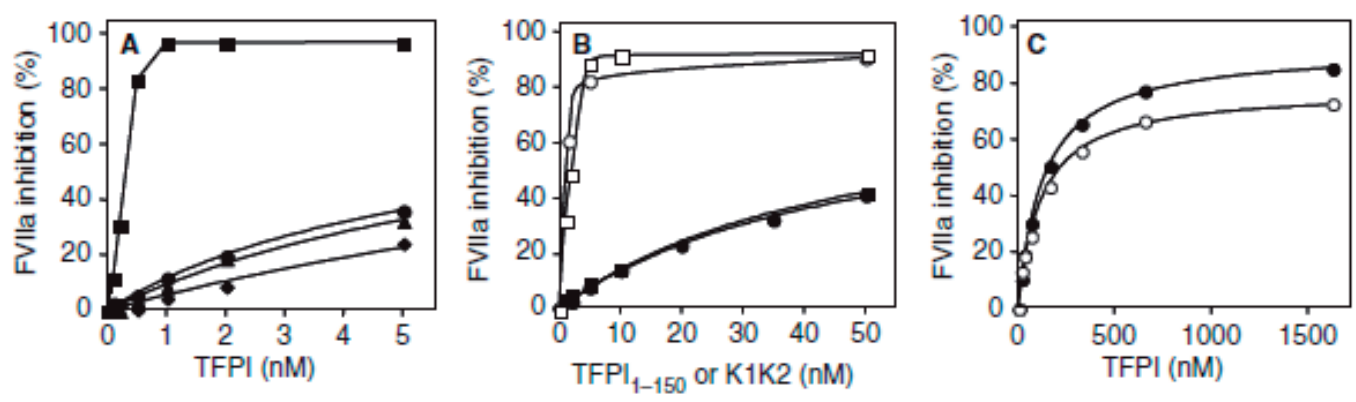

Figure 6: TF-FVIIa inhibition by TFPI and TFPI constructs in the presence of FXa. (A) Percentage of $0.3 \mathrm{nM}$ FVIIa and $5 \mathrm{nM}$ relipidated TF complex inhibited as a function of

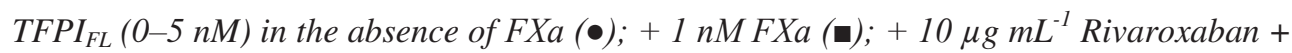

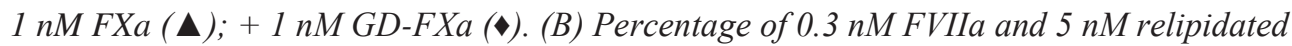
TF complex inhibited as a function of TFPI ${ }_{1-150}$ and $K D 1-K D 2(0-50 \mathrm{nM})$ in the absence of

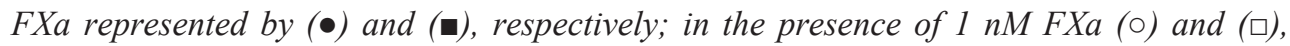
respectively. (C) Percentage of $0.6 \mathrm{nM}$ FVIIa and $50 \mathrm{nM}$ sTF complex inhibited as a function of TFPI $I_{F L}(0-1600 \mathrm{nM})$ in the absence of $\mathrm{FXa}(\bullet)$ and in the presence of $1 \mathrm{nM} F \mathrm{Fa}$ (०). Solid lines represent fits for hyperbolic function (equation 1, Materials and methods). 


\section{Discussion}

Although direct inhibition of TF-FVIIa by TFPI was described by Pederson et al. (19), most of the subsequent studies on FVIIa inhibition by TFPI were performed in the presence of FXa and/or cell surfaces. It is generally accepted that the KD1 domain of TFPI inhibits FVIIa and that KD2 binds and inhibits FXa $(9,17)$. For inhibition of FXa by TFPI there are several reports that show other Kunitz domains (KD1 and KD3) and the C-terminus of TFPI contribute to FXa inhibition (14, 30, 31). As limited information is available on the role of the different Kunitz domains of TFPI in the direct inhibition of FVIIa, we have performed a detailed kinetic analysis of FVIIa inhibition by TFPI $\mathrm{FL}_{\mathrm{FL}}$ and TFPI constructs lacking Kunitz domains and $\mathrm{C}$ - and N-termini. To establish whether phospholipids and TF also contribute to FVIIa inhibition by TFPI, experiments were performed at three different conditions (i.e. in the presence of relipidated TF and sTF and in the absence of TF). Full-length TF, a membrane integral glycoprotein (46 kDa), is a 263 a.a. singlechain polypeptide that consists of a 219 a.a. extracellular N-terminus and a 23 a.a. transmembrane domain followed by an intracellular 21 a.a. C-terminus (32-34).The extracellular region of TF contains the FVII/FVIIa binding domains. sTF lacks both the transmembrane and the intracellular domain. The transmembrane domain of TF plays a crucial role in TF-FVIIa anchorage to the cell surface (35-37), in the activation of FX by TF-FVIIa (38) and in the autoactivation of FVII (39). Hence, experiments were performed in the presence and absence of relipidated full-length TF and STF to obtain information on the role of phospholipids and TF in the 
inhibition of FVIIa by TFPI and TFPI constructs. We show that relipidated TFFVIIa is directly inhibited by TFPI $\mathrm{FL}_{\text {with }}$ a $\mathrm{K}_{\mathrm{i}}$ value of $4.6 \mathrm{nM}$ (Table 1). Progress curves of TF-FVIIa inhibition determined at increasing TFPI bend off at low TFPI concentrations $(<2 \mathrm{nM})$. This is indicative of time-dependent inhibition of FVIIa at low TFPI concentrations, which can be either due to a biphasic slow-tight binding mechanism or slow monophasic binding (27). As this bending-off is only observed at TFPI concentrations $<2 \mathrm{nM}$ (Fig. 2A), it is likely that the time dependent inhibition at low TFPI concentrations is due to slow monophasic inhibition $\left(\mathrm{t}^{1} \frac{2}{2} \sim 5\right.$ min at $2 \mathrm{nM}$ TFPI) and not to a slow-tight binding mechanism as observed for FXa inhibition by TFPI $_{\mathrm{FL}}$ or TFPI ${ }_{1-150}(12-15)$. Inhibition of FVIIa by TFPI was much less efficient for $\operatorname{sTF}\left(K_{i}=122 \mathrm{nM}\right)$ and in the absence of tissue factor $\left(\mathrm{K}_{\mathrm{i}}=1118\right.$ $\mathrm{nM})$. These differences can be either attributed to binding of TFPI to phospholipids and/or TF promoting the interaction between TFPI and FVIIa or to effects of TF and/or PL on the conformation of FVIIa, exposing the active site of FVIIa and making it more accessible to inhibition by TFPI $(40,41)$. A possible role of the KD3-C-terminus in the inhibition of relipidated TF-FVIIa was studied using truncated forms of TFPI (TFPI ${ }_{1-150}$ and $\left.\mathrm{KD} 1-\mathrm{KD} 2\right)$. The $\mathrm{KD} 3-\mathrm{C}$ terminus significantly contributed to the inhibition of relipidated TF-FVIIa by TFPI as the $\mathrm{K}_{\mathrm{i}}$ values of $\mathrm{TFPI}_{1-150}\left(\mathrm{~K}_{\mathrm{i}}=44 \mathrm{nM}\right)$ and $\mathrm{KD} 1-\mathrm{KD} 2\left(\mathrm{~K}_{\mathrm{i}}=36 \mathrm{nM}\right)$ were some 7-10-fold higher than the $\mathrm{K}_{\mathrm{i}}$ determined for $\mathrm{TFPI}_{\mathrm{FL}}\left(\mathrm{K}_{\mathrm{i}}=4.6 \mathrm{nM}\right)$. As the C-terminus of TFPI is known to interact with the phospholipids (42), the absence of the KD3-C- 
terminus might affect the interaction of TFPI with TF and/or FVIIa, which are both bound to the phospholipid surface. However, TFPI ${ }_{1-150}$ and KD1-KD2 also had 58-fold higher $\mathrm{K}_{\mathrm{i}}$ values than $\mathrm{TFPI}_{\mathrm{FL}}$ for inhibition of sTF-FVIIa, which indicates that the KD3-C-terminusis also important for direct interaction with and inhibition of sTF-FVIIa, independent of phospholipid. KD2 of TFPI also contributes towards the direct inhibition of FVIIa by $\mathrm{TFPI}_{\mathrm{FL}}$ or $\mathrm{TFPI}_{1-150}$ as removal of KD2 results in TFPI constructs (KD1 or N-KD1) that are very poor inhibitors of relipidated TFFVIIa with $\mathrm{K}_{\mathrm{i}}$ values (380-434 nM) that are more than 10-12-fold higher than the $\mathrm{K}_{\mathrm{i}}$ of TFPI $\mathrm{I}_{1-150}$ and KD1-KD2 (Table 1). In the presence of sTF the $\mathrm{K}_{\mathrm{i}}$ values for the isolated Kunitz domains were some 3-4-fold increased and in the absence of (s)TF inhibition was not detectable. The (s)TF requirement for FVIIa inhibition by isolated Kunitz domains suggests that FVIIa inhibition by isolated Kunitz domains is a specific phenomenon. Surprisingly, FVIIa was inhibited by (N-)KD1 and by $\mathrm{KD} 2$ with similar $\mathrm{K}_{\mathrm{i}}$ values. This shows that the presence of the other Kunitz domains promotes specific inhibition of TF-FVIIa by KD1, a phenomenon that is similar to that observed for FXa inhibition by KD2 $(14,15)$.

Protein $S$ is a vitamin-K-dependent protein with two distinct anticoagulant functions. Protein S acts as a cofactor of APC in FVa and FVIIIa inactivation (43) and enhances FXa inhibition by TFPI (13). The current study shows that protein S also decreases the $\mathrm{K}_{\mathrm{i}}$ value of relipidated TF-FVIIa inhibition by TFPI, which in the presence of protein $\mathrm{S}\left(\mathrm{K}_{\mathrm{i}}=0.7 \mathrm{nM}\right)$ is some 6-7-fold lower than the $\mathrm{K}_{\mathrm{i}}$ observed in the absence of protein $\mathrm{S}\left(\mathrm{K}_{\mathrm{i}}=4.6 \mathrm{nM}\right)$. Protein $\mathrm{S}$ did not act as a 
cofactor of TFPI in FVIIa inhibition in the presence of anti-protein S antibodies, which shows that the protein $\mathrm{S}$ effect is specific and not due to contaminations in the protein preparations. Protein S did not stimulate relipidated TF-FVIIa inhibition by truncated forms of TFPI (TFPI $1_{1-150}$ and KD1-KD2) and also had no effect on the inhibition of sTF-FVIIa by TFPI $\mathrm{FL}_{\mathrm{FL}}$. This indicates that both the KD3-C-terminus and phospholipids are required for protein S cofactor activity in FVIIa inhibition by TFPI.

Similar observations were made for the cofactor activity of protein $\mathrm{S}$ in FXa inhibition by TFPI, which is also only observed with $\mathrm{TFPI}_{\mathrm{FL}}$ in the presence of phospholipids and not with truncated forms of TFPI or in the absence of phospholipids (44). The KD3-C-terminus requirement for the expression of protein $\mathrm{S}$ cofactor activity is supported by the observations of Ndonwi et al. and Ahnstrom et al. $(16,29)$, who showed that the KD3 domain is essential for protein S binding to TFPI and for the cofactor activity of protein $\mathrm{S}$ in FXa inhibition by TFPI. The possible physiological importance of the TFPI cofactor activity of protein $\mathrm{S}$ is discussed below.

It has been reported that efficient inhibition of TF-FVIIa requires the presence of FXa, which promotes binding of TFPI to TF-FVIIa, and the fast formation of a tight quaternary TF-FVIIa-TFPI-FXa complex in which both FXa and FVIIa are inhibited. We performed experiments in the presence of FXa to further investigate the mechanism of quaternary complex formation. In the presence of $\mathrm{FXa}, \mathrm{TFPI}_{\mathrm{FL}}$ 
rapidly formed a tight 1:1 stoichiometric quaternary complex with TF and FVIIa with a $\mathrm{K}_{\mathrm{i}}$ value $<0.15 \mathrm{nM}$ (Fig. 6). FXa was also able to forma quaternary complex with TF-FVIIa and TFPI ${ }_{1-150}$ and KD1-KD2, but not with KD1 or KD2, which indicates that the presence of both the KD1 and KD2 domains is essential for quaternary complex formation, but that theKD3-C-terminus is not an absolute requirement. Quaternary complex formation appeared to be also strictly dependent on the presence of phospholipids and on the presence of a Gla-domain in FXa because FXa did not stimulate the inhibition of sTF-FVIIa by TFPI and GDFXa had no effect on relipidated TF-FVIIa inhibition by TFPI. Together these data indicate that actually a pentenary (quintenary) TF-FVIIa-TFPI-FXa-PL complex rather than a quaternary complex is the basis of physiological TF-FVIIa inhibition by TFPI.

The formation of the quaternary TF-FVIIa-TFPI-FXa complex is fast and efficient. We were not able to follow the quaternary complex formation in time and also did not succeed in measuring the $\mathrm{K}_{\mathrm{i}}$ or $\mathrm{K}_{\mathrm{d}}$ of the quaternary complex because at FXa concentrations in the range of the FVIIa concentration a tight stoichiometric complex was formed. This suggests that in the presence of FXa, inhibition of TFFVIIa by TFPI is so efficient that it may not require protein S. Indeed Ndonwi and Broze reported that in a model system containing purified proteins, protein $\mathrm{S}$ does not enhance TFPI inhibition of TF-FVIIa but promotes FXa inhibition by TFPI (45). Experiments in more complex reaction systems (e.g. plasma) are required to appreciate the role of TFPI as an anticoagulant protein in down-regulating 
thrombin formation and to quantify the contribution of TF-FVIIa and FXa inhibition by TFPI and the effects of protein S. One may question whether direct inhibition of TF-FVIIa by TFPI in the presence of phospholipids and protein $\mathrm{S}\left(\mathrm{K}_{\mathrm{i}}\right.$ $\sim 0.7 \mathrm{nM}$ ) is physiologically important (plasma full-length TFPI concentration $0.25 \mathrm{nM}$ ). However, the local TFPI concentration at the site of thrombus formation may be substantially higher than $0.25 \mathrm{nM}$ (e.g. through the release of TFPI from platelets at the growing thrombus). Under such conditions, local high concentrations of TFPI can directly inhibit TF-FVIIa, thereby contributing to the down-regulation of thrombin formation. An important role for TFPI released from platelets in regulating thrombus formation is indicated by a study of Maroney et al. (46), who demonstrated that in hemophilic mice with $\mathrm{TFPI}^{-1}$ hematopoietic cells blood loss on tail transection was significantly decreased.

In addition, it should also be emphasized that in a normal population the plasma TFPI concentration shows a large variation and individuals may have TFPI levels that are two to three times higher than the population average $(0.25 \mathrm{nM})$. Levels of TFPI also considerably increase during heparin treatment (47) and are significantly elevated in pathological conditions such as cancer or coronary heart disease (48). In these situations direct inhibition of TF-FVIIa by TFPI may contribute to the inhibition of coagulation. 


\section{Addendum}

S. Peraramelli designed and performed the experiments, analyzed the data and wrote the manuscript; S. Thomassen and A. Heinzmann assisted in performing the experiments; J. Rosing supervised the project, designed the experiments, analyzed data and revised the manuscript; T. Hackeng supervised the project and revised the manuscript; R. Hartmann provided TFPI constructs and revised the manuscript ; M. Dockal provided TFPI constructs, and contributed to data analysis and revising the manuscript ; F. Scheiflinger critically revised the manuscript.

\section{Disclosure of Conflict of Interests}

JR receives research support from, and acts as consultant for, Baxter Innovations GmbH. MD, RH and FS are full-time employees of Baxter Innovations GmbH. None of the other authors declares any conflict of interest. JR receives research support from, and acts as consultant of Baxter Innovations GmbH. None of the other authors declares any conflict of interest. 


\section{References}

1. Wilcox JN, Smith KM, Schwartz SM, et al. Localization of tissue factor in the normal vessel wall and in the atherosclerotic plaque. Proc Natl Acad Sci U S A 1989;86(8):2839-43.

2. Morrissey JH, Macik BG, Neuenschwander PF, et al. Quantitation of activated factor VII levels in plasma using a tissue factor mutant selectively deficient in promoting factor VII activation. Blood 1993;81(3):734-44.

3. Nemerson Y. The reaction between bovine brain tissue factor and factors VII and X. Biochemistry 1966;5(2):601-8.

4. Osterud B, Rapaport SI. Activation of factor IX by the reaction product of tissue factor and factor VII: additional pathway for initiating blood coagulation. Proc Natl Acad Sci U S A 1977;74(12):5260-4.

5. Bom VJ, Bertina RM. The contributions of $\mathrm{Ca} 2+$, phospholipids and tissue-factor apoprotein to the activation of human blood-coagulation factor $\mathrm{X}$ by activated factor VII. Biochem J 1990;265(2):327-36.

6. Salemink I, Franssen J, Willems GM, et al. Inhibition of tissue factorfactor VIIa-catalyzed factor $\mathrm{X}$ activation by factor Xa-tissue factor pathway inhibitor. A rotating disc study on the effect of phospholipid membrane composition. J Biol Chem 1999;274(40):28225-32. 
7. Sanders NL, Bajaj SP, Zivelin A, et al. Inhibition of tissue factor/factor VIIa activity in plasma requires factor $\mathrm{X}$ and an additional plasma component. Blood 1985;66(1):204-12.

8. Wun TC, Kretzmer KK, Girard TJ, et al. Cloning and characterization of a cDNA coding for the lipoprotein-associated coagulation inhibitor shows that it consists of three tandem Kunitz-type inhibitory domains. J Biol Chem 1988;263(13):6001-4.

9. Girard TJ, Warren LA, Novotny WF, et al. Functional significance of the Kunitz-type inhibitory domains of lipoprotein-associated coagulation inhibitor. Nature 1989;338(6215):518-20.

10. Chan JC. Gene targeting in hemostasis. tissue factor pathway inhibitor. Front Biosci 2001;6:D216-21.

11. Broze GJ, Jr., Girard TJ, Novotny WF. Regulation of coagulation by a multivalent Kunitz-type inhibitor. Biochemistry 1990;29(33):7539-46.

12. Huang ZF, Wun TC, Broze GJ, Jr. Kinetics of factor Xa inhibition by tissue factor pathway inhibitor. J Biol Chem 1993;268(36):26950-5.

13. Hackeng TM, Sere KM, Tans G, et al. Protein S stimulates inhibition of the tissue factor pathway by tissue factor pathway inhibitor. Proc Natl Acad Sci U S A 2006;103(9):3106-11.

14. Higuchi DA, Wun TC, Likert KM, et al. The effect of leukocyte elastase on tissue factor pathway inhibitor. Blood 1992;79(7):1712-9. 
15. Peraramelli S, Suylen DP, Rosing J, et al. The Kunitz 1 and Kunitz 3 domains of tissue factor pathway inhibitor are required for efficient inhibition of factor Xa. Thromb Haemost 2012;108(2).

16. Ndonwi M, Tuley EA, Broze GJ, Jr. The Kunitz-3 domain of TFPI-alpha is required for protein S-dependent enhancement of factor Xa inhibition. Blood 2010;116(8):1344-51.

17. Broze GJ, Jr., Warren LA, Novotny WF, et al. The lipoprotein-associated coagulation inhibitor that inhibits the factor VII-tissue factor complex also inhibits factor Xa: insight into its possible mechanism of action. Blood 1988;71(2):335-43.

18. Warn-Cramer BJ, Rao LV, Maki SL, et al. Modifications of extrinsic pathway inhibitor (EPI) and factor Xa that affect their ability to interact and to inhibit factor VIIa/tissue factor: evidence for a two-step model of inhibition. Thromb Haemost 1988;60(3):453-6.

19. Pedersen AH, Nordfang O, Norris F, et al. Recombinant human extrinsic pathway inhibitor. Production, isolation, and characterization of its inhibitory activity on tissue factor-initiated coagulation reactions. J Biol Chem 1990;265(28):16786-93.

20. Hamik A, Setiadi H, Bu G, et al. Down-regulation of monocyte tissue factor mediated by tissue factor pathway inhibitor and the low density lipoprotein receptor-related protein. J Biol Chem 1999;274(8):4962-9. 
21. Diaz-Collier JA, Palmier MO, Kretzmer KK, et al. Refold and characterization of recombinant tissue factor pathway inhibitor expressed in Escherichia coli. Thromb Haemost 1994;71(3):339-46.

22. Esnouf MP, Lloyd PH, Jesty J. A method for the simultaneous isolation of factor X and prothrombin from bovine plasma. Biochem J 1973;131(4):781-9.

23. Girard TJ, Broze GJ, Jr. Tissue factor pathway inhibitor. Methods Enzymol 1993;222:195-209.

24. Verma AK, Brighton TA. The direct factor Xa inhibitor rivaroxaban. Med J Aust 2009;190(7):379-83.

25. Samama MM. The mechanism of action of rivaroxaban--an oral, direct Factor Xa inhibitor--compared with other anticoagulants. Thromb Res 2011;127(6):497-504.

26. Lazareno S, Birdsall NJ. Estimation of competitive antagonist affinity from functional inhibition curves using the Gaddum, Schild and Cheng-Prusoff equations. British journal of pharmacology 1993;109(4):1110-9.

27. Morrison JF, Walsh CT. The behavior and significance of slow-binding enzyme inhibitors. Advances in enzymology and related areas of molecular biology 1988;61:201-301.

28. Mackman N. Alternatively spliced tissue factor - one cut too many? Thromb Haemost 2007;97(1):5-8. 
29. Ahnstrom J, Andersson HM, Hockey V, et al. Identification of functionally important residues in TFPI Kunitz domain 3 required for the enhancement of its activity by protein S. Blood 2012;120(25):5059-62.

30. Piro O, Broze GJ, Jr. Role for the Kunitz-3 domain of tissue factor pathway inhibitor-alpha in cell surface binding. Circulation 2004;110(23):3567-72.

31. Wesselschmidt R, Likert K, Girard T, et al. Tissue factor pathway inhibitor: the carboxy-terminus is required for optimal inhibition of factor Xa. Blood 1992;79(8):2004-10.

32. Petersen LC, Valentin S, Hedner U. Regulation of the extrinsic pathway system in health and disease: the role of factor VIIa and tissue factor pathway inhibitor. Thromb Res 1995;79(1):1-47.

33. Chu AJ. Tissue factor mediates inflammation. Arch Biochem Biophys 2005;440(2):123-32.

34. Nemerson Y. Tissue factor and hemostasis. Blood 1988;71(1):1-8.

35. Ruf W, Rehemtulla A, Morrissey JH, et al. Phospholipid-independent and dependent interactions required for tissue factor receptor and cofactor function. $\mathrm{J}$ Biol Chem 1991;266(24):16256.

36. Neuenschwander PF, Morrissey JH. Deletion of the membrane anchoring region of tissue factor abolishes autoactivation of factor VII but not cofactor function. Analysis of a mutant with a selective deficiency in activity. J Biol Chem 1992;267(20):14477-82. 
37. Paborsky LR, Caras IW, Fisher KL, et al. Lipid association, but not the transmembrane domain, is required for tissue factor activity. Substitution of the transmembrane domain with a phosphatidylinositol anchor. J Biol Chem 1991;266(32):21911-6.

38. Waxman E, Ross JB, Laue TM, et al. Tissue factor and its extracellular soluble domain: the relationship between intermolecular association with factor VIIa and enzymatic activity of the complex. Biochemistry 1992;31(16):3998-4003.

39. Fiore MM, Neuenschwander PF, Morrissey JH. The biochemical basis for the apparent defect of soluble mutant tissue factor in enhancing the proteolytic activities of factor VIIa. J Biol Chem 1994;269(1):143-9.

40. Lawson JH, Butenas S, Ribarik N, et al. Complex-dependent inhibition of factor VIIa by antithrombin III and heparin. J Biol Chem 1993;268(2):767-70.

41. Rand $\mathrm{KD}$, Jorgensen $\mathrm{TJ}$, Olsen $\mathrm{OH}$, et al. Allosteric activation of coagulation factor VIIa visualized by hydrogen exchange. J Biol Chem 2006;281(32):23018-24.

42. Valentin S, Schousboe I. Factor Xa enhances the binding of tissue factor pathway inhibitor to acidic phospholipids. Thromb Haemost 1996;75(5):796-800.

43. Dahlback B. Protein S and C4b-binding protein: components involved in the regulation of the protein $\mathrm{C}$ anticoagulant system. Thromb Haemost 1991;66(1):49-61 . 


\section{Chapter 4}

44. van Wijnen M, Stam JG, van't Veer C, et al. The interaction of protein S with the phospholipid surface is essential for the activated protein C-independent activity of protein S. Thromb Haemost 1996;76(3):397-403.

45. Ndonwi M, Broze G, Jr. Protein $\mathrm{S}$ enhances the tissue factor pathway inhibitor inhibition of factor Xa but not its inhibition of factor VIIa-tissue factor. J Thromb Haemost 2008;6(6):1044-6.

46. Maroney SA, Cooley BC, Ferrel JP, et al. Absence of hematopoietic tissue factor pathway inhibitor mitigates bleeding in mice with hemophilia. Proc Natl Acad Sci U S A 2012;109(10):3927-31.

47. Sandset PM, Abildgaard U, Larsen ML. Heparin induces release of extrinsic coagulation pathway inhibitor (EPI). Thromb Res 1988;50(6):803-13.

48. Lindahl AK, Sandset PM, Abildgaard U. The present status of tissue factor pathway inhibitor. Blood Coagul Fibrinolysis 1992;3(4):439-49. 


\section{Chapter 5}

\section{Inhibition of TF:FVIIa-catalysed FIX}

and FX activation by TFPI and TFPI constructs

Peraramelli S, Thomassen S, Heinzmann A, Rosing J, Hackeng TM, Hartmann R, Scheiflinger F, Dockal M

Journal of Thrombosis and Haemostasis 2014; 11: 704-714 
Chapter 5 


\section{Abstract}

Background: TFPI is a Kunitz-type protease inhibitor, which down-regulates the extrinsic coagulation pathway by inhibiting FXa and FVIIa. All three Kunitz domains (KD1, KD2 and KD3) and protein S are required for optimal inhibition of FXa and FVIIa. There is limited information on Kunitz domain requirements of the inhibition of TF:FVIIa-catalysed FIX and FX activation by TFPI.

Aim: To investigate the role of the Kunitz domains of TFPI and protein $S$ in the inhibition of FX and FIX activation

Methods: Inhibition of TF:FVIIa-catalysed FX and FIX activation by full-length TFPI (TFPI $\mathrm{FL}_{\mathrm{L}}$ ) and TFPI constructs was quantified from progress curves of FXa and FIXa generation measured with chromogenic substrates.

Results and Conclusions: TFPI $\mathrm{FL}_{\mathrm{F}}$ inhibited TF:FVIIa-catalysed FIX activation with a $\mathrm{K}_{\mathrm{i}}$ of $16.7 \mathrm{nM}$. Protein $\mathrm{S}$ reduced the $\mathrm{K}_{\mathrm{i}}$ to $1.0 \mathrm{nM}$. TFPI ${ }_{1-150}$ and KD1-KD2 had 10-fold higher $\mathrm{K}_{\mathrm{i}}$ values and were not stimulated by protein S. Single Kunitz domains were poor inhibitors of TF:FVIIa-catalysed FIX activation $\left(\mathrm{K}_{\mathrm{i}}>800 \mathrm{nM}\right)$. FX activation was measured at limiting FVIIa and excess TF or vice versa. At both conditions, $\mathrm{TFPI}_{\mathrm{FL}}, \mathrm{TFPI}_{1-150}$ and $\mathrm{KD} 1-\mathrm{KD} 2$ showed similar inhibition of FX activation. However, at low phospholipid concentrations, $\mathrm{TFPI}_{\mathrm{FL}}$ was $\sim 15$-fold more active than $\mathrm{TFPI}_{1-150}$ or KD1-KD2. Apparently, excess phospholipids act as

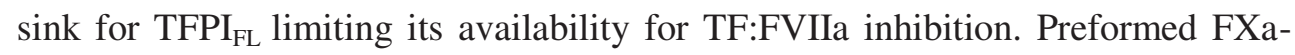
TFPI $_{\mathrm{FL} / 1-150}$ complexes rapidly and stoichiometrically inhibited FIX and FX 


\section{Chapter 5}

activation by TF:FVIIa indicating that binary TFPI-FXa complex formation is the limiting step in TF:FVIIa inhibition. Protein $\mathrm{S}$ also enhanced inhibition of TF:FVIIa-catalysed FX activation by TFPI. 


\section{Introduction}

Tissue injury exposes tissue factor (TF), an integral membrane protein, which readily forms a complex with circulating factor VIIa (FVIIa). The TF:FVIIa complex subsequently activates the zymogens factor FIX and FX to their active forms FIXa and FXa $(1,2)$.

TFPI, a Kunitz-type protease inhibitor, is the major physiological inhibitor of TF:FVIIa. Alternative splicing of TFPI mRNA results in two isoforms, TFPI $\alpha$ and TFPI $\beta$ (3-6). TFPI $\alpha$ that is present in plasma, platelets and endothelial cells consists of a negatively charged $\mathrm{N}$-terminus, followed by 3 Kunitz domains (KD1, $\mathrm{KD} 2$ and KD3) and a positively charged C-terminus (3). KD1 binds and inhibits FVIIa, KD2 binds and inhibits FXa $(7,8), \mathrm{KD} 3$ is required for stimulation of the anticoagulant activity of TFPI by protein S (9) and the C-terminus promotes binding of TFPI to negatively charged surfaces (10). TFPI $\beta$ lacks KD3 and has a different C-terminus to which a GPI anchor is attached which covalently associates TFPI $\beta$ to the endothelium (7).

The current manuscript focuses on TFPI $\alpha$ (from hereon called TFPI) and its kinetics of inhibition of FIX and FX activation. TFPI regulates TF:FVIIa-catalysed FX activation by directly inhibiting FXa $(7,11)$ and by inhibiting TF:FVIIa via either a FXa-dependent mechanism which involves the formation of a tight quaternary TF:FVIIa-FXa-TFPI complex $(7,8,12)$ or a FXa-independent mechanism which requires high TFPI concentrations (13-15). Protein S acts as 
cofactor of TFPI, which enhances direct inhibition of both FXa (16-18) and TF:FVIIa (13) by TFPI.

Detailed kinetic studies indicated that TFPI constructs containing multiple TFPI domains are much better inhibitors of FVIIa and FXa than the isolated KD1 and KD2 domains $(10,15,18-22)$ which shows that all Kunitz domains and the basic carboxy terminal domain are required for efficient inhibition of FVIIa by KD1 and FXa by KD2.

In addition to full-length TFPI (TFPI $\mathrm{FL}_{\mathrm{F}}$ ), plasma contains several truncated forms of TFPI (without KD3 and/or C-terminus) the major part of which is bound to lipoproteins $(23,24)$ and which express considerably less anticoagulant activity in clotting assays than full-length TFPI (25-27). Although the inhibition of TF:FVIIacatalysed FX activation has been investigated in a variety of assay systems (28-33) not much is known about the role of the C-terminus, $\mathrm{N}$-terminus and the different Kunitz domains of TFPI and protein S in the inhibition of TF:FVIIa-catalysed FIX and FX activation. Particularly, limited information is available on the inhibition of TF:FVIIa-catalysed FIX activation by TFPI.

In the present study we investigated the role of different Kunitz domains of TFPI, and protein S, in the inhibition of TF:FVIIa-catalysed FIX and FX activation. The current experiments, which were performed in a model system containing purified proteins, provide new information on the down-regulation of extrinsic and intrinsic FX activation by TFPI. 


\section{Materials and Methods}

\section{Materials}

Spectrozyme FIXa (D-leucyl-phenylglycyl-arginine-para-nitroanilide diacetate) and $\quad$ CS-11(65) (N- $\alpha$-Benzyloxycarbonyl-D-arginyl-glycyl-L-arginine-pnitroaniline-dihydrochloride) were purchased from American Diagnostica (Stamford, CT) and Hyphen BioMed (Mason, OH), respectively. 1,2-Dioleoyl-snglycero-3-phosphocholine (DOPC), 1,2-dioleoyl-sn-glycero-3-phosphoserine (DOPS), and 1,2-dioleoyl-sn-glycero-3-phosphoethanolamine (DOPE) were obtained from Avanti Polar Lipids (Delfzijl, The Netherlands). Phospholipid vesicles (20\% DOPS/20\% DOPE/60\% DOPC) were prepared as described (34). Rivaroxaban was purchased from Bayer Health Care (Leverkusen, Germany).

\section{Proteins}

Recombinant TFPI ${ }_{\mathrm{FL}}$ produced in a bacterial expression system (Escherichia coli), was kindly provided by $\mathrm{T}$. Lindhout (Cardiovascular Research Institute Maastricht). TFPI ${ }_{1-150}, \mathrm{KD} 1-\mathrm{KD} 2, \mathrm{KD} 1$ and $\mathrm{KD} 2$ were purified from a bacterial expression system as described (15). TFPI $\mathrm{FL}_{\mathrm{FL}}, \mathrm{TFPI}_{1-150}$ and $\mathrm{KD} 1-\mathrm{KD} 2$ concentrations were determined by titrating with bovine FXa $(15,35)$.

TF (Innovin) was purchased from Siemens Healthcare (Marburg, Germany). One vial of TF was dissolved in $2.5 \mathrm{~mL} \mathrm{H} \mathrm{H}_{2} \mathrm{O}$ and dialysed against $25 \mathrm{mM}$ Hepes (nH 7.5) $175 \mathrm{mM} \mathrm{NaCl}$. TF concentrations were determined with the Imuhind 
Tissue Factor ELISA Kit $\mathrm{Nr}$ 845. Phosphate analysis (36) and thin layer chromatography (37) showed that a typical dialysed TF preparation $(\sim 20 \mathrm{nM})$ contained $100 \mu \mathrm{M}$ phospholipid composed of $29 \%$ phosphatidylserine and $71 \%$ phosphatidylcholine. FVIIa was purchased from Novo Nordisk (Bagsvaerd, Denmark). Human FXa and sheep polyclonal anti-protein S antibodies were from Enzyme Research Laboratories (South Bend, IN, USA). FX was purchased from Innovative Research (Novi, MI, USA). FIX, FIXa and protein S were from Haematologic Technologies (Vermont, USA).

\section{Effect of TFPI $\mathrm{FL}_{\mathrm{FL}}$ or TFPI constructs on TF:FVIIa-catalysed FIX} activation

FVIIa, TF, Spectrozyme FIXa, rivaroxaban and different amounts of $\mathrm{TFPI}_{\mathrm{FL}}$, or TFPI constructs were preincubated in the absence or presence of protein $\mathrm{S}$ or phospholipid vesicles for 7 minutes at $37{ }^{\circ} \mathrm{C}$ in $\mathrm{HNBSA}$ containing $3 \mathrm{mM} \mathrm{CaCl}_{2}$. Subsequently, 200 nM FIX was added and FIX activation, which is a measure for non-inhibited FVIIa, was followed at $405 \mathrm{~nm}$ in an Ultra Microplate Reader (BioTek, Burlington, VT, USA) for 45 minutes. Concentrations of reactants are indicated in the figure legends. In some experiments TFPI/TFPI constructs were replaced by preformed FXa-TFPI complexes that were obtained by incubating 2 $\mathrm{nM} F X a$ and $2 \mathrm{nM} \mathrm{TFPI}_{\mathrm{FL}}$ or $2 \mathrm{nM} \mathrm{TFPI}_{1-150}$ during 60 minutes at room 
temperature which allowed the formation of a tight 1:1 stoichiometric FXa-TFPI or FXa-TFPI ${ }_{1-150}$ complex.

Effect of TFPI ${ }_{\mathrm{FL}}$ or TFPI constructs on TF:FVIIa-catalysed FX activation

FVIIa, TF,CS-11(65) and TFPI, TFPI constructs or preformed FXa-TFPI or FXaTFPI $_{1-150}$ complex (see above) were incubated with or without extra phospholipids for 7 minutes at $37{ }^{\circ} \mathrm{C}$ in $\mathrm{HNBSA}$ containing $3 \mathrm{mM} \mathrm{CaCl}_{2}$. Subsequently, $\mathrm{FX}$ or FX plus protein $\mathrm{S}$ was added and the rate of FX activation was followed at $405 \mathrm{~nm}$ in an Ultra Microplate Reader for 45 minutes. Absorbance changes were corrected for chromogenic substrate consumption (38). The first derivative of corrected data gives FXa generated in time. The second derivative taken at a fixed time point (usually between 2-4 minutes) is measure a for the amount of FVIIa inhibited.

Calculation of $\mathrm{IC}_{50} / \mathrm{K}_{\mathrm{i}}$ values for inhibition of FIX or $\mathrm{FX}$ activation by TFPI and TFPI constructs

From the rates of FX or FIX activation the percentage inhibition of FVIIa by TFPI or TFPI constructs was calculated. The percentage FVIIa inhibition was plotted as function of the TFPI (construct) concentration [TFPI] and fitted to the Langmuir binding isotherm: 
$\mathrm{I}=\mathrm{I}_{\max } \cdot[\mathrm{TFPI}] /\left(\mathrm{IC}_{50}+[\mathrm{TFPI}]\right)$

Where, $\mathrm{I}$ is the $\%$ of inhibition of FVIIa, $\mathrm{I}_{\max }$ is the maximal inhibition (\%) of FVIIa and $\mathrm{IC}_{50}$ is the concentration of TFPI or TFPI constructs at which $50 \%$ of the maximal inhibition of FVIIa is observed. The presence of FIX may affect the $\mathrm{IC}_{50}$ of TFPI inhibition through competition with TFPI for the active site of FVIIa. However, TFPI titrations performed at 50, 100 and 200 nM FIX yielded, similar $\mathrm{IC}_{50}$ values (data not shown). This demonstrates that FIX did not affect the $\mathrm{IC}_{50}$ values and that the $\mathrm{IC}_{50}$ of TFPI for the inhibition of FIX activation is equal to. $\mathrm{K}_{\mathrm{i}}$. For inhibition of TF:FVIIa-catalysed FX activation $\mathrm{IC}_{50}$ values were not taken to be equal to the $\mathrm{K}_{\mathrm{i}}$ because the efficacy by which TFPI inhibits FX activation may depend on the FX concentration. Since the FX concentration in our FX activation experiments $(100 \mathrm{nM})$ was close to the plasma concentration, the $\mathrm{IC}_{50}$ values for TFPI likely reflect its physiological efficacy.

Results

Methodology to measure inhibition of TF:FVIIa-catalysed FIX and FX activation by TFPI and TFPI constructs

Since the local concentrations of TF and FVIIa on the vessel wall and in blood may largely vary, FIX and FX activation experiments were performed at limiting 
FVIIa and excess TF or vice versa both at high and low phospholipid concentrations.

To study the effect of TFPI $\mathrm{FL}_{\text {L }}$ and TFPI constructs on TF:FVIIa-catalysed FIX activation, FIXa generation was followed with the chromogenic substrate Spectrozyme FIXa. Progress curves of Spectrozyme FIXa conversion in the absence and presence of TFPI (constructs) were parabolas (Fig. 1A), which after taking the first derivative yielded straight lines (Fig. 1B) from which the rates of FIX activation and the percentages of inhibition by TFPI can be calculated. Plots of inhibition of FIX activation (\%) as function of the TFPI (constructs) concentration were fitted to a hyperbola and yielded $\mathrm{K}_{\mathrm{i}}$ values for TFPI (construct). Similarly, FX activation by TF:FVIIa was followed with the FXaspecific chromogenic substrate CS-11(65) (Fig. 1C). The first derivative of the data yielded FXa generated in time (Fig. 1D). In contrast to FIXa generation in the presence of TFPI, which was linear in time (Fig. 1B), FXa generation was gradually inhibited as the result of slow quaternary (TF:FVIIa-TFPI-FXa) complex formation.

At low TFPI concentrations inhibition was incomplete, at intermediate TFPI concentrations FX activation came to a complete stop after 8-10 min and at high TFPI concentrations there was even a loss of FXa activity at later time points due to slow inhibition of FXa by TFPI. 

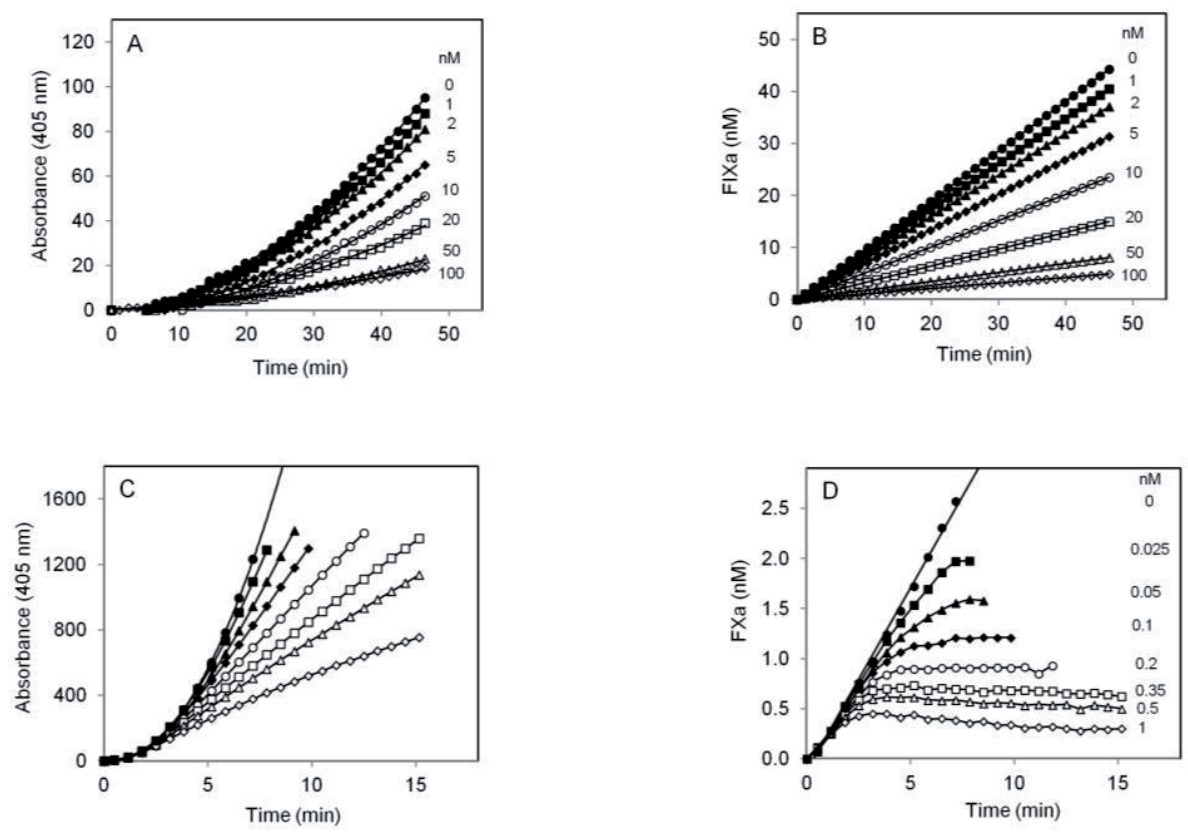

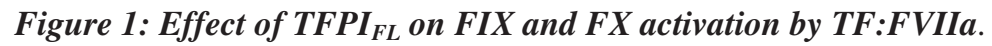

FIX activation: (A) Progress curves of conversion of $500 \mu \mathrm{M}$ Spectrozyme FIXa by FIXa generated during the activation of 200 nM FIX by 5 nM TF (25 $\mu$ M phospholipid) and 50 pM FVIIa in the presence of $0 n M(\bullet), 1 n M(\bullet), 2 n M(\mathbf{\Delta}), 5 n M(\bullet), 10 n M(0), 20 n M$ (口), $50 \mathrm{nM}(\Delta)$ and $100 \mathrm{nM}(\diamond) T F P I_{F L}$. Solid lines represent least square fits to a parabola. (B) First derivative of the progress curves presented in Fig. 1A. Solid lines represent least square fits to a straight line.

FX activation: (C) Progress curves of $200 \mu M$ CS-11(65) substrate conversion by FXa generated during the activation of 100 nM FX by 5 nM TF (25 $\mu$ M phospholipid) and 1 pM FVIIa in the presence of $0 n M(\bullet), 0.025 n M(\bullet), 0.05 n M(\mathbf{\Delta}), 0.1 n M(\diamond), 0.2 n M(0)$, $0.35 n M(\square), 0.5 n M(\Delta)$ and $1 \mathrm{nM}(\diamond) T F P I_{F L}$. The solid line for $0 \mathrm{nM}$ TFPI represents $a$ least square fit to a parabola. Solid lines for all other TFPI concentrations were obtained by joining the data points. (D) First derivative of the progress curves presented in Fig. 1C plotted as function of time. Solid line for 0 nM TFPI represents a least square fit to a parabola. Solid lines for all other TFPI concentrations were obtained by joining the data points. 
Table 1. $\mathrm{K}_{\mathrm{i}}$ values of TFPI (constructs) in FIX activation by TF:FVIIa.

\begin{tabular}{|c|c|c|c|c|c|}
\hline & \multicolumn{2}{|c|}{$\begin{array}{c}\mathrm{K}_{\mathrm{i}} \pm \mathrm{SEM}(\mathrm{nM}) \\
5 \mathrm{nM} \text { TF, } 50 \mathrm{pM} \text { FVIIa } \\
25 \mu \mathrm{M} \text { PL }\end{array}$} & \multicolumn{2}{|c|}{$\begin{array}{c}\mathrm{K}_{\mathrm{i}} \pm \mathrm{SEM}(\mathrm{nM}) \\
0.1 \mathrm{nM} \mathrm{TF}, 2 \mathrm{nM} \\
\text { FVIIa } \\
25 \mu \mathrm{M} \text { PL }\end{array}$} & $\begin{array}{l}\mathrm{K}_{\mathrm{i}} \pm \mathrm{SEM} \\
(\mathrm{nM}) \\
0.1 \mathrm{nM} \mathrm{TF}, 2 \\
\text { nM FVIIa } \\
0.5 \mu \mathrm{M} \text { PL }\end{array}$ \\
\hline & $\begin{array}{c}\text { no protein } \\
\mathrm{S}\end{array}$ & + protein $S$ & $\begin{array}{c}\text { no protein } \\
\mathrm{S}\end{array}$ & $\begin{array}{c}+ \text { protein } \\
\mathrm{S}\end{array}$ & no protein $S$ \\
\hline $\mathrm{TFPI}_{\mathrm{FL}}$ & $16.7 \pm 4.2$ & $1.0 \pm 0.1$ & $16.9 \pm 3.9$ & $1.8 \pm 0.2$ & $1.0 \pm 0.1$ \\
\hline $\mathrm{TFPI}_{1-150}$ & $54.0 \pm 4.4$ & $62.2 \pm 8.0$ & $96.5 \pm 12.8$ & - & $38.6 \pm 12.4$ \\
\hline KD1 & $1400 \pm 400$ & - & - & - & - \\
\hline KD2 & $850 \pm 50$ & - & - & - & - \\
\hline
\end{tabular}

$K_{i}$ values were obtained from the data presented in Fig. 2-4. SEM were obtained from least-squares fits of the data to a hyperbola using GraphPad Prism 6.

FIX activation by TF:FVIIa in presence of $\mathrm{TFPI}_{\mathrm{FL}}$ and TFPI

\section{constructs}

In the experiments in which the effect of TFPI on FIX activation was studied, TF:FVIIa was preincubated with TFPI prior to the addition of FIX, resulting in monophasic inhibition ofFIX activation. Monophasic inhibition under these conditions was confirmed by adding TFPI and FIX to TF:FVIIa in the presence of chromogenic substrate, without preincubation, resulting in identical monophasic inhibition patterns (data not shown). Plots of rates of FIX activation as function of TFPI $_{\mathrm{FL}}$ or TFPI construct concentration were derived from progress curves of 
Spectrozyme FIXa conversion (cf. Fig. 1AB) and were fitted to a hyperbola which yielded the $\mathrm{K}_{\mathrm{i}}$ for inhibition of TF:FVIIa-catalysed FIX activation by TFPI $\mathrm{FL}_{\mathrm{FL}}$ or TFPI constructs (Fig. 2, Table 1). At limiting FVIIa (50 pM) and high TF (5 nM), TFPI $_{F L}$ inhibited FIX activation by TF:FVIIa with a $\mathrm{K}_{\mathrm{i}}$ value of $16.7 \mathrm{nM}$. TFPI $\mathrm{I}_{1-150}$ which lacks the Kunitz-3 (KD3) and C-terminus showed a higher $\mathrm{K}_{\mathrm{i}}$ value (54 $n M)$. Single Kunitz domains were very poor inhibitors of TF:FVIIa with $K_{i}$ values $1400 \mathrm{nM}$ and $850 \mathrm{nM}$ for KD1 and KD2, respectively. The different Ki values for $\mathrm{TFPI}_{\mathrm{FL}}$ and TFPI constructs show that all Kunitz domains of TFPI are required for efficient inhibition of TF:FVIIa-catalysed FIX activation by TFPI.

Similar $\mathrm{K}_{\mathrm{i}}$ values for TFPI and $\mathrm{TFPI}_{1-150}$ were obtained for FIX activation determined at limiting TF and excess FVIIa plus $25 \mu \mathrm{M}$ phospholipid vesicles (Table 1). However, when the amount of phospholipid in the reaction mixtures was decreased by lowering the TF concentration (data not shown) or by omitting added phospholipids at low TF and excess FVIIa, the $\mathrm{K}_{\mathrm{i}}$ for TFPI decreased from 16.9 $\mathrm{nM}$ to $1 \mathrm{nM}$ while phospholipids had much less effect on the $\mathrm{K}_{\mathrm{i}}$ for $\mathrm{TFPI}_{1-150}$ (Table 1). 

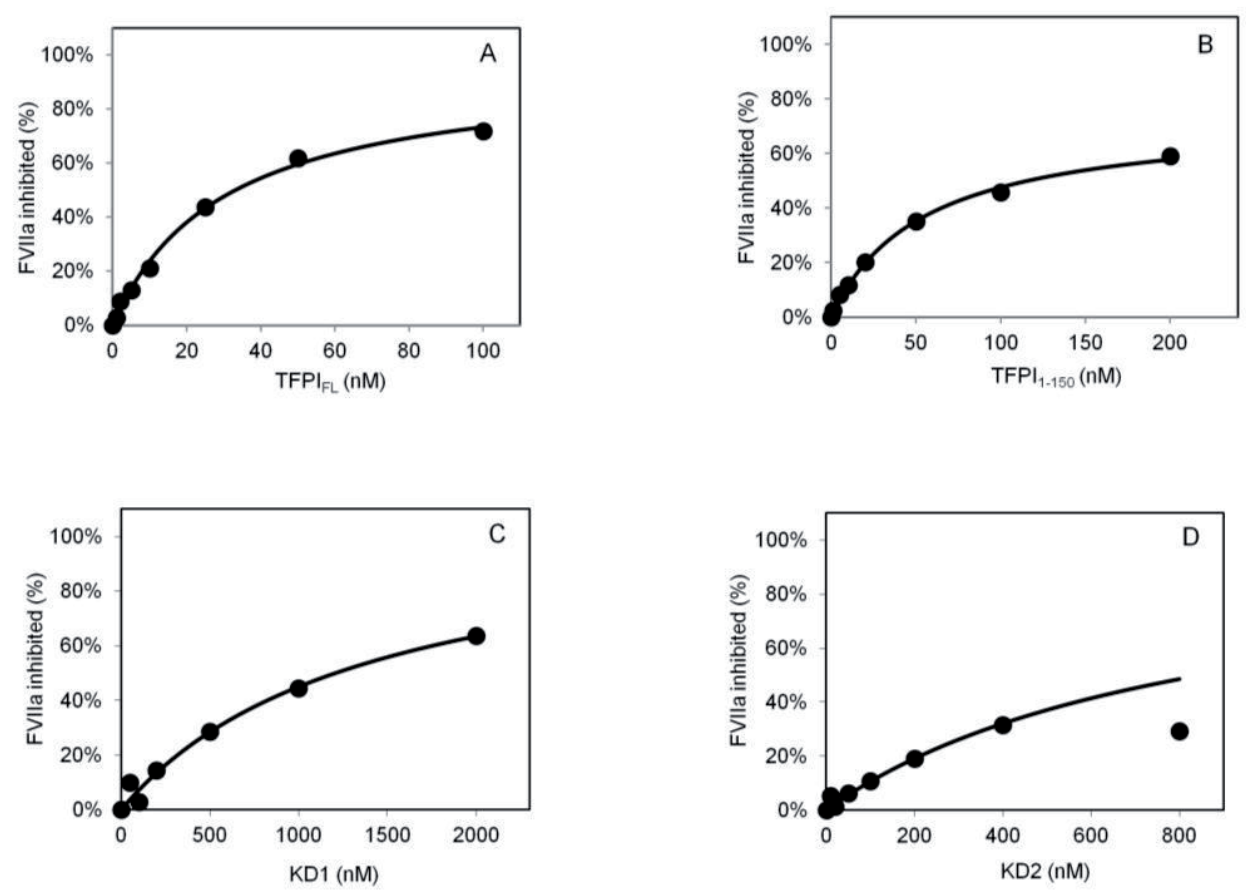

Figure 2: FIX activation by TF:FVIIa in presence of TFPI and TFPI constructs.

Time courses of FIX activation by $5 \mathrm{nM}$ TF (25 $\mu$ M phospholipid) and 50 pM FVIIa were determined in the presence of varying amounts of TFPI or TFPI constructs as described in the Methods section ( $c f$. Fig 1A,B). From the rates of FIX activation determined in the absence and presence of TFPI or TFPI construct the percentage inhibition of TF:FVIIa was calculated which was plotted as function of (A) TFPI $F L(0-100 \mathrm{nM})$, (B) TFPI $\operatorname{Til50}_{1}(0$ 200 nM), (C) KD1(0-2000 nM) and (D) KD2 (0-800 nM). The solid lines represent least square fits to a hyperbolic function (eq.1). The 800 nM point of Fig. 2D has not been included in the fitting. 


\section{Effect of protein $S$ on the inhibition of TF:FVIIa-catalysed FIX}

\section{activation by $\mathrm{TFPI}_{\mathrm{FL}}$ and $\mathrm{TFPI}_{1-150}$}

Protein S is a plasma glycoprotein which not only serves as cofactor of activated protein $\mathrm{C}$, but which also enhances the anticoagulant activity of TFPI, both in models systems and in plasma $(16,39)$. Protein $S$ decreased the $K_{i}$ of TFPI for the inhibition of FIX activation from $16.7 \mathrm{nM}$ (no protein $\mathrm{S}$ ) to $1.0 \mathrm{nM}$ (with protein S) bringing it in the range of the physiological $\mathrm{TFPI}_{\mathrm{FL}}$ concentration (Fig. 3A, Table 1). Protein $\mathrm{S}$ had no effect on the inhibition of TF:FVIIa-catalysed FIX activation by $\mathrm{TFPI}_{1-150}$ (Fig. 3B, Table 1), which shows that the presence of the KD3-C terminus of TFPI is a prerequisite for the expression of TFPI cofactor activity of protein S. Inhibition of TF:FVIIa-catalysed FIX activation by $1 \mathrm{nM}$ TFPI at increasing protein $\mathrm{S}$ concentrations showed that protein $\mathrm{S}$ stimulated TFPI 9-fold with an $\mathrm{EC}_{50}$ of $76.8 \mathrm{nM}$ (data not shown) which is below the plasma protein $\mathrm{S}$ concentration $(\sim 350 \mathrm{nM})$. Unfortunately, the effect of protein $\mathrm{S}$ on the inhibition of TF:FVIIa-catalysed FIX activation could not be studied at low phospholipid concentrations since purified protein S preparations contain protein S multimers $(40,41)$ that bind with a high affinity to phospholipids and inhibit FIX activation at low phospholipid concentrations in the absence of TFPI. 

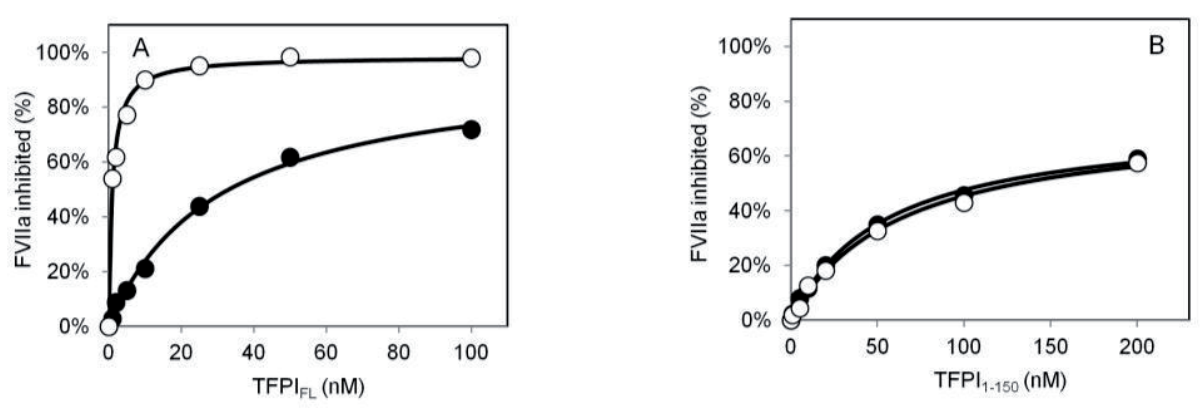

Figure 3: FIX activation by TF:FVIIa in presence of TFPI $_{F L}$ and TFPI $_{1-150}$ with and without protein $S$.

Time courses of FIX activation by 5 nM TF (25 $\mu$ M phospholipid) and 50 pM FVIIa were determined in the presence of varying amounts of $\operatorname{TFPI}_{F L}(A)$ or $\operatorname{TFPI}_{1-150}$ (B) without protein $S(\bullet)$ and with $100 \mathrm{nM}$ protein S (०) as described in the Methods section (cf. Fig $1 A, B)$. From the rates of FIX activation determined in the absence and presence of TFPI $I_{F L}$ or TFPI $I_{1-150}$ the percentage inhibition of TF:FVIIa was calculated which was plotted as function of the TFPI FL or TFPI $I_{1-150}$ concentration. The solid lines represent least square fits to a hyperbolic function (eq.1).

\section{Effect of preformed FXa-TFPI $\mathrm{FL}_{\mathrm{LL}}$ and $\mathrm{FXa}^{-\mathrm{TFPI}_{1-150}}$ complexes}

\section{on TF:FVIIa-catalysed FIX activation}

The experiments presented above were performed in the absence of FXa. To avoid any influence of potential contaminating $\mathrm{FX}(\mathrm{a})$, the reaction mixtures contained rivaroxaban, a potent $\mathrm{FXa}$ inhibitor (42), which precludes a contribution of FXa to the inhibition of TF:FVIIa via quaternary complex formation. Unfortunately, inhibition of TF:FVIIa-catalysed FIX activation could not be followed in the presence of FXa since the chromogenic substrate for FIXa (Spectrozyme FIXa) is 
converted by FXa at a 350-fold higher rate than by FIXa (data not shown). However, it was possible to study the inhibition of TF:FVIIa-catalysed FIX activation by preformed $\mathrm{FXa}-\mathrm{TFPI} \mathrm{FL}_{\mathrm{F}}$ or $\mathrm{FXa}-\mathrm{TFPI}_{1-150}$ complexes since in this experimental set-up rivaroxaban can be present during FIX activation to inhibit any free FXa. Both preformed FXa-TFPI $\mathrm{FL}_{\mathrm{L}}$ or $\mathrm{FXa}-\mathrm{TFPI}_{1-150}$ complexes were very potent inhibitors of TF:FVIIa-catalysed FIX activation which inhibited FIX activation in a stoichiometric manner i.e. $\mathrm{K}_{\mathrm{i}}$ values were in the range of the concentration TF:FVIIa complex present in the reaction mixture (Fig. 4).

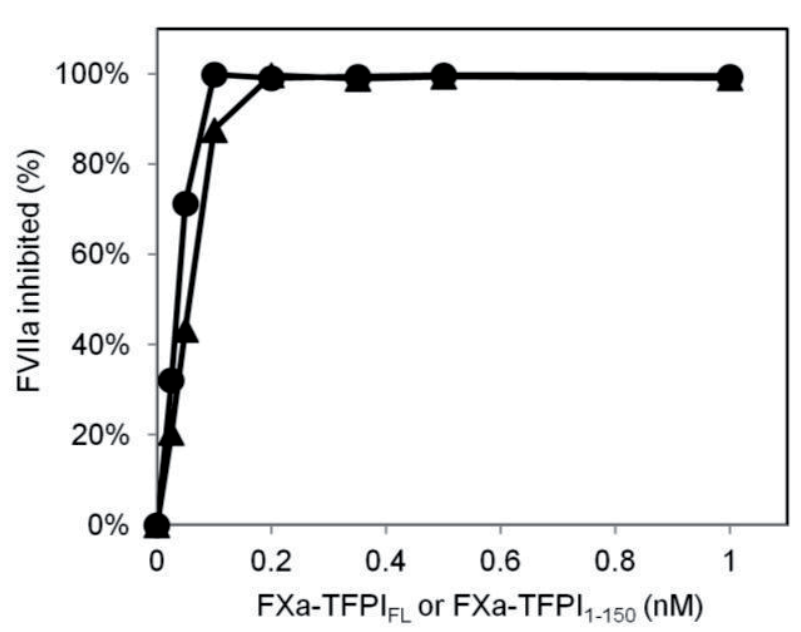

Figure 4. Effect of preformed FXa-TFPI $_{F L}$ or FXa-TFPI ${ }_{1-150}$ complexes on FIX activation by TF:FVIIa.

Time courses of FIX activation by 5 nM TF (25 $\mu$ M phospholipid) and 50 pM FVIIa were determined in the presence of varying amounts of preformed FXa$T_{F P I}$ or $F X a-T F P I_{1-150}$ complex $(0-1 \quad n M)$ as described in the Methods section (cf. Fig 1A,B).

From the rates of FIX activation determined in the absence and presence of FXa-TFPI $F_{F L}$ or FXa-TFPI ${ }_{1-150}$ complex the percentage inhibition of TF:FVII a was calculated which was plotted as function of the FXa-TFPI $I_{F L}(\bullet)$ or FXa-TFPI $I_{1-150}(\mathbf{\Delta})$ concentration. 


\section{FX activation by TF:FVIIa in presence of TFPI and TFPI}

\section{constructs}

TF, FVIIa, FXa and TFPI form a tight quaternary complex that shuts down the extrinsic coagulation pathway (7). Recently we reported that truncated forms of TFPI that lack KD3 and the C-terminus can also form a quaternary complex with FXa, FVIIa and TF (15). In these experiments FXa was allowed to pre-form a binary complex with TFPI that was then added to TF:FVIIa, the inhibition of which was subsequently followed with a FVIIa-specific chromogenic substrate (15). However, at physiological conditions FXa first has to be generated which then reacts with TFPI and TF:FVIIa to form a quaternary complex. Hence, quaternary complex formation studied during FX activation mimics physiological conditions.

At limiting FVIIa $(1 \mathrm{pM})$ and excess TF $(5 \mathrm{nM})$ the TFPI forms tested $\left(\mathrm{TFPI}_{\mathrm{FL}}\right.$, TFPI $_{1-150}$ and KD1-KD2) inhibited TF:FVIIa-catalysed FX activation with similar efficiency (Fig. 5A). FX activation was also determined at 3.5 pM FVIIa and, 0.1 $\mathrm{nM} \mathrm{TF}$ conditions at which $\mathrm{TF}$ is still in excess of FVIIa but at which the phospholipid concentration $([\mathrm{PL}]=0.5 \mu \mathrm{M})$ in the reaction mixture is 50 times less than at $5 \mathrm{nM}$ TF $([\mathrm{PL}]=25 \mu \mathrm{M})$. At $0.1 \mathrm{nM} \mathrm{TF}, \mathrm{TFPI}_{\mathrm{FL}}$ was approximately 8fold more active than at $5 \mathrm{nM} \mathrm{TF}$ (Table 2) and 15-30 times more active as inhibitor of TF:FVIIa-catalysed FX activation than the truncated forms of TFPI (Fig. 5B, Table 2). Visual inspection of the progress curves of FXa generation 
(Fig. 5AB) and quantitative analysis (Table 2) indicates that phospholipids hardly affected the inhibitory activity of $\mathrm{TFPI}_{1-150}$ and $\mathrm{KD} 1-\mathrm{KD} 2$, but considerably reduced the anticoagulant activity of $\mathrm{TFPI}_{\mathrm{FL}}$. Also in experiments performed at limiting TF and excess FVIIa, TFPI $\mathrm{FL}_{\mathrm{L}}$ was a much better inhibitor of TF:FVIIacatalysed FX activation in the absence of added phospholipids $\left(\mathrm{K}_{\mathrm{i}}=0.061 \mathrm{nM}\right)$ than in the presence of $25 \mu \mathrm{M}$ phospholipids $\left(\mathrm{K}_{\mathrm{i}}=0.47 \mathrm{nM}\right)$, while $\mathrm{TFPI}_{1-150}$ and KD1-KD2 showed a similar inhibition pattern in the absence and presence of phospholipids (Fig. 5CD, Table 2). Single Kunitz domains (KD1 and KD2) were poor inhibitors of TF:FVIIa-catalysed FX activation (Table 2), which inhibited TF:FVIIa at high concentrations $(>50 \mathrm{nM})$ and which, in contrast to $\mathrm{TFPI}_{\mathrm{FL}}, \mathrm{TFPI}_{1-}$ 150 or KD1-KD2, were not able to completely inhibit TF:FVIIa (data not shown).

\section{Effect of preformed FXa-TFPI $\mathrm{FL}_{\text {and }}$ FX-TFPI ${ }_{1-150}$ complexes on}

\section{FX activation by TF:FVIIa}

$\mathrm{TFPI}_{\mathrm{FL}}$ and $\mathrm{TFPI}_{1-150}$ were preincubated with FXa to form a tight binary complex. After preincubation FXa was fully complexed with TFPI as there was no FXa activity measurable with a FXa-specific chromogenic substrate. At limiting FVIIa and low TF $(0.1 \mathrm{nM})$ or high TF $(5 \mathrm{nM})$, both the FXa-TFPI $\mathrm{FL}_{\mathrm{L}}$ and FXa-TFPI $\mathrm{I}_{1-150}$ complex equally well inhibited FX activation by TF:FVIIa with $\mathrm{K}_{\mathrm{i}}$ values ranging between 0.01 and $0.026 \mathrm{nM}$ (Table 2). When the FXa-TFPI ${ }_{\mathrm{FL}}$ and FXa-TFPI $\mathrm{I}_{1-150}$ complexes were compared to free $\mathrm{TFPI}_{\mathrm{FL}}$ or $\mathrm{TFPI}_{1-150}$ at low phospholipid 

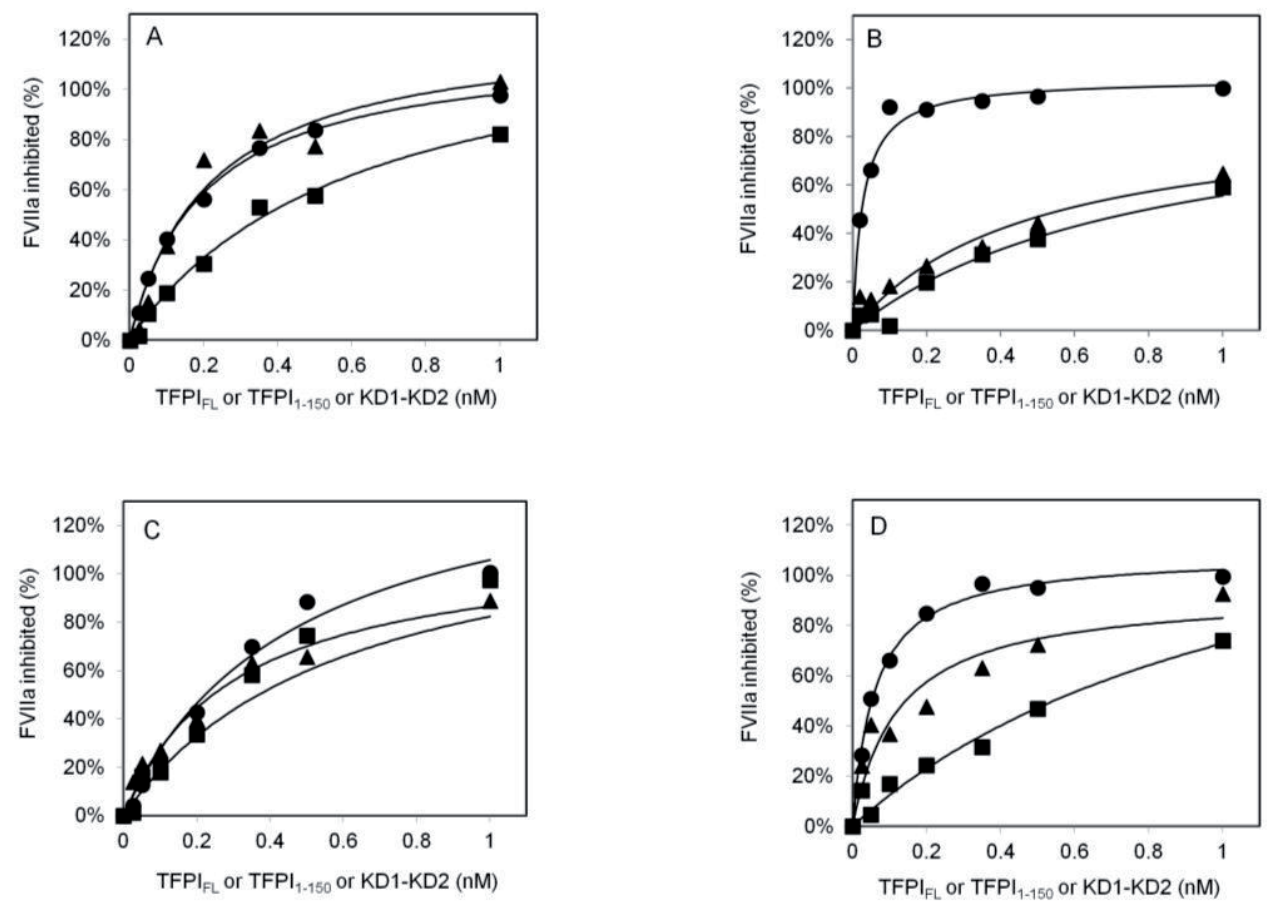

Figure 5. Effect of TFPI FL TFPI $_{1-150}$ and KD1-KD2 on FX activation by TF:FVIIa

Time courses of FX activation by TF:FVII a were determined in the presence of varying amounts of TFPI or TFPI construct as described in the Methods section (cf. Fig 1C,D). Limiting FVIIa: (A) Inhibition of FX activation by 1 pM FVIIa and $5 \mathrm{nM}$ relipidated TF (25 $\mu$ M phospholipid) as a function of $\operatorname{TFPI}_{F L}(\bullet), \operatorname{TFPI}_{1-150}(\mathbf{\bullet})$ or KD1-KD2 ( $\left.\mathbf{\Delta}\right)$.

(B) Inhibition of FX activation by 3 pM FVIIa and $0.1 \mathrm{nM}$ relipidated $T F(0.5 \mu M$

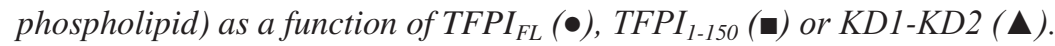

Limiting TF: (C) Inhibition of FX activation by $0.25 \mathrm{nM} F$ VIIa and $3.5 \mathrm{pM}$ TF in presence of $25 \mu M$ added phospholipid vesicles (20/60/20 PS/PC/PE) as function of TFPI FL $_{(\bullet),}$ TFPI $_{1-150}$ (-) or KD1-KD2 ( $\mathbf{( \Delta )}$. (D) Plot of percentage of inhibition of FX activation by 0.25 nM FVIIa and 10.5 pM TF (52.5 nM phospholipid) as function of TFPI $F L$ (•), TFPI 150 (घ) or KD1-KD2 ( $\mathbf{\Delta})$.

The percentage inhibition of TF:FVIIa was calculated from the rates of FX activation determined in the absence and presence of TFPI or TFPI construct. The solid lines represent fits to a hyperbolic function (eq.1). 
concentration, $\mathrm{TFPI}_{\mathrm{FL}}$ inhibited the $\mathrm{FX}$ activation similar to the preformed complexes. However, compared with the FXa-TFPI ${ }_{1-150}$ complex, free TFPI $1-150$ was a very poor inhibitor of FX activation (Fig. 6, Table 2).

\section{Effect of protein $\mathrm{S}$ on quaternary complex formation}

Protein S was also tested for its ability to act as cofactor of TFPI in the inhibition of FX activation. At limiting FVIIa and $5 \mathrm{nM}$ TF, protein $\mathrm{S}$ considerably enhanced the inhibition of FX activation by TFPI (Fig. 7, Table 2). This was not due to direct inhibition of the FXa but was the result of inhibition of TF:FVIIa because it is unlikely that $25 \mathrm{pM} \mathrm{TFPI}_{\mathrm{FL}}$ in presence of protein $\mathrm{S}$ quantitatively contributed to the inhibition of the high concentration of FXa that was generated $(2 \mathrm{nM})$. This effect of protein $\mathrm{S}$ on quaternary complex formation was confirmed with an antiprotein $\mathrm{S}$ antibody which fully blocked the ability of protein $\mathrm{S}$ to enhance the inhibitory activity of TFPI on FX activation by TF:FVIIa. 


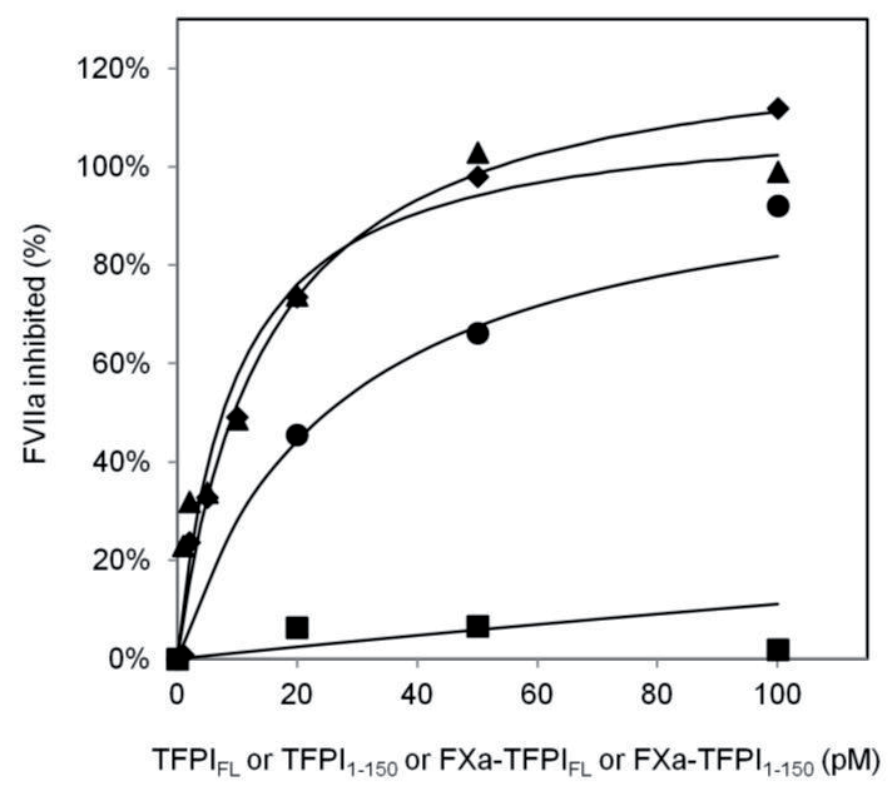

Figure 6. Effect of TFPI FL,$T F P I_{1-150}$ and preformed TFPI $F L^{-F X a}$ and TFPI $I_{1-150}-F X a$ complexes on FX activation by TF:FVIIa at low PL.

Time courses of FX activation by 1 pM FVIIa and $0.1 n M$ relipidated TF $(0.5 \mu M$ phospholipid) were determined in the presence of $\operatorname{TFPI}_{F L}(\bullet), T F P I_{1-150}(\mathbf{\bullet})$, pre-formed $F X a$ -

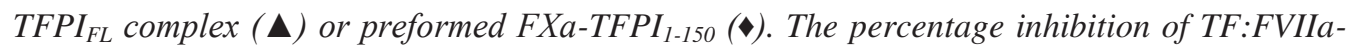
catalysed FX activation was calculated from the rates of FX activation determined in the absence and presence of TFPI or TFPI-FXa complex and plotted as function of the TFPI $F L$, $T F P I_{1-150}$, or preformed TFPI $F L^{-} F X a$ or $T F P I_{1-150}-F X$ a complex concentration and fitted to a hyperbola to yield $I C_{50} / K_{i}$ values. 


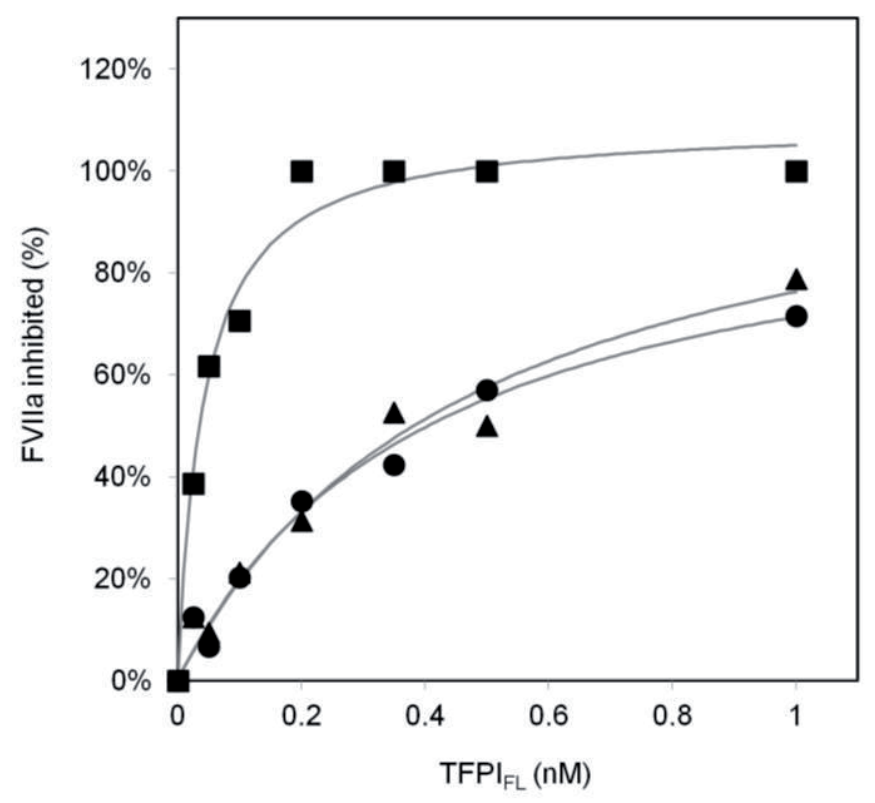

Figure 7. Effect of protein $S$ on the inhibition of TF:FVIIa-catalysed FX activation by $\operatorname{TFPI}_{F L}$

Time courses of FX activation by 1 pM FVIIa and 5 nM relipidated TF (25 $\mu M$ phospholipid) were determined in the presence of $T F P I_{F L}(\bullet), T F P I_{F L}+100 n M$ protein $S$

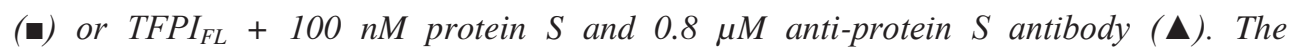
percentage inhibition of TF:FVIIa-catalysed FX activation, calculated from the rates of $F X$ activation determined in the absence and presence of TFPI, was plotted a function of the $T F P I_{F L}$ concentration and fitted to a hyperbola to yield $K_{i}$ values. 


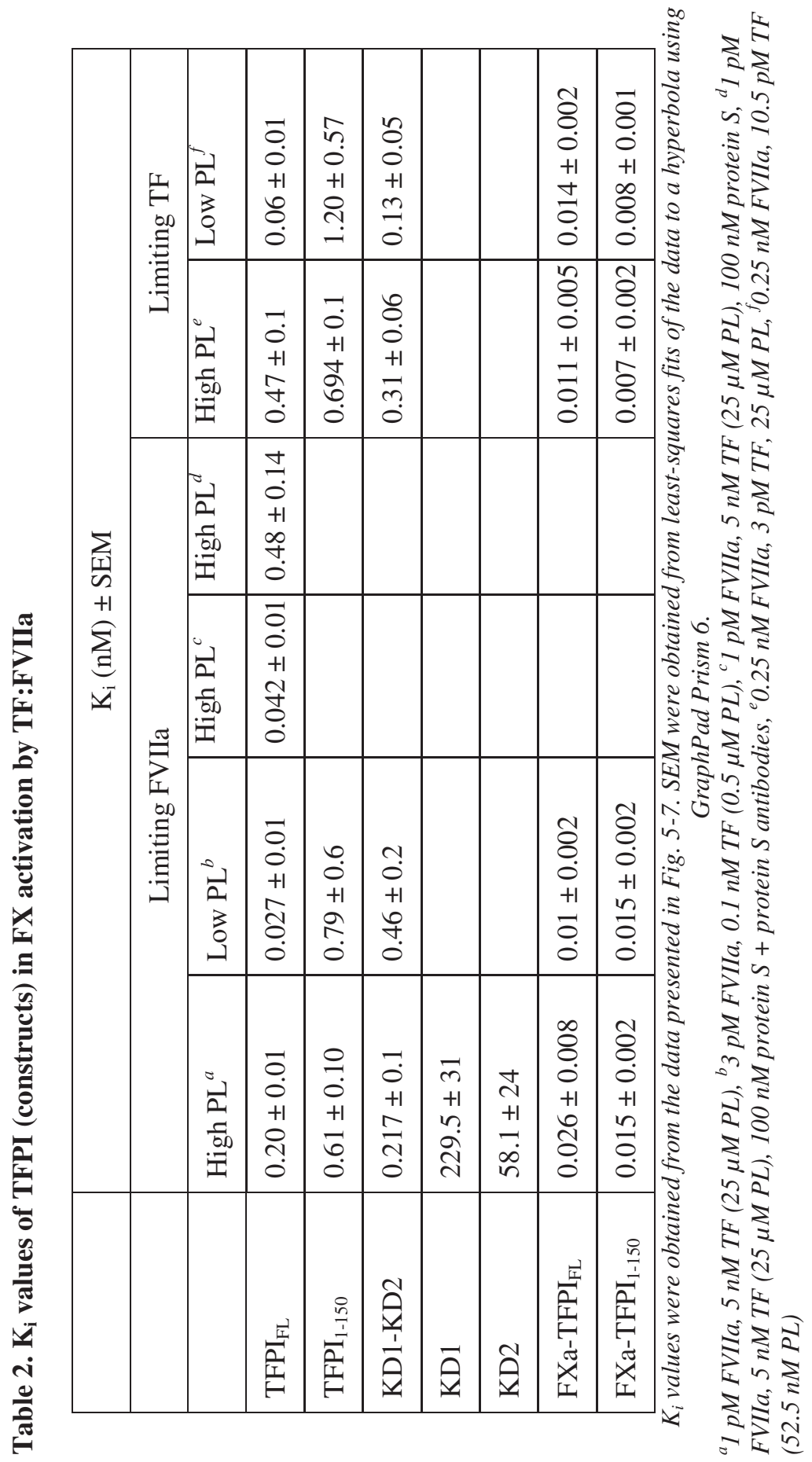




\section{Chapter 5}

\section{Discussion}

TFPI is an important anticoagulant protein which down-regulates the extrinsic coagulation pathway by directly inhibiting FXa and TF:FVIIa. Although early reports showed that KD1 inhibits FVIIa and KD2 inhibits FXa $(7,8)$, it was later demonstrated that isolated KD1 and KD2 are poor inhibitors of FVIIa (15) and FXa (18), respectively and that all Kunitz domains are involved in the direct inhibition of FXa $(18,19)$ and TF:FVIIa $(28)$ by TFPI. However, much less is known about the role of the different Kunitz domains in the inhibition of TF:FVIIa-catalysed FX and FIX activation. A detailed study showed that, in the absence of FXa, inhibition of TF:FVIIa-catalysed FIX activation by TFPI was hardly or not detectable (32).

We show that TFPI ${ }_{\mathrm{FL}}, \mathrm{TFPI}_{1-150}, \mathrm{KD} 1$ and $\mathrm{KD} 2$ can all inhibit TF:FVIIacatalysed FIX activation in the absence of FXa. The efficacy of inhibition decreases in the order TFPI $\mathrm{FL}_{\mathrm{L}}>\mathrm{TFPI}_{1-150}>\mathrm{KD} 2>\mathrm{KD} 1$ (Table 1) which indicates that all Kunitz domains and the C-terminus contribute to the inhibition of TF:FVIIacatalysed FIX activation. The $\mathrm{K}_{\mathrm{i}}$ value of $\mathrm{TFPI}_{1-150}$ is that high that truncated forms of TFPI that circulate in blood will hardly contribute to the inhibition of TF:FVIIacatalysed FIX activation when no FXa is present. At high phospholipid concentrations $(25 \mu \mathrm{M})$ the $\mathrm{K}_{\mathrm{i}}$ for $\mathrm{TFPI}_{\mathrm{FL}}(16.7 \mathrm{nM})$ is also far above the plasma $\mathrm{TFPI}_{\mathrm{FL}}$ concentration $(0.5 \mathrm{nM})$ indicating that under these conditions direct inhibition of FIX activation by TFPI will be of limited physiological importance. However, at low phospholipid concentrations and in the presence of protein S, the 
$\mathrm{K}_{\mathrm{i}}$ for TFPI becomes $\sim 1 \mathrm{nM}$ (Table 1) and direct inhibition of TF:FVIIa-catalysed FIX activation by TFPI without involvement of FXa may contribute to the downregulation of coagulation, particularly in individuals with high circulating TFPI or at sites of thrombus formation where local TFPI concentrations may be higher than in plasma as the result of TFPI released from platelets.

FXa greatly stimulates the inhibition of TF:FVIIa by TFPI, a phenomenon that is due to the formation of a tight quaternary TF:FVIIa-TFPI-FXa complex (7, 43). Our current approach did not allow simultaneous measurement of inhibition of TF:FVIIa-catalysed FX and FIX activation by TFPI since the chromogenic substrate used to follow FIXa generation (Spectrozyme FIXa) is rapidly cleaved by FXa. However, we were able to determine the inhibition of FIX activation via quaternary complex formation by using preformed $\mathrm{TFPI}_{\mathrm{FL}}-\mathrm{FXa}$ or $\mathrm{TFPI}_{1-150}-\mathrm{FXa}$ complexes as TF:FVIIa inhibitors. Both preformed complexes were very potent inhibitors that inhibited TF:FVIIa-catalysed FIX activation in a stoichiometric manner with $\mathrm{K}_{\mathrm{i}}$ values $<<1 \mathrm{nM}$ (Fig. 4).

The kinetics of inhibition of TF:FVIIa-catalysed FX activation by TFPI greatly differed from that of FIX activation (Fig. 1CD). TFPI gradually inhibited $\mathrm{FX}$ activation with incomplete inhibition at low $\mathrm{TFPI}_{\mathrm{FL}}\left(\left[\mathrm{TFPI}_{\mathrm{FL}}\right]<100 \mathrm{pM}\right)$, complete inhibition at intermediate $\operatorname{TFPI}_{\mathrm{FL}}\left(\left[\mathrm{TFPI}_{\mathrm{FL}}\right]<350 \mathrm{pM}\right)$ and complete inhibition and a subsequent loss of FXa activity at high TFPI $\left(\left[\mathrm{TFPI}_{\mathrm{FL}}\right]<1000 \mathrm{pM}\right)$. In reaction mixtures which contained a high phospholipid concentration $(\sim 25 \mu \mathrm{M})$, 
similar inhibition patterns were observed with $\mathrm{TFPI}_{\mathrm{FL}}, \mathrm{KD} 1-\mathrm{KD} 2$ and $\mathrm{TFPI}_{1-150}$ and there appeared to be little difference in the effectiveness of inhibition between full length TFPI and both truncated forms of TFPI. However, when the phospholipid concentration in the reaction mixture was decreased to $0.5 \mu \mathrm{M}$ the efficacy by which TFPI $_{\mathrm{FL}}$ inhibited TF:FVIIa-catalysed FX activation was increased $\sim 7$-fold while lowering the phospholipid concentration did not enhance the inhibitory activity of TFPI ${ }_{1-150}$ and KD1-KD2 (Table 2). We hypothesize that phospholipids bind $\mathrm{TFPI}_{\mathrm{FL}}$ or the TFPI-FXa complex through interactions with the C-terminus of TFPI and the $\gamma$-carboxy glutamic acid domain of FXa and that as a consequence high phospholipid concentrations reduce the $\mathrm{TFPI}_{\mathrm{FL}}$ and/or TFPI-FXa complex that is available for inhibition of TF:FVIIa. However, it should be emphasized that in the presence $\mathrm{Ca}^{2+}$-ions only the $\mathrm{TFPI}_{\mathrm{FL}}-\mathrm{FX}$ complex binds with a high affinity to negatively charged phospholipids whereas binding of $\mathrm{TFPI}_{\mathrm{FL}}$ alone or complexes between FXa and truncated TFPI is hardly detectable (44). This may explain why the inhibitory activity of $\mathrm{TFPI}_{1-150}$ and KD1-KD2, which both lack the KD3-C terminus and which do not bind to phospholipids, was hardly affected at high phospholipid concentrations. The isolated Kunitz domains (KD1 and KD2) were very poor inhibitors of TF:FVIIa-catalysed $\mathrm{FX}$ activation which had $\mathrm{K}_{\mathrm{i}}$ values that were several orders of magnitude higher than the $\mathrm{K}_{\mathrm{i}}$ of $\mathrm{TFPI}_{\mathrm{FL}}$ (Table 2).

Preformed $\mathrm{TFPI}_{\mathrm{FL}}-\mathrm{FXa}$ and $\mathrm{TFPI}_{1-150}-\mathrm{FXa}$ complexes appeared to be very potent inhibitors of FX activation at low as well as high phospholipid 
concentrations (Fig. 6, Table 2 which inhibited FX activation with $\mathrm{K}_{\mathrm{i}}$ values between 0.01 and $0.03 \mathrm{nM}$ (Table 2). In contrast to inhibition by $\mathrm{TFPI}_{\mathrm{FL}}$ and TFPI $_{1-150}$ which was slow, the preformed complexes inhibited FX activation without a measurable lag. These data indicate that the limiting factor in the inhibition of FX activation by TFPI is the interaction/reaction between TFPI and FXa which is slow in case of TFPI (45) and in addition inefficient in case of TFPI ${ }_{150}$ because it lacks the KD3-C terminus (18).

Protein S also enhanced the inhibition of TF:FVIIa-catalysed FIX activation by TFPI (Fig. 7, Table 2). While the effect of protein $S$ on FIX activation is explained by enhancing the direct inhibition of TF:FVIIa by TFPI, protein S likely has three effects in case of FX activation: 1) it promotes quaternary complex formation either directly or by enhancing FXa-TFPI complex formation near TF:FVIIa (at low TFPI concentrations), 2) it promotes direct inhibition of FXa by TFPI without subsequent quaternary complex formation (at intermediate and high TFPI concentrations) and 3) it promotes direct inhibition of TF:FVIIa by TFPI (at high TFPI concentrations). Our observations that protein $\mathrm{S}$ stimulates TFPI inhibition TF:FVIIa-catalysed FIX and FX activation seem to conflict data of Ndonwi and Broze (9) who reported that protein S does not enhance the inhibitory activity of TFPI in FIX and FX activation by TF:FVIIa. However, there are important differences between our experimental conditions and those of Ndonwi and Broze. We measured FX activation at limiting FVIIa and excess TF (1 pM 
FVIIa/5 nM TF) whereas Ndwoni and Broze (9) had a limiting amount of FVIIa and TF (1 pM). Another difference which likely explains why we observed a stimulatory effect of protein $\mathrm{S}$ is the TFPI concentration. Ndwoni and Broze performed experiments at a single TFPI concentration $(1 \mathrm{nM})$ whereas we titrated with TFPI and used upto 40-fold lower concentrations (Fig. 1D). Also in FIX activation experiments there is an important difference. Our activation mixtures contained a FXa inhibitor (rivaroxaban) to prevent any contribution of FXa to the TF:FVIIa inhibition via quaternary complex formation. Ndonwi and Broze had FX present which after conversion to FXa allows efficient inhibition of TF:FVIIa via quaternary complex formation which likely overwhelmed the stimulatory effect of protein $\mathrm{S}$ as observed in our experiments.

In summary, we have shown that although the isolated Kunitz domains of TFPI can inhibit TF:FVIIa-catalysed FIX and FX activation, efficient inhibition requires the presence of all three Kunitz domains, even in the absence of quaternary complex formation i.e. in case of inhibition of FIX activation in the absence of FXa. The three Kunitz domains also contribute to quaternary complex formation and are likely important for the interaction between FXa and TFPI which is required for quaternary complex formation. Conditions that enhance FXaTFPI complex formation e.g. the presence of KD3 and protein $\mathrm{S}$ also promote the inhibition of TF:FVIIa. When the quaternary complex cannot be formed because there is no FXa, TFPI alone also inhibits TF:FVIIa which considering the $\mathrm{K}_{\mathrm{i}}$ (1 
$\mathrm{nM}$ ) in the presence of protein S may be physiologically important, particularly in patients with elevated plasma TFPI concentrations $(46,47)$ or during treatment with heparin which has been reported to increase plasma TFPI levels by releasing TFPI from the endothelium (48). 


\section{Acknowledgements}

We would like to thank L. Herfs for technical support.

\section{Addendum}

S. Peraramelli designed and performed the experiments, analyzed the data and wrote the manuscript; S. Thomassen and A. Heinzmann assisted in performing the experiments; J. Rosing supervised the project, designed the experiments, analyzed data and revised the manuscript; T. Hackeng supervised the project and revised the manuscript; R. Hartmann provided TFPI constructs and revised the manuscript; M. Dockal provided TFPI constructs, contributed in data analysis and revising the manuscript; F. Scheiflinger critically revised the manuscript.

\section{Disclosure of Conflict of Interest}

JR receives research support from, and acts as consultant of Baxter Innovations

GmbH. MD, RH and FS are full time employees of Baxter Innovations GmbH. None of the other authors declare any conflict of interest. 


\section{References}

1. Osterud B, Rapaport SI. Activation of factor IX by the reaction product of tissue factor and factor VII: additional pathway for initiating blood coagulation. Proc Natl Acad Sci U S A 1977;74(12):5260-4.

2. Silverberg SA, Nemerson Y, Zur M. Kinetics of the activation of bovine coagulation factor $\mathrm{X}$ by components of the extrinsic pathway. Kinetic behavior of two-chain factor VII in the presence and absence of tissue factor. J Biol Chem 1977;252(23):8481-8.

3. Wun TC, Kretzmer KK, Girard TJ, et al. Cloning and characterization of a cDNA coding for the lipoprotein-associated coagulation inhibitor shows that it consists of three tandem Kunitz-type inhibitory domains. J Biol Chem 1988;263(13):6001-4.

4. Chuang TF, Sargeant RB, Hougie C. The intrinsic activation of factor X in blood coagulation. Biochimica et biophysica acta 1972;273(2):287-91.

5. Zhang J, Piro O, Lu L, et al. Glycosyl phosphatidylinositol anchorage of tissue factor pathway inhibitor. Circulation 2003;108(5):623-7.

6. Maroney SA, Ellery PE, Mast AE. Alternatively spliced isoforms of tissue factor pathway inhibitor. Thromb Res 2010;125 Suppl 1:S52-6.

7. Broze GJ, Jr., Warren LA, Novotny WF, et al. The lipoprotein-associated coagulation inhibitor that inhibits the factor VII-tissue factor complex also inhibits factor Xa: insight into its possible mechanism of action. Blood 1988;71(2):335-43. 
8. Girard TJ, Warren LA, Novotny WF, et al. Functional significance of the Kunitz-type inhibitory domains of lipoprotein-associated coagulation inhibitor. Nature 1989;338(6215):518-20.

9. Ndonwi M, Tuley EA, Broze GJ, Jr. The Kunitz-3 domain of TFPI-alpha is required for protein S-dependent enhancement of factor Xa inhibition. Blood 2010;116(8):1344-51.

10. Wesselschmidt R, Likert $\mathrm{K}$, Girard $\mathrm{T}$, et al. Tissue factor pathway inhibitor: the carboxy-terminus is required for optimal inhibition of factor Xa. Blood 1992;79(8):2004-10.

11. Huang ZF, Wun TC, Broze GJ, Jr. Kinetics of factor Xa inhibition by tissue factor pathway inhibitor. J Biol Chem 1993;268(36):26950-5.

12. Broze GJ, Jr., Girard TJ, Novotny WF. Regulation of coagulation by a multivalent Kunitz-type inhibitor. Biochemistry 1990;29(33):7539-46.

13. Pedersen AH, Nordfang O, Norris F, et al. Recombinant human extrinsic pathway inhibitor. Production, isolation, and characterization of its inhibitory activity on tissue factor-initiated coagulation reactions. J Biol Chem 1990;265(28):16786-93.

14. Callander NS, Rao LV, Nordfang O, et al. Mechanisms of binding of recombinant extrinsic pathway inhibitor (rEPI) to cultured cell surfaces. Evidence that rEPI can bind to and inhibit factor VIIa-tissue factor complexes in the absence of factor Xa. J Biol Chem 1992;267(2):876-82. 
15. Peraramelli S, Thomassen S, Heinzmann A, et al. Direct Inhibition Of Factor VIIa By TFPI And TFPI Constructs. J Thromb Haemost 2013;11(4):70414.

16. Hackeng TM, Sere KM, Tans G, et al. Protein S stimulates inhibition of the tissue factor pathway by tissue factor pathway inhibitor. Proc Natl Acad Sci U S A 2006;103(9):3106-11.

17. Ndonwi M, Broze G, Jr. Protein S enhances the tissue factor pathway inhibitor inhibition of factor Xa but not its inhibition of factor VIIa-tissue factor. J Thromb Haemost 2008;6(6):1044-6.

18. Peraramelli S, Suylen DP, Rosing J, et al. The Kunitz 1 and Kunitz 3 domains of tissue factor pathway inhibitor are required for efficient inhibition of factor Xa. Thromb Haemost 2012;108(2):266-76.

19. Higuchi DA, Wun TC, Likert KM, et al. The effect of leukocyte elastase on tissue factor pathway inhibitor. Blood 1992;79(7):1712-9.

20. Wesselschmidt R, Likert K, Huang Z, et al. Structural requirements for tissue factor pathway inhibitor interactions with factor Xa and heparin. Blood Coagul Fibrinolysis 1993;4(5):661-9.

21. Petersen LC, Bjorn SE, Olsen OH, et al. Inhibitory properties of separate recombinant Kunitz-type-protease-inhibitor domains from tissue-factor-pathway inhibitor. Eur J Biochem 1996;235(1-2):310-6. 
22. Cunningham AC, Hasty KA, Enghild JJ, et al. Structural and functional characterization of tissue factor pathway inhibitor following degradation by matrix metalloproteinase-8. Biochem J 2002;367(Pt 2):451-8.

23. Novotny WF, Girard TJ, Miletich JP, et al. Purification and characterization of the lipoprotein-associated coagulation inhibitor from human plasma. J Biol Chem 1989;264(31):18832-7.

24. Broze GJ, Jr., Lange GW, Duffin KL, et al. Heterogeneity of plasma tissue factor pathway inhibitor. Blood Coagul Fibrinolysis 1994;5(4):551-9.

25. Sandset PM, Bendz B. Tissue factor pathway inhibitor: clinical deficiency states. Thromb Haemost 1997;78(1):467-70.

26. Hansen JB, Huseby KR, Huseby NE, et al. Tissue factor pathway inhibitor in complex with low density lipoprotein isolated from human plasma does not possess anticoagulant function in tissue factor-induced coagulation in vitro. Thromb Res 1997;85(5):413-25.

27. Dahm AE, Andersen TO, Rosendaal F, et al. A novel anticoagulant activity assay of tissue factor pathway inhibitor I (TFPI). J Thromb Haemost 2005;3(4):651-8.

28. Hamamoto T, Yamamoto M, Nordfang O, et al. Inhibitory properties of full-length and truncated recombinant tissue factor pathway inhibitor (TFPI). Evidence that the third Kunitz-type domain of TFPI is not essential for the 
inhibition of factor VIIa-tissue factor complexes on cell surfaces. J Biol Chem 1993;268(12):8704-10.

29. Valentin S, Reutlingsperger CP, Nordfang O, et al. Inhibition of factor X activation at extracellular matrix of fibroblasts during flow conditions: a comparison between tissue factor pathway inhibitor and inactive factor VIIa. Thromb Haemost 1995;74(6):1478-85.

30. Baugh RJ, Broze GJ, Jr., Krishnaswamy S. Regulation of extrinsic pathway factor Xa formation by tissue factor pathway inhibitor. J Biol Chem 1998;273(8):4378-86.

31. Salemink I, Franssen J, Willems GM, et al. Inhibition of tissue factorfactor VIIa-catalyzed factor $\mathrm{X}$ activation by factor Xa-tissue factor pathway inhibitor. A rotating disc study on the effect of phospholipid membrane composition. J Biol Chem 1999;274(40):28225-32.

32. Lu G, Broze GJ, Jr., Krishnaswamy S. Formation of factors IXa and Xa by the extrinsic pathway: differential regulation by tissue factor pathway inhibitor and antithrombin III. J Biol Chem 2004;279(17):17241-9.

33. Maroney SA, Ellery PE, Wood JP, et al. Comparison of the inhibitory activities of human tissue factor pathway inhibitor (TFPI)alpha and TFPIbeta. J Thromb Haemost 2013;11(5):911-8. 
34. Sere KM, Rosing J, Hackeng TM. Inhibition of thrombin generation by protein $\mathrm{S}$ at low procoagulant stimuli: implications for maintenance of the hemostatic balance. Blood 2004;104(12):3624-30.

35. Girard TJ, Broze GJ, Jr. Tissue factor pathway inhibitor. Methods Enzymol 1993;222:195-209.

36. Bligh EG, Dyer WJ. A rapid method of total lipid extraction and purification. Canadian journal of biochemistry and physiology 1959;37(8):911-7.

37. Ruggieri S. Separation of the methyl esters of fatty acids by thin layer chromatography. Nature 1962;193:1282-3.

38. Hemker HC, Giesen P, Al Dieri R, et al. Calibrated automated thrombin generation measurement in clotting plasma. Pathophysiology of haemostasis and thrombosis 2003;33(1):4-15.

39. Ndonwi M, Tuley EA, Broze GJ, Jr. The Kunitz-3 domain of TFPI-alpha is required for protein S-dependent enhancement of factor Xa inhibition. Blood 2010;116(8):1344-51.

40. Sere KM, Janssen MP, Willems GM, et al. Purified protein S contains multimeric forms with increased APC-independent anticoagulant activity. Biochemistry 2001;40(30):8852-60.

41. Sere KM, Willems GM, Rosing J, et al. Protein S multimers are generated in vitro and affect protein S structure-function analyses. Seminars in hematology 2006;43(1 Suppl 1):S111-20. 
42. Verma AK, Brighton TA. The direct factor Xa inhibitor rivaroxaban. Med J Aust 2009;190(7):379-83.

43. Warn-Cramer BJ, Rao LV, Maki SL, et al. Modifications of extrinsic pathway inhibitor (EPI) and factor Xa that affect their ability to interact and to inhibit factor VIIa/tissue factor: evidence for a two-step model of inhibition. Thromb Haemost 1988;60(3):453-6.

44. Willems GM, Janssen MP, Salemink I, et al. Transient high affinity binding of tissue factor pathway inhibitor-factor Xa complexes to negatively charged phospholipid membranes. Biochemistry 1998;37(10):3321-8.

45. Morrison JF, Walsh CT. The behavior and significance of slow-binding enzyme inhibitors. Advances in enzymology and related areas of molecular biology 1988;61:201-301.

46. Lindahl AK, Sandset PM, Abildgaard U. The present status of tissue factor pathway inhibitor. Blood Coagul Fibrinolysis 1992;3(4):439-49.

47. Vincent LM, Tran S, Livaja R, et al. Coagulation factor V(A2440G) causes east Texas bleeding disorder via TFPIalpha. $\mathrm{J}$ Clin Invest 2013;123(9):3777-87.

48. Sandset PM, Abildgaard U, Larsen ML. Heparin induces release of extrinsic coagulation pathway inhibitor (EPI). Thromb Res 1988;50(6):803-13. 



\section{Chapter 6}

\section{Role of exosite binding modulators in the inhibition of FXa by TFPI}

Peraramelli S, Thomassen S, Heinzmann A, Hackeng TM, Hartmann R, Scheiflinger F, Dockal M, Rosing J

(Manuscript under review in Thrombosis and Haemostasis) 
Chapter 6 


\section{Abstract}

Background: Tissue factor pathway inhibitor (TFPI) down-regulates the extrinsic coagulation pathway by inhibiting FXa and FVIIa. Both TFPI and FXa interact with several plasma proteins (e.g. prothrombin, FV/FVa, protein S) and nonproteinic compounds (e.g. phospholipids, heparin).

Aim: To investigate effects of ligands that bind to FXa and TFPI on FXa inhibition by full length TFPI (designated TFPI) and truncated TFPI (TFPI $\left.{ }_{1-150}\right)$.

Methods: Inhibition of FXa by TFPI and TFPI ${ }_{1-150}$ and effects of phospholipids, heparin, prothrombin, FV, FVa, and protein $\mathrm{S}$ thereon was quantified from progress curves of conversion of the FXa-specific chromogenic substrate CS11(65).

Results: Low concentrations negatively charged phospholipids $(\sim 10 \mu \mathrm{M})$ already maximally stimulated (up to 5-6-fold) FXa inhibition by TFPI. Unfractionated heparin at concentrations $(0.2-1 \mathrm{U} / \mathrm{ml})$ enhanced FXa inhibition by TFPI $\sim 8$-fold, but impaired inhibition at concentrations $>1 \mathrm{U} / \mathrm{ml}$. Physiological protein $\mathrm{S}$ and FV concentrations both enhanced FXa inhibition by TFPI 2-3 fold. In contrast, thrombin-activated FV (FVa) impaired the ability of TFPI to inhibit FXa. FXa inhibition by $\mathrm{TFPI}_{1-150}$ was not affected by FV, FVa, protein $\mathrm{S}$, phospholipids and heparin. TFPI potently inhibited FXa-catalysed prothrombin activation in the absence of FVa, but hardly inhibited prothrombin activation in the presence of 
thrombin-activated FVa.

Summary and Conclusions: Physiological concentrations TFPI $(0.25-0.5 \mathrm{nM}$ TFPI) inhibit FXa with a $t_{1 / 2}$ between 3-15 min. Direct FXa inhibition by TFPI is modulated by physiological concentrations prothrombin, FV, FVa, protein S, phospholipids and heparin indicating the importance of these modulators for the in vivo anticoagulant activity of TFPI. 


\section{Introduction}

Tissue factor pathway inhibitor (TFPI) is a multivalent Kunitz type protease inhibitor that inhibits both the tissue factor-factor VIIa (TF-FVIIa) complex $(1,2)$ and factor Xa (FXa) (3). Alternative splicing of TFPI mRNA results in two isoforms, TFPI $\alpha$ (4) and TFPI $\beta$ (5). TFPI $\alpha$ consists of a negatively charged amino terminus (N-terminus), three tandem Kunitz domains (KD1, KD2 and KD3) and a positively charged carboxyl terminus (C-terminus) (4). TFPI $\beta$ lacks KD3 and has a different C-terminus to which a GPI anchor is attached which covalently associates TFPI $\beta$ to the endothelium (6). Free full length TFPI $\alpha$ which from hereon will be designated as TFPI, circulates in plasma at a concentration of $0.25-0.50 \mathrm{nM}$ (7). FXa, the serine protease which activates prothrombin to thrombin, is inhibited by TFPI via a so-called slow-tight binding mechanism which is characterized by rapid formation of a small amount of loose encounter complex between FXa and TFPI which subsequently slowly isomerizes to a tight FXa•TFPI ${ }^{*}$ complex (8-10). In the presence of FXa, TFPI readily inhibits the tissue factor-factor VIIa (TF-FVIIa) complex by forming a tight quaternary complex (TFPI-FXa-TF-FVIIa) (3), thus shutting down the initiation of coagulation.

Plasma contains many proteins and non-proteinic compounds (e.g. $\mathrm{Ca}^{2+}-$ ions, phospholipids and drugs like heparin) that bind to the active site or to exosites of procoagulant and anticoagulant proteins and that modulate the activity of the coagulation cascade. Both TFPI and FXa are multi-domain proteins that have the 
ability to interact with several plasma proteins and non-proteinic compounds, some of which bind both to TFPI and FXa. KD1 and KD2 of TFPI bind to and inhibit FXa and FVIIa, respectively (7), KD3 has been reported to interact with protein S $(11,12)$ and heparin-like molecules $(13,14)$ and the basic C-terminus of TFPI binds to FV (15) negatively charged phospholipids (16) and heparin (17). FXa not only interacts with its substrates e.g. prothrombin, FV and FVII but also with FVa and protein S (18), coagulation inhibitors (TFPI (9) and AT (19)) and with $\mathrm{Ca}^{2+}$ ions and negatively charged surfaces like heparin and phospholipids (20).

Since TFPI and FXa share many ligands it is to be expected that these ligands and also those that bind either to TFPI or FXa might affect (enhance or diminish) FXa inhibition by TFPI. Indeed it has been reported that phospholipids (9), heparin (9), FV $(21)$ and FVa $(9,21)$ and protein S $(22)$ stimulate FXa inhibition by TFPI and that prothrombin protects FXa against TFPI inhibition (23). However, the reaction conditions (e.g. the TFPI concentration) at which the effects of these modulators were tested widely varied. Recently, a number of publications indicated that the interactions between TFPI and its modulators not only occur in vitro but that they are also important determinants of the plasma TFPI level (24) and the expression of anticoagulant activity of TFPI in vivo $(25,26)$. To appreciate the physiological effects of TFPI modulators we have quantified their effects on FXa inhibition by TFPI at concentrations that are close to those at which they circulate in plasma. 


\section{Materials and Methods}

\section{Materials}

The chromogenic substrates CS-11(65) (N- $\alpha$-Benzyloxycarbonyl-D-arginyl-glycylL-arginine-p-nitroaniline-dihydrochloride), CBS-2238 (H-D-Phenylalanyl-Lpipecolyl-L-arginine-p-nitroaniline dihydrochloride) and the fluorogenic thrombin substrate I-1140 (Z-Gly-Gly-Arg-AMC-HCl) were purchased from Hyphen BioMed (Mason, OH), Celsus-Biomat BV (Geleen, Netherlands) and Bachem (Bubendorf, Switzerland), respectively. 1,2-Dioleoyl-sn-glycero-3-phosphocholine (DOPC), 1,2-dioleoyl-sn-glycero-3-phosphoserine (DOPS), and 1,2-dioleoyl-snglycero-3-phosphoethanolamine (DOPE) were obtained from Avanti Polar Lipids (Delfzijl, The Netherlands). Phospholipid vesicles were prepared as described earlier (27).

\section{Proteins}

Recombinant human full length TFPI $\left(\mathrm{TFPI}_{1-276}\right)$, produced in a bacterial expression system (Escherichia coli), was kindly provided by T. Lindhout (Cardiovascular Research Institute Maastricht). TFPI ${ }_{1-150}$ was expressed in a bacterial expression system (E. coli) BL21(DE3)pLysS (Merck, Darmstadt, Germany) using the expression vector pET19b (Merck, Darmstadt, Germany). The proteins were purified from inclusion bodies. Cell pellets were solubilised in $8 \mathrm{M}$ 
urea, $20 \mathrm{mM}$ DTT, and $50 \mathrm{mM}$ Tris/ $/ \mathrm{HCl} \mathrm{pH}$ 8.0. TFPI 1-150 $_{\text {was }}$ folded in $50 \mathrm{mM}$ Tris- $\mathrm{HCl} \mathrm{pH}$ 10.0, $1.1 \mathrm{mM}$ oxidized glutathione by rapid dilution followed by dialysis against $20 \mathrm{mM}$ Tris/HCl pH 7.0. Purification was performed by a two-step procedure, a Q-Sepharose column followed by a Streptavidin affinity column with an immobilized peptide specific towards TFPI (28). TFPI and TFPI ${ }_{1-150}$ concentrations were determined by titrating $1 \mathrm{nM}$ bFXa with increasing amounts TFPI or TFPI ${ }_{1-150}(29)$

Human FXa (FXa) and prothrombin were purchased from ERL (Indiana, USA) and bovine FXa (bFXa) was purified from bovine plasma (30). TF (Innovin) was purchased from Siemens Healthcare (Marburg, Germany). Unfractionated heparin was purchased from Leo Pharma (Amsterdam, Netherlands). Fraxiparine, a low molecular weight heparin (LMWH) and fondaparinux (pentasaccharide) were obtained from GlaxoSmithKline (Zeist, Netherlands). Protein S, FV and thrombinactivated FV (FVa) were purchased from Haematologic Technologies Inc. (Vermont, USA).

Inhibition of FXa by TFPI and TFPI ${ }_{1-150}$ in presence of heparin, low molecular weight heparin or pentasaccharide

A reaction mixture containing the FXa-specific chromogenic substrate CS11(65), TFPI or TFPI $\mathrm{T}_{1-150}$ and unfractionated heparin, low molecular weight heparin or pentasaccharide in HNBSA buffer with $3 \mathrm{mM} \mathrm{CaCl}_{2}$ was incubated for 
7 min at $37{ }^{\circ} \mathrm{C}$. Subsequently, FXa was added and chromogenic substrate conversion, which is a measure for non-inhibited FXa, was followed at $405 \mathrm{~nm}$ in an Ultra Microplate Reader (Bio-Tek, Burlington, VT) until a steady state rate of substrate conversion was achieved. The final concentrations in the well were: 0.1 nM FXa, $125 \mu \mathrm{M}$ CS-11(65), $2 \mathrm{nM}$ TFPI or $2 \mathrm{nM}$ TFPI $_{1-150}$, and heparin (0-12.5 $\mathrm{U} / \mathrm{ml}), \mathrm{LMWH}(0-50 \mathrm{U} / \mathrm{mL})$ or pentasaccharide $(0-800 \mu \mathrm{g} / \mathrm{ml})$.

\section{Inhibition of FXa by TFPI in presence of protein S, FV, FVa or prothrombin}

TFPI was incubated for 7 minutes at $37{ }^{\circ} \mathrm{C}$ in HNBSA buffer containing $125 \mu \mathrm{M} \mathrm{CS}(11) 65,3 \mathrm{mM} \mathrm{CaCl} 2,30 \mu \mathrm{M}$ DOPS/DOPC/DOPE (20/60/20, M/M/M) phospholipid vesicles and FV, FVa, protein S or prothrombin. Subsequently, prewarmed FXa was added. Chromogenic substrate conversion, which is a measure for non-inhibited FXa, was followed at $405 \mathrm{~nm}$ in an Ultra Microplate Reader (Bio-Tek, Burlington, VT) for 60 minutes.

Effect of TFPI on prothrombin activation by FXa in the absence and presence of $\mathrm{FVa}$

Different amounts of TFPI $(0-10 \mathrm{nM}), 234 \mu \mathrm{M}$ CBS2238, $100 \mu \mathrm{M}$ phospholipids (20/60/20; DOPS/DOPC/DOPE), $3 \mathrm{mM} \mathrm{CaCl}_{2}$ and $1 \mu \mathrm{M}$ 
prothrombin were preincubated for 7 minutes at $37{ }^{\circ} \mathrm{C}$ in HNBSA buffer. Subsequently, $0.1 \mathrm{nM}$ FXa (without FVa) or $5 \mathrm{pM}$ FXa (with $5 \mathrm{nM} \mathrm{FVa)} \mathrm{was}$ added and thrombin generation, which is a measure for non-inhibited FXa, was followed at $405 \mathrm{~nm}$ in an Ultra Microplate Reader (Bio-Tek, Burlington, VT) for 60 minutes. First derivative of progress curves yield the amount of thrombin generated as function of time at the different TFPI concentrations.

\section{Kinetic Analysis}

Inhibition of FXa by TFPI (Scheme 1) occurs via rapid formation of a loose FXa $\bullet$ TFPI encounter complex that subsequently slowly isomerizes to a tight FXa•TFPI ${ }^{*}$ complex $(8,10)$.

$\mathrm{FXa}+\mathrm{TFPI} \leftrightarrows \mathrm{FXa} \cdot \mathrm{TFPI} \leftrightarrows \mathrm{FXa}^{\mathrm{TFPP}} * \quad$ Scheme 1

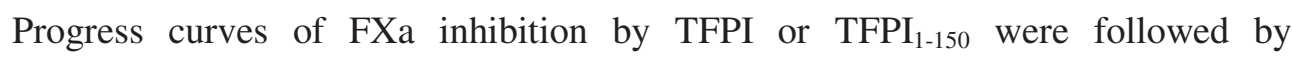
continuous measurement of chromogenic substrate conversion and fitting the data to the integrated rate equation (10) for slow-tight binding inhibition (eq. 1)

$A_{t}=A_{0}+(v s . t)+\left(v_{0}-v_{s}\right) \cdot\left(1-\exp \left(-k_{o b s} \cdot t\right)\right) / k_{\text {obs }}$ eq. 1

where, $A_{t}$ is absorbance at $405 \mathrm{~nm}$ at time $t, A_{0}$ is initial absorbance at $405 \mathrm{~nm}, \mathrm{v}_{\mathrm{s}}$ is final steady state velocity, $\mathrm{v}_{0}$ is initial velocity and $\mathrm{k}_{\mathrm{obs}}$ is the apparent rate constant for the transition from $\mathrm{v}_{0}$ to $\mathrm{v}_{\mathrm{s}}\left(\mathrm{FXa} \bullet \mathrm{TFPI}\right.$ to $\left.\mathrm{FXa} \cdot \mathrm{TFPI}{ }^{*}\right)$. In the results section we have presented both progress curves of chromogenic substrate conversion with lines fitted according to eq. 1 and first derivative of these fits representing the loss 
of FXa activity as function of time. The extent by which the modulators affected the activity of TFPI was calculated from the time required to achieve $50 \%$ inhibition $\left(\mathrm{t}_{1 / 2}\right)$ of FXa by TFPI obtained from the first derivatives of progress curves of FXa inhibition.

\section{Results}

\section{Effect of phospholipids on FXa inhibition by TFPI}

It has been reported that TFPI is a much better FXa inhibitor in the absence than in the presence of $\mathrm{Ca}^{2+}$ ions (31). However, when reaction mixtures in addition to $\mathrm{Ca}^{2+}$ ions contain phospholipid vesicles, TFPI regains its anticoagulant activity and even becomes a better FXa inhibitor than in the absence of $\mathrm{Ca}^{2+}$ ions $(9,31)$.

The stimulatory effect of phospholipids is thought to be due to coordinate binding and positioning of TFPI and FXa on the phospholipid surface (template) which requires the C-terminus of TFPI, the Gla-domain of FXa and the presence of negatively charged phospholipids in the membrane surface (16). Little information is available on the effect of the concentration and composition of phospholipid vesicles on the inhibition of FXa by TFPI. Hence, we determined the effect of varying concentrations of phospholipid vesicles with different composition on FXa inhibition by TFPI. Vesicles composed of dioleoylphosphatidylserine, 
dioleoylphosphatidylethanolamine and dioleoylphosphatidylcholine (DOPS/DOPE/DOPC, 20/20/60, M/M/M) appeared to be more effective than DOPS/DOPC (10/90, M/M) vesicles in stimulating FXa inhibition by TFPI (Fig. 1A-D). A concentration of 5-10 $\mu \mathrm{M}$ DOPS/DOPE/DOPC (20/20/60, M/M/M) was already sufficient to obtain maximal stimulation of FXa inhibition by TFPI, whereas approximately $50 \mu \mathrm{M}$ DOPS/DOPC (10/90) vesicles were required to obtain maximal FXa inhibition by TFPI. Phospholipids had virtually no effect on the inhibition of FXa by TFPI $1-150$ (data not shown).

\section{Effect of heparin on FXa inhibition by TFPI and TFPI constructs}

TFPI and FXa not only bind to phospholipids but also to heparin. TFPI binds to heparin via its KD3-C terminus (32) and FXa binds to heparin via an exosite on the heavy chain comprising the basic residues Arg-93, Lys-96, Arg-125, Arg-165, Lys-169, Lys-236, and Arg-240 (33). In agreement with the literature (34) we observed that unfractionated heparin greatly enhanced FXa inhibition by $0.5 \mathrm{nM}$ TFPI (Fig. 2AB) and that $\mathrm{TFPI}_{1-150}$ which lacks the KD3 and C-terminus was not stimulated by heparin (data not shown). Rather low concentrations of heparin (0.01-0.05 U/mL) already considerably enhanced the inhibitory activity of TFPI and optimal stimulation was observed at $0.2 \mathrm{U} / \mathrm{mL}$. 

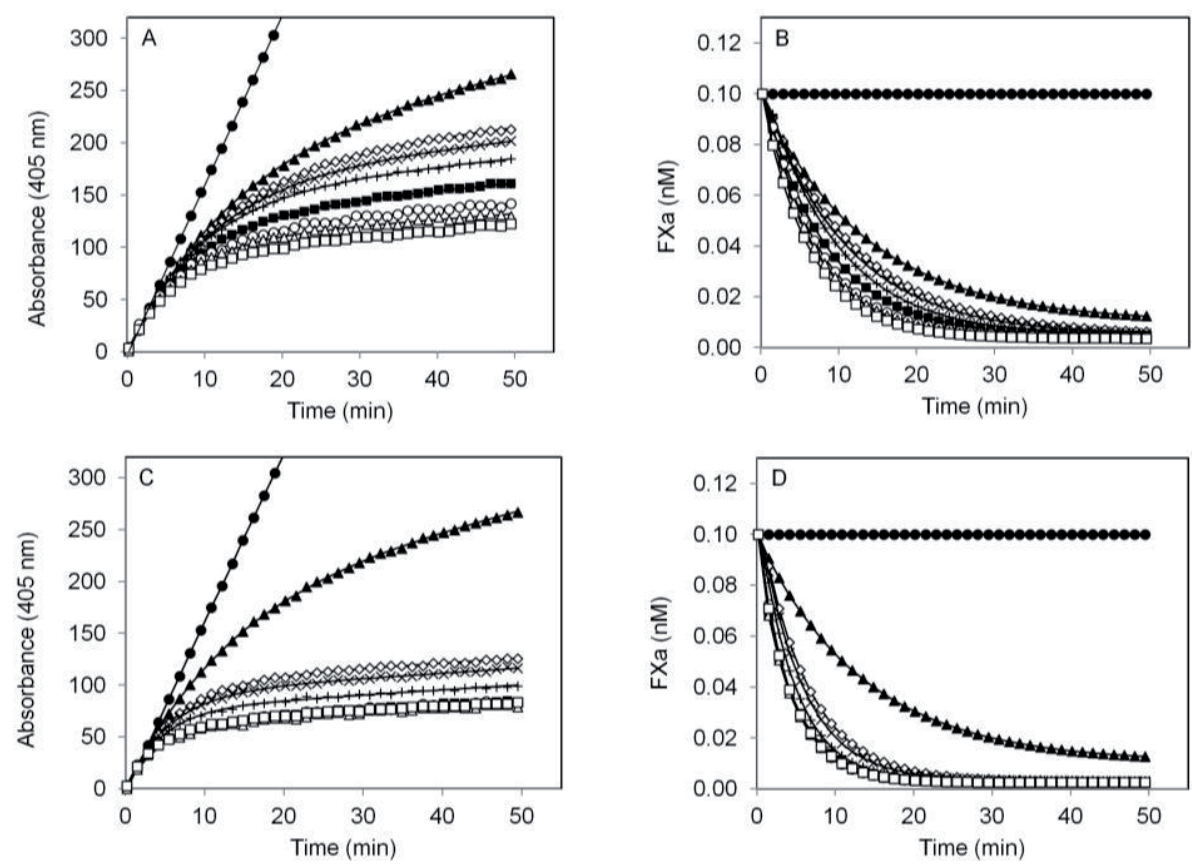

Figure 1: Effect of phospholipids on FXa inhibition by TFPI.

Progress curves of conversion of $125 \mu$ M CS(11)65 by 0.1 nM FXa, 2 nM TFPI and 3 mM $\mathrm{CaCl}_{2}$ were determined at different phospholipid concentrations as described in the experimental procedures. The closed dots (•) represent CS(11)65 conversion by FXa in the absence of TFPI and phospholipids. With TFPI, the phospholipid concentrations were 0 $\mu M(\mathbf{\Delta}), 1 \mu M(\diamond), 2 \mu M(\times), 5 \mu M(+), 10 \mu M(\mathbf{\square}), 30 \mu M(\circ), 50 \mu M(\Delta)$ or $80 \mu M(\square)$ 10/90 DOPS/DOPC vesicles (A) or 20/60/20 DOPS/DOPC/DOPE vesicles (C). The progress curves of CS(11)65 conversion were fitted to eq. 1 and first derivatives of the fits, which represent inhibition of FXa as function of time, are shown in panels $B$ (10/90 DOPS/DOPC) and D (20/60/20 DOPS/DOPC/DOPE). 
At higher heparin concentrations the stimulatory effect gradually disappeared and at a concentration $>100 \mathrm{U} / \mathrm{mL}$ heparin even counteracted TFPI inhibition of FXa. FXa inhibition of TFPI was also enhanced by low molecular weight heparin (Fig. 2CD). However, low molecular weight heparin appeared to be less effective in TFPI stimulation than unfractionated heparin.

A chemically synthesized pentasaccharide which mimics the heparin site that binds to AT and which enhances inhibition of FXa by AT but which does not bind to FXa had, even at concentrations 200-fold higher than required for full inhibition of thrombin generation in plasma, no effect on FXa inhibition by TFPI (data not shown). This indicates that pentasaccharide does not act as a template that enhances FXa inhibition by TFPI. We also tested the effect of heparin on the inhibition of TF:FVIIa-catalysed FX activation by TFPI. Heparin was less effective in stimulating TFPI inhibition of TF:FVIIa-catalysed FX activation than inhibition of FXa. Up to $0.2 \mathrm{U} / \mathrm{mL}$ heparin had virtually no effect on the inhibition of FX activation by TFPI, but higher heparin concentrations considerably enhanced the inhibitory activity of TFPI. Fig. 3 shows the results of an experiment in which we determined the effect of varying TFPI concentrations on TF:FVIIa-catalysed FX activation in the absence (Fig. 3A) and presence of $0.5 \mathrm{U} / \mathrm{mL}$ unfractionated heparin (Fig. 3B). 

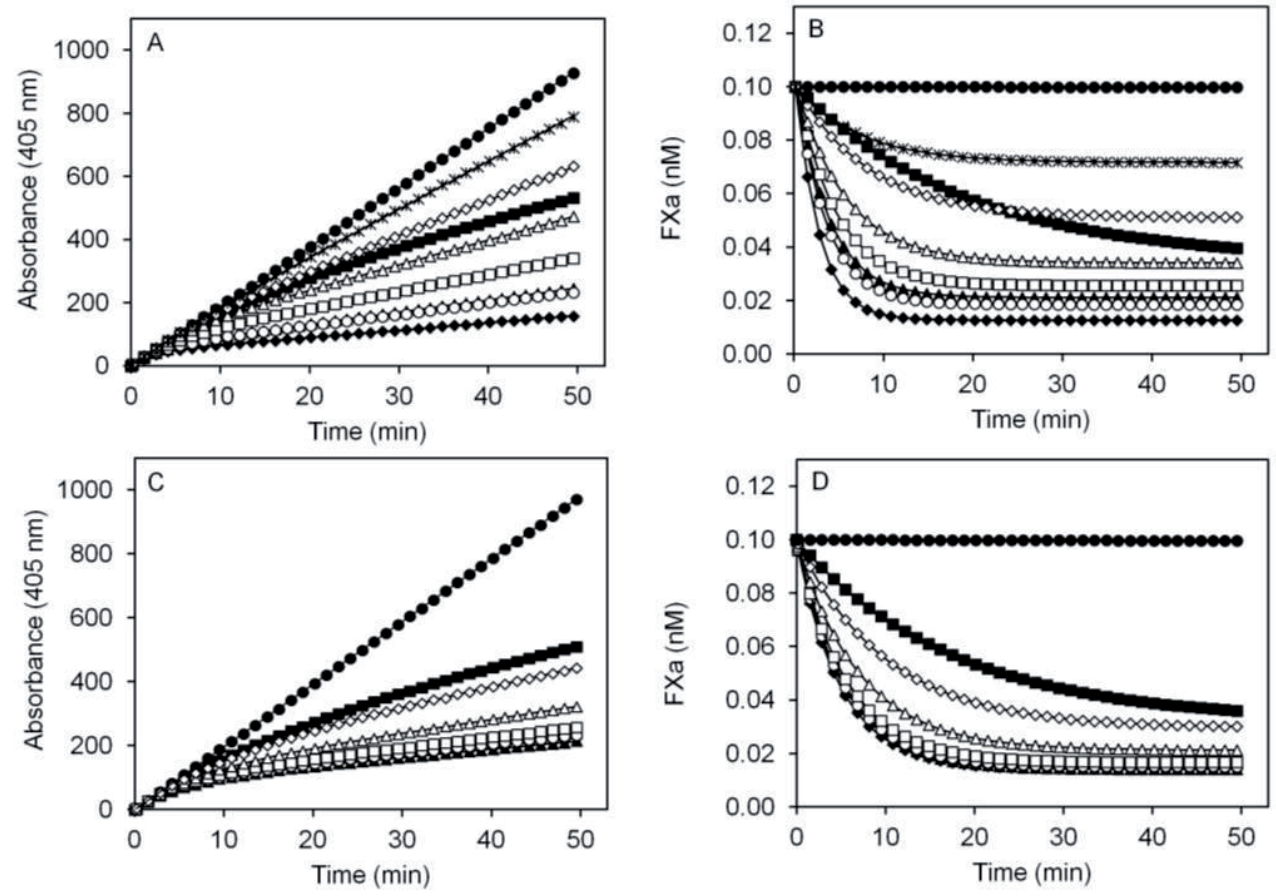

Figure 2: Effect of heparin and low molecular weight heparin on FXa inhibition by TFPI.

Progress curves of conversion of $125 \mu M$ CS(11)65 by 0.1 nM FXa, 0.5 nM TFPI and 3 $m M \mathrm{CaCl}_{2}$ were determined at different heparin concentrations as described in the experimental procedures. The closed dots (•) represent CS(11)65 conversion by FXa in the absence of TFPI and heparin. With TFPI, the heparin concentrations were, $0 \mathrm{U} / \mathrm{ml}$ (-), $0.01 \mathrm{U} / \mathrm{ml}(\mathbf{\Delta}), 2.0 \mathrm{U} / \mathrm{ml}(\diamond), 20 \mathrm{U} / \mathrm{ml}$ (०), $50 \mathrm{U} / \mathrm{ml}$ (口), $100 \mathrm{U} / \mathrm{ml}(\Delta), 200 \mathrm{U} / \mathrm{ml}(\diamond), 500$ $\mathrm{U} / \mathrm{ml}$ (*) unfractionated heparin (panel A) or $0 \mathrm{U} / \mathrm{ml}(\mathbf{\bullet}), 1.0 \mathrm{U} / \mathrm{ml}(\mathbf{\Delta}), 2.0 \mathrm{U} / \mathrm{ml}(\bullet), 5.0$ $\mathrm{U} / \mathrm{ml}(\circ), 10 \mathrm{U} / \mathrm{ml}(\square), 20 \mathrm{U} / \mathrm{ml}(\Delta), 50 \mathrm{U} / \mathrm{ml}(\diamond)$ low molecular weight heparin (panel C). The progress curves of CS(11)65 conversion were fitted to eq. 1 and first derivatives of the fits which represent inhibition of FXa as function of time are shown in panel $B$ for unfractionated heparin and panel D for low molecular weight heparin. 
Heparin considerably enhanced the inhibition of FXa generation both at low and at high TFPI concentrations. At $0.025 \mathrm{nM}$ and $0.05 \mathrm{nM}$ TFPI, which are TFPI concentrations well below the plasma TFPI concentration $(0.25-0.5 \mathrm{nM})$, virtually no inhibition of FX activation was observed in the absence of heparin while in the presence of heparin FX activation was completely blocked within 2 $\min$.

Since $0.025-0.05$ nM TFPI can quantitatively not account for the reduction in the amount of FXa that was generated $(1.5 \mathrm{nM})$ via direct inhibition of FXa, we conclude that heparin stimulates the inhibition of TF:FVIIa by TFPI by enhancing quaternary complex formation. However, at high TFPI concentrations $(0.5 \mathrm{nM}$ and $1 \mathrm{nM}$ ) stimulation of direct inhibition of FXa by TFPI may contribute to the reduction of FXa generation in the presence of heparin.

\section{Effect of protein $\mathrm{S}$ and FV on the inhibition of FXa by TFPI}

It has been reported that in reaction mixtures that contain phospholipids and $\mathrm{Ca}^{2+}-$ ions inhibition of FXa by full length TFPI is stimulated by protein S and that protein S does not enhance FXa inhibition by a truncated TFPI that lacks KD3 and C-terminus (22). Furthermore, it was demonstrated that protein S binds to the KD3 domain of TFPI (35) and that part of the TFPI present in plasma is bound to protein S (24). A possible explanation for the TFPI cofactor activity of protein $S$ is that the protein S-TFPI complex binds to phospholipids via the Gla-domain of protein S 
thus increasing the concentration TFPI that is bound to the phospholipid surface and promoting the inhibition of phospholipid-bound FXa $(11,22,36)$.
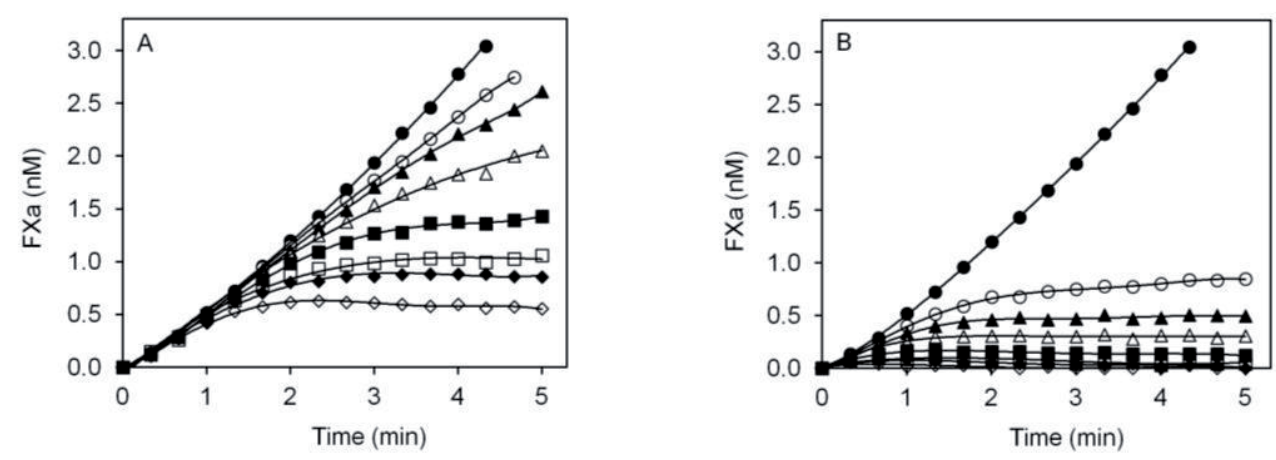

Figure 3: Effect of unfractionated heparin on the inhibition of TF-FVIIa-catalyzed FX activation by TFPI.

Progress curves of FXa generation during the activation of 100 nM FX by 2 pM FVIIa, 5 $n M T F$ (25 $\mu$ M phospholipid) and $3 \mathrm{mM} \mathrm{CaCl}_{2}$ were determined with, $200 \mu \mathrm{M} \mathrm{CS}-11(65)$ at varying TFPI concentrations in the absence (A) and presence (B) of $0.5 \mathrm{U} / \mathrm{ml}$ unfractionated heparin. The TFPI concentrations were $0 \mathrm{nM}(\bullet), 0.025 \mathrm{nM}(\mathrm{0}), 0.05 \mathrm{nM}$ $(\mathbf{\Delta}), 0.1 n M(\Delta), 0.2 n M(\mathbf{\square}), 0.35 n M(\square), 0.5 n M(\diamond)$ and $1 n M(\diamond)$ TFPI. The lines shown in the figure, which represent the FXa that is generated in the reaction mixture as function of time, are the first derivatives of the progress curves of p-nitroaniline produced from CS11(65).

Castoldi et al. (37) showed that FV also forms a complex with TFPI and that part of the full length TFPI present in plasma circulates in complex with FV. On the basis of these observations we decided to investigate whether FV, like protein $\mathrm{S}$, may also stimulate FXa inhibition by TFPI. 
Fig. 4A,B shows that a physiological concentration FV $(20 \mathrm{nM})$ indeed enhanced FXa inhibition by TFPI and had a stimulatory effect that was quantitatively similar to $80 \mathrm{nM}$ protein $\mathrm{S}$. When both $\mathrm{FV}$ and protein $\mathrm{S}$ were present in the reaction mixture stimulation of TFPI was even more pronounced. The first derivatives of progress curves of FXa inhibition which represent the loss of FXa activity as a function of time (Fig. 4B) show that both FV and protein S enhance encounter complex formation (see Scheme 1) as illustrated by the more pronounced loss of FXa activity immediately after mixing FXa and TFPI. Like protein S, FV only stimulates FXa inhibition by full length TFPI and not by TFPI ${ }_{1}$. 150 (data not shown). We also demonstrated that thrombin-cleaved protein S, which is not active as cofactor of APC in FVa inactivation (38), has the same cofactor activity as non-cleaved protein $\mathrm{S}$ in FXa inhibition by TFPI (K. Winckers et al. manuscript in preparation).

The experiment presented in Fig. 4A,B was performed at single protein $\mathrm{S}$ $(80 \mathrm{nM})$ and FV $(20 \mathrm{nM})$ concentrations. Protein $\mathrm{S}$ and FV titrations at a fixed TFPI concentration $(0.5 \mathrm{nM})$ showed that a very low protein $\mathrm{S}$ concentration (10 nM) already fully stimulates TFPI and that FV enhances FXa inhibition by TFPI with an $\mathrm{EC}_{50}$ of $\sim 5 \mathrm{nM}$ (Fig. 4C,D). 

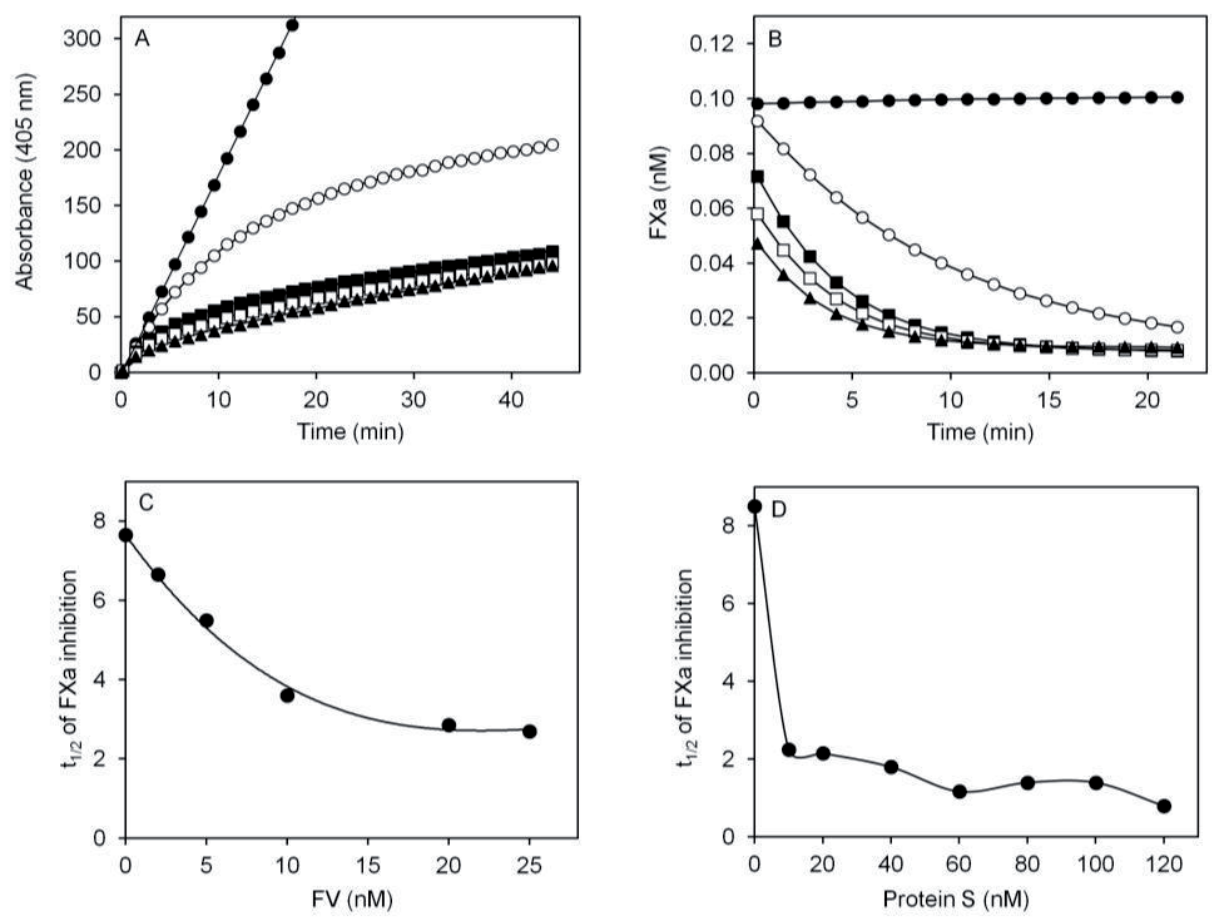

Figure 4. Effect of protein $S$ and FV on FXa inhibition by TFPI.

(A) Progress curves of conversion of $125 \mu \mathrm{M} \mathrm{CS(11)65} \mathrm{by} 0.1 \mathrm{nM} \mathrm{FXa}, 3 \mathrm{mM} \mathrm{CaCl} 2$ and $30 \mu \mathrm{M}$ phospholipids (20/60/20 DOPS/DOPC/DOPE) and no TFPI (•), 0.5 nM TFPI (०), $0.5 \mathrm{nM}$ TFPI and $20 \mathrm{nM} \mathrm{FV}(\mathbf{\square}), 0.5 \mathrm{nM}$ TFPI and $80 \mathrm{nM}$ PS (口) and $0.5 \mathrm{nM}$ TFPI, $20 \mathrm{nM}$ $F V$ and $80 \mathrm{nM} P S(\mathbf{\Delta})$. (B) First derivative of the data shown in panel A representing FXa generation as function of time. (C,D) Effect of varying $F V(C)$ and protein $S(D)$ concentrations on FXa inhibition by TFPI. The experiment was performed as described at panel $A / B$ at $F V$ and protein $S$ concentrations indicated in the figure. Plotted is $t_{1 / 2}$ (time required to inhibit $50 \%$ of FXa present) as function of the FV or protein $S$ concentration ( $t_{1 / 2}$ was obtained from progress curves of FXa inhibition like presented in panel B). 

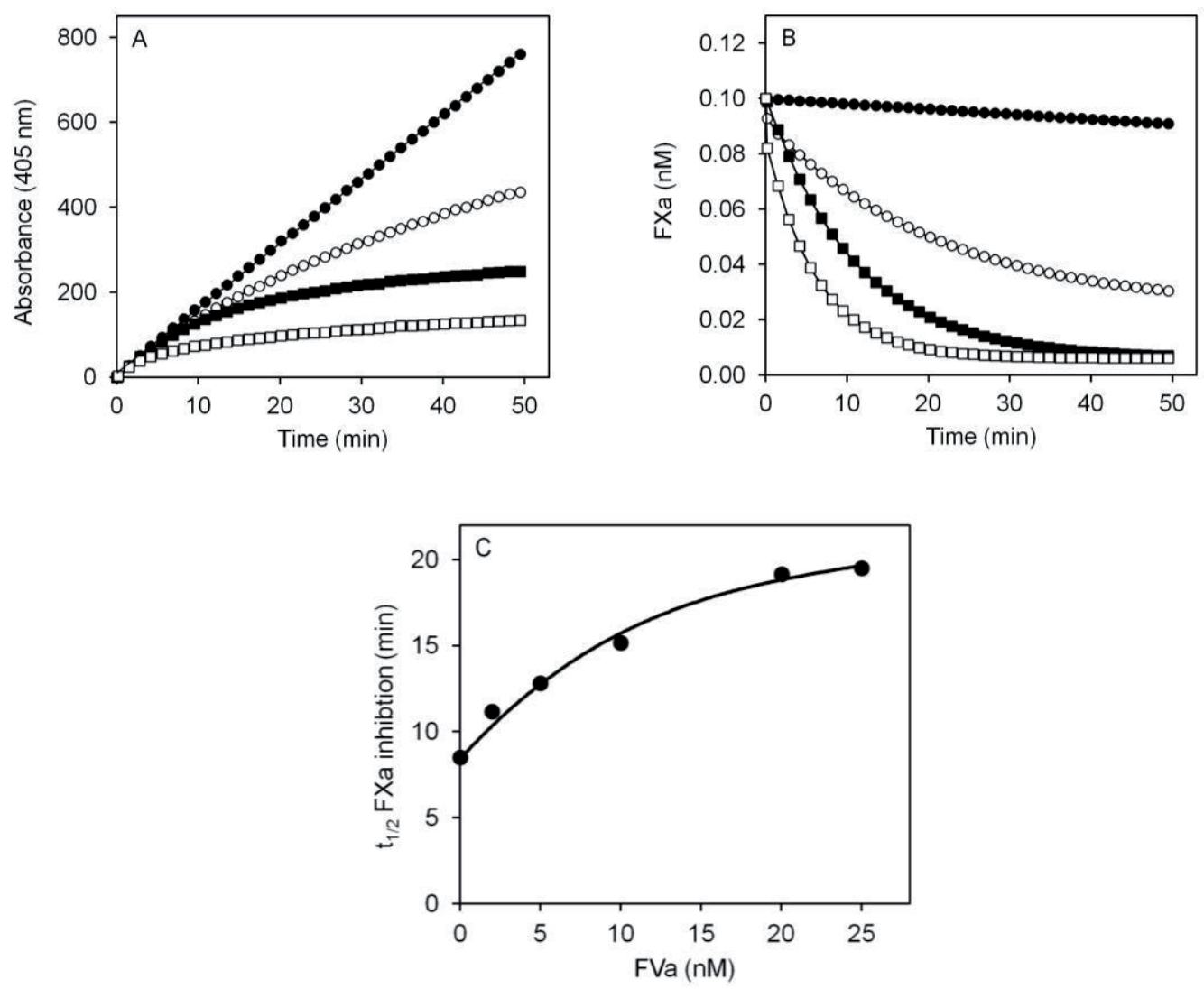

Figure 5. Effect of FV and FVa on FXa inhibition by TFPI.

(A) Progress curves of conversion of $125 \mu \mathrm{M} \mathrm{CS}(11) 65$ by $0.1 \mathrm{nM} \mathrm{FXa}, 3 \mathrm{mM} \mathrm{CaCl} \mathrm{Cl}_{2}$ and $30 \mu M$ phospholipids (20/60/20 DOPS/DOPC/DOPE) and 0 nM TFPI (•), 0.5 nM TFPI (ロ), $0.5 n M$ TFPI and $20 n M F V a(0)$, and $0.5 n M$ TFPI and $20 n M F V$ (口). (B) First derivative of the data presented in panel A representing FXa generation as function of time. (C) Effect of varying FVa (concentrations on FXa inhibition by TFPI. The experiment was performed as described at panel $A / B$ at FVa concentrations indicated in the figure. Plotted is $t_{1 / 2}$ (time required to inhibit $50 \%$ of FXa present) as function of the FVa ( $t_{1 / 2}$ was obtained from progress curves of FXa inhibition like presented in panel B). 

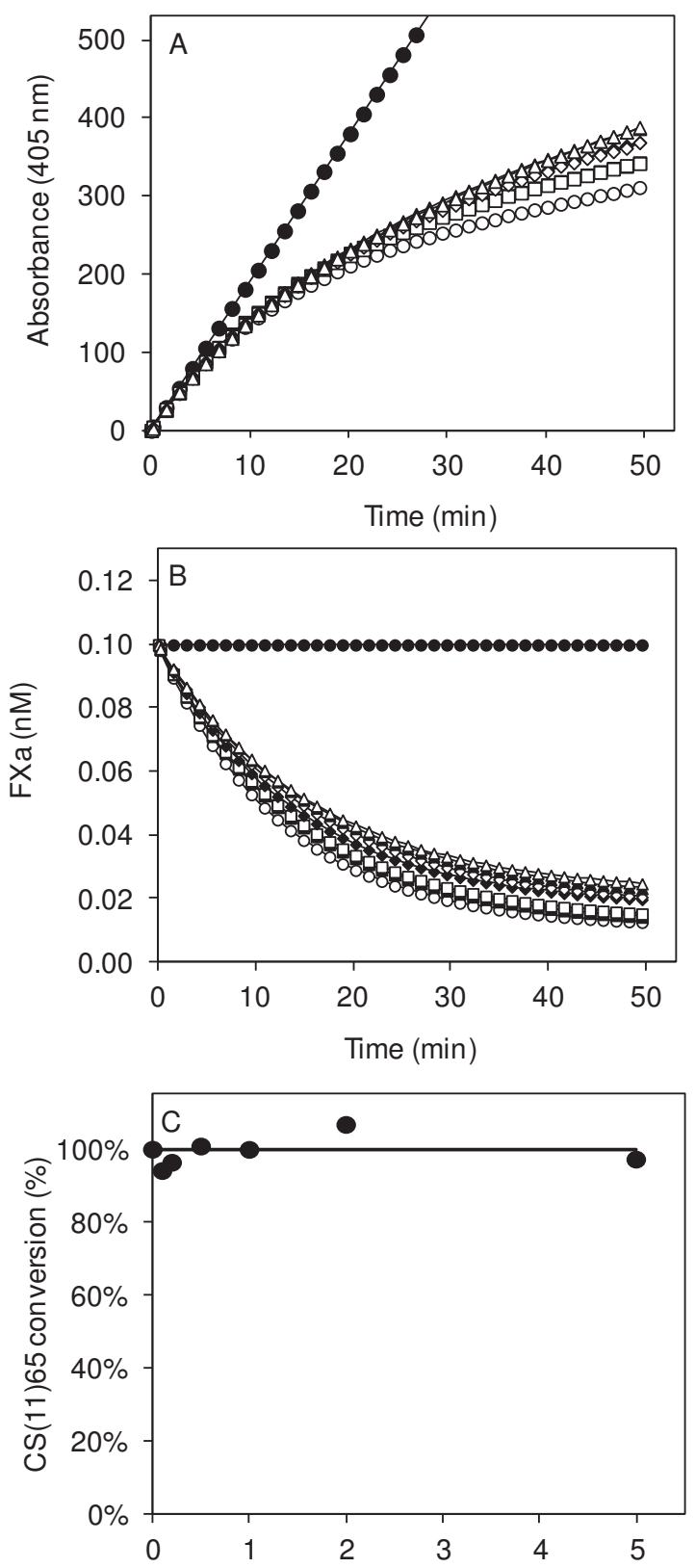

Prothrombin $(\mu \mathrm{M})$
Figure 6. Effect of prothrombin on FXa inhibition by TFPI and on chromogenic substrate conversion by $\mathrm{FXa}$.

(A) Progress curves of conversion of $125 \mu M$ CS(11)65 by 0.1 nM FXa, 3 $m \mathrm{MCaCl}_{2}$ and $30 \mu \mathrm{M}$ phospholipids (20/60/20 DOPS/DOPC/DOPE) and 0 nM TFPI (•), 0.5 nM TFPI (०), and 0.5 nM TFPI in the presence of $0.1 \mu M$ prothrombin (匹), $0.2 \mu M$ prothrombin (口), $0.5 \quad \mu M$ prothrombin (४), $1 \mu M$ prothrombin

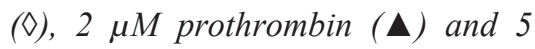
$\mu M$ prothrombin ( $\Delta)$. (B) First derivative of the data presented in panel $A$ representing $F X a$ activity as function of time. (C) Effect of varying prothrombin concentrations on the rate of chromogenic substrate conversion (125 $\mu M$ CS(11)65) by $0.2 \mathrm{nM} \mathrm{FXa}$ in the presence of $3 \mathrm{mM}$ $\mathrm{CaCl}_{2}$ and $100 \mu \mathrm{M}$ phospholipids (20/60/20 DOPS/DOPC/DOPE). 


\section{Effect of FVa on the inhibition of FXa by TFPI}

Recently it was reported that the C-terminus of TFPI contains a basic sequence that binds with a rather high affinity to an acidic region in the B-domain of FV which is located close to what becomes the light chain of FVa after activation of FV with thrombin $(39,40)$. Furthermore, it was demonstrated that activation of FV with thrombin, which results in the removal of the B-domain of FV, yields a form of FVa that lacks the above-mentioned acidic region and hence does not bind TFPI (40).

In Fig. $5 \mathrm{AB}$ it is shown that FVa, obtained after activation of FV with thrombin and removal of the B-domain via purification, protects FXa against inhibition by TFPI. From the data presented in Fig. 5B it can be calculated that at $0.5 \mathrm{nM}$ TFPI, which is a concentration close to the plasma TFPI concentration, the $t_{1 / 2}$ of FXa inhibition by TFPI increased from $3.6 \mathrm{~min}$ (with FV) to $8.3 \mathrm{~min}$ (no FV and no FVa) to $20.2 \mathrm{~min}$ (with FVa). These changes of $t_{1 / 2}$ indicate that at physiological TFPI concentrations FV enhanced the activity of TFPI $~ 2.5$-fold, whereas the same concentration of FVa inhibited the TFPI activity on FXa $\sim 2.5$-fold. FVa only partially protects FXa against inhibition by TFPI with an $\mathrm{EC}_{50}$ of $\sim 10 \mathrm{nM}$ (Fig. $5 C)$. 


\section{Effect of prothrombin on the inhibition of FXa by TFPI}

Since TFPI is an active site-directed inhibitor of FXa, one might expect that prothrombin, which is the natural substrate of FXa, can compete with TFPI for the active site of FXa and protect FXa against inhibition by TFPI. We tested the effect of prothrombin on FXa inhibition by TFPI in the presence of phospholipids and $\mathrm{Ca}^{2+}$ ions. It appeared that prothrombin concentrations up to $5 \mu \mathrm{M}$, which is more than 10 -fold above the Km value (41) hardly protected FXa against inhibition by TFPI (Fig. 6AB). Together with the observation that $5 \mu \mathrm{M}$ prothrombin also had virtually no effect on the amidolytic activity of FXa (Fig. 6C) this suggests that, the active site of FXa is not occupied by prothrombin and is still accessible for chromogenic substrate as well as TFPI despite the fact that the prothrombin concentration is far above the $\mathrm{Km}$. The experiment presented in Fig. $6 \mathrm{C}$ shows that the low amount of thrombin that is formed in the reaction mixture (Fig. 6A-C) does not contribute to the conversion of the FXa-specific chromogenic substrate.

Effect of TFPI on FXa-catalysed prothrombin activation in presence and absence of $\mathrm{FVa}$

TFPI may actually have two anticoagulant effects: 1) the formation of a quaternary TFPI-FXa-TF-FVIIa complex which shuts down the extrinsic 
coagulation pathway $(3,42)$ and 2$)$ direct inhibition of FXa which will reduce FXacatalysed prothrombin activation.

The effect of TFPI on FXa-catalysed prothrombin activation was determined in the absence and presence of FVa. Prothrombin activation was started by adding FXa to reaction mixtures that contained prothrombin, phospholipid vesicles, $\mathrm{Ca}^{2+}$ ions, the thrombin-specific chromogenic substrate S2238 and varying TFPI concentrations either in the absence or presence of FVa. Rates of thrombin formation, obtained from the progress curves of S2238 conversion, were expressed as percentage of the rate obtained in the absence of TFPI and plotted as function of the TFPI concentration (Fig. 7). Prothrombin activation in the absence of FVa was readily inhibited by TFPI with an $\mathrm{IC}_{50}$ of $\sim 1 \mathrm{nM}$ whereas FXa-catalysed prothrombin activation in the presence of FVa was hardly inhibited by TFPI (less than $15 \%$ inhibition at $10 \mathrm{nM}$ TFPI). The protection of FXa for inhibition by TFPI in the presence of $\mathrm{FVa}$ and prothrombin was much more pronounced than the protection of FXa by FVa alone (cf. Fig. 5) or prothrombin alone (Fig. 6). This indicates that the presence of both FVa and prothrombin are required to fully protect $\mathrm{FXa}$ against inhibition by TFPI (see also discussion). 


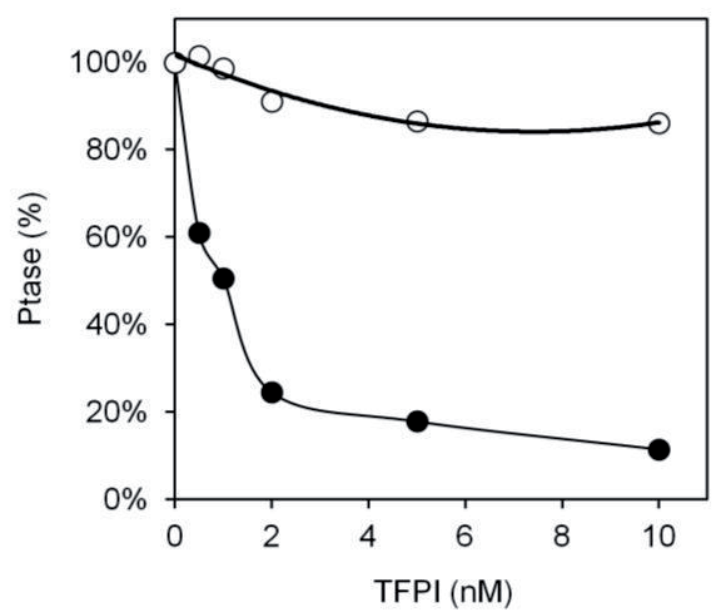

Figure 7. Effect of TFPI on FXa-catalysed prothrombin activation with and without FVa.

Rates of activation of $1 \mu M$ prothrombin by $0.1 \mathrm{nM} F X a(\bullet)$ or $0.5 \mathrm{pM} \mathrm{FXa}$ and $5 \mathrm{nM} F V \mathrm{a}$ (०) in presence of $3 \mathrm{mM} \mathrm{CaCl}, 100 \mu \mathrm{M}$ phospholipids (20/60/20 DOPS/DOPC/DOPE) and varying concentrations TFPI (0-10 nM) were determined with the thrombin-specific chromogenic substrate S2238 and expressed as \% of the rate determined in the absence of TFPI. 


\section{Discussion}

Blood coagulation is a tightly regulated process which involves many proteinprotein and protein-phospholipid interactions. We intended to understand the role of various exosite-binding molecules in the regulation of FXa inhibition by TFPI. It is well established that TFPI can directly inhibit FXa and that TFPI together with FXa and TF:FVIIa forms a quaternary complex that shuts down the extrinsic coagulation pathway (7). Since blood coagulation takes place in a complex environment (blood) that contains many proteins and compounds that can interact with FXa and TFPI, we have investigated the effect of various plasma proteins and non-proteinic plasma compounds that bind to factor Xa and/or TFPI on the inhibition of FXa by TFPI.

Soon after the discovery of TFPI, than called LACI (3) or EPI (1), it was reported that TFPI binds to negatively charged phospholipid vesicles (16) and that phospholipids in the presence of $\mathrm{Ca}^{2+}$ ions stimulate FXa inhibition by TFPI (9). Since relatively little is known about the phospholipid requirement we investigated the effects of phospholipid concentration and composition on FXa inhibition by TFPI. It appears that relatively low concentrations of phospholipids $(10 \mu \mathrm{M})$ are required for optimal stimulation of inhibition and that phospholipid vesicles composed of DOPS/DOPE/DOPC (20/20/60 M/M/M) are more effective in enhancing the inhibitory activity of TFPI than vesicles containing less DOPS and no DOPE (DOPS/DOPC (10/90 M/M). The stimulatory effects of phospholipids on 
enzymatic reactions and protein-protein interactions within the haemostatic system are generally thought to be the result of a template mechanism in which simultaneous but independent binding of two proteins (e.g. enzyme and substrate) to phospholipid membranes promotes the association and reaction between the proteins $(43)$. Since both TFPI and FXa $(9,44)$ have been reported to bind to phospholipids such a mechanism may also explain the stimulatory effect of phospholipids on FXa inhibition by TFPI. However, the affinity of TFPI for negatively charged membranes particularly in the presence of $\mathrm{Ca}^{2+}$-ions is rather low (16), whereas TFPI in complex with FXa binds with a very high affinity (Kd $5 \mathrm{nM}$ ) to phospholipid bilayers (45). Since TFPI has a low affinity for phospholipids it is difficult to envision that phospholipid concentrations of $10 \mu \mathrm{M}$ already give maximal stimulation of FXa inhibition. Together with the observation that excess phospholipids does not diminish enhancement of TFPI inhibition of FXa makes it questionable whether the stimulatory effect of phospholipids on FXa inhibition by TFPI is explained by a template model. Considering the high affinity of TFPI-FXa complex for phospholipids there is an alternative mechanism by which phospholipids can stimulate FXa inhibition by TFPI and that is by binding the TFPI-FXa encounter complex that is formed in free solution. FXa inhibition by TFPI occurs via a so-called slow-tight binding mechanism (8) which consists of two steps in which in step 1 rapidly a small amount of TFPI-FXa complex (the socalled encounter complex) is formed which in step 2 is slowly isomerises to a tight 
TFPI-FXa complex (Scheme 1). If the encounter complex formed in step 1 binds with a high affinity to phospholipids i.e. phospholipids act as a sink for the product of step 1, the reaction is pulled to the right resulting in stimulation of FXa inhibition by TFPI.

Heparin is a highly sulphated glycosaminoglycan which binds both FXa and TFPI and which has been reported to stimulate FXa inhibition by TFPI $(9,46)$. We investigated the effect of heparin and heparin derivatives on the inhibition of FXa and TF:FVIIa-catalysed FX activation by TFPI. We confirmed older data that both unfractionated heparin and low molecular weight heparin $(13,47)$ stimulate FXa inhibition by TFPI in a concentration-dependent manner and that pentasaccharide has no effect on FXa inhibition (48). The stimulatory effect of heparin on FXa inhibition by TFPI likely occurs via a template mechanism since a heparin titration over a wide concentration range showed that stimulation exhibits an optimum after which it becomes gradually less and at high concentrations (> 500 U/mL) heparin even inhibits FXa inhibition by TFPI. It is interesting to note that very low heparin concentrations $(0.05 \mathrm{U} / \mathrm{mL})$ already enhance FXa inhibition by TFPI $\sim 8$-fold.

There are no studies on the direct effect of heparin on the inhibition of TF:FVIIa-catalysed FX activation. Jesty et al (49) investigated the effect of heparin on the inhibition of FX activation by preformed FXa-TFPI complexes and showed that heparin did not stimulate but slow down the inhibition of TF:FVIIa-catalysed FX activation by TFPI-FXa complex approximately 3 -fold. We determined the 
effect of heparin on FX activation by TFPI and demonstrated that heparin stimulates the ability of TFPI to inhibit FX activation by TF:FVIIa. It should be emphasized that in the case of FX activation it is difficult to distinguish between effects of heparin on TFPI inhibition of the product FXa and on inhibition of TFFVIIa i.e. stimulation of quaternary complex formation by heparin. However, Fig. 3 shows that heparin considerably enhanced the inhibition of FXa activation by $0.025 \mathrm{nM}$ TFPI which is a TFPI concentration that is too low to quantitatively account for the reduction in the amount of FXa that was generated $(1.5 \mathrm{nM})$ via direct FXa inhibition, which demonstrates that heparin stimulates the inhibition of TF:FVIIa by TFPI. This effect may be explained by heparin stimulation of the formation of the binary TFPI-FXa complex with FXa produced in situ by the extrinsic Xase and subsequent enhancement of quaternary complex formation resulting in more pronounced inhibition of TF:FVIIa-catalysed FX activation. These data show that during treatment of patients heparin actually can express anticoagulant effects via three independent mechanisms i.e. 1) potentiation of inhibition of activated coagulation factors by antithrombin $(50), 2)$ promoting the release of TFPI from endothelial cells (13) and 3) enhancing inhibition of FXa and TF:FVIIa by TFPI.

It has been reported that both protein $\mathrm{S}$ and FV bind to TFPI and that the major part of full length TFPI present in plasma circulates in complex with FV (37) and protein S (24). Protein S binds via its SHBG-like domain (36) to the KD3 
domain of TFPI and stimulates FXa inhibition by TFPI (35). It has been proposed that the protein S-TFPI complex binds to phospholipids thereby increasing the concentration of phospholipid-bound TFPI and bringing TFPI and FXa into proper juxtaposition for encounter complex formation, which results in a stimulation of FXa inhibition by TFPI $(11,22,36)$. With respect to TFPI-FV interaction it was recently shown that an alternatively spliced form of FV (FV-short) which is present in small amounts in plasma of healthy individuals binds TFPI with a high affinity (51). FV-short was discovered in a patient with a splicing mutation that substantially increases both the plasma FV-short and the plasma TFPI concentration and that that is associated with the so-called east Texas bleeding disorder (51). Later it was shown that a small positively charged amino acid sequence of the C-domain of TFPI binds to an acidic region in the C-terminus of the B-domain of FV that is exposed in FV-short $(39,40)$ and that is removed after activation of FV by thrombin. Since the interactions of protein S and FV with TFPI share many similarities we have compared the effects of protein S, FV and FVa on FXa inhibition by TFPI. Physiological concentrations of protein S and FV stimulate the inhibition of FXa by $0.5 \mathrm{nM}$ TFPI some 3- to 4-fold and the combination of protein S plus FV increases the anticoagulant activity of TFPI $\sim 5$ fold (Fig. 4). With respect to FV, Mast and Broze (21) showed that FV also enhanced FXa inhibition by TFPI at a high TFPI concentration (5 nM). Stimulation of TFPI by protein S and FV is only observed in the presence of phospholipids and 
requires the presence of the KD3-C terminus of TFPI since protein $\mathrm{S}$ and $\mathrm{FV}$ did not enhance of FXa inhibition by truncated forms of TFPI (TFPI $\left.{ }_{1-150}\right)$. Inspection of progress curves of FXa inhibition shows that protein S and FV have two effects on TFPI inhibition of FXa. They both promote the formation of the encounter complex as illustrated by the increase of the instantaneous inhibition of an appreciable amount of FXa (Fig. 4), which subsequently results a faster tight complex formation by increasing the apparent first order rate constant $\left(\mathrm{k}_{\mathrm{obs}}\right)$ for the transition of the weak to the tight TFPI-FXa complex (see equation 1). FV and protein $\mathrm{S}$ titrations show that $\mathrm{FV}$ and protein $\mathrm{S}$ stimulated FXa inhibition by 0.5 $\mathrm{nM}$ TFPI with $\mathrm{EC}_{50}$ 's of $1.8 \mathrm{nM}$ and below $10 \mathrm{nM}$, respectively which is well below their plasma concentration. Also Ndonwi and Broze (52) reported a low protein $\mathrm{S}$ requirement $\left(\mathrm{IC}_{50}=10 \mathrm{nM}\right)$ for the enhancement of $\mathrm{FXa}$ inhibition by TFPI. In contrast to FV, purified thrombin-activated FV (FVa) inhibited FXa inhibition by $0.5 \mathrm{nM}$ TFPI approximately 2-fold (Fig. 5) with an $\mathrm{EC}_{50}$ of $5.2 \mathrm{nM}$ (Fig. 5). This observation contrasts an earlier report of Huang et al. (9) who demonstrated that FVa enhances FXa inhibition by TFPI by lowering the the $\mathrm{K}_{\mathrm{i}}$ for encounter complex formation $\sim 7$-fold. However, the $\mathrm{K}_{\mathrm{i}}$ of TFPI determined by Huang et al. (9) in the presence of FVa was $2.4 \mathrm{nM}$ which is considerably higher than the TFPI concentration $(0.5 \mathrm{nM})$ used in our experiments. Indeed we observed (data not shown) that at $5 \mathrm{nM}$ TFPI FVa did not affect the activity of TFPI in the early phase of FXa inhibition, but slowed down the transition of the 
encounter to the tight FXa-TFPI complex, a phenomenon was also reported by Mast and Broze (21).

Since TFPI is an active-site directed inhibitor of FXa, one might expect that substrates of FXa compete with TFPI for occupation of the active site and thereby protect FXa against inhibition by TFPI. However, we observed that in the presence of $\mathrm{Ca}^{2+}$-ions and negatively charged phospholipid vesicles the natural FXa substrate prothrombin hardly affected inhibition of FXa by TFPI (Fig. 6AB) at prothrombin concentrations far above the Km for prothrombin i.e. at conditions at which FXa is saturated with its substrate prothrombin. Since prothrombin also had no effect on the conversion of the FXa-specific chromogenic substrate CS11(65) (Fig. 6C) this indicates that even at saturating prothrombin concentrations the active site of FXa is available for inhibition by TFPI and for chromogenic substrate conversion indicating that prothrombin is actually bound to a secondary binding site on FXa without occupying the active site $(53,54)$. Fig. $7 \mathrm{~A}$ shows that at prothrombin concentrations $(5 \mu \mathrm{M})$ that are 10 -fold above the $\mathrm{Km}$ for prothrombin, which was $0.5 \mu \mathrm{M}$ at the conditions of this experiment (data not shown), TFPI is a very potent inhibitor of FXa-catalyzed prothrombin activation. However, in the presence of FVa, TFPI hardly inhibits FXa-catalyzed prothrombin activation (Fig. 7A). Since the presence of FVa can quantitatively not account for the lack of inhibition (Fig. 7) this indicates that under these conditions prothrombin protects FXa against inhibition by TFPI an observation that was made earlier also by other 
research groups (23). However, we observed that prothrombin does not protect FXa from inhibition by TFPI when there is no FVa and only protects FXa that is in complex with FVa (Fig. 7). Apparently, FVa promotes the transition of prothrombin bound at secondary binding site with a free active site to a form of FXa-bound prothrombin that interacts with the active site of FXa and that protects FXa against inhibition by TFPI. This phenomenon may be responsible for the dramatic increase of the $\mathrm{k}_{\mathrm{cat}}$ of prothrombin activation caused by $\mathrm{FVa}$ (55).

In summary, our data show several plasma proteins involved in coagulation modulate the anticoagulant activity of TFPI. These modulating effects should be taken into account when considering the effectivity by which TFPI down-regulates thrombin formation initiated via the extrinsic coagulation pathway. In the light of recent reports on the interaction between FV and TFPI $(15,37)$ particularly the effects on TFPI of FV and FVa either alone or in combination with prothrombin are important. 


\section{Addendum}

S. Peraramelli* analysed the data and wrote the manuscript; S. Thomassen* designed, performed the experiments and revised the manuscript, A. Heinzmann assisted in performing the experiments, J. Rosing supervised the project, designed the experiments, analysed data and revised the manuscript, T. Hackeng supervised the project and revised the manuscript, R. Hartmann provided with TFPI constructs and revised the manuscript, $\mathrm{M}$. Dockal provided with TFPI constructs, contributed in data analysis and revising the manuscript, F. Scheiflinger critically revised the manuscript.

* Authors contribute equally

\section{Disclosure of Conflict of Interest}

JR receives research support from, and acts as consultant of Baxter Innovations GmbH. MD, RH and FS are full time employees of Baxter Innovations GmbH. None of the other authors declares any conflict of interest. 


\section{References}

1. Rao LV, Rapaport SI. Studies of a mechanism inhibiting the initiation of the extrinsic pathway of coagulation. Blood 1987;69(2):645-51.

2. Broze GJ, Jr., Warren LA, Girard JJ, et al. Isolation of the lipoprotein associated coagulation inhibitor produced by HepG2 (human hepatoma) cells using bovine factor Xa affinity chromatography. Thromb Res 1987;48(2):253-9.

3. Broze GJ, Jr., Warren LA, Novotny WF, et al. The lipoprotein-associated coagulation inhibitor that inhibits the factor VII-tissue factor complex also inhibits factor Xa: insight into its possible mechanism of action. Blood 1988;71(2):335-43.

4. Wun TC, Kretzmer KK, Girard TJ, et al. Cloning and characterization of a cDNA coding for the lipoprotein-associated coagulation inhibitor shows that it consists of three tandem Kunitz-type inhibitory domains. J Biol Chem 1988;263(13):6001-4.

5. Chang JY, Monroe DM, Oliver JA, et al. TFPIbeta, a second product from the mouse tissue factor pathway inhibitor (TFPI) gene. Thromb Haemost 1999;81(1):45-9.

6. Zhang J, Piro O, Lu L, et al. Glycosyl phosphatidylinositol anchorage of tissue factor pathway inhibitor. Circulation 2003;108(5):623-7.

7. Girard TJ, Warren LA, Novotny WF, et al. Functional significance of the Kunitz-type inhibitory domains of lipoprotein-associated coagulation inhibitor. Nature 1989;338(6215):518-20. 
8. Broze GJ, Jr., Girard TJ, Novotny WF. Regulation of coagulation by a multivalent Kunitz-type inhibitor. Biochemistry 1990;29(33):7539-46.

9. Huang ZF, Wun TC, Broze GJ, Jr. Kinetics of factor Xa inhibition by tissue factor pathway inhibitor. J Biol Chem 1993;268(36):26950-5.

10. Morrison JF, Walsh CT. The behavior and significance of slow-binding enzyme inhibitors. Advances in enzymology and related areas of molecular biology 1988;61:201-301.

11. Ndonwi M, Tuley EA, Broze GJ, Jr. The Kunitz-3 domain of TFPI-alpha is required for protein S-dependent enhancement of factor Xa inhibition. Blood 2010;116(8):1344-51.

12. Ahnstrom J, Andersson HM, Hockey V, et al. Identification of functionally important residues in TFPI Kunitz domain 3 required for the enhancement of its activity by protein S. Blood 2012;120(25):5059-62

13. Sandset PM, Abildgaard U, Larsen ML. Heparin induces release of extrinsic coagulation pathway inhibitor (EPI). Thromb Res 1988;50(6):803-13.

14. Lindahl AK, Abildgaard U, Stokke G. Release of extrinsic pathway inhibitor after heparin injection: increased response in cancer patients. Thromb Res 1990;59(3):651-6.

15. Ndonwi M, Girard TJ, Broze GJ, Jr. The C-terminus of tissue factor pathway inhibitor alpha is required for its interaction with factors $\mathrm{V}$ and Va. J Thromb Haemost 2012;10(9):1944-6. 
16. Valentin S, Schousboe I. Factor Xa enhances the binding of tissue factor pathway inhibitor to acidic phospholipids. Thromb Haemost 1996;75(5):796-800.

17. Valentin S, Nordfang O, Bregengard C, et al. Evidence that the C-terminus of tissue factor pathway inhibitor (TFPI) is essential for its in vitro and in vivo interaction with lipoproteins. Blood Coagul Fibrinolysis 1993;4(5):713-20.

18. Yegneswaran S, Hackeng TM, Dawson PE, et al. The thrombin-sensitive region of protein $\mathrm{S}$ mediates phospholipid-dependent interaction with factor Xa. $\mathrm{J}$ Biol Chem 2008;283(48):33046-52.

19. Bjork I, Olson ST. Antithrombin. A bloody important serpin. Adv Exp Med Biol 1997;425:17-33.

20. McRae SJ, Stafford AR, Fredenburgh JC, et al. In the presence of phospholipids, glycosaminoglycans potentiate factor Xa-mediated protein C activation by modulating factor Xa activity. Biochemistry 2007;46(13):4195-203.

21. Mast AE, Broze GJ, Jr. Physiological concentrations of tissue factor pathway inhibitor do not inhibit prothrombinase. Blood 1996;87(5):1845-50.

22. Hackeng TM, Sere KM, Tans G, et al. Protein S stimulates inhibition of the tissue factor pathway by tissue factor pathway inhibitor. Proc Natl Acad Sci U S A 2006;103(9):3106-11.

23. Franssen J, Salemink I, Willems GM, et al. Prothrombinase is protected from inactivation by tissue factor pathway inhibitor: competition between prothrombin and inhibitor. Biochem J 1997;323 ( Pt 1):33-7. 
24. Castoldi E, Simioni P, Tormene D, et al. Hereditary and acquired protein S deficiencies are associated with low TFPI levels in plasma. J Thromb Haemost 2010;8(2):294-300.

25. Lindahl AK, Jacobsen PB, Sandset PM, et al. Tissue factor pathway inhibitor with high anticoagulant activity is increased in post-heparin plasma and in plasma from cancer patients. Blood Coagul Fibrinolysis 1991;2(6):713-21.

26. Nishiyama K, Ogawa H, Yasue H, et al. Heparin-releasable endothelial cell-associated tissue factor pathway inhibitor (TFPI) is increased in the coronary circulation after coronary spasm in patients with coronary spastic angina. Thromb Res 1998;89(3):137-46.

27. Sere KM, Rosing J, Hackeng TM. Inhibition of thrombin generation by protein $\mathrm{S}$ at low procoagulant stimuli: implications for maintenance of the hemostatic balance. Blood 2004;104(12):3624-30.

28. Dockal M, Hartmann R, Fries M, et al. Small peptides blocking inhibition of factor Xa and tissue factor-factor VIIa by tissue factor pathway inhibitor (TFPI). J Biol Chem 2015;289(3):1732-41.

29. Girard TJ, Broze GJ, Jr. Tissue factor pathway inhibitor. Methods Enzymol 1993;222:195-209.

30. Esnouf MP, Lloyd PH, Jesty J. A method for the simultaneous isolation of factor X and prothrombin from bovine plasma. Biochem J 1973;131(4):781-9. 
31. Peraramelli S, Suylen DP, Rosing J, et al. The Kunitz 1 and Kunitz 3 domains of tissue factor pathway inhibitor are required for efficient inhibition of factor Xa. Thromb Haemost 2012;108(2):266-76.

32. Kato H. Tissue factor pathway inhibitor; its structure, function and clinical significance. Pol J Pharmacol 1996;48(1):67-72.

33. Rezaie AR. Heparin-binding exosite of factor Xa. Trends in cardiovascular medicine 2000;10(8):333-8.

34. Abildgaard U. Heparin/low molecular weight heparin and tissue factor pathway inhibitor. Haemostasis 1993;23 Suppl 1:103-6.

35. Ndonwi M, Tuley EA, Broze GJ, Jr. The Kunitz-3 domain of TFPI-alpha is required for protein S-dependent enhancement of factor Xa inhibition. Blood 2010;116(8):1344-51.

36. Reglinska-Matveyev N, Andersson HM, Rezende SM, et al. TFPI cofactor function of protein S: essential role of the protein S SHBG-like domain. Blood 2014;123(25):3979-87.

37. Duckers C, Simioni P, Spiezia L, et al. Low plasma levels of tissue factor pathway inhibitor in patients with congenital factor $\mathrm{V}$ deficiency. Blood 2008;112(9):3615-23.

38. Walker FJ. Regulation of vitamin K-dependent protein S. Inactivation by thrombin. J Biol Chem 1984;259(16):10335-9. 
39. Broze GJ, Jr., Girard TJ. Factor V, tissue factor pathway inhibitor, and east Texas bleeding disorder. J Clin Invest 2013;123(9):3710-2.

40. Wood JP, Bunce MW, Maroney SA, et al. Tissue factor pathway inhibitoralpha inhibits prothrombinase during the initiation of blood coagulation. Proc Natl Acad Sci U S A 2013;110(44):17838-43.

41. Rosing J, Tans G, Govers-Riemslag JW, et al. The role of phospholipids and factor Va in the prothrombinase complex. J Biol Chem 1980;255(1):274-83.

42. Warn-Cramer BJ, Rao LV, Maki SL, et al. Modifications of extrinsic pathway inhibitor (EPI) and factor Xa that affect their ability to interact and to inhibit factor VIIa/tissue factor: evidence for a two-step model of inhibition. Thromb Haemost 1988;60(3):453-6.

43. Wesselschmidt R, Likert K, Huang Z, et al. Structural requirements for tissue factor pathway inhibitor interactions with factor Xa and heparin. Blood Coagul Fibrinolysis 1993;4(5):661-9.

44. Lindhout T, Franssen J, Willems G. Kinetics of the inhibition of tissue factor-factor VIIa by tissue factor pathway inhibitor. Thromb Haemost 1995;74(3):910-5.

45. Willems GM, Janssen MP, Salemink I, et al. Transient high affinity binding of tissue factor pathway inhibitor-factor Xa complexes to negatively charged phospholipid membranes. Biochemistry 1998;37(10):3321-8. 
46. Enjyoji K, Miyata T, Kamikubo Y, et al. Effect of heparin on the inhibition of factor Xa by tissue factor pathway inhibitor: a segment, Gly212-Phe243, of the third Kunitz domain is a heparin-binding site. Biochemistry 1995;34(17):5725-35.

47. Tollefsen DM. Insight into the mechanism of action of heparin cofactor II. Thromb Haemost 1995;74(5):1209-14.

48. Walenga JM, Jeske WP, Samama MM, et al. Fondaparinux: a synthetic heparin pentasaccharide as a new antithrombotic agent. Expert Opin Investig Drugs 2002;11(3):397-407.

49. Jesty J, Wun TC, Lorenz A. Kinetics of the inhibition of factor Xa and the tissue factor-factor VIIa complex by the tissue factor pathway inhibitor in the presence and absence of heparin. Biochemistry 1994;33(42):12686-94.

50. Olson ST, Chuang YJ. Heparin activates antithrombin anticoagulant function by generating new interaction sites (exosites) for blood clotting proteinases. Trends in cardiovascular medicine 2002;12(8):331-8.

51. Vincent LM, Tran S, Livaja R, et al. Coagulation factor V(A2440G) causes east Texas bleeding disorder via TFPIalpha. J Clin Invest 2013;123(9):3777-87.

52. Ndonwi M, Broze G, Jr. Protein S enhances the tissue factor pathway inhibitor inhibition of factor Xa but not its inhibition of factor VIIa-tissue factor. J Thromb Haemost 2008;6(6):1044-6.

53. Krishnaswamy S. Exosite-driven substrate specificity and function in coagulation. J Thromb Haemost 2005;3(1):54-67. 
54. Krishnaswamy S. The transition of prothrombin to thrombin. J Thromb Haemost 2013;11 Suppl 1:265-76.

55. van Rijn JL, Govers-Riemslag JW, Zwaal RF, et al. Kinetic studies of prothrombin activation: effect of factor Va and phospholipids on the formation of the enzyme-substrate complex. Biochemistry 1984;23(20):4557-64. 


\section{Chapter 7}

General Discussion and Summary 
Chapter 7 


\section{Role of different TFPI Kunitz domains in FXa inhibition}

TFPI inhibits FXa by a so-called slow-tight mechanism involving the fast formation of a limited amount of an initial encounter complex followed by a slow isomerization step and the formation of a tight TFPI-FXa complex (1-3). In 2006 Hackeng et al. (4) reported that protein S not only acts as cofactor of APC in FVa and FVIIa inactivation, but also expresses APC-independent anticoagulant activity by enhancing FXa inhibition by TFPI. In chapter 2 we have presented experiments which show that in the absence of APC thrombin generation is inhibited by TFPI and protein S only at low TF concentrations. At high TF concentrations thrombin generation is hardly, if at all, inhibited by TFPI and protein S despite the fact that under these conditions the TF concentration is still considerably lower (more than 20 -fold) than the plasma TFPI concentration. The lack of inhibition of thrombin generation by TFPI/protein S at high TF concentrations is likely explained by the fact that TFPI is a slow inhibitor which is not able to control the explosive FXa generation at high TF. However, in the presence of APC, TFPI is also a determinant of thrombin generation at high TF concentrations. Apparently, APC sufficiently slows down thrombin generation to give TFPI enough time to inhibit FXa and TF-FVIIa and to contribute to the down-regulation of coagulation even at a high TF concentration. In chapter 2 we show (Fig. 3B) that under these conditions the expression of TFPI anticoagulant activity is fully dependent on the 
presence of protein S. Thus, in the presence of APC protein S has two important anticoagulant functions and acts as cofactor of both APC and TFPI.

Although short after the discovery of TFPI it was reported that the K2 domain of TFPI inhibits FXa $(2,5)$, several studies indicated the involvement of other TFPI domains in FXa inhibition (6-10). However, the activities of TFPI fragments in FXa inhibition were not studied in sufficient detail to dissect the importance of the different TFPI domains in the two steps (encounter complex formation and isomerisation to the tight TFPI-FXa complex) that describe the mechanism of FXa inhibition by TFPI. To obtain better insight of the mechanism of FXa inhibition by TFPI, we performed a detailed kinetic study using various truncated forms of TFPI as FXa inhibitors and applying the kinetic equations of Morrison and Walsh (3) to determine the $\mathrm{K}_{\mathrm{i}}$ and $\mathrm{K}_{\mathrm{i}}^{*}$ values of encounter and tight TFPI-FXa complex formation, respectively. In chapter 3 we report that both the isolated $\mathrm{K} 2$ domain and a $\mathrm{K} 2 \mathrm{~K} 3$ construct were poor FXa inhibitors which in contrast to full length TFPI inhibited FXa in a monophasic fashion. The high $\mathrm{K}_{\mathrm{i}}$ values for $\mathrm{K} 2(\sim 20 \mathrm{nM})$ and $\mathrm{K} 2 \mathrm{~K} 3(\sim 4 \mathrm{nM})$ together with the observation that inhibition is monophasic suggest that these constructs are unable to form a tight complex. TFPI ${ }_{1-161}(\mathrm{~N}$-term-K1-K2) and K1K2 both showed the characteristic biphasic progress curves indicative of tight complex formation via a slow-tight binding mechanism. Since TFPI constructs without K1 domain show monophasic inhibition of FXa and constructs without K3 domain show biphasic inhibition but 
have high Ki values for encounter complex formation (Chapter 3, Table 2) we conclude that the K2 domain of TFPI targets the active site and inhibits FXa, that the $\mathrm{K} 1$ domain is required for the isomerisation of the encounter to the tight TFPIFXa complex and that the K3 domain promotes the formation of the encounter complex. The importance of the K1 domain for the isomerisation step was later supported by a publication (11) in which it was shown that a small peptide that binds with a high affinity to the K1 domain of TFPI changes the inhibition of FXa from biphasic to monophasic and prevents the transition of the loose to the tight TFPI-FXa complex. The reports that protein S enhances FXa inhibition by TFPI by promoting encounter complex formation (4) and that protein S binds to the K3 domain of TFPI (12) support our proposal that the K3 domain enhances the formation of encounter complex.

Table 2 in Chapter 3 furthermore shows that the $K_{i}$ values of encounter complex formation observed for TFPI $\mathrm{FL}_{\text {a }}$ and TFPI constructs $\left(\mathrm{TFPI}_{1-161}\right.$ and $\left.\mathrm{K} 1 \mathrm{~K} 2\right)$ which all contain a K1 domain are significantly higher than those of K2K3 which indicates that $\mathrm{K} 1$ not only promotes tight complex formation but at the same time hinders the formation of the encounter complex.

$\mathrm{Ca}^{2+}$ ions and phospholipids play a crucial role in FXa inhibition by TFPI. The interaction between FXa and TFPI is greatly enhanced by the positively charged C-terminus of TFPI (8) and the negatively charged $\gamma$-carboxyglutamate (Gla) domain of factor Xa (Chapter 3, Table 3). In the presence of $\mathrm{Ca}^{2+}$-ions TFPI 
is considerably less effective as FXa inhibitor which is presumably due to $\mathrm{Ca}^{2+}$ binding to the Gla-domain of FXa thereby changing it charge and preventing the ionic interaction with the C-terminus of TFPI. The presence of phospholipids partially abrogates the $\mathrm{Ca}^{2+}$ inhibition of TFPI. Since the interaction between Cterminus of TFPI and the Gla-domain of FXa is only observed in the absence of $\mathrm{Ca}^{2+}$ ions it is questionable whether it also occurs in vivo. Taken together the observations presented in chapter 3 show that all Kunitz domains are essential for efficient FXa inhibition by TFPI.

\section{Modulators of TFPI in FXa inhibition}

Coagulation is a complex mechanism not only involving enzymes, substrates and inhibitors but also proteins and non-proteinic components that regulate the coagulation process and direct it to either the procoagulant or anticoagulant pathway. In 1977, Fenton et al.(13) introduced the concept of exosites in coagulation proteinases, and the studies in molecular modeling of coagulation proteinase domains were done by Furie et al. in 1982 (14). For example, thrombin has two exosites, exosite I mediates binding to fibrinogen, fibrin, PAR-1 and PAR4 substrate recognition and hirudin binding (15-20) and exosite II mediates interaction with heparin (21), a specific monoclonal antibody (22), the fragment 2 domain of prothrombin (23) and with inhibitors from snake venoms (24). Exosite I of thrombin is formed by a two stretches of basic residues (loops 34-40 and 70-80). Upon folding of thrombin these loops neighbor each other (25) and form the 
binding site for fibrinogen. Exosite II is more basic than exosite I and was originally identified to bind to heparin (16).

Similarly, FXa also has two major exosites (exosite I and exosite II) $(18,26)$. In contrast to thrombin, both loops 34-40 and 70-80 of FXa are negatively charged. Loop 34-40 of FXa appears to have an important role in the interaction between FXa and the Kunitz 2 domain of TFPI $(27,28)$. FXa has been reported to interact with the parallel surface on pentasaccharide-activated antithrombin (29), and the region of FXa topologically equivalent to exosite II of thrombin is presumably involved in the binding of FXa to heparin and FVa (30). Most importantly, one or more exosites on FXa and FVa are involved in prothrombin recognition by prothrombinase complex (31-33). The $\gamma$-carboxyglutamic acid (Gla) domain of FXa contains 11 Gla residues and hence is a highly anionic amino-terminal domain (34). The Gla domain is required for calcium-dependent binding to phospholipid membranes, which serves to localize the reactions in which Gla-containing coagulation factors participate at the surface of physiologic membranes (35). Similar to coagulation factors, various proteins and non-proteinic components bind to coagulation inhibitors like TFPI. For example TFPI interacts with protein S (4, 36), FV and FVa (37), heparin (2) and phospholipids (2). In chapter 6, we report to what extent these ligands of FXa and TFPI modulate FXa inhibition by TFPI.

FV acts as a modulator of TFPI which, like protein S, enhances the inhibition of FXa. However, activated FV (FVa) has an opposite effect and 
impedes FXa inhibition by TFPI. This might be due to formation of a complex between FXa and FVa and partial protection of this complex is against TFPI inhibition. In this respect it is interesting to note that in the presence of phospholipids FVa also partially protects FXa from inhibition by antithrombin both in the absence (38) and presence of heparin (39).

Heparin is a glycosaminoglycan, which not only stimulates the inhibition of thrombin and FXa by antithrombin, but also enhances the inhibition of FXa by TFPI (8). In chapter 6 we showed that very low heparin concentrations $(0.05$ U/mL) already enhance FXa inhibition by TFPI $\sim 8$-fold. When FX was activated by TF-FVIIa in presence of TFPI and heparin, we observed that inhibition of TFFVIIa by TFPI was also accelerated in presence of heparin. This effect may be explained by heparin stimulation of the formation of the binary TFPI-FXa complex with FXa produced by the extrinsic Xase and subsequent enhancement of quaternary complex formation resulting in more pronounced inhibition of TF:FVIIa-catalysed FX activation. Heparin stimulation of the inhibition of both FXa and TF:FVIIa occurred at heparin concentrations that are in the range of the plasma heparin concentration achieved during treatment of patients (40). This suggests that heparin stimulation of TFPI may contribute to the over-all anticoagulant effect of heparin in patients treated with heparin. 
TFPI binds to negatively charged phospholipid vesicles (41) and in the presence of $\mathrm{Ca}^{2+}$ ions phospholipids stimulate FXa inhibition by TFPI (2). Our experiments indicate that low concentrations of phospholipids $(10 \mu \mathrm{M})$ were already sufficient for optimal stimulation of inhibition. Due to a low binding affinity of TFPI to negatively charged phospholipids in presence of $\mathrm{Ca}^{2+}$ ions (41, 42) and since excess phospholipids does not counteract FXa inhibition by TFPI, we speculated that the interaction and inhibition of FXa by TFPI in the presence of phospholipids might be via template mechanism as proposed for heparin. On the other hand the FXa-TFPI complex binds to phospholipids with high affinity that is characterised by a Kd that is $\sim 10$ times lower than the Kd of FXa alone (42). Since, FXa inhibition by TFPI occurs via a two step mechanism i.e. rapid formation of a small amount of encounter complex (step 1) followed by slow transition to a tight TFPI-FXa complex (step 2), we speculate that the encounter complex binds with a high affinity to phospholipids which pulls the equilibrium of step 1 in the direction of encounter complex formation resulting in more pronounced inhibition of FXa.

TFPI appeared to be a potent inhibitor of FXa-catalysed prothrombin activation in the absence of FVa even at saturating prothrombin concentrations whereas prothrombin activation in the presence of FVa was hardly inhibited by TFPI. We propose that in absence of FVa prothrombin, which is the natural substrate for FXa, binds to a secondary site (exosite) on FXa with limited 
occupation of the active site. Hence, the active site of FXa is accessible to TFPI and FXa can be inhibited by TFPI. We further hypothesize that in presence of FVa, prothrombin shifts from the FXa exosite to active site which results in a more than 1000-fold enhancement of thrombin formation (43) and which protects FXa from inhibition by TFPI.

The noticeable similarity is that all modulators mentioned above bind to the K3 and/or C-terminus domain of TFPI as the truncated forms $\left(\mathrm{TFPI}_{1-150}, \mathrm{~K} 1 \mathrm{~K} 2\right)$ were not able to bind. This also shows that K3, which was always considered (2) as not having any role in the inhibition of FXa, contributes towards FXa inhibition by binding to cofactors, modulators and surfaces that enhance or inhibit the anticoagulant activity of TFPI $(4,44,45)$. Along with binding to modulators it also enhances the initial encounter complex formation as discussed in chapter 3 .

In summary, our data show several plasma proteins involved in coagulation modulate the anticoagulant activity of TFPI. These modulating effects should be taken into account when considering the effectivity by which TFPI down-regulates thrombin formation initiated in plasma via the extrinsic coagulation pathway.

Direct inhibition of TF-FVIIa by TFPI

TFPI inhibits TF-FVIIa via a rather complicated mechanism. It is hypothesized that TFPI binds to ternary complex of TF-FVIIa-FXa present on the phospholipids to 
form a tight quaternary complex in which both FVIIa and FXa are inhibited (46). We have investigated whether TFPI can efficiently inhibit TF-FVIIa in the absence of FXa. Pedersen et al. (47) earlier showed that TFPI can inhibit TF-FVIIa in a FXa-independent fashion but with a rather high $\mathrm{K}_{\mathrm{i}}$ of $10 \mathrm{nM}$ which indicates that direct inhibition of TF-FVIIa by TFPI is of limited physiological relevance. In chapter 4 of thesis we further investigated the mechanism of inhibition of TFFVIIa by TFPI and the role of different Kunitz domains therein. Using a chromogenic substrate specific for FVIIa to follow inhibition by TFPI in a model system we demonstrated that $\mathrm{TFPI}_{\mathrm{FL}}$ inhibits TF-FVIIa with a $\mathrm{K}_{\mathrm{i}}$ value of $\sim 5 \mathrm{nM}$ which decreased to $0.7 \mathrm{nM}$ in presence of protein $\mathrm{S}$, a value that is close to the

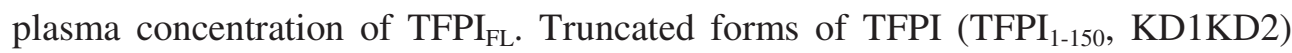
that lack $\mathrm{K} 3$ and $\mathrm{C}$-terminus, had 10-fold higher $\mathrm{K}_{\mathrm{i}}$ values and single Kunitz domains (N-KD1, KD1 and KD2) showed 100-fold higher $\mathrm{K}_{\mathrm{i}}$ values (Table 1 of chapter 4) indicating that for direct and efficient inhibition of TF-FVIIa all Kunitz domains of $\mathrm{TFPI}_{\mathrm{FL}}$ are required. A soluble form of $\mathrm{TF}$ which lacks its transmembrane and cytoplasmic domains and which does not contain phospholipids had a 25 -fold higher $\mathrm{K}_{\mathrm{i}}$ value compared to full length $\mathrm{TF}$ which is relipidated by the manufacturer and which contains negatively charged phospholipids. This observation also shows the importance of phospholipids in the inhibition of TF-FVIIa by TFPI. 
Instead of using an artificial chromogenic substrate (Spectrozyme FVIIa) in chapter 5, we also used the physiological substrate FIX to study TF-FVIIa inhibition by TFPI. FIX activation by TF-FVIIa was inhibited by TFPI $_{F L}$ with a 3fold higher $\mathrm{K}_{\mathrm{i}}$ value than observed with chromogenic substrate. In this system protein $\mathrm{S}$ also exhibited TFPI cofactor activity and reduced $\mathrm{K}_{\mathrm{i}}$ value for TFPI from $16.7 \mathrm{nM}$ to $1.0 \mathrm{nM}$. This shows that in plasma where protein $\mathrm{S}$ is present direct inhibition of TF-FVIIa by TFPI may contribute to the anticoagulant activity of TFPI.

TFPI that is complex with FXa inhibits TF:FVIIa-catalysed FIX activation with a $\mathrm{K}_{\mathrm{i}}(\sim 0.5 \mathrm{nM})$ that is considerably lower than the Ki of TFPI that is not in complex with FXa $\left(\mathrm{K}_{\mathrm{i}}=16.7 \mathrm{nM}\right)$. Interestingly, preformed TFPI-FXa and TFPI . $_{\text {- }}$ ${ }_{150}$-FXa complexes were both potent inhibitors of FIX activation and had similar $\mathrm{K}_{\mathrm{i}}$ values showing that truncated forms of TFPI are able to efficiently form a quaternary complex. This observation seems to be in contrast with reports $(7,48)$ in which full length TFPI is considered to be much better inhibitor and truncated versions of TFPI and with experiments in TFPI-depleted plasma reconstituted with $\mathrm{TFPI}_{\mathrm{FL}}$ and C-terminus truncated TFPI which showed that $\mathrm{TFPI}_{\mathrm{FL}}$ was a much better inhibitor (7). Apparently, the formation of the TFPI-FXa complex, which is more efficient with $\mathrm{TFPI}_{\mathrm{FL}}$ than with $\mathrm{TFPI}_{1-150}$, is the limiting step in the inhibition of TF:FVIIa via quaternary complex formation. To obtain more information on the importance of TFPI-FXa complex formation for the inhibition of TF:FVIIa, we 
investigated the effects of TFPI and TFPI constructs in TF:FVIIa-catalysed FX activation.

\section{TF-FVIIa-catalysed FX activation in presence of TFPI}

In chapter 5, we studied TF-FVIIa inhibition by TFPI in a model system in which progress curves of FX activation were used to follow the inhibition of TF:FVIIa. $\mathrm{TFPI}_{\mathrm{FL}}$ and truncated TFPI (TFPI $1-150$ and $\left.\mathrm{KD} 1 \mathrm{KD} 2\right)$ had similar inhibitory activity at high TF $(5 \mathrm{nM})$ but when TF concentration was reduced 50 times $(0.1 \mathrm{nM})$ TFPI $_{\mathrm{FL}}$ was a much better inhibitor which inhibited TF:FVIIa-catalysed FX activation with a $K_{i}$ value that was a $\sim 7$ fold lower than the $K_{i}$ of the truncated forms of TFPI (Table 2, chapter 5). We showed that this decrease of the $\mathrm{K}_{\mathrm{i}}$ of TFPI $_{\mathrm{FL}}$ was due to the lower phospholipid concentration at low TF and we hypothesized that phospholipids bind $\mathrm{TFPI}_{\mathrm{FL}}$ or the TFPI-FXa complex through interactions with the C-terminus of TFPI and the $\gamma$-carboxyglutamic acid domain of FXa and that as a consequence high phospholipid concentrations reduce the TFPI $I_{\mathrm{FL}}$ and/or TFPI-FXa complex that is available for inhibition of TF:FVIIa. Since truncated forms of TFPI lack C-terminus, reducing the phospholipid concentration does not affect their inhibitory activity.

Protein S acts cofactor of TFPI both in FXa inhibition (4) and in the direct inhibition of TF-FVIIa when quantified with chromogenic substrate or with the natural substrate FIX (chapter 4 and 5). We also performed experiments in which we studied the effect protein $\mathrm{S}$ on the inhibition of TF:FVIIa-catalysed FX 
activation by TFPI. In contrast to the literature in which it was reported that protein $\mathrm{S}$ is not a cofactor of TFPI in the inhibition of TF:FVIIa via quaternary complex formation (49) we showed that protein $\mathrm{S}$ enhances the inhibition of TF:FVIIacatalysed FX activation by TFPI. The conflicting results can be attributed to the difference in conditions at which the experiments were performed. We measured FX at limiting FVIIa and excess TF (1 pM FVIIa/5 nM TF) whereas Ndwoni and Broze had a limiting amount of FVIIa (1 pM) and TF (1 pM). We titrated with TFPI and used TFPI concentrations that were up to 40 -fold lower than the fixed TFPI concentration (1 $\mathrm{nM})$ used by Ndonwi and Broze. Hence in our experiments in many data points $[\mathrm{TFPI}]_{\text {total }}<<[\mathrm{FXa}]_{\text {formed }}$ which means that only a very small (virtually undetectable) fraction of the FXa generated can (will) be inhibited by TFPI which allows separation of protein S effects on TFPI inhibition of TF:FVIIa from protein $\mathrm{S}$ effects on TFPI inhibition of FXa. The conditions of the FIX activation experiments were also different. Our experiments were performed in the presence rivaroxaban which is a potent FXa inhibitor which prevents a contribution of FXa to the inhibition of TF:FVIIa via quaternary complex formation. Ndonwi and Broze (49) determined the inhibition of TF:FVIIa-catalysed FIX activation in the presence of FX which during the experiment was likely converted to FXa thus enabling efficient inhibition of TF:FVIIa via quaternary complex formation which will have overwhelmed the stimulatory effect of protein $S$ on the inhibition of TF:FVIIa by TFPI that we observed in our experiments. 


\section{Conclusions and future perspective}

TFPI is Kunitz type protease inhibitor that consists of a negatively charged Nterminus, three Kunitz domains designated $\mathrm{K} 1, \mathrm{~K} 2$ and $\mathrm{K} 3$, and a positively charged C-terminus. Short after the discovery of TFPI it was reported that TFPI down-regulates the extrinsic coagulation pathway by inhibiting TF-FVIIa and FXa and that the K1 domain binds and inhibits FVIIa and that K2 binds and inhibits FXa. The fact that isolated Kunitz domains were very poor inhibitors of FVIIa and FXa indicated that the other Kunitz domain and possibly also the $\mathrm{N}$ - and $\mathrm{C}$ terminus contribute to the inhibition of FVIIa and FXa. In this thesis, we have presented a detailed study on the kinetics of inhibition of FVIIa and FXa by TFPI to dissect the effects of the various TFPI domains in the mechanism of inhibition.

Our study shows that TFPI alone i.e. in the absence of FXa is able to inhibit FVIIa. In addition to the K1 domain, TFPI requires the K2 and K2 domains of TFPI, relipidated TF and protein $\mathrm{S}$ to bring the $\mathrm{K}_{\mathrm{i}}$ of direct FVIIa inhibition in the range of the plasma TFPI concentration. However, it is difficult to quantify to what extent inhibition of TF-FVIIa independent of FXa i.e. independent of quaternary TFPI-FXa-TF-FVIIa complex contributes to the down regulation of the extrinsic pathway by TFPI. To answer this question TFPI variants with a modified K2 domain that do not inhibit FXa will be very helpful.

The kinetic analysis of FXa inhibition by TFPI and TFPI constructs demonstrated that in the two-step slow-tight binding mechanism of FXa inhibition 
the $\mathrm{K} 3$ domain promotes the formation of the weak encounter complex and that $\mathrm{K} 1$ is required for the transition of the weak encounter to the tight TFPI-FXa complex that completes FXa inhibition. This knowledge is important for the development of TFPI inhibitors that are currently developed for the treatment of haemophilia (11, $50,51)$.

Both TFPI and FXa are known to interact with a wide variety of plasma components (proteins and non-proteinic compounds) that either bind to exosites or to protein domains that are directly involved in inhibition (TFPI) or enzyme activity (active site of FXa). Negatively charged surfaces like phospholipids and heparin greatly stimulate TFPI inhibition of FXa. Protein S and FV which both bind to TFPI also enhance FXa inhibition by TFPI in model systems as well as in plasma. However, FVa protects FXa against inhibition by TFPI, particularly in the presence of prothrombin. These modulating effects have to be taken into account when considering the expression of TFPI anticoagulant activity in plasma. 


\section{References}

1. Broze GJ, Jr., Warren LA, Novotny WF, et al. The lipoprotein-associated coagulation inhibitor that inhibits the factor VII-tissue factor complex also inhibits factor Xa: insight into its possible mechanism of action. Blood 1988;71(2):335-43.

2. Huang ZF, Wun TC, Broze GJ, Jr. Kinetics of factor Xa inhibition by tissue factor pathway inhibitor. J Biol Chem 1993;268(36):26950-5.

3. Morrison JF, Walsh CT. The behavior and significance of slow-binding enzyme inhibitors. Advances in enzymology and related areas of molecular biology 1988;61:201-301.

4. Hackeng TM, Sere KM, Tans G, et al. Protein S stimulates inhibition of the tissue factor pathway by tissue factor pathway inhibitor. Proc Natl Acad Sci U S A 2006;103(9):3106-11.

5. Girard TJ, Warren LA, Novotny WF, et al. Functional significance of the Kunitz-type inhibitory domains of lipoprotein-associated coagulation inhibitor. Nature 1989;338(6215):518-20.

6. Higuchi DA, Wun TC, Likert KM, et al. The effect of leukocyte elastase on tissue factor pathway inhibitor. Blood 1992;79(7):1712-9.

7. Wesselschmidt R, Likert $\mathrm{K}$, Girard $\mathrm{T}$, et al. Tissue factor pathway inhibitor: the carboxy-terminus is required for optimal inhibition of factor Xa. Blood 1992;79(8):2004-10. 
8. Wesselschmidt R, Likert K, Huang Z, et al. Structural requirements for tissue factor pathway inhibitor interactions with factor Xa and heparin. Blood Coagul Fibrinolysis 1993;4(5):661-9.

9. Petersen LC, Bjorn SE, Olsen OH, et al. Inhibitory properties of separate recombinant Kunitz-type-protease-inhibitor domains from tissue-factor-pathway inhibitor. Eur J Biochem 1996;235(1-2):310-6.

10. Cunningham AC, Hasty KA, Enghild JJ, et al. Structural and functional characterization of tissue factor pathway inhibitor following degradation by matrix metalloproteinase-8. Biochem J 2002;367(Pt 2):451-8.

11. Dockal M, Hartmann R, Fries M, et al. Small peptides blocking inhibition of factor Xa and tissue factor-factor VIIa by tissue factor pathway inhibitor (TFPI). J Biol Chem 2014;289(3):1732-41.

12. Ndonwi M, Tuley EA, Broze GJ, Jr. The Kunitz-3 domain of TFPI-alpha is required for protein S-dependent enhancement of factor Xa inhibition. Blood 2010;116(8):1344-51.

13. Bing DH, Cory M, Fenton JW, 2nd. Exo-site affinity labeling of human thrombins. Similar labeling on the A chain and B chain/fragments of clotting alpha- and nonclotting gamma/beta-thrombins. J Biol Chem 1977;252(22):802734. 
14. Furie B, Bing DH, Feldmann RJ, et al. Computer-generated models of blood coagulation factor Xa, factor IXa, and thrombin based upon structural homology with other serine proteases. J Biol Chem 1982;257(7):3875-82.

15. Lane DA, Philippou H, Huntington JA. Directing thrombin. Blood 2005;106(8):2605-12.

16. Huntington JA. Molecular recognition mechanisms of thrombin. J Thromb Haemost 2005;3(8):1861-72.

17. Bode W. Structure and interaction modes of thrombin. Blood Cells Mol Dis 2006;36(2):122-30.

18. Page MJ, Macgillivray RT, Di Cera E. Determinants of specificity in coagulation proteases. J Thromb Haemost 2005;3(11):2401-8.

19. Friedrich R, Panizzi P, Fuentes-Prior P, et al. Staphylocoagulase is a prototype for the mechanism of cofactor-induced zymogen activation. Nature 2003;425(6957):535-9.

20. Skrzypczak-Jankun E, Carperos VE, Ravichandran KG, et al. Structure of the hirugen and hirulog 1 complexes of alpha-thrombin. J Mol Biol 1991;221(4):1379-93.

21. Carter WJ, Cama E, Huntington JA. Crystal structure of thrombin bound to heparin. J Biol Chem 2005;280(4):2745-9.

22. Colwell NS, Blinder MA, Tsiang M, et al. Allosteric effects of a monoclonal antibody against thrombin exosite II. Biochemistry 1999;38(8):2610. 
23. Arni RK, Padmanabhan K, Padmanabhan KP, et al. Structure of the noncovalent complex of prothrombin kringle 2 with PPACK-thrombin. Chem Phys Lipids 1994;67-68:59-66.

24. Bode W. The structure of thrombin, a chameleon-like proteinase. J Thromb Haemost 2005;3(11):2379-88.

25. Wu QY, Sheehan JP, Tsiang M, et al. Single amino acid substitutions dissociate fibrinogen-clotting and thrombomodulin-binding activities of human thrombin. Proc Natl Acad Sci U S A 1991;88(15):6775-9.

26. Bock PE, Panizzi P, Verhamme IM. Exosites in the substrate specificity of blood coagulation reactions. J Thromb Haemost 2007;5 Suppl 1:81-94.

27. Burgering MJ, Orbons LP, van der Doelen A, et al. The second Kunitz domain of human tissue factor pathway inhibitor: cloning, structure determination and interaction with factor Xa. J Mol Biol 1997;269(3):395-407.

28. Mine S, Yamazaki T, Miyata T, et al. Structural mechanism for heparinbinding of the third Kunitz domain of human tissue factor pathway inhibitor. Biochemistry 2002;41(1):78-85.

29. Chuang YJ, Swanson R, Raja SM, et al. Heparin enhances the specificity of antithrombin for thrombin and factor Xa independent of the reactive center loop sequence. Evidence for an exosite determinant of factor Xa specificity in heparinactivated antithrombin. J Biol Chem 2001;276(18):14961-71. 
30. Rezaie AR. Identification of basic residues in the heparin-binding exosite of factor Xa critical for heparin and factor Va binding. J Biol Chem 2000;275(5):3320-7.

31. Krishnaswamy S, Betz A. Exosites determine macromolecular substrate recognition by prothrombinase. Biochemistry 1997;36(40):12080-6.

32. Betz A, Krishnaswamy S. Regions remote from the site of cleavage determine macromolecular substrate recognition by the prothrombinase complex. $\mathrm{J}$ Biol Chem 1998;273(17):10709-18.

33. Wilkens M, Krishnaswamy S. The contribution of factor Xa to exositedependent substrate recognition by prothrombinase. J Biol Chem 2002;277(11):9366-74.

34. Whinna HC, Lesesky EB, Monroe DM, et al. Role of the gammacarboxyglutamic acid domain of activated factor $\mathrm{X}$ in the presence of calcium during inhibition by antithrombin-heparin. J Thromb Haemost 2004;2(7):1127-34.

35. Sunnerhagen M, Forsen S, Hoffren AM, et al. Structure of the $\mathrm{Ca}(2+)$-free Gla domain sheds light on membrane binding of blood coagulation proteins. Nat Struct Biol 1995;2(6):504-9.

36. Ndonwi M, Tuley EA, Broze GJ, Jr. The Kunitz-3 domain of TFPI-alpha is required for protein S-dependent enhancement of factor Xa inhibition. Blood 2010;116(8):1344-51. 
37. Ndonwi M, Girard TJ, Broze GJ, Jr. The C-terminus of tissue factor pathway inhibitor alpha is required for its interaction with factors $\mathrm{V}$ and $\mathrm{Va}$. $\mathrm{J}$ Thromb Haemost 2012;10(9):1944-6.

38. Walker FJ, Esmon CT. The effects of phospholipid and factor Va on the inhibition of factor Xa by antithrombin III. Biochem Biophys Res Commun 1979;90(2):641-7.

39. Brufatto N, Ward A, Nesheim ME. Factor Xa is highly protected from antithrombin-fondaparinux and antithrombin-enoxaparin when incorporated into the prothrombinase complex. J Thromb Haemost 2003;1(6):1258-63.

40. Hirsh J, Anand SS, Halperin JL, et al. Guide to anticoagulant therapy: Heparin : a statement for healthcare professionals from the American Heart Association. Circulation 2001;103(24):2994-3018.

41. Valentin S, Schousboe I. Factor Xa enhances the binding of tissue factor pathway inhibitor to acidic phospholipids. Thromb Haemost 1996;75(5):796-800.

42. Willems GM, Janssen MP, Salemink I, et al. Transient high affinity binding of tissue factor pathway inhibitor-factor Xa complexes to negatively charged phospholipid membranes. Biochemistry 1998;37(10):3321-8.

43. Rosing J, Tans G, Govers-Riemslag JW, et al. The role of phospholipids and factor Va in the prothrombinase complex. J Biol Chem 1980;255(1):274-83. 
44. Duckers C, Simioni P, Spiezia L, et al. Low plasma levels of tissue factor pathway inhibitor in patients with congenital factor $\mathrm{V}$ deficiency. Blood 2008;112(9):3615-23.

45. Kato H. Tissue factor pathway inhibitor; its structure, function and clinical significance. Pol J Pharmacol 1996;48(1):67-72.

46. Baugh RJ, Broze GJ, Jr., Krishnaswamy S. Regulation of extrinsic pathway factor Xa formation by tissue factor pathway inhibitor. J Biol Chem 1998;273(8):4378-86.

47. Pedersen AH, Nordfang O, Norris F, et al. Recombinant human extrinsic pathway inhibitor. Production, isolation, and characterization of its inhibitory activity on tissue factor-initiated coagulation reactions. J Biol Chem 1990;265(28):16786-93.

48. Lindhout T, Willems G, Blezer R, et al. Kinetics of the inhibition of human factor Xa by full-length and truncated recombinant tissue factor pathway inhibitor. Biochem J 1994;297 ( Pt 1):131-6.

49. Ndonwi M, Broze G, Jr. Protein S enhances the tissue factor pathway inhibitor inhibition of factor Xa but not its inhibition of factor VIIa-tissue factor. $\mathrm{J}$ Thromb Haemost 2008;6(6):1044-6.

50. Waters EK, Genga RM, Thomson HA, et al. Aptamer BAX 499 mediates inhibition of tissue factor pathway inhibitor via interaction with multiple domains of the protein. J Thromb Haemost 2013;11(6):1137-45. 
51. Hilden I, Lauritzen B, Sorensen BB, et al. Hemostatic effect of a monoclonal antibody mAb 2021 blocking the interaction between FXa and TFPI in a rabbit hemophilia model. Blood 2012;119(24):5871-8. 


\section{Appendix}

\section{Samenvatting}

\section{Valorisation}

\section{Curriculum Vitae}

List of Publication

Acknowledgments 

Samenvatting 
Appendix 
Tissue factor pathway inhibitor (TFPI) is een protease remmer die is opgebouwd uit een negatief geladen $\mathrm{N}$-terminus gevolgd door drie Kunitz domeinen (K1, K2 en K3) en een positief geladen C-terminus. TFPI reguleert de extrinsieke stollingsroute via remming van de geactiveerde stollingsfactoren FXa en FVIIa. FXa remming door TFPI wordt gestimuleerd door protein S, een vitamine Kafhankelijk anticoagulant eiwit wat niet alleen functioneert als cofactor van TFPI maar ook van geactiveerd protein C (APC), de serine protease die de stolling remt via proteolytische inactivering van FVa en FVIIIa.

In hoofdstuk 2 laten we zien dat in afwezigheid van APC, TFPI gestimuleerd wordt door protein $\mathrm{S}$ en de trombinevorming vooral remt wanneer deze gestart wordt met lage tissue factor (TF) concentraties. Bij hoge tissue factor concentraties (> $10 \mathrm{pM}$ ) is TFPI, zelfs in aanwezigheid van protein $\mathrm{S}$, niet in staat de trombinevorming te remmen. Echter wanneer er APC aanwezig is, treedt TFPI ook remmer van de trombinevorming op bij hoge TF concentraties. Dit betekent dat in aanwezigheid van APC protein S twee belangrijke anticoagulante functies heeft en zowel een cofactor is van APC als van TFPI. De betekenis van protein S wordt geillustreerd door de waarneming dat in afwezigheid van protein S, APC en TFPI nauwelijks in staat zijn de trombine vorming te remmen (Fig. 3, hoofdstuk 2).

Remming van FXa door TFPI verloopt in twee stappen: in eerste instantie wordt er snel een kleine hoeveelheid FXa-TFPI complex gevormd wat vervolgens via een langzame isomerisatiereactie wordt omgezet in een complex het z.g. FXa-TFPI* 
complex waarin TFPI en FXa een sterke interactie aangegaan zijn, wat geïllustreerd wordt door de lage dissociatieconstante van het FXa-TFPI* complex $\left(\mathrm{K}_{\mathrm{i}}{ }^{*}=0.02-0.1 \mathrm{nM}\right)$. In zowel het FXa-TFPI als het FXa-TFPI* complex wordt het actieve centrum van FXa bezet door het K2 domein van TFPI. In hoofdstuk 3 laten we, met behulp van TFPI fragmenten, zien dat de andere Kunitz domeinen van TFPI een belangrijke rol spelen in de remming van FXa door TFPI. Het geïsoleerde K2 domein blijkt een slechte remmer van FXa te zijn die, in tegenstelling tot TFPI, de amidolytische activiteit van FXa in een 1-stapsreactie remt. Een TFPI fragment bestaande uit de Kunitz domeinen K2 en K3 is een veel betere remmer van FXa dan het K2 domein, maar remt FXa nog steeds via een 1stapsreactie. TFPI fragmenten die de Kunitz domeinen K1 en K2 bevatten (K1-K2 en TFPI $_{1-161}$ ) blijkennet als het volledige TFPI molecuul FXa te remmen via een 2stapsreactie. Echter, zowel K1-K2 als $\mathrm{TFPI}_{1-161}$, die beide het $\mathrm{K} 3$ domein missen, blijken in vergelijking met TFPI $_{\mathrm{FL}}$ veel minder efficiënt te zijn in de vorming van het initiële FXa-TFPI complex. Op basis van deze waarnemingen concluderen we dat het $\mathrm{K} 1$ domein nodig is voor de isomerisatie van het initieel gevormde FXaTFPI complex naar het FXa-TFPI* complex en dat het K3 domein de vorming van het initiële FXa-TFPI complex bevordert. Het feit dat protein S aan het K3 domain bindt en de vorming van het FXa-TFPI complex verder stimuleert, ondersteunt ons voorstel dat het $\mathrm{K} 3$ domein een belangrijke rol speelt in de vorming van het initiële FXa-TFPI complex. Op basis van de waarneming dat TFPI $\mathrm{FL}_{\mathrm{FXa}}$ remt met een $\mathrm{K}_{\mathrm{i}}$ 
die 10-maal hoger is dande $\mathrm{K}_{\mathrm{i}}$ die gemeten is voor een TFPI fragment bestaande uit $\mathrm{K} 2$, $\mathrm{K} 3$ en de $\mathrm{C}$-terminus, stellen we voor dat het $\mathrm{K} 1$ domein niet alleen nodig is voor de isomerisatie van het FXa-TFPI naar het FXa•TFPI* complex, maar tevens de vorming van het initiële FXa•TFPI complex remt.

In de afwezigheid van $\mathrm{Ca}^{2+}$-ionen, is $\mathrm{TFPI}_{\mathrm{FL}}$ een aanzienlijk betereremmer van $\mathrm{FXa}$ dan van FXa wat het $\gamma$-carboxyglutamine zuur bevattende domein mist. $\mathrm{Ca}^{2+}$-ion en werken de FXa remming door $\mathrm{TFPI}_{\mathrm{FL}}$ tegen, maar hebben geen effect op de remming door TFPI constructen zonder C-terminus. Dit geeft aan dat, in afwezigheid van $\mathrm{Ca}^{2+}$-ion en, interacties tussen de C-terminus van TFPI en het Gladomein van FXa de remming van FXa door TFPI bevorderen.

In hoofdstuk 4 hebben we de rol van de verschillende Kunitz domeinen in de remming van FVIIa door TFPI bestudeerd. In dit hoofdstuk werd de remming van FVIIa gevolgd met een FVIIa-specifiek chromogeen substraat. TFPI $\mathrm{FL}_{\mathrm{L}}$ remde TFFVIIa via een langzame monofasische reactie $\left(\mathrm{t}^{1 / 2} \sim 5 \mathrm{~min}\right.$ bij $\left.2 \mathrm{nM} \mathrm{TFPI}_{\mathrm{FL}}\right)$ die gekarakteriseerd wordt door $\mathrm{K}_{\mathrm{i}}$ van $4.6 \mathrm{nM}$. In afwezigheid van TF, bleek TFPI $\mathrm{FL}_{\mathrm{L}}$ een zeer slechte FVIIa remmer te zijn met een $\mathrm{K}_{\mathrm{i}}$ waarde van $1118 \mathrm{nM}$ en in deaanwezigheid van een TF fragment (sTF) wat niet aan een phospholipide oppervlak bindt werd een $K_{i}$ gemeten van $122 \mathrm{nM}$. Dit geeft aan dat phospholipidenen TF de FVIIa remming door $\mathrm{TFPI}_{\mathrm{FL}}$ aanzienlijk stimuleren. TFPI constructenzonder $\mathrm{K} 3$ domein en C-terminus $\left(\mathrm{TFPI}_{1-150}\right.$ en $\left.\mathrm{K} 1-\mathrm{K} 2\right)$ waren $7-10$ 
keer minder effectief dan TFPI ${ }_{\mathrm{FL}}$ in de remming van TF-FVIIa. Dit laat zien dat de KD3-C-terminus een belangrijke rol speelt in de directe remming van FVIIa door TFPI. Kunitz domein 1 was vergeleken met K1-K2, een slechte TF-FVIIa remmer $\left(\mathrm{K}_{\mathrm{i}}=434 \mathrm{nM}\right)$, wat aangeeft dat het $\mathrm{K} 2$ domein van TFPI niet alleen FXa remt, maar ook belangrijk is voor de remming van FVIIa. Protein $\mathrm{S}$ stimuleerdede remming van TF-FVIIa door TFPI $_{\mathrm{FL}}\left(\mathrm{K}_{\mathrm{i}}=0.7 \mathrm{nM}\right)$, maar had geen effect op de remming door TFPI fragmenten. In aanwezigheid van FXa, werd een TF-FVIIaTFPI-FXa complex gevormd met $\mathrm{TFPI}_{\mathrm{FL}}$, TFPI ${ }_{1-150}$ en $\mathrm{KD} 1-\mathrm{KD} 2$, met respectievelijke $\mathrm{K}_{\mathrm{i}}$ waarden $<0.15 \mathrm{nM}, 0.5 \mathrm{nM}$ en $0.8 \mathrm{nM}$. Dit toont aan dat de aanwezigheid van de KD3-C-terminus geen absolute voorwaarde is voor de vorming van het quaternaire TF-FVIIa-TFPI-FXa complex. Met FXa zonder Gladomein en in afwezigheid van phospholipiden werd er echter geen quaternair TFFVIIa-TFPI-FXa complex gevormd.

In hoofdstuk 5 wordt een vergelijkbare studie gepresenteerd waarin de remming van TF-FVIIa niet gekwantificeerd wordt met behulp van een FVIIa-specifiek chromogeen substraat, maar door het volgen van de remming van de activering van de natuurlijke TF-FVIIa substraten FX en FIX. TFPI ${ }_{F L}$ remdede FIX activering door TF:FVIIa met een $\mathrm{K}_{\mathrm{i}}$ van $16.7 \mathrm{nM}$. In aanwezigheid van protein $\mathrm{S}$ daalde de $\mathrm{K}_{\mathrm{i}}$ naar $1.0 \mathrm{nM}$. TFPI ${ }_{1-150}$ en KD1-KD2 remden de FIX activering met $\mathrm{K}_{\mathrm{i}}$ waarden die ongeveer 10-maal hoger waren dan die van $\mathrm{TFPI}_{\mathrm{FL}}$ en de remming door $\mathrm{TFPI}_{1-}$ 
${ }_{150}$ en KD1-KD2 werd niet gestimuleerd door protein S. De losse Kunitz domeinen (K1 en K2) remden de FIX activering door TF:FVIIa nauwelijks ( $\left.\mathrm{K}_{\mathrm{i}}>800 \mathrm{nM}\right)$.

FX activering werd gemeten bij een beperkende concentratie FVIIa en een overmaat TF of omgekeerd d.w.z. bij een beperkende concentratie TF en een overmaat FVIIa. Onder beide condities waren $\mathrm{TFPI}_{\mathrm{FL}}, \mathrm{TFPI}_{1-150}$ en KD1-KD2 even effectief in de remming van de FX activering. Echter, $\mathrm{TFPI}_{\mathrm{FL}}$ was $\sim 15$-keer meer actief als $\mathrm{TFPI}_{1-150}$ en KD1-KD2 wanneer de FX activering gemeten werd bij een lage phospholipideconcentratie. We stellen voor dat een overmaat phospholipide TFPI $_{F L}$ wegvangt waardoor er minder TFPI $I_{F L}$ beschikbaar is voor de remming van TF:FVIIa. FXa-TFPI ${ }_{\mathrm{FL}}$ en FXa-TFPI ${ }_{1-150}$ complexen, die vooraf gevormd waren door preïncubatie van $\mathrm{FXa}$ met $\mathrm{TFPI}_{\mathrm{FL}}$ of $\mathrm{TFPI}_{1-150}$, waren snelle en stoichiometrische remmers van zowel de FIX als de FX activering door TF:FVIIa. Dit geeft aan dat de vorming van het binaire TFPI-FXa complex de snelheid beperkende stap is in de remming van TF:FVIIa. Verder is het van belang te vermelden dat protein $\mathrm{S}$ ook de TFPI remming van de FX activering door TF:FVIIa stimuleerde.

Zowel FXa als TFPI gaan interacties aan met verschillen in plasma aanwezige componenten zoals de stollingseiwitten prothrombine, FV/FVa, en protein $\mathrm{S}$ en niet-eiwit verbindingen zoals phospholipide en heparine. In hoofdstuk 6 hebben we het effect van deze componenten op de remming van FXa door TFPI en TFPI 
150 bestudeerd.

Lage concentraties negatief geladen phospholipiden $(\sim 10 \mu \mathrm{M})$ waren voldoende om de remming van FXa door TFPI maximaal (5-6 maal) te stimuleren. Nietgefractioneerd heparine $(0.2-1 \mathrm{U} / \mathrm{ml})$ stimuleerde de remming van FXa door TFPI $\sim 8$ keer. Echter,heparine concentraties $>1 \mathrm{U} / \mathrm{ml}$ vertraagden de remming van FXa door TFPI. Physiologische protein S en FV concentraties stimuleerden de FXa remming door TFPI ongeveer 2-3 maal. Trombine-geactiveerd FV (FVa) vertraagde het remmende effect van TFPI. Remming van FXa door TFPI ${ }_{1-150}$ werd niet beïnvloed door FV, FVa, protein S, phospholipiden en heparine wat aangeeft de Kunitz domein $\mathrm{K} 3$ en de C-terminus nodig zijn voor de interacties met deze TFPI modulatoren. TFPI was een potente remmer van de door FXa gekatalyseerde prothrombine activering in afwezigheid van FVa, maar had nauwelijks effect op de prothrombine activering in aanwezigheid van FVa wat verkregen was na activering van FV door trombine. Het feit de effecten van prothrombine, FV, FVa, protein S, phospholipidenen heparine op de remming van FXa door TFPI gemeten werden bij physiologische concentraties geeft aan dat deze modulatoreneen belangrijk effect hebben op de in vivo anticoagulante activiteitvan TFPI. 


\section{Valorisation}


TFPI levels and risks of venous thrombosis and bleeding disorders.

Tissue factor pathway inhibitor (TFPI) is a multivalent Kunitz-type protease inhibitor which down-regulates the extrinsic coagulation pathway by inhibiting FXa via its Kunitz 2 domain and FVIIa via its Kunitz1 domain. In in vitro experiments TFPI is a powerful regulator of thrombin generation both in the absence and in the presence of APC (1) which together with the observation that mice lacking the TFPI gene died in utero (2) is indicative for an important physiological function of TFPI. Therefore it is not surprising that low levels of TFPI are associated with an increased risk of venous thrombosis (3) and that high levels of TFPI are associated with a moderate to severe bleeding disorder $(4,5)$.

Implications of the findings presented in this thesis for the association between low TFPI levels and risk of venous thrombosis

Venous thromboembolism (VTE) is a disease that includes both deep vein thrombosis (DVT) and pulmonary embolism (PE). It is a common disorder with a recurring tendency which may result in long-term complications like postthrombotic syndrome. Venous thromboembolism often results from a combination of hereditary and acquired risk factors. Venous thromboembolism is the third most common cardiovascular illness after blockage of coronary artery (known as acute coronary syndrome) and stroke (6). About $30 \%$ of the of patients with symptomatic VTE develop pulmonary embolism (PE), whereas some 70\% deep vein thrombosis 
(DVT). VTE recurs in about $7 \%$ patients, 6 months after the initial event notwithstanding the anticoagulant therapy. Some $6 \%$ of the patients with DVT and $12 \%$ of the patients with PE die within 1 month of diagnosis (7).

According to literature, a low level of TFPI is associated with an increased risk both of a first VTE $(3,8,9)$ and recurrent VTE (9). To establish the risk of developing VTE, these studies measured the plasma levels of free TFPI antigen or total TFPI antigen with ELISA's or the TFPI activity with functional tests that quantify total TFPI (full length and truncated TFPI) (10) or only full length TFPI (11). Despite the fact that TFPI is a major determinant of in vitro thrombin generation both in the absence and presence of APC $(12,13)$ and that TFPI levels in plasma vary widely (e.g. total TFPI varies between 10 and $65 \mathrm{ng} / \mathrm{mL}$ (14)) low TFPI levels are a mild risk factor of VT that only becomes significant at TFPI levels below the $5^{\text {th }}$ percentile (3). A possible explanation for this low risk is that the assays used to quantify the plasma TFPI levels in epidemiological studies do not reflect the TFPI level that regulates thrombus formation. For instance, in addition to the various forms of TFPI present in plasma, TFPI is present in platelets (15) and in/on the endothelium $(16,17)$, which may play an important role in the down-regulation of thrombin formation. The fact that these activities of TFPI do not contribute to the TFPI assays used in epidemiological studies may explain the relatively low VT risk associated with low plasma TFPI levels. In addition, our observations that truncated forms of TFPI express rather low activities in the 
inhibition of FXa (chapter 3), TF:FVIIa (chapter 4) and TF:FVIIa-catalysed FIX and FX activation (chapter 5) while they contribute to the TFPI levels used to quantify TFPI in plasma in epidemiological studies may have reduced the power of the risk analysis. Since the in vivo functional activity of TFPI is modulated by several plasma components (chapter 6) assays of TFPI that do not involve the effect of these modulators (antigen assays and functional TFPI total tests (11)) will not be the first choice tests for establishing the VTE risk of TFPI in epidemiological studies. Assays, the outcome of which include the effects of modulators like protein S and FV may give more reliable odds ratios for the VTE risk of low TFPI levels. One such assay is the thrombin generation-based functional TFPI test developed in our laboratory in Maastricht $(18,19)$ in which thrombin generation is determined at a low TF concentration in the absence and presence of anti-TFPI antibodies.

\section{Effect of heparin on the anticoagulant activity of TFPI}

In chapter 6, we described the effects of both unfractionated and low molecular weight heparin on the inhibition of FXa and TF:FVIIa by TFPI. Very low concentrations of heparin $(0.01 \mathrm{U} / \mathrm{ml})$ considerably enhanced FXa inhibition by TFPI and optimum stimulation was attained at $0.2 \mathrm{U} / \mathrm{ml}$ heparin. High concentrations $(>0.5 \mathrm{U} / \mathrm{ml})$ of heparin counteracted the anticoagulant activity of TFPI making it a less efficient inhibitor of FXa. In chapter 6 we show that TF- 
FVIIa inhibition by TFPI is also stimulated in presence of heparin. Administration of heparin is an important therapy in the prevention and treatment of VTE $(20,21)$. Our study confirms that the anticoagulant effect of heparin is not limited to enhancement of the inhibition of activated coagulation factors by antithrombin (22), but that stimulation of the inhibition of FXa and TF-FVIIa by TFPI and the heparin-induced release of TFPI from the endothelium also contribute to the therapeutic effect of heparin during the treatment of patients with venous thrombosis (23).

\section{TFPI as target in haemophilia treatment:}

TFPI is not only associated with an increased risk of VT, but also plays role in bleeding. This is illustrated by a recent publication in which the so-called east Texas bleeding disorder is described [4]. This disorder is associated with a point mutation in FV gene (A2440G), which results in the enhanced expression of a FV molecule with a reduced molecular weight (FV-short). FV-short lacks a large part of the B domain and has an acidic region exposed that, compared to full length FV, binds TFPI with a 10-fold higher affinity and which can explain the 10-fold increase of the plasma level of TFPI $(4,5,24)$. This elevated level of TFPI increases the bleeding risk in patients with the A2440G mutation.

Considering its important role in maintaining the haemostatic balance, TFPI may also be a target for the treatment of patients with congenital bleeding disorders like 
haemophilia A or haemophilia B. Haemophilia A or B are caused by a deficiency or complete absence of coagulation factor VIII (FVIII) or factor IX (FIX), respectively. Both haemophilia A and haemophilia B are X-linked disorders which represent the large majority of inherited deficiencies of coagulation factors, occurring in $\sim 0.02 \%$ and $0.002 \%$ of male population, respectively, without any racial predisposition (25). An indication of severe haemophilia is bleeding in soft tissue and joints leading to joint damage despite on-going treatment. Prophylaxis, that is infusion of clotting factors, has been used for treating haemophilia for a long time but is not universally implemented because these treatments are expensive; require intravenous infusion and formation of inhibitors is typical. Alternative therapies, like targeting and inhibiting natural anticoagulants such as TFPI (26), activated protein $C(27,28)$ or antithrombin $(29)$ may have the potential advantages of lower cost, oral administration, and absence of inhibitor formation.

Inhibition of TFPI as a potential treatment for haemophilia was reported for the first time by Erhardtsen et al. (26) who showed that antibodies against TFPI reduced the bleeding time in haemophilic rabbits. Since then several studies were published in which molecules were investigated which target and abrogate the anticoagulant activity of TFPI. These compounds include:

1) non-anticoagulant sulfated polysaccharides (NASP), which like heparin are sulfated polysaccharides, a subset of which (pentosanpolysulphate, PPS and fucoidans) were shown to inhibit TFPI and improve haemostasis in haemophilic 
mice $(30,31)$. Recent studies by Zhang et al (32) on fucoidan show the charge density and sugar units required to find the optimal pro and anticoagulant nature.

2) an aptamer called ARC19499 (BAX499) that binds to multiple domains (Kunitz 1, Kunitz 3 and C-terminus) of TFPI and that impairs but not fully prevents the inhibition of FXa by TFPI (33). Protein $\mathrm{S}$ was shown to compete and in its presence the efficacy of BAX 499 peptide was reduced.

3) a monoclonal antibody against TFPI (mAb 2021) that binds with a high-affinity to the Kunitz 2 domain TFPI thereby preventing inhibition of FXa and reducing bleeding in a rabbit haemophilia model (34)

4) a small peptide that binds with a high affinity to the Kunitz 1 domain of TFPI and that impairs inhibition of FXa and TF:FVIIa by TFPI and enhances thrombin generation in plasma (35).

It is interesting to note that amongst the TFPI antagonists that are currently in development for haemophilia treatment there are compounds that target different Kunitz domains of TFPI i.e. Kunitz domain 1 (35) or Kunitz domain 2 (33). In chapter 3, 4 and 5 of this thesis it is shown that the role of the different Kunitz domains of TFPI in the inhibition of FXa and TF-FVIIa is rather complex and not limited to inhibition of FVIIa by Kunitz 1 and FXa by Kunitz 2. This thesis shows that all Kunitz domains contribute to the inhibition of FXa (chapter 3) and FVIIa (chapter 4 and 5) and that several plasma components that bind to TFPI and/or FXa modulate the anticoagulant activity of TFPI (chapter 6). We showed that in the 
two-step mechanism of inhibition of FXa by TFPI, the Kunitz3 domain promotes the formation of the initial encounter complex and is required for the expression of Valorisation protein $\mathrm{S}$ cofactor function and that the Kunitz 1 domain is necessary for isomerisation of the loose encounter into the tight FXa-TFPI complex. Our observations provide important information for developing TFPI antagonists that efficiently can block TFPI. For instance the Kunitz 1 requirement for isomerisation step explains why a peptide that is directed against the Kunitz 1 domain of TFPI (35) is a partial TFPI inhibitor which allows rapid formation of the encounter complex and only prevents the isomerisation to the tight complex. Considering the two-step mechanism of FXa inhibition by TFPI one would predict that TFPI antagonists that knock out the function of both the Kunitz 1 and Kunitz 2 domains would be more effective TFPI inhibitors. Indeed, Dockal et $\mathrm{al}^{1}$ recently reported at the $56^{\text {th }}$ ASH meeting in San Francisco, CA, a synergistic effect of a fusion peptide which consisted of a linear peptide that binds to the N-terminus and Kunitz 1 domain of TFPI and that was linked to a cyclic peptide that binds to a construct composed of the Kunitz 1 and Kunitz 2 domains of TFPI. This fusion peptide effectively neutralised the anticoagulant activity of TFPI even at concentrations that were some 40 -fold higher than the TFPI level in normal plasma. These observations support the notion that detailed knowledge of the mechanism of

\footnotetext{
${ }^{1}$ Dockal M., et al. Molecular Characterization of the Synergistic Effect on TFPI Inhibition By Fusion of Two Inhibitory Peptides. Abstract 1484, 56th ASH Annual meeting, San Francisco CA, 2015
} 
action of TFPI is important for the design of tailor-made TFPI antagonists for the treatment of bleeding disorders.

Below table shows a comparison between all the above discussed TFPI antagonists.

Table 1: Comparison of different TFPI antagonists.

\begin{tabular}{|c|c|c|c|c|}
\hline & Peptide $^{a}$ & $\mathrm{NASP}^{(31)}$ & Aptamer $^{(33)}$ & $\mathrm{mAb}^{(34)}$ \\
\hline $\begin{array}{l}\text { TFPI domain } \\
\text { interaction }\end{array}$ & $\begin{array}{l}\mathrm{N} \text { terminus, } \\
\text { Kunitz } 1 \text { and } \\
\text { Kunitz } 2\end{array}$ & $\begin{array}{c}\text { Probably } \\
\text { binds to } \\
\text { Kunitz } 3 \text { and } \\
\text { C-terminus }\end{array}$ & $\begin{array}{l}\text { Kunitz 1, } \\
\text { Kunitz3 and } \\
\text { C-terminus }\end{array}$ & Kunitz 2 \\
\hline $\begin{array}{c}\text { Inhibition } \\
\text { ofFXa and/or } \\
\text { TF-FVIIa }\end{array}$ & Both & Both & Both & Both \\
\hline $\begin{array}{c}\text { Target of } \\
\text { inhibition } \\
\text { (Various TFPI } \\
\text { forms) }\end{array}$ & $\begin{array}{l}\text { Inhibits all } \\
\text { forms of TFPI }\end{array}$ & $\begin{array}{l}\text { Doesn't } \\
\text { inhibits K3 } \\
\text { and C- } \\
\text { terminal } \\
\text { truncated } \\
\text { form }\end{array}$ & $\begin{array}{c}\text { Doesn't } \\
\text { inhibit K1-K2 } \\
\text { form and } \\
\text { TFPI } \beta \text {, less } \\
\text { efficiently C- } \\
\text { terminal } \\
\text { truncated } \\
\text { form }\end{array}$ & $\begin{array}{c}\text { Inhibits all } \\
\text { forms of TFPI }\end{array}$ \\
\hline $\begin{array}{l}\text { Cross- } \\
\text { reactivity }\end{array}$ & $\begin{array}{l}\text { No cross- } \\
\text { reaction }\end{array}$ & $\begin{array}{l}\text { Interacts with } \\
\text { selectins } \\
\text { expressed on } \\
\text { hematopoetic } \\
\text { and vascular } \\
\text { cells }\end{array}$ & $\begin{array}{l}\text { No cross- } \\
\text { reaction }\end{array}$ & $\begin{array}{l}\text { No cross- } \\
\text { reaction }\end{array}$ \\
\hline $\begin{array}{l}\text { Inhibitory } \\
\text { activity in } \\
\text { presence of } \\
\text { protein } S\end{array}$ & Not affected & Not affected & Reduced & Not affected \\
\hline $\begin{array}{c}\text { Affect in } \\
\text { activity at high } \\
\text { dosage }\end{array}$ & $\begin{array}{c}\text { No adverse } \\
\text { effect }\end{array}$ & $\begin{array}{c}\text { At high } \\
\text { dosage shows } \\
\text { anticoagulant } \\
\text { proterties }\end{array}$ & $\begin{array}{c}\text { No adeverse } \\
\text { effect }\end{array}$ & $\begin{array}{c}\text { No adverse } \\
\text { effect }\end{array}$ \\
\hline
\end{tabular}




\begin{tabular}{|c|c|c|c|c|}
\hline $\begin{array}{c}\text { Mode of } \\
\text { administration }\end{array}$ & Subcutaneous & $\begin{array}{c}\text { Oral and } \\
\text { subcutaneous }\end{array}$ & Subcutaneous & $\begin{array}{c}\text { Oral and } \\
\text { subcutaneous }\end{array}$ \\
\hline $\begin{array}{c}\text { Risk of } \\
\text { antibody } \\
\text { development }\end{array}$ & None & None & None & None \\
\hline $\begin{array}{c}\text { Requirmentof } \\
\text { rFVIII for } \\
\text { optimal } \\
\text { activity }\end{array}$ & Not required & Required & Not required & Required \\
\hline $\begin{array}{c}\text { Effectivity } \\
\text { (in vitro/in } \\
\text { vivo) }\end{array}$ & $\begin{array}{c}\text { Both in vitro } \\
\text { and in vivo }\end{array}$ & $\begin{array}{c}\text { Less efficient } \\
\text { in vivo }\end{array}$ & $\begin{array}{c}\text { Less efficient } \\
\text { in vivo }\end{array}$ & $\begin{array}{c}\text { Both in vitro } \\
\text { and in vivo }\end{array}$ \\
\hline $\begin{array}{c}\text { Bioavailability } \\
\text { Can be } \\
\text { synthesized }\end{array}$ & $\begin{array}{c}\text { Obtained } \\
\text { from seaweed }\end{array}$ & $\begin{array}{c}\text { Can be } \\
\text { synthesized }\end{array}$ & $\begin{array}{c}\text { No proper } \\
\text { estimate }\end{array}$ \\
\hline
\end{tabular}

${ }^{a}$ Dockal M., et al. Molecular Characterization of the Synergistic Effect on TFPI Inhibition By Fusion of Two Inhibitory Peptides. Abstract 1484, 56th ASH Annual meeting, San Francisco CA, 2015 


\section{References}

1. Hackeng TM, Maurissen LF, Castoldi E, et al. Regulation of TFPI function by protein S. J Thromb Haemost 2009;7 Suppl 1:165-8.

2. Huang ZF, Higuchi D, Lasky N, et al. Tissue factor pathway inhibitor gene disruption produces intrauterine lethality in mice. Blood 1997;90(3):944-51.

3. Dahm A, Van Hylckama Vlieg A, Bendz B, et al. Low levels of tissue factor pathway inhibitor (TFPI) increase the risk of venous thrombosis. Blood 2003;101(11):4387-92.

4. Vincent LM, Tran S, Livaja R, et al. Coagulation factor V(A2440G) causes east Texas bleeding disorder via TFPIalpha. J Clin Invest 2013;123(9):3777-87.

5. Broze GJ, Jr., Girard TJ. Factor V, tissue factor pathway inhibitor, and east Texas bleeding disorder. J Clin Invest 2013;123(9):3710-2.

6. Goldhaber SZ. Pulmonary embolism thrombolysis: a clarion call for international collaboration. J Am Coll Cardiol 1992;19(2):246-7.

7. White RH. The epidemiology of venous thromboembolism. Circulation 2003;107(23 Suppl 1):I4-8.

8. Dahm A, Rosendaal FR, Andersen TO, et al. Tissue factor pathway inhibitor anticoagulant activity: risk for venous thrombosis and effect of hormonal state. Br J Haematol 2006;132(3):333-8.

9. Hoke M, Kyrle PA, Minar E, et al. Tissue factor pathway inhibitor and the risk of recurrent venous thromboembolism. Thromb Haemost 2005;94(4):787-90. 
10. Bendz B, Andersen TO, Sandset PM. A new sensitive chromogenic substrate assay of tissue factor pathway inhibitor type 1. Thromb Res 2000;97(6):463-72.

11. Dahm AE, Andersen TO, Rosendaal F, et al. A novel anticoagulant activity assay of tissue factor pathway inhibitor I (TFPI). J Thromb Haemost 2005;3(4):651-8.

12. de Visser MC, van Hylckama Vlieg A, Tans G, et al. Determinants of the APTT- and ETP-based APC sensitivity tests. J Thromb Haemost 2005;3(7):148894.

13. Dielis AW, Castoldi E, Spronk HM, et al. Coagulation factors and the protein $\mathrm{C}$ system as determinants of thrombin generation in a normal population. $\mathrm{J}$ Thromb Haemost 2008;6(1):125-31.

14. Zakai NA, Lutsey PL, Folsom AR, et al. Total tissue factor pathway inhibitor and venous thrombosis. The Longitudinal Investigation of Thromboembolism Etiology. Thromb Haemost 2010;104(2):207-12.

15. Novotny WF, Girard TJ, Miletich JP, et al. Platelets secrete a coagulation inhibitor functionally and antigenically similar to the lipoprotein associated coagulation inhibitor. Blood 1988;72(6):2020-5.

16. Bajaj MS, Kuppuswamy MN, Saito H, et al. Cultured normal human hepatocytes do not synthesize lipoprotein-associated coagulation inhibitor: 
evidence that endothelium is the principal site of its synthesis. Proc Natl Acad Sci U S A 1990;87(22):8869-73.

17. Ameri A, Kuppuswamy MN, Basu S, et al. Expression of tissue factor pathway inhibitor by cultured endothelial cells in response to inflammatory mediators. Blood 1992;79(12):3219-26.

18. Maurissen LF, Castoldi E, Simioni P, et al. Thrombin generation-based assays to measure the activity of the TFPI-protein $\mathrm{S}$ pathway in plasma from normal and protein S-deficient individuals. J Thromb Haemost 2010;8(4):750-8.

19. Winckers K, Ten Cate-Hoek AJ, Beekers KC, et al. Impaired tissue factor pathway inhibitor function is associated with recurrent venous thromboembolism in patients with first unprovoked deep venous thrombosis. J Thromb Haemost 2012;10(10):2208-11.

20. Savage KJ, Wells PS, Schulz V, et al. Outpatient use of low molecular weight heparin (Dalteparin) for the treatment of deep vein thrombosis of the upper extremity. Thromb Haemost 1999;82(3):1008-10.

21. McRae SJ, Ginsberg JS. Initial treatment of venous thromboembolism. Circulation 2004;110(9 Suppl 1):I3-9.

22. Abildgaard U, Lindahl AK, Sandset PM. Heparin requires both antithrombin and extrinsic pathway inhibitor for its anticoagulant effect in human blood. Haemostasis 1991;21(4):254-7.

23. Hansen JB, Sandset PM. Differential effects of low molecular weight 
heparin and unfractionated heparin on circulating levels of antithrombin and tissue factor pathway inhibitor (TFPI): a possible mechanism for difference in therapeutic efficacy. Thromb Res 1998;91(4):177-81.

24. Wood JP, Bunce MW, Maroney SA, et al. Tissue factor pathway inhibitoralpha inhibits prothrombinase during the initiation of blood coagulation. Proc Natl Acad Sci U S A 2013;110(44):17838-43.

25. Mannucci PM, Tuddenham EG. The hemophilias--from royal genes to gene therapy. N Engl J Med 2001;344(23):1773-9.

26. Erhardtsen E, Ezban M, Madsen MT, et al. Blocking of tissue factor pathway inhibitor (TFPI) shortens the bleeding time in rabbits with antibody induced haemophilia A. Blood Coagul Fibrinolysis 1995;6(5):388-94.

27. Butenas S, Orfeo T, Kalafatis M, et al. Peptidomimetic inhibitors for activated protein C: implications for hemophilia management. J Thromb Haemost 2006;4(11):2411-6.

28. Brummel-Ziedins KE, Whelihan MF, Rivard GE, et al. Activated protein C inhibitor for correction of thrombin generation in hemophilia A blood and plasma1. J Thromb Haemost 2011;9(11):2262-7.

29. Shetty S, Ghosh K. Novel therapeutic approaches for haemophilia. Haemophilia 2015; 21(2):152-61.

30. Liu T, Scallan CD, Broze GJ, Jr., et al. Improved coagulation in bleeding disorders by Non-Anticoagulant Sulfated Polysaccharides (NASP). Thromb 
Haemost 2006;95(1):68-76.

31. Prasad S, Lillicrap D, Labelle A, et al. Efficacy and safety of a new-class hemostatic drug candidate, AV513, in dogs with hemophilia A. Blood 2008;111(2):672-9.

32. Zhang Z, Till S, Jiang C, et al. Structure-activity relationship of the proand anticoagulant effects of Fucus vesiculosus fucoidan. Thromb Haemost 2014;111(3):429-37.

33. Waters EK, Genga RM, Thomson HA, et al. Aptamer BAX 499 mediates inhibition of tissue factor pathway inhibitor via interaction with multiple domains of the protein. J Thromb Haemost 2013;11(6):1137-45.

34. Hilden I, Lauritzen B, Sorensen BB, et al. Hemostatic effect of a monoclonal antibody mAb 2021 blocking the interaction between FXa and TFPI in a rabbit hemophilia model. Blood 2012;119(24):5871-8.

35. Dockal M, Hartmann R, Fries M, et al. Small peptides blocking inhibition of factor Xa and tissue factor-factor VIIa by tissue factor pathway inhibitor (TFPI). J Biol Chem 2014;289(3):1732-41. 


\section{Curriculum Vitae}


Appendix 
Sameera Peraramelli was born on February 15, 1985 in Andhra Pradesh, India. In 2002, she started studying BSc (H) Biochemistry at Sri Venkateswara College, Delhi University. In 2005, she obtained merit cum scholarship to study at India's prestigious and top most institute "Indian Institute of Science" as Integrated $\mathrm{PhD}$ student. During her masters she worked at an immunology laboratory in the department of Molecular and cell biology for 6 months and did her masters project for 2 years at Department of Biochemistry under supervision of Prof. dr. D.N. Rao. She obtained her Masters degree in May 2008. She started her PhD research in September 2008 at the department of Biochemistry (Cardiovascular Research Institute (CARIM), Maastricht University) with Prof. dr. Tilman M. Hackeng and Prof. dr. Jan Rosing. 



\section{List of Publications}


Appendix 


\section{Published Papers}

1. Peraramelli S, Suylen DP, Rosing J, Hackeng TM. The Kunitz 1 and Kunitz 3 domains of tissue factor pathway inhibitor are required for efficient inhibition of factor Xa. Thromb Haemost. 2012 Jul 25;108(2):266-76.

2. Peraramelli S, Rosing J, Hackeng TM. TFPI-dependent activities of protein S. Thromb Res. 2012 May;129Suppl 2:S23-6.

3. Peraramelli S, Thomassen S, Heinzmann A, Rosing J, Hackeng TM, Scheiflinger F, Hartmann R, Dockal M. Direct inhibition of factor VIIa by TFPI and TFPI constructs. J Thromb Haemost. 2013 Apr;11(4):704-14.

4. Peraramelli S, Thomassen S, Heinzmann A, Rosing J, Hackeng TM, Scheiflinger F, Hartmann R, Dockal M. Inhibition of TF:FVIIa-catalysed FIX and FX activation by TFPI and TFPI constructs.

J Thromb Haemost. 2014 Nov;12(11):1826-37

5. Peraramelli $\mathbf{S}^{\#}$, Thomassen $\mathrm{S}^{\#}$, Heinzmann A, Rosing J, Hackeng TM, Scheiflinger F, Hartmann R, Dockal M. Role of exosite binding modulators in the inhibition of FXa by TFPI. (Under review in Thrombosis and Haemostasis). \# Authors contribute equally.

\section{Oral and Poster Presentations}

1. Peraramelli S, Suylen DP, Rosing J, Hackeng TM. Role of Kunitz 1 and Kunitz 3 domains of TFPI in the mechanism of FXa inhibition. NVTH symposium 2011, Koudekerke, the Netherlands. (Oral) 
2. Peraramelli S, Thomassen S, Heinzmann A, Rosing J, Hackeng TM, Scheiflinger F, Hartmann R, Dockal M. Direct inhibition of factor VIIa by TFPI and TFPI constructs. XXIV ISTH congress 2013, Amsterdam, the Netherlands. (Oral)

3. Peraramelli S, Thomassen S, Heinzmann A, Rosing J, Hackeng TM, Scheiflinger F, Hartmann R, Dockal M. Inhibition of TF:FVIIa-catalysed FIX and FX activation by TFPI and TFPI constructs.

XXIV ISTH congress 2013, Amsterdam, the Netherlands. (Oral)

4. Peraramelli S, Suylen DP, Rosing J, Hackeng TM. Role of Kunitz 1 and Kunitz 3 domains of TFPI in the mechanism of FXa inhibition. XXIII ISTH congress 2011, Kyoto, Japan. (Poster)

\section{Awards}

1. Award for scientific excellence at the Netherlands Society of Thrombosis and Haemostasis (NVTH), NVTH symposium, Koudekerke, the Netherlands (2011)

2. Young Investigator Award of the International Society on Thrombosis and Haemostasis (ISTH), XXIV ISTH congress, Amsterdam, the Netherlands (2013) 
Acknowledgement 
At times our own light goes out and is rekindled by a spark from another person. Each of us has cause to think with deep gratitude of those who have lighted the flame within us.

Albert Schweitzer

I am grateful for this opportunity to thank all those who have contributed during my $\mathrm{PhD}$ dissertation. Working as a $\mathrm{PhD}$ student at Maastricht University, the Netherlands was a significant and life changing experience for me. In all these years, many people were instrumental directly or indirectly in shaping up my academic career. It was hardly possible for me to thrive in my doctoral work without precious support of these personalities. Here is a small tribute to all those people.

Prof. dr. Tilman M. Hackeng, dear Sir, First of all thank you for giving me an opportunity to work in your lab. Your valuable guidance, encouragement, enthusiasm and friendly nature helped me to complete my research work in a creditable manner. Thanks for believing in me during my hard times. I am thankful to you for being patient during all these years and helping me achieve this milestone in my career.

Prof. dr. Jan Rosing, dear Sir, Thank you very much for introducing me to the world of Biochemistry. Your adept supervision helped me understand the complicated biochemical inhibitory kinetics of TFPI. I cherish till date our fruitful conversations that gave me tremendous insight into blood coagulation. I would also 
like to thank you for being extremely patient during all these years and always being there to help and guide me.

I would like to thank all members of my thesis assessment committee: Prof. Dr. Aalt Bast, Prof. Dr. Erik Biessen, Prof. Dr. Frans Ramaekers and Dr. Kees van 't Veer for assessment and valuable comments.

This thesis wouldn't be possible without our collaborators at Baxter Innovations GmbH, Vienna Austria

Dr. Friedrich Scheiflinger, dear Fritz, Thank you very much for a fruitful collaboration and I would also like to thank you for your critical manuscript revisions.

Dr. Michael Dockal and Dr. Rudolf Hartmann, dear Michael and Rudi, Thank you for a fruitful collaboration and thoughtful meetings we had every Thursday. Also thank you for providing me with TFPI constructs that were essential for my research. Thank you for your valuable comments on drafts of my manuscript. 
The work environment is very important in determining how enjoyable work is. It is very important to work with smart guys who have a superior level of intellectual bandwidth and still have softer skills as well.

\section{-KM Birla}

I would like to thank my lab members who constantly helped me and supported me during my work at Department of Biochemistry, CARIM, Maastricht University.

Dr. Elisabetta Castoldi, dear Betta, You have always been very friendly, helping, kind and gentle to me. I remember our long conversations during weekends (especially), because of you I never felt lonely. I always admired your love for research. You are a very good listener too. I really cherished your company.

Dr. Gerry Nicolaes, dear Gerry, Thank you letting me use your lab equipments for my molecular biology experiments. I remember our in depth discussion in mapping protein S and TFPI interaction sites. Also I thank you for letting me use Biacore facility.

Dr. Guido Tans, dear Guido, Thank you for chairing our group meetings. Thank you for your valuable inputs during my work presentations.

Dear Trees, Thank you very much for helping out of the way. I respect your professionalism and efficiency. You were always one step ahead in your work. I really felt warm and cared in your presence. I loved cakes that you arranged for your Birthday. Elsa and Lidewij, thanks for your support at the end of my thesis. 
Dear Stella, I think of all lab mates, I spent most of the time working with you. Thank you for helping me during my experiments and more. Your organizational skills are worth mentioning. I loved your pecha-kucha presentation. Keep up the good work.

Dear Dennis, It was nice working with you on my first project. Thanks for successfully synthesizing Kunitz domains of TFPI. They were very helpful for my research.

Dear Alexandra, It was nice to work with you. Thank you for helping me for some of my experiments.

Dear Simone, Thanks for letting us know the rules and handling hazardous substances.

Dear Roy, Thank you your help during my molecular biology and Biacore experiments.

Dr. Pieter Van de Vijver, dear Pieter, It was nice to share same office with you. You were always kind and considerate. Thank you for helping me in editing my manuscript figures for my second publication.

Dr. Karin Wildhagen, dear Karin, You were very sweet and understanding girl. Thank you for coming for my wedding. I was wonderful to have you there. Dr. Jiang Du, dear Jiang, You are very cheerful, helping and hard-working guy. I had nice time during conferences and our Poland trip. Dear Farida, It was nice to have you as my office mate after Kristien left. It was nice having friendly conversations 
with you. Thank you for being part of my wedding. All you ladies looked fabulous that day in traditional Indian wear.

I would also like to take this opportunity to thank all my colleagues who are and were from our group Svetlana, Connie, Olivier, Francesca, Ingrid, Linda, Kim, Liesbeth, Kanin, Rory and Hans.

A friend is one that knows you as you are, understands where you have been, accepts what you have become, and still, gently allows you to grow.

- William Shakespeare

Dr. Kristien Winckers, dear Kristien, I always felt we were something more than just batchmates and colleagues. You were the one who gave me your laptop during my first week of joining the lab as my desktop wasn't available. You were the one who helped me to buy stuff from Ikea when I moved to new apartment. You were always there to lend your supporting hand. You seem to be strong person outside but by nature you are very soft, considerate and lovely. I had great time sitting next to you, sharing same office. You are very energetic and enthusiastic person. And yes, our Japan trip was wonderful lifetime memory.

Dr. Barbara Zarzycka, dear Barbara, You are wonderful gift that I fortunately got in my life. I really don't remember when I first met you but it didn't take much time for me to be friends with you. You are such a warm and beautiful person. I consider you one of my best friends that distance can't take away. The time that we 
spent together is unforgettable. Your food was delicious whether it was Carrot cake, Pierogi, Golabki, Apple pancakes or Pizza, I loved them all (see I still remember the names). Thanks for organizing trip to Poland, it was wonderful. I always loved our tennis practice sessions and bike rides. I can't thank you enough for coming for my wedding, you looked amazing in saree. It was nice to have you there, we had a blast. I don't think this place is enough to describe our friendship. But I miss our days together.

Dear Martijn, Thank you for being a nice and caring friend. You were always a delight. Thanks for all your help. You looked good in Indian dress. Thanks for being a part of my wedding.

Dear Catie, You are very energetic, creative, enthusiastic and very sweet person. You are walking encyclopedia, I don't understand from where you get all the information. You are simply amazing. I remember we first met during ISAM meeting which I was planning to skip because I was upset that day for some reason. But still I don't know what made me attend that meeting. I tell you, till date I thank God for making me attend the meeting and introducing me to you. We did everything right from cooking, making T-shirts, organizing events, selling food on Queen's day, henna applying, photo shoot, movie nights, shopping and lots and lots of gossip. You helped me in every possible way. You made my wedding special, you looked stunning in saree. You are one of my best friends and will stay with me lifelong. I miss our days together. 
Dear Willem, You are a very humble and a true gentleman. Thanks for being a nice friend.

Dear Olga, You are one of the sweetest persons I have met in my life. Thank you for buying and playing violin on my wedding. Thanks for being part of my wedding. You looked absolutely pretty in Indian wear.

Dear Mitrajit and Subhashis, You guys are wonderful people. I had absolutely great time during our lunch meeting, tea time, cricket match watching and our epic Greece trip. It is great to have friends like you. Thanks for being part of my life.

Dear Pranali, It was nice to have you as a friend. Our time together was nice. We did cooking, shopping and gossips. I loved the time that we spent together.

I would like to thank my masters friends Maya (we had amazing and unforgettable time together), Chetna (a well wisher and very sweet person), Vidhi, Shveta, Faraz, Sandhya, Shuruchi, Moorthy, Shradha and Varun.

Prof. Dr. D.N. Rao, dear Sir, I would like to thank you for your valuable guidance. You are one of my favorite mentors. Thank you for giving me an opportunity to work in your lab.

Prof. Dr. Srivivasan, dear Sir, Thank you very much for being my student advisor. I always loved interacting with you. You were very considerate and nice to me. 
The only rock I know that stays steady, the only institution I know that works, is the family.

- Lee Lacocca

Snithik, My beautiful baby, thanks for being a part of my life. You amaze me with your skills and flatter me with your innocent smile. I learn many things from you every day.

Jayant, Hubby! thank you for just being in my life. Thanks for making me very comfortable and happy. You are not just husband but a friend for life time. I can't imagine anyone else in your place. Thanks for being there for me.

Dr. Krishna Chaitanya, dear Bhai (brother), I don't want to thank you because thanking you is not enough. You are my inspiration, my role model and my mentor. I learnt so much from you. God has been very grateful to me for giving me a brother like you. You were always there for me. Your kindness, understanding, unlimited and unconditioned love has driven me all through my life.

Dear Dad, Without your love and support I couldn't have achieved this milestone. Thanks for always being there for me. I love you very much, you mean a lot to me. Dear Amma (Mom), Amma you are the force that protects, teaches, inspires and motivates me. If I can be at least half efficient, nice, warm hearted, understanding and hard working as you, then I would consider myself successful. I learnt everything from you. God blessed me with a mother like you. So, today I want to 
dedicate my $\mathrm{PhD}$ thesis to you. This is all because of you. Thank you for being my lifeline.

My trust in God flows out of the experience of his loving me, day in and day out, whether the day is stormy or fair, whether I'm sick or in good health, whether I'm in a state of grace or disgrace. He comes to me where I live and loves me as I am.

- Brennan Manning

Thank you GOD for helping me all though my life to achieve this goal. Thank you very much. 